\title{
Failure to adapt
}

Citation for published version (APA):

Huysse-Gaytandjieva, A. (2015). Failure to adapt. [Doctoral Thesis, Maastricht University]. Maastricht University. https://doi.org/10.26481/dis.20150416ah

Document status and date:

Published: 01/01/2015

DOI:

10.26481/dis.20150416ah

Document Version:

Publisher's PDF, also known as Version of record

\section{Please check the document version of this publication:}

- A submitted manuscript is the version of the article upon submission and before peer-review. There can be important differences between the submitted version and the official published version of record.

People interested in the research are advised to contact the author for the final version of the publication, or visit the DOI to the publisher's website.

- The final author version and the galley proof are versions of the publication after peer review.

- The final published version features the final layout of the paper including the volume, issue and page numbers.

Link to publication

\footnotetext{
General rights rights.

- You may freely distribute the URL identifying the publication in the public portal. please follow below link for the End User Agreement:

www.umlib.nl/taverne-license

Take down policy

If you believe that this document breaches copyright please contact us at:

repository@maastrichtuniversity.nl

providing details and we will investigate your claim.
}

Copyright and moral rights for the publications made accessible in the public portal are retained by the authors and/or other copyright owners and it is a condition of accessing publications that users recognise and abide by the legal requirements associated with these

- Users may download and print one copy of any publication from the public portal for the purpose of private study or research.

- You may not further distribute the material or use it for any profit-making activity or commercial gain

If the publication is distributed under the terms of Article $25 \mathrm{fa}$ of the Dutch Copyright Act, indicated by the "Taverne" license above, 


\section{FAILURE TO ADAPT}

ANNA HUYSSE-GAYTANDJIEVA 


\section{FAILURE TO ADAPT}

(C) ANNA HuYsSE-GAYTANDJIEVA, 2015

ALL RIGHTS RESERVED. No PART OF THIS PUbLICATION MAY BE REPRODUCED, STORED IN A RETRIEVAL SYSTEM, OR TRANSMITTED IN ANY FORM OR BY ANY MEANS, ELECTRONIC, MECHANICAL, PHOTOCOPYING, RECORDING OR OTHERWISE, WITHOUT WRITTEN PERMISSION FROM THE AUTHOR. FOR SOME OF THE PUBLISHED ARTICLES THE COPYRIGHT HAS BEEN TRANSFERRED TO THE RESPECTIVE PUBLISHER.

ISBN

Cover: Encaustic painting on wood; Author: Anna Huysse-Gaytandjieva Printed by: 


\title{
FAILURE TO ADAPT
}

\author{
Dissertation \\ to obtain the degree of Doctor at Maastricht University, \\ on the authority of the Rector Magnificus, Prof. dr. L. L. P. Soete \\ in accordance with the Board of the Deans, \\ to be defended in public on Thursday 16 April 2015, at 16.00 hours
} by Anna Huysse-Gaytandjieva 


\section{Supervisor:}

Prof. Dr. W. Groot

\section{Co-supervisor:}

Dr. M. Pavlova

\section{Assessment Committee:}

Prof. Dr. S.M.A.A. Evers (Chair)

Prof. Dr. P. Hom (Arizona State University)

Prof. Dr. A.P. Nieboer (Erasmus University Rotterdam)

Prof. Dr. F. Nijhuis

Prof. Dr. F.R.N. Zijlstra 
With all my love to my daughter Iris

You are so wonderful just the way you are!

Thank you for the gifts you are offering me daily.

I am so grateful that you are in my life. 
CHAPTER 1

GENERAL INTRODUCTION

CHAPTER 2

A NEW PERSPECTIVE ON JOB LOCK. 35

CHAPTER 3

WHY DO SOME EMPLOYEES FALL INTO AND FAIL TO EXIT A JOB-

LOCK SITUATION? 63

CHAPTER 4

JOB EMBEDDEDNESS AND THE SELF .93

CHAPTER 5

LOW SELF-ESTEEM PREDICTS FUTURE UNEMPLOYMENT 128

CHAPTER 6

WHY DO WE FAIL TO ADAPT TO A DIFFERENT CULTURE?. 151

CHAPTER 7

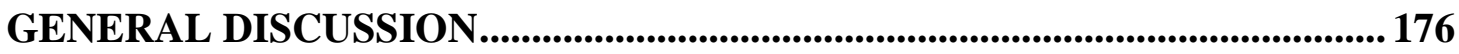

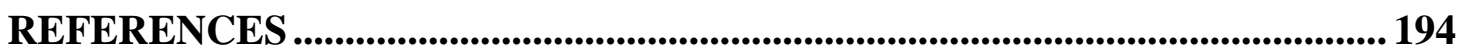

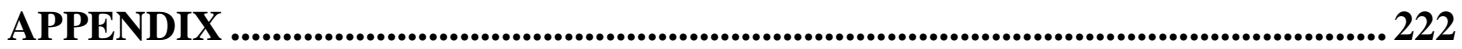

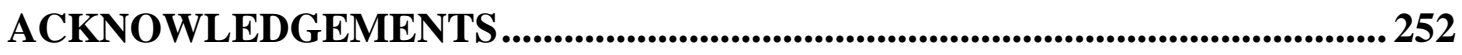

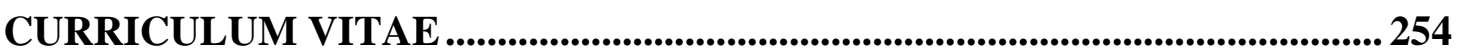


Chapter 1

General introduction 
Chapter 1: General introduction

\subsection{The scope of the study}

One of the most important relationships for humans is the employment relation (Warr, 2002). Work is a vital part of adult life (Erikson, 1980). For an employee, the job provides income, social contacts, opportunities for self-development and brings about a sense of contribution to society. However, the employee and employer enter the employment relationship with different objectives. Sometimes, the interaction between an employee and his/her work environment leads to misfit and dissatisfaction. Moreover, the current dynamic social and economic context places additional demands on both the employee and employer as well as on the relationship between them (Fuller \& Ward, 2012; Pulakos, Arad, Donovan, \& Plamondon, 2000). The EU research report on social sciences and humanities in 2006 (EU research on social sciences and humanities, 2006) shows that the new work patterns (increased 'atypical' forms of employment, increased part time jobs, decreased on-the job training), changes in workplace social norms (increased job intensity; pressure on employees, and demand for extra efforts at work; increased usage of incentives to boost employees' motivation), and inequalities in socio-economic status (increased female labor force) have affected the quality of life and wellbeing of the EU working population. As a result, the employer-employee relationship is changing. It is becoming less stable and lasts shorter (Murrell, Frieze, \& Olson, 1996). The extent of job mobility in European countries in 2005 varies from $5.6 \%$ (Greece) to $22.9 \%$ (the UK), with average of $8.8 \%$ (Andersen, Haahr, Hansen, \& Holm-Pedersen, April 2008). According to the European Commission report in 2012 (Fuller \& Ward, 2012), the average employment rate on the European Union labor markets was $64.3 \%$ and unemployment rate reached $10.4 \%$. Uncertainty and risks on the labor market have increased. Furthermore, the health care, pension and welfare systems of most European Union countries are under increased pressure to cope with the demands of the ageing population (Thompson, Foubister, \& Mossialos, 2009). Also, with the free movement 
Chapter 1: General introduction

of human capital and the globalization of businesses, it is often expected from employees to be able to adjust to different country contexts and cultures, and to the cultural diversity on the work floor (Black, Mendenhall, \& Oddou, 1991). About $6.4 \%$ of the total European Union population consists of non-nationals (Vasileva, 2010). Those people are generally younger than nationals, which increases the likelihood that they participate in the labor market. Changes, like those mentioned above, call upon people's capacity to adapt (Beerel, 2009). This dissertation focuses on employees' adaptation to changes related to employment at different levels. In particular, we study the individual adaptation at the organizational, country and trans-cultural level.

\subsection{Adaptation at the organizational level}

At the organizational level, this dissertation focuses on employees' responses to job dissatisfaction as an antecedent of adaptation at the work place, as well as on the importance of personality in the adaptation process and labor market behavior.

\subsubsection{Job dissatisfaction as an antecedent of adaptation}

Job satisfaction has been shown to be the most important discriminator between employees who stay on the job and those who quit (Gaertner \& Nollen, 1992). Although job dissatisfaction is not the only path that leads to changes in employment, it is an unpleasant experience, which serves as a drive for action. An alternative response to job dissatisfaction is adaptation while remaining at the same job. Successful adaptation to feelings of dissatisfaction at work implies that an employee adjusts and consequently, job satisfaction improves (Rosse \& Miller, 1984). Adaptation theory suggests that in response to job dissatisfaction, employees exhibit different behaviors. There are basically two ways in which 
Chapter 1: General introduction

scientists relate job satisfaction to behavior: to the separate individual behavior or to broad underlying behavioral families. Below, we discuss both of them.

\subsubsection{Job dissatisfaction and individual behavior (job turnover)}

Job dissatisfaction has been related to separate individual behavior such as turnover, absenteeism, lateness, etc. The more an employee becomes dissatisfied at work, the more likely he/she is to engage in impulsive reactive behavior (quitting, disengaging, retaliation), rather than adaptive behavior (problem solving or adjusting expectations) (Rosse \& Saturay, 2004).

Successful adaptation is seen as an alleviation from work dissatisfaction as a result of some adjusting mechanism (Rosse \& Hulin, 1985). Based on compensatory models of behavior, if exhibited behavior affects the source of dissatisfaction, it is seen as a successful form of adaptation and engaging in other behavior form is unnecessary (Miller \& Rosse, 2002). Thus, we can expect that people, who experience job dissatisfaction, are triggered to engage in a certain form of adaptation. As Hulin's work (Hulin, 1991) points out, withdrawal behavior is a part of the adaptation process. In the long run, when the exhibited adaptation strategies have not led to a successful adaptation, job turnover might be a favorable approach to the employee and to the company.

Some scholars claim that job dissatisfaction precedes job turnover while others argue that dissatisfaction without job turnover is a very common phenomenon (Krausz, 2002).

Traditional job turnover models are based on the idea that the turnover process begins with a feeling of job dissatisfaction followed by searching and evaluating alternative options, and searching for another job (March \& Simon, 1958; Mobley, 1977). Miller and Rosse (Miller \& Rosse, 2002) perceive job dissatisfaction as a trigger, which motivates an evaluation process. Job turnover models have been influenced by decision theory, attitude theory, sociology and 
labor economics (Steel \& Lounsbury, 2009b). Over time, the organizational psychology research in the area of job turnover has taken two different directions - the process approach and the content approach. In particular, the process school emphasizes the importance of individual characteristics in the decision making process that leads to job turnover, while the content approach looks at job turnover by pointing out the importance of organizational factors. Bluedorn (Bluedorn, 1982) uses a combination of the process and content approach in the development of an unified job turnover model. The author views dissatisfaction as the initial point that directs to the decision making process which passes through several phases and eventually leads to turnover.

Many studies have corroborated a strong "bond" between work dissatisfaction and job mobility (Greenberg \& Baron, 2003; Hom, Caranikas-Walker, Prussia, \& Griffeth, 1992; Hom \& Griffeth, 1991; Krausz, Sagie, \& Bidermann, 2000; Mobley, 1977; Mobley, Griffeth, Hand, \& Meglino, 1979; Porter, 1973; Warters \& Roach, 1973). The other way around, job mobility has been found to increase employee satisfaction (Ehrenberg \& Smith, 2000). Moreover, those who stay dissatisfied longer before leaving, may cost the company more due to their negative attitude and the withdrawal behavior they display, compared to those who leave shortly after they think of quitting (Hanisch, 2002). A long-term inability to adjust, adapt or bring changes may lead to distress (Rosse \& Hulin, 1985). Eventually, distress contributes to physical and mental health problems of an employee (Nicoletti, 2006; Rosse \& Hulin, 1985) accompanied with low productivity for the company (Chmiel, 2000; Cranny, Smith, \& Stone, 1992; Iaffaldano \& Muchinsky, 1985; Judge, Thoresen, Bono, \& Patton, 2001; Petty, McGee, \& Cavender, 1984) and may eventually lead to the loss of work and unemployment (Carsten \& Spector, 1987; Gibson, 2007).

It is therefore relevant for employers to know how to adequately manage the interaction with their employees in order to keep them motivated and productive. At the same time, the 
Chapter 1: General introduction

knowledge how to adapt to feelings of job dissatisfaction is pertinent for employees in order to be satisfied, and to remain healthy and happy.

Most job turnover models include two major categories of explanatory variables. One emphasizes job attitudes (satisfaction and commitment) and the other emphasizes the ease of movement (perceived alternatives and job search behavior). Hom and Griffeth (Hom \& Griffeth, 1995) describe fourteen theoretical job turnover models. Regardless of the big number of models, few theorists put emphasis on individual differences. Personality variables are claimed to be poor predictors of turnover (Mobley, et al., 1979; Muchinsky \& Morrow, 1980) and most turnover models do not explicitly include personality (Hom \& Griffeth, 1995). Those models that include personality, use diverse personality variables. Further, despite that the authors hypothesize that individual differences have an effect on job turnover (Hom \& Griffeth, 1995; March \& Simon, 1958; Mobley, et al., 1979; Rosse \& Miller, 2000; Steers \& Mowday, 1981), there is no consensus about the approach to be used when measuring personality to explain variations in withdrawal behavior (Rosse \& Noel, 1996). The psychological literature review of Rosse and Noel summarizes the individual characteristics that have been taken in account when studying withdrawal (Rosse \& Noel, 1996):

- Demographic characteristics: age, gender, tenure, and family responsibilities

- Cognitive abilities

- Personality - BIG five, perceived control

- Values and interests

- Disposition, affect and temperament

In addition to this, from a labor economics perspective, turnover can be explained by factors such as: rational economic choice, expected utility, labor market supply and demand, job search, available job opportunities, compensation and investment. Rational choices are 
Chapter 1: General introduction

defined as satisfying "some elementary requirements of consistency and coherence" (Tversky \& Kahneman, 1981). People seek both utility maximization and psychological balance (Goldsmith, Sedo, Darity, \& Hamilton, 2004).

\subsubsection{Job dissatisfaction as a part of a group of behaviors}

Job dissatisfaction has also been related to a group of behaviors. There is an understanding that behavior that is correlated with job dissatisfaction shares a universal theme - behavioral withdrawal from work (Herzberg, Mausner, \& Snyderman, 1964), and that separate behavior can be better understood when taken as an expression of broad underlying behavioral families (Miller \& Rosse, 2002). How withdrawal is differentiated varies. For example, Hanisch and her colleagues (Hanisch \& Hulin, 1990; Hanisch \& Hulin, 1991) differentiate work withdrawal and job withdrawal. Work withdrawal is related to behavior which brings temporary escape from work such as less time spent on a duty, coming late or leaving early from work. Job withdrawal includes behavior which takes the employee completely away from the company and the job. Examples of such behavior are job turnover or the decision to retire. The other way to distinguish between withdrawal behaviors is to take into account actions and psychological alternatives (Henne \& Locke, 1985). Further, Beehr and Gupta (Beehr \& Gupta, 1978) propose distinguishing between behavioral withdrawal and psychological withdrawal.

In 1985, Rosse and Hulin (Rosse \& Hulin, 1985) developed a general model of adaptation, which assumes as alternative forms of adaptation to a dissatisfying work environment multiple withdrawal behaviors and efforts to change working conditions. Further, negative health outcomes are also considered consequences of dissatisfaction with work. Hulin and his colleagues (Hanisch, Hulin, \& Roznowski, 1998) stress the relationship between attitude and behavior. Both job affect and job adaptation are seen as important for organizational 
Chapter 1: General introduction

withdrawal (Hulin, 1991). Inspired by March and Simon's model (March \& Simon, 1958) that emphasizes both job dissatisfaction and ease of movement as important for turnover, some scientists have paid attention to different responses to dissatisfaction and to the group of people who fail to adapt (Hulin, 1991; Hulin, Roznowski, \& Hachiya, 1985; Rosse, Boss, \& Johnson, 1991; Rosse \& Hulin, 1985; Rosse \& Miller, 2000; Rosse \& Saturay, 2004). The results show that being unhappy and failing to adapt either by withdrawing or implementing changes, leads to deteriorating physical and mental health (Rosse \& Hulin, 1985). In this dissertation, we focus on the model of adaptive work behavior developed by Miller and Rose (Miller \& Rosse, 2002) because it integrates the latest adaptation research developments. Two district drivers of behavior are recognized: job (dis)satisfaction and workplace emotions. Job dissatisfaction is seen as a primary motivator for adaptation, and work emotions are seen as the proximal cause of impulsive behavior. The model focuses on work role adaptation. The authors (Miller \& Rosse, 2002) propose multiple behavioral families as a way to adapt to job dissatisfaction: behavior withdrawal, psychological withdrawal, voice, and retaliation. Adaptation is differentiated as positive when it helps to lessen job dissatisfaction, as negative if job dissatisfaction increases, and as neutral when there is no effect on job dissatisfaction. Personal experience, social norms, modeling, environmental limitations and facilitators are hypothesized to determine the choice of behavior family. The proposed behavioral families result from either negative emotions (impulsive quitting, avoidance, cathartic retaliation) or dissatisfaction (problem solving, planned exit, planned avoidance, equity-enhancing retaliation, and capitulation). The authors see job dissatisfaction as central for adaptation due to the fact that there is a continuous tendency toward behavior maintenance. After the employee concludes that he/she is dissatisfied with his/her job, a review and estimate of the different ways of responding follows. The hypothesis of this model is that whether impulsive or thoughtful responses 
manifest themselves, depends on emotional arousability, emotional reserve, and emotion control. In this model, emotional arousability refers to affect intensity. Thus, other things equal, employees who feel a very strong emotion, are more emotionally arousable and more inclined to react impulsively. Emotional control is defined as "a learned self-management skill” (Miller \& Rosse, 2002). When an employee has emotional control, he/she is more likely to evaluate the current situation and not to react impulsively. Emotional reserve is defined as the ability to experience negative emotions and to proceed working undisturbed. The authors argue that when the emotional reserve is large, the employee can handle an additional trigger of dissatisfaction and stay focused on the tasks. Due to the fact that the drive of impulsive behaviors is a negative emotion rather than job dissatisfaction, impulsive behavior would not necessary lead to an increase of job satisfaction.

The adaptive behaviors that follow from job dissatisfaction are: problem solving, planned exit, planned avoidance, equity-enhancing retaliation, and capitulation. Problem solving relates to useful efforts to solve problems, to lessen or remove job dissatisfaction. Planned exit is related to avoiding job dissatisfaction behavior or so called work withdrawal - quit, transfer, or retirement. Planned avoidance are short-term strategies of avoiding job dissatisfaction as taking big breaks at work, coming late, etc. Equity-enhancing retaliation refers to violent or aggressive behavior (stealing, gossiping, sabotaging the production process) which is seen as a coping mechanism. Capitulation reveals the behavior of those employees who do not actively respond to job dissatisfaction (adjustment without any behavioral change). Though, this strategy is adaptive only in a short run.

We can deduce that when the executed adaptation strategies are not working, and thus, do not reduce job dissatisfaction (neutral adaptation), job mobility might be a functional strategy (Dalton \& Todor, 1993). For individuals, job mobility helps to develop the full potential of the employees by providing them with new experiences and opportunities for self- 
Chapter 1: General introduction

development and promotion, and provides the opportunity to benefit from alternative job opportunities. It is a mechanism for upward social mobility (Muchinsky \& Morrow, 1980; Van Ham, 2002), a way to achieve wage increases (Lichter, 1983), a way to deal with job dissatisfaction (Hom \& Griffeth, 1995), or a manner to avoid un(der)employment (Simpson, 1992). However, when people are not able to change or to leave their unsatisfactory situation they might feel themselves locked-up in their job. This situation may produce harmful effects both for the individual and the organization.

\subsubsection{Job lock and being 'stuck'}

Economists use the term 'job lock' to describe the situation of being dissatisfied with a job and staying at the same job. Psychologists use terms like 'being stuck' and 'neutral adaptation' to describe the same situation. A relatively small amount of research has been carried out with respect to job lock, and especially on bringing the economic and psychology dimensions of job lock together.

In economics, research on job lock is almost exclusively focused on the impact of an employer pension fund participation and/or health insurance and their limited portability on decreased job mobility (Bansak \& Raphael, 2008; Benjamin, Pransky, \& Savageau, 2008; Boyle \& Lahey, 2010; Dorsey, 1995; Fitzenberger \& Kunze, 2005; Gruber \& Madrian, 1994; Gruber \& Madrian, 1993; Hamersma \& Kim, 2009; Harris \& Adams, 2007; Ippolito, 1991; Kapur, 1998; Kim \& Philips, 2010; Madrian, 1994; Stroupe, Kinney, \& Kniesner, 2000). Nevertheless, no clear and consistent operationalization of the term job lock is provided in the economic literature. Definitions vary from: "employees feel they cannot change jobs, or are afraid to change jobs, because they might lose their health insurance benefits" (Kapur, 1998; Kennedy, Drago, Sloan, \& Wooden, 1994), and "workers may decide to keep jobs they would rather leave due to the non-portability of health insurance coverage across jobs" (Adnet, 
Bougheas, \& Georgellis, 2004), to "the reluctance of an individual to leave his or her current position for another because of the fear of losing health benefits or being forced to pay more for the same level of benefits" (Hamersma \& Kim, 2009; Holtz-Eakin, Penrod, \& Rosen, 1996). Thus, in the economic literature, job lock is related to job immobility due to nontransferable job investments (pension fund and/or health care benefits). It should be acknowledged that this literature is mainly based on studies conducted in the US. The magnitude and statistical significance of the job lock effect varies across studies. Some report a considerable impact of job lock on job mobility (a decrease between $20 \%$ and 40\%) and a reduction of the voluntary turnover rate of those with employer-provided health insurance (Gruber \& Madrian, 1993). Other studies show that job lock reduces turnover for men confronting a chronic illness by about $41 \%$ but has no effect for women (Stroupe, et al., 2000). Further, job lock is claimed to be a short-term problem (Holtz-Eakin, et al., 1996) and it is argued that there is "little evidence that health insurance provision interferes with job mobility in either the US or Germany" (Holtz-Eakin, et al., 1996). We should keep in mind that non-portable health insurance and pension rights are typical for the US labor market and generally do not apply to Europe. Additionally, some researchers find that the job-lock effect is statistically insignificant (Kapur, 1998) and they question the existence of job lock (HoltzEakin, et al., 1996).

The psychology literature has paid more attention to dissatisfied employees, who leave their job, than to those who stay. Nevertheless, continuance commitment (Allen \& Meyer, 1990), job embeddedness (Mitchell, Holtom, Lee, Sablynski, \& Erez, 2001; Mitchell, Holtom, Lee, Sablynski, \& Erez, in press), and job investments (Farrell \& Rusbult, 1981) provide an explanation why employees stay in an unsatisfactory job. Employees stay in an unsatisfactory job if: (1) they have invested in their job and perceive a lack of alternatives (Allen \& Meyer, 1990); (2) they have made job investments (e.g. non-portable skills, retirement programs) that 
increase commitment by increasing the costs of leaving the organization (Farrell \& Rusbult, 1981); (3) they are stuck in the web of job embeddedness. Personality characteristics (such as extraversion, neuroticism, optimism and self-esteem) are rarely included in economic empirical papers (Nicoletti, 2006). Psychological research on employees' feeling of being 'stuck' also provides a clarification of the reasons that keep employees hooked in their job even if they are dissatisfied. The theoretical model of Hom and colleagues (Hom, Mitchell, Lee, \& Griffeth, 2012) proposes that individual differences such as core self-evaluation, collectivism, gender role ideology, family power, corporate power, demographic background influence stay/leave preferences and decision control. Further, the recent study of Woo and Allen (Woo \& Allen, 2013) analyzes the effect of positive and negative affectivity, openness, and a proactive personality when differentiating stayers and leavers.

Dissatisfaction is perceived in psychological research as an unpleasant experience which consequently provides an incentive to search for ways to lessen dissatisfaction (Rosse \& Miller, 2000). Thus, being dissatisfied is supposed to play the role of a trigger for change, a catalyst for action (Dawis \& Lofquist, 1984). However, people respond differently to dissatisfaction (Rosse \& Saturay, 2004): some, but not all employees, search and find another job when they are dissatisfied. Nevertheless, the role of external factors such as employer pension fund participation and health insurance arrangements are not taken into account in the psychology literature on the absence of such changes when being dissatisfied with the job. In this dissertation, the economic and psychology aspects of job lock are combined to explore the state of job lock as well as the transitions from and to this state. The latter is important because much more is known about the reasons why employees leave than about the psychological processes behind staying with the organization (Sablynski, Lee, Mitchell, Burton, \& Holtom, 2002). Furthermore, the same models that explain the process of quitting are expected to explain staying as well. Another limitation in the current research is that there 
is still little empirical evidence particularly on individual differences (Hom, et al., 2012). The dominant models of employee withdrawal have not put emphasis on the role of individual differences (Rosse \& Noel, 1996). There has been the implicit assumption that all dissatisfied and non-committed employees are more likely to quit. Though the ease of movement has been considered (March \& Simon, 1958), mobility has not been seen as driven by personality but more by external factors (Rosse \& Noel, 1996). Self-reported measures of satisfaction are believed to reflect mainly a cognitive aspect but it can be that they also reveal an emotional side of well-being (for example mood) and personality traits (for example extraversion, neuroticism, optimism and self-esteem) (Nicoletti, 2006). Further, most of the models which relate attitude and behavior (the theory of reasoned action (TRA) and the theory of planned behavior (TPB)) place the emphasis on the intention to leave as an important variable to understand and predict who would leave and who would stay. However, the intentions-ofquitting model tells us only who is likely to leave, but not who is likely to stay (Udechukwu \& Mujtaba, 2007). The falsifiability of these models is questioned due to the fact that the intentions depend on behaviors (Byrka, 2009). Additionally, job search is different from separation (Boudreau, Boswell, Judge, \& Bretz, 2001). Recent research shows that job search might be a way to deal with job dissatisfaction, by searching for alternatives which are evaluated against the current position, and not an intention to leave (Blau, 1993; Bretz, Boudreau, \& Judge, 1994; Kirschenbaum \& Weisberg, 1994). Besides, there is "no sound empirical or theoretical basis for making decisions about temporal intervals over which to aggregate or even study organizational withdrawal" (Hanisch, et al., 1998). Previous research does not clarify how long it takes for people to adapt and what is the time lag between different adaptation decisions. Time between the wish to leave and the decision to leave may also vary between different job turnover models. Further, it has not been considered that 
Chapter 1: General introduction

different personality characteristics may influence the long-term inability to adapt compared with the short term one.

Above, we discussed the role of work attitudes in the face of job dissatisfaction and adaptation to it. Though, the opposite opinion also exists, namely that work attitudes have a very little impact on employee retention and leaving (Griffeth, Hom, \& Gaertner, 2000). Even high levels of job dissatisfaction need not necessarily result in job turnover and job lock.

\subsubsection{Adaptation without job dissatisfaction}

Models like the unfolding model (Lee \& Mitchell, 1994) presume that job turnover might be completely unrelated to affect (job dissatisfaction), but related to a "shock to the system", a significant event that triggers an employee to evaluate his/her job and may lead to job-to-job mobility.

Further, influenced by this opinion, a non-attitudinal concept that explains why employees keep stuck in their jobs has been developed. This concept, which is also explored in this dissertation, is called job embeddedness.

\subsubsection{Job embeddedness}

The situation of employee 'being stuck' can be also outlined from the job embeddedness perspective. Job embeddedness is like a net or a web in which one can become 'stuck' (Mitchell, et al., 2001). The job embeddedness theory of turnover includes both on- and offthe job factors that have an impact on staying. The essential aspects of job embeddedness are: (1) the extent to which people have links to other people/activities; (2) the extent to which their jobs fit with the other aspects in their life; (3) what they would sacrifice if they make the decision to leave. These aspects are called links, fit, and sacrifice. The effect of on- and offjob links, fit and sacrifice may differ across people and jobs. Further, the authors of the job 
embeddedness model (Mitchell, et al., 2001) argue that people can become embedded in various ways and that there might be differences by occupation or personality. Being less embedded does not necessary mean that an employee will leave, e.g. an employee who has high job satisfaction but scores low on job embeddedness (Mitchell \& Lee, 2001). High job embeddedness is expected to increase the likelihood that individuals will deal more adaptively to negative events at work (Mitchell, et al., 2001).

In their review article, Hom and colleagues (Hom, et al., 2012) sketch an integrative theory of withdrawal profiles. Based on the assumption that psychology of staying may be very different from that of leaving, and involving different type of attitudes and motives (Cho, Johanson, \& Guchait, 2009; Hom, et al., 2012; Mitchell, et al., 2001; Steel \& Lounsbury, 2009a; Westaby, 2005b), some authors make a distinction between different types of stayers and leavers. The differentiation is made on the basis of the preferred employment status (desired stay or leaving) and decision control (low/high perceived control over desired state: staying or leaving). Nevertheless, they assume that some people can be inclined for both or neither. Stayers are divided into: enthusiastic (embedded engaged, engaged, slackers - those who like the job because it is easy or not demanding) and reluctant (trapped, contractual). Leavers are set apart as: reluctant (coerced, involuntary, resistant) and enthusiastic (voluntary, externally aligned, mutually separated). Inspired by the work of Hom and colleagues (Hom, et al., 2012), other scientists induce the following stayers: embedded, detached and seekers: dissatisfied and script-driven (Woo \& Allen, 2013). Personality characteristics as positive and negative affectivity, openness, and proactive personality show to have predictive effect. Though, when taken in consideration together with attitudinal and motivational variables, personality characteristics show less significant predictive effect than when taken alone (Woo \& Allen, 2013). 
Chapter 1: General introduction

Despite the initial perspective on job embeddedness as a positive phenomenon that leads to job retention and high performance, scientists have started to recognize the possible negative effects of job embeddedness, when an embedded employee feels stuck. Still, the understanding about the 'dark' side of job embeddedness is limited and further research is needed (Barnard \& Curry, 2011; Crossley, Bennett, Jex, \& Burnfield, 2007; Holtom, Burton, \& Crossley, 2012; Sekiguchi, Burton, \& Sablinski, 2008). This dissertation explores the negative aspects of job embeddedness. The attempt to contribute to the limited research about the negative side of job embeddedness, can be facilitated by connecting job embeddedness to emotional regulation.

\subsubsection{Emotional regulation}

Individuals' goals and motivations (e.g. for attachments, achievements) are guided by emotions. Research shows a number of integrated circuits in the brain that give rise to different type of emotion which regulate motivation (Depue \& Morrone-Strupinsky, 2005). In particular, these are: drive (a focus on doing and achieving), threat (with a focus on threat and self-protection), and soothing system (a focus on contentment and feeling safe). Each of them is designed to do different things. The drive system is the motivational system. It strengthens our desires and some goals - both material and those linked to self-esteem (e.g., seeking status). The threat system is oriented towards fast detection of threat and giving rise to such feelings as anxiety, anger or disgust. As a consequence, a reaction in the form of fight, flight and submission in order to protect ourselves, is formed. The evolution of attachment behavior utilizes the third system: the soothing (compassion). From an evolutionary perspective, when animals are not threatened and they do not need to seek resources, they can become content. This system is related to a sense of peacefulness, well-being and serenity. 
Chapter 1: General introduction

The ability to construct self-identities serves important role-regulating and engaging functions (McGregor \& Marigold, 2003). Self-evaluation and self-identity help people keep track on the social space that they are operating in. Further, Gilbert (Gilbert, 1989) relates self-esteem to drive, self-criticism to threat, self-compassion to soothing system.

\subsubsection{The role of different aspects of self on job embeddedness}

What distinguishes humans from other species is the capacity to self reflect. This brought humans extraordinary capabilities as introspection, planning behavior, being able to see the point of view of someone else, and an opportunity to choose who we want to be. However, the self has also brought humans difficulties, especially when these new capabilities come together with old brain emotions (anger, anxiety, sadness, joy, lust). Two types of threats are differentiated: internal and external (Gilbert, 2009b). Internal threats relate to what emerges and is created inside oneself (self-devaluation and self-criticism). External threats relate to the external world, how one exists in the mind of others, what others might do. Experiencing internal threats activates the threat system. Low self-esteem is a non-conscious strategy to cope with a threatening social world (Gilbert, 2002). Crocker and Canevello (Crocker \& Canevello, 2012) list the following individual differences in self-esteem: level, stability, contingencies, implicitly, and motives. At the organizational level, this dissertation contributes to the model of job embeddedness, incorporating individual differences in selfesteem: level, contingencies ('if ...then..' rules), and motives. Further, we add to the limited knowledge of self-compassion in organizational literature.

\subsection{Adaptation at the country level}

Unemployment is one of the most frequently studied social events. Its complexity has captured the attention of scientists from different disciplines who offer diverse explanations to 
job loss. The research shows that being without a job has an impact on both a micro and a macro level. At the micro level, for the individual, job loss leads to a decrease in income (Waters \& Moore, 2001; Wilhelm \& Ridley, 1988), less well-being and more stress (Creed, Machin, \& Hicks, 1999; Goldsmith, Veum, \& Darity, 1996a; Waters \& Moore, 2001; Winefield \& Tiggemann, 1990), health deterioration (Goldney, 1997), lower self-esteem (Creed, Bloxsome, \& Johnston, 2001; Goldsmith, et al., 1996a; Hammer, 1993; Jahoda, 1982; Seligman, 1975; Shamir, 1986; Warr, 1987; Waters \& Moore, 2002a), depression (Howe, Levy, \& Caplan, 2004; Lerner et al., 2004; Pearlin, Lieberman, Menaghan, \& Mullan, 1981; Schaufeli, 1988; Taris, 2002), entry into psychiatric hospitals (Blakely, Collings, \& Atkinson, 2003) and in some cases even suicide (Blakely, et al., 2003; Lewis \& Sloggett, 1998; Preti \& Miotto, 1999). At the macro level, in most countries, some sort of unemployment payment to those without work exists, which implies that a higher unemployment rate means more resources are spent on unemployment benefits. Additionally the higher costs for financing unemployment, joblessness are associated with other social problems such as crime (Baumeister, Smart, \& Boden, 1996; Raphael \& Winter-Ebmer, 1999), poverty (Weich \& Lewis, 1998), a chronic dependency on state support (Emler, 2001), and ill-health (Dooley, 2003; Friedland \& Price, 2003; Goldney, 1997; Hammer, 1993; Kong, Perrucci, \& Perrucci, 1993; Schaufeli, 1988; Taris, 2002; Warr, 1989).

Economists vary in their opinion on the causes of unemployment. The reasons provided range from: mismatches between demand and supply of employees with certain skills (structural unemployment); labor market inefficiencies; discouraging employment regulation such as unionization and taxes; sticky wages and efficiency wages. In psychology research, the emphasis is on the consequences of unemployment on well-being (Jahoda, 1981, 1982; Mayo, 1993; Peterson, Maier, \& Seligman, 1993; Warr, 1983). Though, there are few studies examining the reverse relationship (Feinstein, 2000; Kasl, 1982). 
Some social psychologists like Erickson, Jahoda, Warr and Seligman suppose that joblessness may harm peoples' psychological well-being and may lead to a "decline in cognitive performance, motivation and perception of self-worth" (Goldsmith, et al., 1996a; Goldsmith, Veum, \& Darity, 1997). Furthermore, Kasl's in his work talks about a reverse causation hypothesis (Kasl, 1982). The literature does not provide a comprehensive causal model to explain the effect of self-esteem on the chance to become unemployed. The studies that tried to study this effect, did not distinguish between moderating, mediating and confounding variables in their models while this is essential for causal modeling (Greenland, 2003; Greenland \& Robins, 1986; Greenland, Robins, \& Pearl, 1999; Robins, Hernan, \& Brumback, 2000). Additionally, the term cause and effect has been used when in fact just an association between the variables has been analyzed.

A comparison of employed with unemployed people "leaves open the question whether job loss and unemployment cause low psychological well-being or whether people who are chronically more depressed are more likely to become unemployed while the less distressed stay in work" (Warr, 1983). Furthermore, there is no theoretical framework to explain how and why self-esteem may lead to unemployment.

Since the 1970s, the self and its related phenomena is a main construct within psychology, sociology, and other social and behavior sciences (Leary \& Tangney, 2003). Within the self literature, self-esteem is the most often used construct. As Lane (Lane, 1993) quotes "selfesteem is perhaps the most important primary good". Moreover, to understand people's behavior without knowledge about self-esteem is not possible (Leary \& Tangney, 2003). Furthermore, diminished self-esteem is classified as an influential explanatory variable in the origin of major social problems (Mecca, Smelser, \& Vasconcellos, 1989). Thus, self-esteem is an effect of psychological and social causes and a cause of social problems (Mecca, et al., 1989). Lower self-esteem is an important independent variable (condition, cause, and factor) 
Chapter 1: General introduction

in the origin of the main public problems. The author summarizes that it is as much an effect as it is a cause.

In this dissertation, we face the challenge to offer an explanation how self-esteem causes involuntary unemployment. Further, previous research on self-esteem has mainly a correlational nature (Kling, Hyde, Showers, \& Buswell, 1999). Nevertheless, a cause-effect relationship demands a differentiation between moderating, mediating and confounding variables (Greenland, 2003; Robins, et al., 2000).

\subsection{Adaptation at a trans-cultural level}

Every aspect of the adaptation process can be strongly influenced by culture (Helman, 2007). Immigrants are confronted with a large scale of extra challenges (ambiguous signals), frequently competing value systems which raise strong emotions and often lead to distress (Ward, Bochner, \& Furnham, 2001). Previous research has consistently demonstrated that immigrants suffer from higher levels of emotional distress and poorer mental health compared with the host populations (Bhugra, 2004). There are adverse psychological or psychopathological consequences of problems to adapt to a foreign culture: mental health (increased levels of depression, anxiety, low self-esteem and other psychological problems) (Aroian \& Norris, 2002), employment, and lost benefits for the whole society (MaydellStevens, Masgoret, \& Ward, 2007). Immigrants lose support (such as a loss of familiar culture, mother country, family and community) and often may need support in different forms. Though, in spite of the plenitude of cross-cultural adaptation models, these have limited application in counseling and psychotherapy. In this dissertation, we try to understand trans-cultural adaptation problems of a group of immigrants and develop a supportive, therapeutic method for them. It is essential to understand and manage the contacts between culturally diverse people to reduce stresses and differences. 
Chapter 1: General introduction

\subsubsection{Trans-cultural adaptation}

Culture is a collective characteristic which shows up in behavior (Hofstede \& McCrae, 2004). Hofstede (Hofstede, 2001) differentiates the following cultural dimensions: power distance (power and inequality), individualism versus collectivism (the extent to which people are integrated in groups), masculinity versus femininity (assertive and caring poles), uncertainty avoidance (tolerance for unstructured situations), long-term versus short term orientation (tolerance to uncertainty). It can be expected that the larger the cultural distance between home and host country, the more demanding the process of adaptation would be.

At its core, cross-cultural adaptation is a "commonplace process of learning to live with change and difference - in this instance, a changed environment and different people, different norms, different standards, and different customs" (Anderson, 1994). Different models lead to different definitions of cross-cultural adaptation. Four broad groups of models describing cross-cultural adaptation, can be distinguished (Anderson, 1994). The first group sees cultural shock as a mechanism for adaptation to a foreign culture. The second group looks upon crosscultural adaptation as a learning process. The third group of models looks upon cross-cultural adaptation as a process of recovery and learning. And the fourth group of models looks at the phenomenon as a dynamic and cyclical process of tension reduction.

The modern modification of the culture shock model gets away from the disease as outcome but emphasizes the crisis on personality or identity as a consequence of a culture shock (Adler, 1975). Cultural shock theory argues that cultural adaptation goes through four phases: honeymoon, withdrawal, adjustment, and enthusiasm. Honeymoon stage concerns the first exposure to the new culture and excitement related to it. However, the cultural shock may also begin during this stage. Eventually the differences lead to unpleasant feelings and excitement gives way to confrontation and the withdrawal stage takes place. The following adjustment stage describes the process of cultural acceptance and adaptation. And the last stage is the 
Chapter 1: General introduction

enthusiasm stage. So called full adaptation that is related to this last phase, does not mean total conversion. As past research shows, bicultural people (those who choose elements from both home and host culture) adjust much better than those who fully adopt or reject the new culture, or reject both home and host culture (Yamada \& Singelis, 1999).

There is a widespread understanding that crossing cultural boundaries is often accompanied by stress (Ward, et al., 2001). A culture shock is associated with stress, anxiety, misunderstanding and feelings of being lost or not fitting. Related to stress, Selye (Selye, 1956) presents a model of adaptive reaction to stress. The so called general adaptation syndrome is defined as "the sum of all non-specific, systemic reactions of the body which ensue upon long continued exposure to stress" (Selye, 1946). In this model, Selye studies the effects of stress and specifies three stages that people are passing through when exposed to stress: alarm, resistance, and exhaustion. When people identify stress then their body reacts with a state of alarm in order to protect them. If the stressor continues, it demands adaptation because the body cannot go on with it endlessly. The exhaustion is the last phase of the model where the body cannot sustain its normal function. If this stage prolongs, illness would appear.

\subsubsection{Positive Psychotherapy and trans-cultural adaptation}

In this dissertation, we explore the trans-cultural adaptation problems among three groups defined based on their expectations towards the host country: work, contact and future. In our attempt to provide more understanding on the problems people face and to develop a method to work with them, Positive Psychotherapy as an interdisciplinary approach is applied. Positive Psychotherapy is a trans-cultural approach and as a consequence can be directly applied to people from different cultures. The terminology is developed in such a way in order to be understandable independently from culture, race, educational level. It analyses the 
person both as an individual and as a group member, and is applicable to a variety of complaints. Moreover, it is applicable in other than psychotherapy settings as management, education, prevention. Positive Psychotherapy is attractive because it is a short-term therapy and shows cost efficiency. In addition to this, it shows lasting stability of the therapeutic effects (quality assurance and effectiveness longitudinal study) (Tritt, Loew, Meyer, Werner, \& Peseschkian, 1999a).

Positive Psychotherapy is a meta-theory. It offers a framework within which different methods and schools of thought can be used to complement each other; psychotherapy and self-help walk hand in hand during the 5 stages of therapy. Scientific foundations of Positive Psychotherapy lay in psychology (psychodynamic and behavioral), medicine (psychosomatic) and philosophy (the Baha''1' Faith) (Cope, 2008). Positive Psychotherapy has a humanistic world-view (Peseschkian, 1987). It gives answers to the following questions: What do all people have in common and how do they differ? The word "positive" in the name of Positive Psychotherapy comes from the Latin "positum", i.e. what is factual and given. Thus the client comes to therapy not just with his/her problems but also with capacities to deal with them. Positive Psychotherapy is based on differentiation analysis. It is differentiating behavior, i.e. separating the conflict-free behavioral trends from the symptom itself. The symptom can then be understood as a capacity to react in an individually specific way. Actual capacities play a central role in Positive Psychotherapy. They have already existed in many different forms before the development of Positive Psychotherapy (Peseschkian, 1987), for example, the pleasure and the reality principle (Freud, 1971) and Erickson's basic virtues/strengths (Erikson, 1964). The contribution of Positive Psychotherapy is that it systematically takes actual capacities into account as psychosocial dimensions. Every human being possesses two capacities: primary (capacities to love) and secondary (capacities to know). They are called actual because they are manifested in many different ways in daily life and actually affect a 
human's life. Actual capabilities are developed in close connection with the three dimensions - body, environment, and time. Capacities to love are expressions of the ability to love and be loved. Positive Psychotherapy distinguishes four models of capacity to love which represent typical relationships that the individuals establish: to the I, to the Thou, to the $\mathrm{We}$, and to the Origin-We. The relationship to the I is learned in the relationship between the parents and the child and the parents and the siblings. Relationship to Thou is the way parents relate to each other. The We is the relationship the child learns by observing the parents' interactions with the social environment, friends, interest groups, etc. The Origin -We relationship is developed on the basis of the parents' approach towards religion and view on the world. Capacities to know represent the individual ability to learn and teach (Appendix D). Four modes of knowing are differentiated. Which mode and to what extent would unfold depends on the environment: body/senses, intellect/reason, contacts/tradition, intuition. Further, subconsciousness plays a role in the functioning of the four modes. Peseschkian (Peseschkian, 1987) stresses that actual capacities show up in: norms, values, behavior patterns, expectations, internal and external conflict, and triggers and causes of illness. Actual capacities also have flexibility-fixation and active-passive dimensions. Thus, Positive Psychotherapy looks upon capacities as:

- $\quad$ potentials for psychosocial development (for those undeveloped capacities)

- remaining subconscious

- becoming a source of conflict

When capacities serve as a source of conflict, these may include conflicts between any social relationship, for example a multicultural setting. Positive Psychotherapy discriminates between three conflicts: actual, basic and subconscious conflict (Appendix E). The contents of the subconscious are the conflicts between primary and secondary capacities (repressed or suppressed actual capacities), undifferentiated and undeveloped actual capacities. When 
Chapter 1: General introduction

conflicts arise one can consider the possibility of misunderstanding. Though, the other way around is also true: misunderstandings are related to the "ways of thinking, schematization, and attitudes which, to a large degree, influence our behavior and also our behavior towards ourselves" (Peseschkian, 1987).

An essential tool in Positive Psychotherapy for identifying conflicts and dealing with them is the balance model (Appendix D). The Balance Model can be described as an individual frame of four basic personal modes:

- To perceive oneself and the other with body senses

- To act and to regulate yourself with reason

- To be in contact with others by means of experience and tradition

- To imagine future, meaning, faith by means of intuition

These four modes are linked to the four modes of learning and knowing. Thus, in this way we can figure out how people make sense of themselves, the environment and how they test reality.

Positive Psychotherapy goes through 5 stages: observation, taking inventory, situational encouragement, and verbalization. The observation stage is a fusion stage, when the client and therapist are building trust in each other. Here, the client presents his view on the current problems. The therapist helps to figure out what is the function of the symptom. At the second stage - taking inventory - we are moving from symptom to conflict, differentiation starts. At the third stage of situational encouragement, resource point of reference is applied. The fourth stage - verbalization is motivation oriented. Here, the conflict contents are discussed and specific problem solving techniques are taught. At the stage of expansion of goals the patient's readiness for change, his motivation and the total psychotherapy sessions are discussed. The therapist encourages the client to form at least three goals for the future period. 
Chapter 1: General introduction

When capacities serve as a source of conflict, these may include conflicts between any social relationship, for example a multicultural setting. Positive Psychotherapy discriminates between three conflicts: actual, basic and subconscious conflict. Appendix E depicts them.

\subsection{Aim and objectives of dissertation}

As Diener and his colleagues stated (Diener, Lucas, \& Scollon, 2009), researchers are facing the challenge to discover the factors that control the adaptation process as well as better understand individual differences in adaptation. This dissertation contributes to our knowledge and insight on adaptation by combining economic and psychology theory in investigating this issue. Knowing that adaptive behavior (those reducing the job dissatisfaction) is trainable (Frayne \& Geringer, 2000), we expect that knowledge about the adaptation process and the individual differences in it, would lead to more adequate actions in order to help employees to deal with adaptation issues on the workplace and to guide employees in efficiently addressing adaptation problems. Nowadays, workplaces require almost continuous adaptation by employees (Yeatts, Folts, \& Knapp, 2000). For foreigners, the changes and the demands to adapt may encompass many more areas (contacts at work and private life, achievement area, values and beliefs, etc.) as the magnitude of the changes may be much higher than for native people. This makes foreigners more susceptible to emotional stress and poor mental health. As explained earlier, the importance for understanding the cross-cultural adaptation and the development of effective strategies in support of foreigners is of great value to them as to society as a whole.

The aim of this dissertation is to explore the factors which influence adaptation to job dissatisfaction and labor market behavior. Given the aim, the study formulates the following objectives: 
- to expand our understanding of how and why employees might fail to adapt to job dissatisfaction; it is assumed that job lock is related to a combination of factors and the factors that push an employee into job lock also prevent exiting job lock and entering long-term job lock.

- to explore the role of personality in labor market behavior and in adaptation in case of job dissatisfaction; we consider that procrastination and low self-esteem increase the chances of job lock; self-compassion is a moderator between self-esteem and job embeddedness; self-esteem is a quality that helps people securing and holding employment; self-esteem has an important economic value

- to understand the problems of a group of people with difficulties to adapt to a foreign culture; we consider that trans-cultural adaptation is a process of interactions.

\subsection{Outline of the dissertation}

In order to achieve our objectives, we take an interdisciplinary approach. As a result of the study objectives, five studies have been conducted. In accordance with the research questions and the nature of the outcome variables, the analyses mainly rely on statistical analyses, with exception of the qualitative nature of the study looking at the adaptation on trans-cultural level. The analyses of the first three studies (Chapter 2, 3, and 5) use data from the British Household Panel Survey (BHPS). The BHPS is an annual longitudinal survey using a nationally representative sample of ca. 10,000 individuals living in 5,000 households in Great Britain. The sample includes only the adult members of the households. Individuals participating in the panel are interviewed in successive waves. Wave-to-wave response rates are about $90 \%$ (Taylor, Brice, Buck, \& Prentice-Lane, 2010). Details about this survey can be found in Taylor, Brice, Buck \& Prentice-Lane (Taylor, et al., 2010). The study on job embeddedness (Chapter 4) uses online questionnaire for the collection of data from 113 
Chapter 1: General introduction

employees in the Netherlands. For our fifth study (Chapter 6), we use data of 44 immigrants collected in two separately working psychotherapy practices. The main results of the study are discussed to draw conclusions for policy and further research (Chapter 7). 


\section{Chapter 2}

\section{A new perspective on job lock}

This chapter draws upon:

Huysse-Gaytandjieva, A., Groot, W., \& Pavlova, M. (2013). A new perspective on job lock. Social Indicators Research, 112 (3), 587-610. 
Chapter 2: A new perspective on job lock

\begin{abstract}
This chapter analyses the situation when employees fail to adapt to overall job dissatisfaction. By combining the existing knowledge in economics on job lock and in psychology on employees' feeling of being 'stuck' at work, the study explains why some employees fail to adapt when dissatisfied with their job. Thus, this chapter aims to expand our understanding of why some employees are job locked or are 'stuck' at their work even though dissatisfied. Using the British Household Panel Survey (BHPS), the possibility of falling in a job-lock state is analyzed to outline a set of factors that explain why employees differ in the way they adjust to job dissatisfaction. We divide these factors into socio-demographic features, personality attributes, type of occupation, employment conditions, type of sector, and workrelated contextual features. Based on results of probit regression analysis, we provide evidence that all these groups of factors can jointly predict the state of job dissatisfaction, the absence of job turnover and job lock (being 'stuck' at job). Moreover, our results suggest that the adaptation to job dissatisfaction could be better understood if personality attributes (such as self-esteem) are included in the analysis. Thus, this study expands our understanding of how and why employees might feel 'stuck' at work and fall in a state of job lock.
\end{abstract}


Chapter 2: A new perspective on job lock

If you're not enjoying your work, you should either change your attitude, or change your job. Count Leo Nikolaevich Tolstoy

\subsection{Introduction}

Successful adaptation to feelings of dissatisfaction at work implies that an employee adjusts and consequently, job dissatisfaction remedies (Rosse \& Miller, 1984). This chapter analyses the situation when an employee fails to adapt to overall job dissatisfaction. As explained in Chapter 1, the inability to adapt to job dissatisfaction may have adverse effects on both the employee and the organization. It may lead to distress for the employee (Martin \& Schermerhorn, 1983; Rosse \& Hulin, 1985). Eventually, distress can cause physical and mental health problems (Rosse \& Hulin, 1985) that could result in low productivity for the organization (Chmiel, 2000). Moreover, employees who stay dissatisfied may cause extra costs for the organization due to their negative attitude and withdrawal behavior that they may display (Hanisch, 2002). Yet, much more is known about the reasons why employees leave the organization than about the situation of staying with the organization even though they remain dissatisfied (Mitchell, et al., 2001).

As outlined in Section 1.2.4., researchers use two terms to describe the situation of being dissatisfied with a job and not quitting. Economists use the term 'job lock' while psychologists refer to this situation as being 'stuck' at work. The term 'job lock' has not been clearly defined in the economic literature but it is mostly associated with employees who do not feel free to leave their jobs because of the limited portability of employer-related pension fund participation and/or health insurance, specifically in the US (Adams, 2004; Berger, Black, \& Scott, 2004; Dorsey, 1995; Gilleskie \& Lutz, 2002; Gruber \& Madrian, 1993; Ippolito, 1991; Kapur, 1998; Madrian, 1994; Moncheit \& Cooper, 1994). Thus, job lock is treated by economists as dependent on external factors. More recent studies on job lock apply a difference-in-differences approach (Madrian, 1994), which allows to distinguish the effect 
Chapter 2: A new perspective on job lock

of employer-provided pension fund and/or health insurance from other (unobservable) factors that might lead to job lock. However, these studies have their shortcomings as well. Except for the additional demographic information, the analytical models applied in job lock studies are lacking personality factors that are essential for explaining behavior such as being dissatisfied with a job and not quitting (Miller \& Rosse, 2002).

At the same time, psychological research on employees' feeling of being 'stuck' at work draws extensively on such personality factors to clarify what keeps employees hooked in their job even if they are dissatisfied. These factors refer to continued commitment (Allen \& Meyer, 1990), job investments (Farrell \& Rusbult, 1981), and job embeddedness (Mitchell, et al., 2001). For example, employees who are dissatisfied with their job may choose to stay if: (1) they perceive a lack of alternatives (Allen \& Meyer, 1990); (2) they perceive that the costs of leaving the organization would be high, for example due to non-portable skills (Farrell \& Rusbult, 1981); (3) they are 'stuck' in the web of job embeddedness, e.g. due to the connection to others or the fit between the job with other aspects of life (Mitchell, et al., 2001). Given these research outcomes in the field of psychology, it becomes apparent that apart from factors discussed in the economic literature, factors related to the personality of the employee, may also explain the decision not to move to another job even though dissatisfied. As Diener and his colleagues stated (Diener, et al., 2009), researchers are facing the challenge to discover the factors that control the adaptation process as well as better understand individual differences in adaptation. Knowing that adaptive behavior (those reducing job dissatisfaction) is trainable (Frayne \& Geringer, 2000), we expect that knowledge about the adaptation process and the individual differences in it, would lead to taking more adequate actions in order to help employees to deal with adaptation issues on the workplace and to guide employees in efficiently addressing adaptation problems. 
Chapter 2: A new perspective on job lock

The aim of this chapter is to combine the existing knowledge on job lock and employees' feeling of being 'stuck' at work to identify a set of factors that explain why some employees fail to adapt when dissatisfied with their job. By combining economic and psychological perspectives, the current study expands our understanding of why some employees are job locked or are 'stuck' at their job even though dissatisfied. Thus, we provide a new perspective on job lock and being 'stuck' at work.

We use data from the British Household Panel Survey (Taylor, et al., 2010). The dataset provides us with longitudinal data that allows us to identify employees who have fallen in the state of job lock (i.e. 'stuck' with their job) since this requires data from several subsequent years. The dataset also allows comparing those in a job-lock situation with other employees. In meta-analysis on intention-behavior relationships, Webb and Sheeran (Webb \& Sheeran, 2006) recommend in future research to use more non-intentional routes to action. In this regard, the longitudinal data in this dataset allows us to apply the peak-end rule to derive the affective value of experience-related variable (such as self-esteem). The peak-end rule implies that the fluctuation in the evaluation of experiences lived across time can be represented by the most extreme (peak) and final (end) evaluation of these experiences (Kahneman, Diener, \& Schwarz, 1999).

The following two sections outline the main findings of previous research in economics and psychology relevant to our study. The subsequent sections present a description of the data and data analysis, the results of our analysis, and their discussion. At the end, conclusions for management and research are drawn.

\subsection{Job lock, being 'stuck' at work and failure to adapt to job dissatisfaction}

Nowadays, workplaces require almost continuous adaptation by employees (Yeatts, et al., 2000). Job dissatisfaction is an antecedent to job adaptation behavior at work (Hulin, 1991; 
Chapter 2: A new perspective on job lock

Judge \& Hulin, 1991). It is an unpleasant experience and as such it provides an incentive for the employee to find a way to deal with it (Hulin, 1991; Rosse \& Miller, 2000). As explained in Section 1.2.3., adaptation theory implies that in response to job dissatisfaction, employees take decisions that result in various behavioral forms. Rosse \& Miller (Rosse \& Miller, 2000) for example, classify these behavioral forms into five categories: problem solving, exit, avoidance, equity-enhancing retaliation, and capitulation. Hulin (Hulin, 1991) provides a classification that comprises of two basic groups: psychological (e.g. lateness, hanging about on the job, and staying away from work responsibilities), and physical (e.g. absenteeism and job turnover). Hirschman (Hischman, 1970) categorizes responses to job dissatisfaction in three categories: exit (i.e. job mobility), voice (comprising the attempts of the employee to change the work environment), and loyalty (passive behavior which implies waiting for things to change).

Despite the differences in these classifications, they all suggest that employees respond differently to job dissatisfaction. Some employees, although not all, search and find another job when they are dissatisfied (i.e. job turnover/mobility). The job turnover could be either internal (i.e. new job within the same organization) or external (i.e. new job within another organization). There is ample evidence that such behavior overall helps employees to increase their job satisfaction (Ehrenberg \& Smith, 2000; Greenberg \& Baron, 2003; Hom, et al., 1992; Hom \& Griffeth, 1991; Krausz, et al., 2000; Mobley, 1977; Mobley, et al., 1979; Porter, 1973; Warters \& Roach, 1973). Other employees however, remain on the same job even though they are unhappy at work (Rosse \& Saturay, 2004). Those who remain on the same job, either adapt successfully and improve the level of their job satisfaction, or fail to adapt and stay dissatisfied (Rosse \& Miller, 1984). We refer to the latter situation as being in job lock (or being 'stuck' at work). 
Chapter 2: A new perspective on job lock

Thus, job lock (or being 'stuck' at work) is seen in this study as the absence of internal or external job turnover even though the employee experiences continuing job dissatisfaction. The identification of factors that contribute to the occurrence of such situation is the core of this study.

To define a plausible set of explanatory factors for our analysis, we reviewed the available empirical evidence related to possible determinants of job lock and being 'stuck' at work tested in previous studies. However, we also reviewed the evidence on possible determinants of job dissatisfaction and absence of job turnover since these two conditions are used to define the situation of job lock (or being 'stuck' at work). We considered evidence reported in both the economics and psychology literature.

Similar to previous reviews (Locke \& Latham, 1990; March \& Simon, 1958; Porter, 1973; Rosse \& Miller, 2000; Spector, 1997), we also found in our review that there are two broad groups of factors that potentially determine the state of job dissatisfaction, absence of internal or external job turnover (job immobility), and/or job lock (or being 'stuck' at work). These are employee's personal characteristics as well as work-related factors. Based on our literature review however, we also identified four specific sub-groups of factors that comprise these two broad groups:

- $\quad$ socio-demographic features, including age, gender, marital status, education and health status (Ang, Goh, \& Koh, 1993; Bender \& Heywood, 2006; Booth \& Francesconi, 1999; Clark, 1996, 1997b; Groot \& Verberne, 1997; Kapur, 1998; Royalty, 1998; Weiss, 1984)

- personality attributes, such as the big five personality traits, self-esteem, locus of control, commitment, job embeddedness, and job investments (Alavi \& Askaripur, 2003; Allen \& Meyer, 1990; Barrick \& Mount, 1991; Farrell \& Rusbult, 1981; 
Chapter 2: A new perspective on job lock

Griffeth \& Hom, 2004; Judge \& Bono, 2001; Judge, et al., 2001; Meyer \& Allen, 1991; Parkes, 1994; Rosse \& Miller, 1984; Rosse \& Noel, 1996; Zlatanovic, 2000)

- employment conditions, for example, the possibility for on-the-job training, insurance portability, employer-related pension plan, union membership, full- or part time work (Disney \& Emmerson, 2002; Dorsey, 1995; Elias, 1994; Gruber \& Madrian, 1993; Hughes \& Bozionelos, 2007; Ippolito, 1991; Krausz, et al., 2000; Meng, 1990) - work-related contextual features, for example unemployment rates in the region (Carsten \& Spector, 1987; Hulin, et al., 1985; March \& Simon, 1958)

The first two sub-groups listed above concern employee's personal characteristics and the last two sub-groups concern work-related factors. Personality characteristics that affect external mobility and internal mobility are considered to be similar, because both types of job mobility encompass adaptation to new environments and socio-emotional losses (Van Vianen, Feij, Krausz, \& Taris, 2003). In addition to this, we consider that variations between different occupations in different sectors might exist with regard to how employees deal with job dissatisfaction. This suggests that the type of occupation and type of sector also need to be added as sub-groups of factors in our analysis. Thus, we define six sub-groups of factors that we expect to determine the state of job dissatisfaction, absence of internal or external job turnover, and/or job lock (or being 'stuck' at work). Although various combinations of these sub-groups of factors have been tested in previous research, none of the studies that we identified, analyses the joint effect of all six-sub groups of factors on job dissatisfaction, absence of internal or external job turnover, and/or job lock (or being 'stuck' at work). We take this as an objective in our analysis.

From all these sub-groups, the group of personality attributes is especially essential for our analysis since we aim to combine economic and psychological perspectives to explain why some employees fall in the state of job lock ('stuck' with their job). In particular, as indicated 
Chapter 2: A new perspective on job lock

by our review of the literature, personality attributes have been taken into account in the area of psychology when studying the situation of being 'stuck' at work but not in the area of economics in conjunction with the group of work-related factors. We specifically focus on self-esteem as a key indicator of personality corresponding to the failure to adapt to job dissatisfaction. In the following section of the chapter, the importance of self-esteem in relation to job dissatisfaction, absence of job turnover, and job lock is discussed.

\subsection{Self-esteem as determinant of job dissatisfaction, job immobility, and job lock}

Judge and Hulin (Judge \& Hulin, 1993) claim that there are four core self-evaluations that determine our disposition towards job satisfaction: self-esteem, general self-efficacy, locus of control, and neuroticism. Core self-evaluation is a single construct. Core-self-evaluations proved to be a better predictor of job satisfaction compared to the BIG Five model (Judge \& Bono, 2001). Judge and Bono (Judge \& Bono, 2001) explicitly note that they consider "selfesteem to be the most fundamental manifestation of core self-evaluations as it represents the overall value that one places on oneself as a person".

Job satisfaction (as well as job dissatisfaction) is one of the attitudes that the employee has towards work. It is related to other personal attitudes as well (Eagly \& Chaiken, 1993). Attitude theory distinguishes between affective (feelings), cognitive (beliefs), and behavioral (actions) attitudes. Attitudes originate from some basic system of values. As a consequence, there is a tendency towards internal consistency of attitudes. In addition, attitudes are perceived to play a role in adaptation by helping people to gain an understanding of the world. Thus, attitude theory argues that work-related attitudes are relatively stable in time and have an impact on behavior (Lecky, 1969; Pervin, 1975; Rogers, 1951).

In the search for an answer to the question of what makes people happier, research shows that self-esteem is one of the main determinants of satisfaction (Sheldon, Elliot, Kim, \& Kasser, 
Chapter 2: A new perspective on job lock

2001). In general, self-esteem is defined as the attitude towards yourself. Correspondingly, people with positive self-esteem are more likely to report satisfaction with various dimensions in life, including job satisfaction (Judge \& Bono, 2001; Locke, McClear, \& Knight, 1996; Zlatanovic, 2000). Rosenberg (Rosenberg, 1979) perceives self-esteem as an attitude related to worthiness as a person and as essential to our behavior. Rosenberg (Rosenberg, 1979) argues that there are several ways in which our attitudes towards ourselves resemble our attitudes towards other things. The resemblances are related to the content of the attitude, direction (positive or negative), and intensity (how stable and long lasting it is). Thus, we can expect that job satisfaction and self-esteem would share the same content, direction, and intensity. In addition, self-esteem has a relation to the occurrence of dissatisfaction (Karanikola, Papathanassoglou, Giannakopoulou, \& Koutroubas, 2007; Salmela-Aro \& Nurmi, 2007), adaptation (Graziano, Jensen Campbell, \& Finch, 1997; Schweitzer, SethSmith, \& Callan, 1992), memory selectivity (Tafarodi, Marshall, \& Milne, 2003) and difficulties with career decision-making (Saka \& Gati, 2007; Sorensen, 2001). Self-esteem is essential to explain job turnover as well. Job turnover models have been influenced by decision theory, attitude theory, sociology and labor economics (Steel \& Lounsbury, 2009a). Different turnover models paid attention to different personality variables but they all hypothesize that individual differences have an effect on job turnover (Hom \& Griffeth, 1995; March \& Simon, 1958; Mobley, et al., 1979; Rosse \& Miller, 2000; Steers \& Mowday, 1981). However, there is no consensus about the approach to the integration of personality in models that try to analyze withdrawals or job turnover (Rosse \& Noel, 1996). Allen and Meyer's three component model of organizational commitment and turnover intentions (Meyer \& Allen, 1991) states that each component (affective, normative, continuance commitment) influences employee's turnover intentions and behavior. The study of Jaros (Jaros, 1997) shows that the relationship between organizational commitment and 
Chapter 2: A new perspective on job lock

turnover intentions may be more multifaceted than described in the Allen and Meyer model. The results of this study show that the three components of commitment have a different effect on turnover intentions. The employees' affective commitment to the organization is the most important component of organizational commitment in predicting turnover intentions (Jaros, 1997). Affective commitment and self-esteem motivate citizenship behavior (Bergami \& Bagozzi, 2000; Tang \& Gilbert, 1994). As Rosse and Miller (Rosse \& Miller, 2000) state, how people deal with dissatisfaction depends on differences in personality and situation. Demographic characteristics have an effect on the way people adapt. Self-esteem also has a strong influence on individual behavior (Baumeister, 1993). People with an above-average level of self-esteem can adjust better and are more socially effective (Jorgensen \& Dusek, 1990). The level of self-esteem may also be seen as a motivational trigger (Wood \& Bandura, 1989). Moreover, employees with low self-esteem more often use passive coping strategies in response to stress than those with high self-esteem (Kinicki \& Latack, 1990; Parker, Chmiel, \& Wall, 1997). Thus, decisions people make are influenced by how they value themselves. Their self-value may be an answer to the discrepancies from the perfect rationality concept (Gao et al., 2004). Those with low self-esteem are more likely to attribute their unsatisfactory situation to themselves (Hirschy \& Morris, 2002) in order to maintain the way they look at themselves (Herzberg, et al., 1964).

Beforehand, turnover is a risky decision (Allen, Renn, Moffitt, \& Vardaman, 2007). Knowing that people with lower self-esteem are reluctant to take risks and engage in new activities (Sorensen, 2001) and are more risk averse (Josephs, Larrick, Steele, \& Nisbett, 1992), it could be expected that they are less inclined to use active coping mechanisms, e.g. search for another job when dissatisfied with their current job.

Further, some people are maximizers and others are satisfiers (Schwartz et al., 2002). Maximizers care more about the outcomes of their decisions and the results of choices may 
Chapter 2: A new perspective on job lock

convey information about themselves. Thus, being a maximizer with low self-esteem might bring even more stress to the person when facing an unsatisfactory situation in the decision process (Schwartz, et al., 2002).

Given the considerations above, the inclusion of self-esteem in our study can be crucial for explaining why people respond in different ways to similar causes and levels of job dissatisfaction, and perform behavior that seem to be irrational in economic terms (not utility maximizing) such as staying in a job lock even though dissatisfied.

\subsection{Data and variables}

For our empirical analysis, we use BHPS data. In this chapter, we only use the data for the period from 1991 to 1996 when suitable questions on job satisfaction and job turnover were used. The sub-sample extracted for our study consists of all men and women in the panel who were employed for at least at two consecutive years (two survey waves) during the period mentioned above (excluding self-employed persons). Thus, the sub-sample includes 17,627 individuals. Due to missing data for job satisfaction, job turnover and/or self-esteem, data for 14,341 individuals are included in the analysis.

The availability of data in the BHPS is the primary criterion applied for the selection and operationalization of variables for our analysis. The following considerations are taken into account:

- Job lock (being 'stuck' at work): Previous research does not indicate how long it takes for employees to adapt and what is the time lag between different adaptation decisions. On the basis of the results of the research of Hanisch (Hanisch, 2002) that shows that the average thinking about quitting is one year, we assume that if an employee continues to be dissatisfied with his/her job for two subsequent years and at the same time stays in the same job, the employee is in a state of job lock. The job lock variable is constructed as a dummy variable 
Chapter 2: A new perspective on job lock

( 0 = job satisfaction and/or internal or external job turnover in one or two subsequent years, i.e. not in job lock; $1=$ job dissatisfaction and absence of internal or external job turnover in two subsequent years, i.e. in job lock).

- Job dissatisfaction: The variable that presents job dissatisfaction is also constructed as a dummy based on the overall measurement of job satisfaction $(0=$ job satisfaction in one or two subsequent years; 1 = job dissatisfaction in two subsequent years). Job satisfaction is measured in the BHPS on a seven-point Likert scale. To transform it to a binary variable that indicates the state of job dissatisfaction, categories from 'somewhat satisfied' to 'completely satisfied' with work are collapsed to 'satisfied', and categories from 'not satisfied at all' to 'neither satisfied nor dissatisfied' are collapsed to 'dissatisfied'. The category 'neither satisfied nor dissatisfied' is seen as indicative of not being all that satisfied with the job and hence, it is included in the 'dissatisfied' category. The reason for this is the existing evidence that respondents frequently give socially desirable answers to questions on job satisfaction (Arnold, Feldman, \& Purbhoo, 1985). Thus, they tend to over-present the level of their job satisfaction, also when stating that they are 'neither satisfied nor dissatisfied' with their job. We use a dummy to specify job dissatisfaction because a single-item measure of job satisfaction (respectively, job dissatisfaction) has proven to be an acceptable measurement instrument (Oshagbemi, 1999; Van Saane, Sluiter, Verbeek, \& Frings-Dresen, 2003; Wanous, Reichers, \& Hudy, 1997).

- Absence of job turnover (job immobility): The variable that presents the absence of job turnover considers both internal and external turnover. It is derived from the measurement of tenure. In the BHPS, tenure is expressed as the date when the employee started working in his/her present position (i.e. not for the present employer), which includes both internal and external job turnover. Thus, the absence of job turnover is a dummy constructed as follows: 0 
Chapter 2: A new perspective on job lock

$=$ internal or external job turnover when tenure is less than two years, and $1=$ absence of internal or external job turnover when tenure is greater or equal to two years.

The main argument for constructing the above variables as dummies is that these variables are used to define the state of job dissatisfaction and the possible reactions to it in a similar fashion. Specifically, the above variables allow us to identify and study the following groups of employees:

- Employees who reported job dissatisfaction for two subsequent years (job dissatisfaction $=1$ )

- Employees who did not change their job for two subsequent years (absence of job turnover $=1$ )

- Employees who fell in the state of job lock (job dissatisfaction $=1$, absence of job turnover $=1$, job lock $=1$ )

Our objective is to explain the probability of falling in one of these states using a set of explanatory variables. For this purpose, the variables job dissatisfaction, absence of job turnover (internal or external) and job lock are taken as dependent variables. The explanatory variables that we use to explain variations in the dependent variables, are presented in Table 2.1.. The selection of the explanatory variables is based on the possible determinants of job dissatisfaction, absence of internal or external job turnover and job lock that we identify above (see the second section) based on a literature review, constrained by the availability in the BHPS. Thus, based on the results of the literature review, we divide the explanatory variables into two main groups (employee's personal characteristics and work-related factors) and in six sub-groups: socio-demographic features, personality attributes, type of occupation, employment conditions, type of sector, and work-related contextual features. For each subgroup, we include relevant explanatory variables to represent that sub-group but depending on the data available in the BHPS. In addition to explanatory variables that represent the six sub- 
Chapter 2: A new perspective on job lock

groups, we also add tenure as explanatory variable to indicate the exact strength of job dissatisfaction and job immobility.

Although the coding of the explanatory variables presented in Table 2.1., is self-explicable, the coding of minimum peak-end self-esteem requires additional explanation. Minimum peakend self-esteem is constructed using the peak-end rule. The peak-end rule is a formula that helps to estimate the global evaluation of a construct (i.e. self-esteem) during a given period (Fredrickson \& Kahneman, 1993b). It states that the affective value of the construct at a certain moment is a simple average of the peak (the most extreme evaluation of the construct during the period) and the end (the evaluation of the construct near the end of the period). A more detailed explanation of peak-ends can be found in Kahneman, Diener \& Schwarz (Kahneman, et al., 1999).

We include minimum peak-end self-esteem due to the personality differences in memory selectivity (Tafarodi, et al., 2003) that respondents may have experienced. The self-esteem variable, and thus, also the resulting minimum peak-end self-esteem, is derived from the answer to the question: "Have you recently been thinking of yourself as a worthless person?". The response is measured on a Likert scale, self-reported measure of self-esteem, which has proven to be appropriate for large scale surveys and longitudinal studies (Robins, Hendin, \& Trzesniewski, 2001). Inclusion of both positively and negatively worded items when measuring self-esteem, prove to bring systematic biases that restricts the measurement of the trait (Horan, Di Stefano, \& Motl, 2003).

\subsection{Data analysis}

Our analysis consists of two steps. First, we test the effect of all explanatory variables shown in Table 2.1., on each of the three dependent variables separately: job dissatisfaction, absence of job turnover (internal and external), and being in job lock. Given the binary nature of the 
Chapter 2: A new perspective on job lock

dependent variable, binary probit regression is used for the analysis (statistics software package STATA). Since the magnitude of the coefficients estimated in a binary regression, does not indicate the exact effect of an explanatory variable on the dependent binary variable (Long, 1997), we also estimate the marginal effects of the explanatory variables. The marginal effects indicate the change in the probability of observing code 1 in the dependent variable (i.e. being dissatisfied, not changing job, or being in job lock respectively) when the explanatory variable is increased with one unit. Marginal effects are also often called discrete changes in probability of being in a given state.

Second, due to the fact that we select only employed people for our study (those who are employed and report their job satisfaction), this may lead to a non-randomly selected sample. Thus, it might be that the sample over-represents more satisfied workers. For this reason, we additionally perform a Heckman type two-step procedure in order to correct for non-randomly selected sample (Heckman, 1979). This procedure also enables us to identify the determinants of turnover among the sample of dissatisfied employees and to analyze why some employees stay with their job even though they remain dissatisfied. First 'being overall job dissatisfied' in two subsequent years is modeled and then 'not changing job despite being dissatisfied' in two subsequent years' is modeled. The occupation variable is chosen as an instrumental variable (variable that predicts job dissatisfaction but is not related to turnover among the dissatisfied employees in the binary regression analysis).

\subsection{Results from the data analysis}

Table 2.1. presents descriptive statistics related to the explanatory variables used in our analysis. As can be seen from the table, the employees included in our analysis, are on average 38 years old. The sample is evenly divided among the gender groups. Most of the employees are married, their subjective health status is on average good and their min peak- 
Chapter 2: A new perspective on job lock

end self-esteem is overall high. Employees are equally distributed among occupation groups and most of them work in the private sector. About one-third of the employees have promotion opportunities. Most employees work full time and only about one-third are parttime employees. Less than one-third of the employees in our analysis are members of a trade union, $64.3 \%$ of them did not receive any job-related training and $21 \%$ reported participation in an employee pension fund.

At the bottom of Table 2.1., the descriptive statistics related to the dependent variables are presented. The table indicates that $6.6 \%$ of the employees in our study, are dissatisfied with their job but did not change their job, i.e. they are in a state of job lock.

Table 2.2. contains the results of the three binary probit regressions for being dissatisfied, not changing job, and being in job lock respectively. The table also presents the discrete changes in the probability of being in those states (i.e. the marginal effects). The estimates of these discrete changes in probability, indicate the effect of a one-unit increase in an explanatory variable on the probability of being dissatisfied, not changing job, and being in job lock respectively (as a percentage).

Overall, the outcomes of this regression analysis show that among all employees, employees with low self-esteem are more likely to experience job dissatisfaction, to be immobile and to be in a state of job lock. In addition to this, employees working in specific occupations (i.e. manager and administrative, associate professional, personal and protective service) less often report job dissatisfaction than other groups of employees and less often fall in a job-lock situation. Employees who are young, without employer pension scheme, and recently employed on the current job (tenure) significantly less often change their job than other employees. At the same time, being young, working long time on the same job and with employer pension scheme is associated with a higher probability of being in job lock compared to all other employees. And finally, the same as for job dissatisfaction, being male 


\section{Chapter 2: A new perspective on job lock}

Table 2.1.: Descriptive statistics

\begin{tabular}{|c|c|c|c|c|c|c|c|}
\hline Variable group & & $\mathrm{N}$ & Range or coding & Frequency & Median & Mean & $\begin{array}{l}\text { Std. } \\
\text { Deviation }\end{array}$ \\
\hline \multirow{4}{*}{$\begin{array}{l}\text { Socio-demographic features } \\
\text { (personal characteristics, } \\
\text { explanatory variables) }\end{array}$} & Age & 17627 & From 15 to 81 & & 37 & 37.757 & 11.9729 \\
\hline & Gender & 17627 & $\begin{array}{l}0=\text { woman } \\
1=\text { man }\end{array}$ & $\begin{array}{l}9039 \\
8588 \\
\end{array}$ & 0 & 0.4872 & 0.49985 \\
\hline & Health status & 17627 & $\begin{array}{l}0=\text { bad } \\
1=\text { good }\end{array}$ & $\begin{array}{l}726 \\
16901 \\
\end{array}$ & 1 & 0.9588 & 0.19873 \\
\hline & Marital status & 17627 & $\begin{array}{l}0=\text { not married } \\
1=\text { married }\end{array}$ & $\begin{array}{l}6816 \\
10811\end{array}$ & 1 & 0.6133 & 0.48700 \\
\hline $\begin{array}{l}\text { Personality attributes } \\
\text { (personal characteristics, } \\
\text { explanatory variables) }\end{array}$ & Min peak-end self-esteem & 14341 & $\begin{array}{l}0=\text { high } \\
1=\text { low }\end{array}$ & $\begin{array}{l}13088 \\
1253\end{array}$ & 0 & 0.0874 & 0.28239 \\
\hline \multirow{9}{*}{$\begin{array}{l}\text { Type of occupation } \\
\text { (work-related factors, } \\
\text { explanatory variables) }\end{array}$} & Manager \& administrators & 17627 & $\begin{array}{l}0=\text { no } \\
1=\text { yes }\end{array}$ & $\begin{array}{l}15429 \\
2198\end{array}$ & 0 & 0.1247 & 0.33038 \\
\hline & Professional & 17627 & $\begin{array}{l}0=\text { no } \\
1=\text { yes }\end{array}$ & $\begin{array}{l}15768 \\
1859\end{array}$ & 0 & 0.1055 & 0.30716 \\
\hline & Associate professional/technical & 17627 & $\begin{array}{l}0=\text { no } \\
1=\text { yes }\end{array}$ & $\begin{array}{l}15736 \\
1891\end{array}$ & 0 & 0.1073 & 0.30948 \\
\hline & Clerical \& secretarial & 17627 & $\begin{array}{l}0=\text { no } \\
1=\text { yes }\end{array}$ & $\begin{array}{l}14081 \\
3546 \\
\end{array}$ & 0 & 0.2012 & 0.40089 \\
\hline & Craft & 17627 & $\begin{array}{l}0=\text { no } \\
1=\text { yes }\end{array}$ & $\begin{array}{l}15799 \\
1828 \\
\end{array}$ & 0 & 0.1037 & 0.30489 \\
\hline & Personal \& protective service & 17627 & $\begin{array}{l}0=\text { no } \\
1=\text { yes }\end{array}$ & $\begin{array}{l}15689 \\
1938\end{array}$ & 0 & 0.1099 & 0.31283 \\
\hline & Sales & 17627 & $\begin{array}{l}0=\text { no } \\
1=\text { yes }\end{array}$ & $\begin{array}{l}16367 \\
1260 \\
\end{array}$ & 0 & 0.0715 & 0.25763 \\
\hline & Plant \& machine & 17627 & $\begin{array}{l}0=\text { no } \\
1=\text { yes }\end{array}$ & $\begin{array}{l}15904 \\
1723 \\
\end{array}$ & 0 & 0.0977 & 0.29698 \\
\hline & Other occupations & 17627 & $\begin{array}{l}0=\text { no } \\
1=\text { yes }\end{array}$ & $\begin{array}{l}16244 \\
1383 \\
\end{array}$ & 0 & 0.0785 & 0.26890 \\
\hline \multirow{5}{*}{$\begin{array}{l}\text { Employment conditions } \\
\text { (work-related factors, } \\
\text { explanatory variables) }\end{array}$} & Member of the trade unions & 17627 & $\begin{array}{l}0=\text { no } \\
1=\text { yes }\end{array}$ & $\begin{array}{l}15245 \\
2382 \\
\end{array}$ & 0 & 0.1351 & 0.34188 \\
\hline & Promotion opportunities & 17627 & $\begin{array}{l}0=\text { no } \\
1=\text { yes }\end{array}$ & $\begin{array}{l}13414 \\
4213\end{array}$ & 0 & 0.2390 & 0.42649 \\
\hline & Employer pension scheme & 17627 & $\begin{array}{l}0=\text { no } \\
1=\text { yes }\end{array}$ & $\begin{array}{l}13925 \\
3702\end{array}$ & 0 & 0.2100 & 0.40733 \\
\hline & On-the-job training & 17627 & $\begin{array}{l}0=\text { no } \\
1=\text { yes }\end{array}$ & $\begin{array}{l}11364 \\
6263 \\
\end{array}$ & 0 & 0.3553 & 0.47862 \\
\hline & Fulltime contract & 17627 & $\begin{array}{l}0=\text { no } \\
1=\text { yes }\end{array}$ & $\begin{array}{l}3841 \\
13786\end{array}$ & 1 & 0.7821 & 0.41283 \\
\hline \multirow{8}{*}{$\begin{array}{l}\text { Type of sector } \\
\text { (work-related factors, } \\
\text { explanatory variables) }\end{array}$} & Private & 17627 & $\begin{array}{l}0=\text { no } \\
1=\text { yes }\end{array}$ & $\begin{array}{l}7736 \\
9891\end{array}$ & 1 & 0.5611 & 0.49626 \\
\hline & Civil & 17627 & $\begin{array}{l}0=\text { no } \\
1=\text { yes }\end{array}$ & $\begin{array}{l}16992 \\
635 \\
\end{array}$ & 0 & 0.0360 & 0.18636 \\
\hline & Governmental & 17627 & $\begin{array}{l}0=\text { no } \\
1=\text { yes }\end{array}$ & $\begin{array}{l}15561 \\
2066\end{array}$ & 0 & 0.1172 & 0.32168 \\
\hline & NHS or higher education & 17627 & $\begin{array}{l}0=\text { no } \\
1=\text { yes }\end{array}$ & $\begin{array}{l}16509 \\
1118\end{array}$ & 0 & 0.0634 & 0.24373 \\
\hline & National industry & 17627 & $\begin{array}{l}0=\text { no } \\
1=\text { yes }\end{array}$ & $\begin{array}{l}17442 \\
185\end{array}$ & 0 & 0.0105 & 0.10191 \\
\hline & Non-profit & 17627 & $\begin{array}{l}0=\text { no } \\
1=\text { yes }\end{array}$ & $\begin{array}{l}17198 \\
429\end{array}$ & 0 & 0.0243 & 0.15410 \\
\hline & Army & 17627 & $\begin{array}{l}0=\text { no } \\
1=\text { yes }\end{array}$ & $\begin{array}{l}17549 \\
78 \\
\end{array}$ & 0 & 0.0044 & 0.06638 \\
\hline & Other sector & 17627 & $\begin{array}{l}0=\text { no } \\
1=\text { yes }\end{array}$ & $\begin{array}{l}7736 \\
9891\end{array}$ & 1 & 0.5611 & 0.49626 \\
\hline $\begin{array}{l}\text { Contextual features } \\
\text { (work-related factors, } \\
\text { explanatory variables) } \\
\end{array}$ & Regional unemployment rate & 17627 & From 6.40 to 13.70 & & 9 & 9.4386 & 1.88590 \\
\hline $\begin{array}{l}\text { Additional } \\
\text { explanatory variable } \\
\text { (indicators of the strength of } \\
\text { dependent variables) }\end{array}$ & Tenure & 17627 & From 0 to 51 & & 3 & 5.4594 & 5.90355 \\
\hline \multirow{3}{*}{$\begin{array}{l}\text { Dependent } \\
\text { variables }\end{array}$} & Job dissatisfaction & 14341 & $\begin{array}{l}0=\text { satisfied } \\
1=\text { not satisfied }\end{array}$ & $\begin{array}{l}16252 \\
1375 \\
\end{array}$ & 0 & 0.0780 & 0.2682 \\
\hline & Absence of job turnover & 14341 & $\begin{array}{l}0=\text { job turnover } \\
1=\text { no job turnover }\end{array}$ & $\begin{array}{l}987 \\
16640 \\
\end{array}$ & 0 & 0.0560 & 0.2299 \\
\hline & Job lock/being 'stuck' & 14341 & $\begin{array}{l}0=\text { not in job lock } \\
1=\text { in job lock }\end{array}$ & $\begin{array}{l}16470 \\
1157\end{array}$ & 0 & 0.0656 & 0.2476 \\
\hline
\end{tabular}




\section{Chapter 2: A new perspective on job lock}

Table 2.2.: Results of binary probit regression

\begin{tabular}{|c|c|c|c|c|c|c|c|c|c|}
\hline \multirow[b]{3}{*}{ Explanatory variable } & \multicolumn{9}{|c|}{ Dependent variables } \\
\hline & \multicolumn{3}{|c|}{$\begin{array}{l}\text { Job dissatisfaction } \\
(0=\text { satisfied; } 1=\text { not satisfied })\end{array}$} & \multicolumn{3}{|c|}{$\begin{array}{l}\text { Immobility / absence of job } \\
\text { turnover } \\
\text { ( } 0=\text { job turnover; } 1=\text { no job } \\
\text { turnover) }\end{array}$} & \multicolumn{3}{|c|}{$\begin{array}{l}\text { Job lock/being 'stuck' } \\
(0=\text { not in job lock; } 1=\text { in job lock })\end{array}$} \\
\hline & Coefficient & Std. Error & $\begin{array}{l}\text { Marginal } \\
\text { effect } \\
\text { (\% points) }\end{array}$ & Coefficient & Std. Error & $\begin{array}{l}\text { Marginal } \\
\text { effect } \\
\text { (\% points) }\end{array}$ & Coefficient & Std. Error & $\begin{array}{l}\text { Marginal } \\
\text { effect } \\
(\% \text { points }) \\
\end{array}$ \\
\hline \multicolumn{10}{|l|}{ Socio-demographic features: } \\
\hline Age & -0.002 & 0.001 & -1.39 & $-0.022 * *$ & 0.003 & -7.61 & $-0.004^{*}$ & 0.002 & -2.40 \\
\hline Gender & $0.403 * *$ & 0.037 & 10.92 & -0.017 & 0.057 & -0.30 & $0.366^{* *}$ & 0.039 & 9.29 \\
\hline Health status & $-0.350 * *$ & 0.066 & -5.31 & -0.046 & 0.127 & -0.36 & $-0.350 * *$ & 0.069 & -5.06 \\
\hline Marital status & -0.024 & 0.034 & -0.69 & -0.077 & 0.058 & -1.33 & 0.011 & 0.037 & 0.29 \\
\hline \multicolumn{10}{|l|}{ Personality attributes } \\
\hline Min peak-end self-esteem & $0.521 * *$ & 0.046 & 11.18 & $0.207 *$ & 0.081 & 2.56 & $0.463 * *$ & 0.051 & 9.27 \\
\hline \multicolumn{10}{|c|}{ Type of occupation (reference category: Clerical \& secretarial ): } \\
\hline Manager \& administrators & $-0.334 * *$ & 0.059 & -5.67 & -0.901 & 0.088 & -1.02 & $-0.330 * *$ & 0.064 & -5.13 \\
\hline Professional & -0.096 & 0.059 & -1.61 & 0.054 & 0.099 & 0.54 & -0.064 & 0.064 & -1.01 \\
\hline Associate professional/technical & $-0.357 * *$ & 0.064 & -5.53 & -0.042 & 0.094 & -0.45 & $-0.320 * *$ & 0.069 & -4.62 \\
\hline Craft & -0.059 & 0.057 & -1.03 & 0.014 & 0.107 & 0.13 & -0.006 & 0.060 & -0.10 \\
\hline Personal \& protective service & $-0.321 * *$ & 0.067 & -4.79 & -0.114 & 0.100 & -1.14 & $-0.290 * *$ & 0.071 & -4.08 \\
\hline Sales & -0.028 & 0.072 & -0.39 & 0.036 & 0.107 & 0.33 & -0.032 & 0.080 & -0.41 \\
\hline Plant \& machine & 0.054 & 0.057 & 0.95 & 0.145 & 0.105 & 1.38 & 0.106 & 0.060 & 1.77 \\
\hline Other occupations & 0.023 & 0.067 & 0.34 & 0.092 & 0.123 & 0.75 & 0.066 & 0.070 & 0.93 \\
\hline \multicolumn{10}{|l|}{ Employment conditions: } \\
\hline Fulltime contract & $0.356^{* *}$ & 0.053 & 6.73 & 0.014 & 0.077 & 0.18 & $0.416^{* *}$ & 0.058 & 7.16 \\
\hline Employer pension scheme & $0.126^{*}$ & 0.051 & 2.46 & $-0.327 * *$ & 0.064 & -5.15 & $0.176^{*}$ & 0.057 & 3.09 \\
\hline Member of the trade unions & 0.158 & 0.056 & 2.81 & -0.109 & 0.071 & -1.58 & 0.081 & 0.063 & 1.26 \\
\hline On-the-job training & -0.045 & 0.034 & -1.35 & 0.027 & 0.056 & 0.49 & -0.029 & 0.034 & -0.81 \\
\hline Promotion opportunities & $-0.399 * *$ & 0.049 & -8.13 & 0.022 & 0.056 & 0.40 & $-0.629 * *$ & 0.061 & -10.55 \\
\hline \multicolumn{10}{|c|}{ Type of sector (reference category: Private): } \\
\hline Civil & $0.283 * *$ & 0.079 & 3.61 & 0.128 & 0.266 & 0.48 & $0.217 *$ & 0.083 & 2.63 \\
\hline Governmental & 0.031 & 0.061 & 0.51 & 0.277 & 0.242 & 1.15 & 0.024 & 0.063 & 0.38 \\
\hline NHS or higher education & -0.079 & 0.081 & -0.97 & 0.262 & 0.246 & 1.06 & -0.110 & 0.085 & -1.29 \\
\hline National industry & $0.518 * *$ & 0.119 & 4.36 & 0.418 & 0.348 & 1.20 & $0.501 * *$ & 0.122 & 4.11 \\
\hline Non-profit & $-0.346^{*}$ & 0.141 & -2.45 & 0.348 & 0.270 & 1.29 & $-0.503 *$ & 0.167 & -3.02 \\
\hline Army & 0.268 & 0.216 & 1.24 & 0.624 & 0.374 & 1.67 & 0.256 & 0.228 & 1.12 \\
\hline Other sector & -0.009 & 0.040 & -0.24 & 0.126 & 0.230 & 0.55 & $-0.117 *$ & 0.041 & -2.81 \\
\hline \multicolumn{10}{|l|}{ Work-related contextual features: } \\
\hline Regional unemployment rate & 0.007 & 0.008 & 0.82 & -0.021 & 0.013 & -1.56 & 0.005 & 0.009 & 0.57 \\
\hline \multicolumn{10}{|l|}{ Other explanatory variables: } \\
\hline Tenure & -0.001 & 0.003 & -0.35 & $-2.306^{* *}$ & 0.112 & -23.26 & $0.012 * *$ & 0.003 & 4.29 \\
\hline \multicolumn{10}{|l|}{ Other model characteristics: } \\
\hline Intercept & $-1.388 * *$ & 0.138 & & $2.892 * *$ & 0.357 & & $-1.470 * *$ & 0.143 & \\
\hline Observations & 14341 & & & 14341 & & & 14341 & & \\
\hline Pseudo $\mathrm{R}^{2}$ & 0.08 & & & 0.52 & & & 0.09 & & \\
\hline
\end{tabular}

* significant at $5 \%$ level; ${ }^{* *}$ significant at $1 \%$ level 
Chapter 2: A new perspective on job lock

with poor health, fulltime on the same job, with employment pension scheme, with no promotion opportunities working in civil and national industry sector significantly increases the probability that an employee is in a state of job lock, while the likelihood that the employee would experience job lock is lower for an employee who works in the nonprofit sector. Thus, when job dissatisfaction, job immobility and job lock are analyzed separately (taking all employees), the regression results for job lock show similarities with the results for job dissatisfaction but also some discrepancies when compared to the results for job immobility. It should be noted however, that in this step of the analysis, we compare those in a job lock situation to all other employees including both job-dissatisfied employees who change their job and job-satisfied employees who do not experience pre-conditions for job lock.

Table 2.3. presents the results of the two-step Heckman model, where we first select employees who are dissatisfied with their job and then we analyze job mobility within this group. This way, we analyze the situation of job lock only among those dissatisfied with their job. The results of the second step of the Heckman model (i.e. for immobility/absence of job turnover) suggest that among employees who report job dissatisfaction for two subsequent years, those who are young, with low self-esteem, without an employer pension scheme, and working for a short time with the employer are more likely to remain immobile even though they are dissatisfied with their job (i.e. are in a job-lock situation).

\subsection{Discussion of the results}

The results of the regression analysis allow us to study three groups of employees, namely employees who reported prolonged job dissatisfaction (in two subsequent years), employees who did not change their job for two subsequent years (incl. internal and external job 
Chapter 2: A new perspective on job lock

turnover), and employees who were in the state of job lock. We discuss here the factors that we identify in our analysis as statistically significant determinants of these states.

Table 2.3.: Heckman selection model of job dissatisfaction on job immobility controlling for occupation

\begin{tabular}{|c|c|c|c|c|}
\hline \multirow[t]{2}{*}{ Variables } & \multicolumn{2}{|c|}{$\begin{array}{c}\text { Job dissatisfied }(1) \\
(0=\text { satisfied; } 1=\text { not satisfied })\end{array}$} & \multicolumn{2}{|c|}{$\begin{array}{c}\text { Immobility/ absence of job turnover } \\
(2) \\
((0=\text { job turnover; } 1=\text { no job turnover })\end{array}$} \\
\hline & Coefficient & Standard error & Coefficient & Standard error \\
\hline Age & .0068 & 0.008 & $-.0221 * *$ & 0.003 \\
\hline Gender & $.0633 * *$ & 0.022 & -.0032 & 0.054 \\
\hline Health status & .0252 & 0.052 & -.0412 & 0.127 \\
\hline Marital status & -.0221 & 0.036 & -.0819 & 0.058 \\
\hline Min peak-end self-esteem & .0535 & 0.079 & $.2120 * *$ & 0.081 \\
\hline Fulltime contract & .0168 & 0.030 & .0053 & 0.074 \\
\hline Employer pension scheme & .0718 & 0.124 & $-.3406 * *$ & 0.062 \\
\hline Member of the trade unions & .0572 & 0.042 & -.0874 & 0.068 \\
\hline On-the-job training & -.0237 & 0.022 & .0158 & 0.055 \\
\hline Promotion opportunities & -.0398 & 0.022 & .0124 & 0.055 \\
\hline Civil & .1540 & 0.132 & .1306 & 0.266 \\
\hline Governmental & -.0111 & 0.158 & .3009 & 0.240 \\
\hline NHS or higher education & .0010 & 0.149 & .2612 & 0.246 \\
\hline National industry & -.1034 & 0.223 & .4583 & 0.347 \\
\hline Non-profit & -.0083 & 0.176 & .3461 & 0.270 \\
\hline Army & -.1118 & 0.276 & 6149 & 0.374 \\
\hline Other sector & .0584 & 0.123 & .1484 & 0.229 \\
\hline Regional unemployment rate & .0051 & 0.009 & -.0227 & 0.013 \\
\hline Tenure & .2509 & 0.473 & $-2.3021 * *$ & 0.1112 \\
\hline Manager \& administrators & -.0310 & 0.299 & & \\
\hline Professional & -.0106 & 0.034 & & \\
\hline Associate professional/technical & -.0412 & 0.031 & & \\
\hline Craft & -.0416 & 0.034 & & \\
\hline Personal \& protective service & -.0066 & 0.033 & & \\
\hline Sales & -.0114 & 0.034 & & \\
\hline Plant \& machine & .0131 & 0.033 & & \\
\hline Other occupations & -.0297 & 0.038 & & \\
\hline Constant & -.2129 & 0.315 & 8.22 & $2.8990 * *(0.353)$ \\
\hline$\rho$ & .3667 & & & \\
\hline$\lambda$ & -.3213 & & & \\
\hline rho & -.8762 & & & \\
\hline Number of observations & 14341 & & & \\
\hline Censored observations & 13362 & & & \\
\hline Uncensored observations & 979 & & & \\
\hline
\end{tabular}

$*$ significant at the $5 \%$ percent level $* *$ significant at the $1 \%$ level 
Chapter 2: A new perspective on job lock

\subsubsection{Socio-demographic features}

From all socio-demographic features included in our analysis, age appears to be a significant determinant of the absence of job turnover and being in job lock (both when we consider all employees and when we consider only those dissatisfied with their job). Gender and health status appear to be significant determinants of job dissatisfaction and being in job lock (when we consider all employees). Marital status does not appear to be a significant determinant in any of the three regression models.

Our results support the findings of a meta-analysis which shows a strong relationship between job satisfaction and health (Faragher, Cass, \& Cooper, 2005). This may be due to the current employment conditions which diminishes job satisfaction. Further, it can be expected that health problems diminish the quality of life and influences overall happiness. Our study confirms the results of the research of Rosse and Hulin (Rosse \& Hulin, 1985) which shows that those employees who are dissatisfied with their job and fail to adapt, thus who are in job lock, experience more physical and mental health problems compared to those employees who adapt successfully.

We find that the increase of age results in a higher probability of job turnover and less chance of being in job lock, but this does not significantly increase the probability of reporting job dissatisfaction. The effect of age on job turnover can be explained by the fact that in our study we do not differentiate between internal and external mobility. From the other side, elderly employees are less likely to end up in job lock, which can be explained by the fact that they adapt better when they grow older, they have had time to find a better match and have less need to change jobs.

We also find that being male significantly increases the chance of being dissatisfied and of being in a job lock (when we take into account all employees). Previous research has also shown that women tend to be more satisfied with their job than men (Clark, 1997a; Sousa- 
Chapter 2: A new perspective on job lock

Poza, 2000). Specifically, women are found to be more likely to quit their jobs (Booth, Francesconi, \& Garcia-Serrano, 1999). An explanation may be that women are more able to refrain from work because they create their identity through interdependent relationships and view their jobs as less central in their lives (Singh, Finn, \& Goulet, 2004). Alternatively, it may be more difficult for a man who is dissatisfied with his work to leave his job, given how important achievement and work are to men's identity. It might be that men invest more in specific human capital (Booth \& Francesconi, 1999). As a consequence, for a man, leaving his job would probably lead to a pay decrease. Men also frequently have the responsibility of being the main income provider. This may also contribute to their higher probability of not changing jobs and ending up in a job lock.

\subsubsection{Personality attributes - minimum peak-end self-esteem}

Self-esteem (specifically, minimum peak-end self-esteem) was used in our analysis to represent the personality attributes that might contribute to falling in a state of job lock. According to our results, peak-end self-esteem shows a statistically significant effect on all three states (being dissatisfied with the job, not changing the job and being in a job lock) and in both steps of the analysis. The probability of reporting job dissatisfaction, staying on the same job and being in job lock increases when self-esteem becomes lower. Furthermore, the increases in minimum peak-end self-esteem increase the odds of staying in the same job. Thus, we can conclude that minimum peak-end self-esteem has an effect on job immobility, currently experienced job dissatisfaction and job lock.

Our study confirms that when we solely have information on the employees' attitude towards himself, we can draw conclusions about the content and direction of his/her attitude towards work (Alavi \& Askaripur, 2003). People with high and low self-esteem differ in their attribution style. Moreover, low self-esteem individuals perceive the "negative events as being 
Chapter 2: A new perspective on job lock

more personally important than subjects with high in self-esteem" (Campbell, Chew, \& Scratchley, 1991). This may be an explanation why when experiencing prolonged job dissatisfaction low self-esteem employees who are dissatisfied with their job, choose more passive forms of adaptation and postpone decision-making compared to those with high selfesteem.

We may expect that people with lower self-esteem invest less in human capital as a result of not foreseeing enough worthy future gains. As a consequence such employees are likely to have less satisfying jobs and fewer opportunities for change on the labor market (Ellis \& Taylor, 1983). On the other side, if we use the arguments of William James (James, 1890), people relate their self-worth to certain areas of their life and there is a strong relationship between differential importance and self-esteem for people with low self-esteem (Pelham \& Swann, 1989). Thus, it might be that those employees who are in job lock connect their selfworth to work and achievement and consequently are more fearful of failure in those areas.

\subsubsection{Type of occupation}

Type of occupation appears significant only for two states: job dissatisfaction and being in job lock (when we take into account all employees). Specifically employees working as managers and administrators, administrative professionals, personal and protective occupations are less likely to be dissatisfied with their job and in a job lock. One of the background principles of Holland's theory (Holland, 1985) is that the choice of occupation is an expression of personality. Thus, occupation is a strong predictor of job satisfaction (Near, Rice, \& Hunt, 1978). Additionally, some occupations have a clear career ladder. Such occupations may provide more promotion opportunities, and the employees may therefore be more satisfied and less eager to move. 
Chapter 2: A new perspective on job lock

\subsubsection{Employment conditions}

Having a fulltime job, employment pension scheme and promotion opportunities are significant for the state of job dissatisfaction and being in job lock (when we consider all employees). This confirms the outcome of previous studies that fulltime workers are less satisfied (Sinclair, Martin, \& Michel, 1999). Besides, our study shows that fulltime working employees are more likely to stay dissatisfied and immobile. This can be explained by the importance of work to those who work fulltime. Additionally, it can be that commitment and job investments are higher for those working fulltime compared with part time workers. Further, availability of promotion opportunities is likely to make employees feel more satisfied and decreases the probability of being in a job lock.

The results of our study show that an employer-related pension scheme is statistically significant for reporting job dissatisfaction and being in job lock, as previous research also shows (Dorsey, 1995). Moreover, we found that employees who have an employer-related pension scheme are significantly more likely to change their job (both when we take into account all employees and only those dissatisfied with their job). This contradicts previous research findings (Gustman, Mitchell, \& Steinmeier, 1994) which reported that British employees who are covered by an employer-pension plan are found to be less mobile compared to those who are not covered. One explanation for our results might be that only when employees are dissatisfied, they remain immobile because of expected future gains and non-transferability of the pension. However, when we take into account all employees, a job lock situation is more often observed among those with a employer-related pension scheme.

\subsubsection{Type of sector}

The type of sector proves to be a strong predictor for the states of being dissatisfied and being in job lock when we take into account all employees. Employees in the non-profit sector are 
Chapter 2: A new perspective on job lock

less likely to be dissatisfied and are less likely to be in job lock than in other sectors. People working in non-profit organizations are highly committed to what they do and highly involved in their jobs because they experience a high utility from their work (Bacchiega \& Borzaga, 2001; Bacchiega \& Borzaga, 2003). Consequently, such employees have less drive to quit.

\subsubsection{Work-related contextual features}

The only contextual feature included in the analysis, is the regional unemployment rate. It appears to be insignificant for all three states and in both steps of the analysis. This can be explained by the fact that the employees' behavior might be influenced not by the actual job availability but by their perceptions of job availability (Van Vianen, et al., 2003).

\subsubsection{Tenure}

Tenure appears to be a significant predictor for job turnover and being in job lock. The longer the tenure the higher the chance that the employee would move. This can be explained by the fact that in our study we do not differentiate between internal and external mobility. And the longer the employee stays in a company the more chance he has to move internally. This also applies to the situation of job lock when we consider only employees who are job dissatisfied. Thus, when dissatisfied with their job, employees who work longer on the same job are more likely to change their job (either infernally or externally) than those who have been recently employed on the current job. However, when we take into account all employees, a job lock situation is more often observed among those who work longer on the same job. 
Chapter 2: A new perspective on job lock

\subsection{Conclusions}

In our study, we have integrated economics and psychology knowledge on job turnover, job dissatisfaction and job lock (being 'stuck' at job). According to our definition of job lock, $6.6 \%$ of the employees included in our analysis are in job lock, which indicates the relevance of the issue to vocational behavior.

The results of our analysis confirm that there are various factors that can explain why employees differ in the way they adjust to job dissatisfaction. We divide these factors into socio-demographic features, personality attributes, type of occupation, employment conditions, type of sector, and work-related contextual features, and provide evidence that all these factors can jointly predict the state of job dissatisfaction, the absence of job turnover and job lock (being 'stuck' at job). Moreover, our results suggest that the adaptation to job dissatisfaction could be better understood if personality attributes such as self-esteem are included in the analysis. Thus, this study expands our understanding of how and why employees might feel 'stuck' at work and fall in a state of job lock.

This study has its limitations, which combined with the results suggest some ideas for future research. In our analyses we include just the employed population. We do not account for labor market exit (those who left the market due to low levels of satisfaction with their job as well as those unable to find employment). Thus, the sample is selective. The use of probit analysis gave us an opportunity to analyze the same individual and organizational characteristics longitudinally. However, due to the fact that all cases are suppressed in probit, there is no way to estimate the variance. Further, for future research it might be interesting to test what type of adaptation behavior employees, who are in job lock, use.

It should be noted however, that cultures have been differentiated as individualism versus collectivism (Hofstede, 2001; Triandis, 2002) or embeddedness versus autonomy (Schwartz \& Boehnke, 2004). Due to the fact that the importance of self-esteem in collectivist and 
Chapter 2: A new perspective on job lock

individualistic nations differs (Brown, Cai, Oakes, \& Deng, 2009; Diener \& Diener, 1996), care should be taken in transferring the results of this study to other cultural contexts.

Despite these limitations, the results of our study might be of interest to researchers studying job mobility, job satisfaction and adaptation as to human resource managers and vocational counselors. It is essential to be aware of the nature of self-esteem in order to be able to diagnose it and treat it properly (Sorensen, 2001). Self-esteem moderates the relationship between role stressors and job satisfaction (Abraham, 1999; Jex \& Elacqua, 1999; Nelson \& LeRouge, 2001). Employers may need to consider the employees' preferences for certain levels of job stress while taking self-esteem in consideration (Nelson \& LeRouge, 2001). Even though there is still a debate, if self-esteem (seen as a personality trait) can be changed, some very promising results can be achieved when employees, human resource managers and vocational counselors pay attention to self-esteem issues. Moreover, there is increasing evidence that the brain constantly adapts, re-wires and re-balances itself (neuroplasticity) contingent on the experiences that someone is going through (Kolb \& Gibb, 2008). Thus, by consistently training to bypass the self-limiting beliefs and self-sabotage, it is possible to establish healthy self-esteem. A powerful form of training are the sentence completion (Branden, 1998) and Acceptance and Commitment therapy exercises (Hayes, 2005; Luoma, Hayes, \& Walser, 2007). Further, applying some advanced meridian therapies, which suggest that every limiting thought, upsetting feeling and memory is associated with disturbances of our body/mind energy system, can bring remarkably quick and thorough therapeutic effects (Connolly, 2004; Dwoskin \& Canfield, 2007; Gallo, 2002; Gallo, 2005; McGraty, Atkinson, Tiller, Glein, \& Warkins, 1995; McGraty, Atkinson, \& Tomasino, 2003). 


\section{Chapter 3}

Why do some employees fall into and fail to exit a job-lock situation?

This chapter draws upon:

Huysse-Gaytandjieva, A., Groot, W., \& Pavlova, M. (2013). Why do some employees fall into and fail to exit a job-lock situation? Journal of Environmental and Public Health, http://dx.doi.org/10.1155/2013/839349 
Chapter 3: Why some employees fall into and fail to exit a job lock situation?

\section{Abstract}

Employees, who are unable to adapt to job dissatisfaction, may find themselves in a job-lock situation (i.e. being dissatisfied with the job but remaining in the same job). Previous studies have paid little attention to the employees' ability to exit a job-lock situation and factors that determine this ability. It remains unclear why some employees who experience job lock are able to exit this state while others remain in job lock. The aim of this study is to investigate this issue. We use longitudinal data from the British Household Panel Survey to identify employees who have fallen in the state of job lock and their subsequent behavior - exiting or remaining in job lock. Our analysis includes 2,949 respondents who are employed for at least three years during the 1991-1996 period and report dissatisfaction with their job for at least two subsequent years. By use of a first-order Markov transition models, we analyze the relevance of socio-demographic features, employment, occupational, sectoral and contextual factors, as well as personality characteristics in explaining the transition or its absence.

Overall the results show that both demographic factors and work-related aspects increase the likelihood that an employee enters the long-term job lock state. Mental health problems and personality characteristics have a significant effect on the probability to stay in long-term job lock (failure to exit the job-lock state). Contrary, having certain occupations, promotion opportunities and working in the private sector increase the chance of an exit from the state of job lock. Our findings indicate a need to develop and incorporate on-job training programs tackling employees' personality characteristics in addition to other factors, in order to prevent job lock. 
Chapter 3: Why some employees fall into and fail to exit a job lock situation?

\subsection{Introduction}

The desire to adapt to feelings of dissatisfaction is natural. Dissatisfied employees are likely to try to reduce their job dissatisfaction and work-related stress by adjusting to their current job or by changing jobs (Cranny, et al., 1992; Dawis \& Lofquist, 1984; Rosse \& Miller, 2000). However, as explained in Chapter 1, some employees fail to adapt to job dissatisfaction. These employees stay dissatisfied even though some of them may exhibit adaptive behavior. When employees are unable to adapt and remain in their unsatisfactory work situation in the long run, they can fall into job lock (become stuck in their job). The work performance of these employees may be reduced, if prolonged dissatisfaction leads to a negative attitude towards their work and withdrawal behavior (Hanisch, 2002), which can bring extra costs to the employing organization.

Various studies in the fields of economics and psychology have investigated the phenomenon of job lock and its determinants following the perspective of their own field (some examples include (Adams, 2004; Allen \& Meyer, 1990; Berger, et al., 2004; Mitchell, et al., 2001)). As is shown in the study presented in Chapter 2, the combination of determinants proposed in the economics and psychology literature is found to have an important role in better understanding why some employees are in a job-lock situation (Huysse-Gaytandjieva, Groot, \& Pavlova, 2013a).

Nevertheless, both economics and psychology studies have paid little attention to the employees' ability to exit a job-lock situation and factors that determine this ability. It remains unclear why some employees who experience job lock are able to exit this state while others remain in job lock. Also, for those employees who leave the state of job lock, it may be asked what the mechanisms are by which this happens - do they adjust by becoming satisfied, do they use mobility as a way of dealing with dissatisfaction, or a combination of both? The 
Chapter 3: Why some employees fall into and fail to exit a job lock situation?

answers to these questions are important in developing interventions to assist employees to reduce work stress and successfully adapt to job dissatisfaction.

The aim of this study is to investigate the process of transition from a job-lock situation (i.e. being dissatisfied with the job but remaining in the same job) to other states, e.g. adjusting and becoming satisfied in the same job (immobile and job satisfied), changing jobs and becoming satisfied (mobile and job satisfied), or changing jobs but again becoming dissatisfied with the new job (mobile and job dissatisfied).

We compare those in job lock, who fail to make a transition, to those who experience one of the three transitions described above. Also, we compare the transition processes from the joblock state with the transition process to the job-lock state.

We combine insights from both economics and psychology studies to identify a set of possible transition determinants. In particular, based on the study results presented in Chapter 2, we make use of the socio-demographic, employment, occupational, sectoral and contextual factors but also of personality characteristics in explaining the transition or its absence. With regard to personality characteristics, we include an indicator of self-esteem as a key characteristic of personality in relation to job lock (Huysse-Gaytandjieva, et al., 2013a). In contrast to previous studies, we also include an indicator of procrastination, which is seen as a consequence of pre-existing personality characteristics (Ferrari, Johnson, \& McCown, 1995). We use data from the BHPS (Taylor, et al., 2010). The BHPS are longitudinal data and allow us to identify employees who have fallen in the state of job lock and their subsequent behavior - exiting or remaining in a job-lock. The dataset also provides indicators of both procrastination and self-esteem, in addition to other relevant factors mentioned above, which allows studying the joint effect of all groups of factors.

The following section provides background information outlining the relation between demographics, work-related factors and in particular personality characteristics 
Chapter 3: Why some employees fall into and fail to exit a job lock situation?

(procrastination and self-esteem) to job lock. The subsequent sections present our research methods and results of our analysis. The chapter concludes by a discussion on the relevance of our findings and suggestions for management and research.

\subsection{Long-term adaptation to job dissatisfaction}

Review studies in the area of economics and psychology (Locke \& Latham, 1990; March \& Simon, 1958; Porter, 1973; Rosse \& Miller, 2000; Spector, 1997) suggest that there are two broad groups of factors that potentially determine the state of job dissatisfaction, absence of turnover (job immobility), and/or job lock (or being 'stuck' at work). These groups are: employee's personal characteristics (socio-demographics and personality attributes) as well as work-related factors. The study in Chapter 2 (Huysse-Gaytandjieva, et al., 2013a) has used an interdisciplinary approach of labor economics and social psychology to study the state of job lock, combines indicators of these factors to explain why employees differ in the way they adjust to job dissatisfaction. Detailed elaboration on the relation between the group of factors and the job-lock state can be found in the previous chapter. In short, the study provides evidence that both group of factors (personal characteristics and work-related factors) can jointly predict the state of job lock. Among employees who report job dissatisfaction for two subsequent years, those who are young, with low self-esteem, without an employer pension scheme, and working for a short time with the employer are more likely to remain immobile even though they are dissatisfied with their job (i.e. are in a job-lock situation). Chapter 2 concludes that the adaptation to job dissatisfaction could be better understood if personality attributes (such as self-esteem) are included in the analysis (Huysse-Gaytandjieva, et al., 2013a). The analysis in this study goes one step further and investigates the effect of personal and work-related factors on falling into a state of long-term job lock (i.e. the inability to exit the job-lock state). In addition to self-esteem, we also include procrastination as a personality 
Chapter 3: Why some employees fall into and fail to exit a job lock situation?

attribute that can explain long-term job lock. Below we specifically discuss the importance of self-esteem and procrastination in relation to long-term job lock, which is seen as a selfregulation failure, i.e. failure to adapt.

\subsection{Self-esteem and procrastination in relation to long-term job lock}

Successful adaptation to job dissatisfaction is seen as an alleviation of the job dissatisfaction level as a result of engaging in some adjusting mechanism (Rosse \& Hulin, 1985). The more an employee becomes dissatisfied at work, the more likely he/she is to engage in impulsive reactive behavior (quitting, disengaging, retaliation), rather than adaptive behavior (problem solving or adjusting expectations) (Rosse \& Saturay, 2004).

There are various personality characteristics related to responses to dissatisfaction and adaptation. The value of self-esteem in the adaptation process is in particular emphasized in the literature (Adler, 1980; Graziano, et al., 1997; Korman, 1977; Nezlek \& Kuppens, 2008; Schweitzer, et al., 1992). Here, we concentrate on the role of positive feelings of self-worth (secure high self-esteem) in prolonged job lock (i.e. the failure to exit a job-lock state).

Self-esteem is shown to be a personality characteristic that protects people against stressful consequences (Lazarus \& Folkman, 1984). Thus, self-esteem is a personality characteristic that prevents people from experiencing long-term feelings of dissatisfaction. People with high self-esteem engage in positive, active attempts to cope with stressors (Ben-Zur, 2002; Carver, Scheier, \& Weintraub, 1989). Numerous studies relate low self-esteem to adjustment problems (Crocker, Luhtanen, Cooper, \& Bouvrette, 2003; Longmore, Manning, Giordano, \& Rudolph, 2004; Rosenberg, Schooler, Schoenbach, \& Rosenberg, 1989; Voss, Markiewicz, \& Doyle, 1999). Further, the ease of movement to another job is related to a subjective perception of available opportunities (Van Vianen, et al., 2003) and self-esteem (Gerhart, 1990; Jackofsky \& Peters, 1983). Those with low self-esteem tend to become preoccupied 
Chapter 3: Why some employees fall into and fail to exit a job lock situation?

with distress emotions, and are more likely to disengage from their goals when under stress. Low self-esteem not only strengthens negative feelings, but also undermines the ability to adequately cope with these feelings (Recktor \& Roger, 1997).

Much of the research about the relationship between self-esteem and health appears to have been done in terms of the influence of self-esteem on health-related behavior. From the other side, in a review of the self-esteem literature, Baumeister, Campbell, Krueger \& Vohs (Baumeister, Campbell, Krueger, \& Vohs, 2003), conclude that the benefits of high selfesteem fall into two categories: enhanced initiative and pleasant feelings. They deduce that self-esteem has little association with health behavior. Additionally, the well-established relationship between self-esteem and psychological well-being (e.g., depression, social anxiety, loneliness) (Blascovich \& Tomaka, 1991) may be an important factor in understanding the relationship between self-esteem and health.

Furthermore, a negative self-image is important for the occurrence of procrastination (Van Eerde, 2003a). Procrastinators show significantly lower self-esteem than non-procrastinators (Ferrari, 1991). Procrastination can be described as avoidance behavior, as "the avoidance of execution of an intended action" (Van Eerde, 2003b). Actions (for example making decisions, searching for another job) have a cognitive importance for the individual but they may bring unpleasant feelings which cause an approach-avoidance conflict. This responds to the Janis and Mann's conflict model of decision making (Janis \& Mann, 1977) which differentiates adaptive and non-adaptive patterns of coping with challenge. One of the non-adaptive patterns is defensive avoidance. It responds to the situation when any available alternative is perceived as risky and the decision-maker is not hopeful to find a better solution. As a consequence, an escape from making a decision by procrastinating is following. Two types of procrastination are distinguished: decisional, the purposive delay in making decisions, and behavioral, delaying tasks to protect oneself due to a vulnerable self-esteem (Ferrari, 1991). Decisional 
Chapter 3: Why some employees fall into and fail to exit a job lock situation?

and behavioral procrastination are significantly correlated with each other (Ferrari, 1994).

Chronic procrastinators compared to non-procrastinators, have high rates of anger, hostility, depression, and actively self-handicap their task performance (Ferrari, 1994).

Procrastination may become dysfunctional when people frequently habitually delay to begin or complete tasks (Ferrari, 1994). It may also affect job mobility i.e. delay mobility. In particular, procrastinators view their self-worth as determined by their ability (Burka \& Yuen, 1983). When people feel incapable of making decisions they might be more inclined to delay making a choice. Procrastinators, when they are dissatisfied with their job, might postpone job-seeking activities. This might be due to lower levels of self-determined job seeking motivation (Senecal \& Guay, 2000) or fear of failure if they try to search for a new job (Ferrari, 1992a; Schouwenburg, 1992). Consequently, this will lead to a delay or lack of job mobility (job turnover). Thus, in the long run, low self-esteem has a strong relationship with procrastination, distress and psychological health. Further, procrastinators fail to react based on their intentions (Van Hooft, Born, Taris, Van der Flier, \& Blonk, 2005) - job search intention and job search behavior. Though, based on the action phases model of Gollwitzer (Gollwitzer, 1996), it is important to distinguish a pre-decisional phase (taking in consideration how to achieve goals) and a post-decisional phase (choice of behavior). In this study, we are concerned with the pre-decisional procrastination phase. The cross-cultural study by Ferrari (Ferrari, O'Callaghan, \& Newbegin, 2005) that investigates the global rates of procrastination in the US, the UK and Australia, concludes that "procrastination is widespread in westernized, individualistic, English-speaking countries”.

Given the above, additionally to self-esteem, in this study, we include procrastination as a variable that can be seen as a consequence of pre-existing personality characteristics as selfesteem and as "an agent for bringing about adverse consequences of its own right" (Ferrari, et al., 1995). With regard to personality characteristics, we argue that people who are in job lock 
Chapter 3: Why some employees fall into and fail to exit a job lock situation?

may perceive themselves incapable of making decisions about adaptation to job dissatisfaction and may postpone making such decisions, or be incapable of changing their unsatisfactory work situation and choose to remain in the same state (Burka \& Yuen, 1983). Thus, both procrastination, i.e. the inability to make timely decisions (Effert \& Ferrari, 1989; Ellis \& Knaus, 1979; Janis \& Mann, 1977), and vulnerable self-esteem may play a role in explaining why some employees fall into or fail to exit a job-lock situation. While the importance of including self-esteem in job-lock models has been shown in our previous research, presented in Chapter 1 (Huysse-Gaytandjieva, et al., 2013a), the relevance of procrastination has not been studied yet. Moreover, little is known about decisional procrastination and its personality correlates (Beswick, Rothblum, \& Mann, 1988; Ferrari \& Emmons, 1994).Various disciplines have shown an interest in and studied procrastination. Economists have related procrastination to a lack of retirement savings behavior (O'Donoghue \& Rabin, 1998), while psychologists relate it to planning personal health issues (Harriott \& Ferrari, 1996; Sirois, 2004; Sirois, Melia-Gordon, \& Pychyl, 2003), regulation (Van Eerde, 2000) and job seeking (Senecal \& Guay, 2000). To our knowledge, till now, no study has considered procrastination directly in relation to job-to-job mobility, which is done in this chapter. On the basis of presented theoretical insights, we expect that employees with low self-esteem, who procrastinate and have mental health problems are more likely to enter longterm job lock compared to those who are with high self-esteem, do not procrastinate and do not have mental health problems.

\subsection{Materials and methods}

\subsubsection{Data}

We use data from the BHPS. Due to the change in the job satisfaction question in 1997, we only use data for the period 1991 to 1996 to assure the comparability across years. We include 
Chapter 3: Why some employees fall into and fail to exit a job lock situation?

in our sample all men and women in the BHPS who are employed for at least three consecutive years (three survey waves) in the period mentioned above, and who report dissatisfaction with their job for at least two subsequent years (2,949 respondents in total). Unemployed and self-employed individuals are excluded.

\subsubsection{Transition models}

To construct the models for our analysis, we use data related to job dissatisfaction and job immobility provided by the BHPS dataset. In particular, the job dissatisfaction variable for our analysis is derived from the BHPS variable that indicates the overall job satisfaction of a respondent measured on a seven-point Likert scale. Thus, we construct a dummy jobdissatisfaction variable for each year $(0=$ job satisfaction; $1=$ job dissatisfaction $)$. As in Chapter 2, the category 'neither satisfied nor dissatisfied' is seen as indicative of not being all that satisfied with the job (Arnold, et al., 1985) and hence, it is included in the 'dissatisfied' category.

We derive the job immobility variable from the BHPS variable that indicates tenure: "What was the date you started working in your present position, by that I mean the beginning of your current spell of the job you are doing now for your present employer?". If in a given year, tenure is greater or equal to one year, job immobility is coded with zero, and if tenure is less than one year, job immobility is coded with one. Thus, a dummy immobility variable is constructed for each year.

We use the operationalization of job lock provided in Chapter 2 (Huysse-Gaytandjieva, et al., 2013a), which is based on results reported by Hanisch (Hanisch, 2002), that the average time thinking about quitting is one year. An employee is in job lock if he/she is dissatisfied with his/her job for two subsequent years and at the same time he/she stays in the same job. Correspondingly, the employee is in a long-term job lock if he/she continues to be dissatisfied 
Chapter 3: Why some employees fall into and fail to exit a job lock situation?

with his/her job for more than two subsequent years and at the same time stays in the same job.

The job-dissatisfaction and job-immobility variables described above, as well as the operational definition of job lock, are used to construct two nominal dependent variables for our analysis to present transitions to and from a job-lock state respectively:

Transitions to the job lock state: $1=$ dissatisfied and immobile in the preceding year and remaining in this state for two subsequent years (thus, prolonged job lock); $2=$ mobile but dissatisfied with the job in the year before the job-lock state; $3=$ immobile but satisfied with the job in the year before the job-lock state; $4=$ mobile and satisfied with the job in the year before the job-lock state.

Transitions from the job lock state: 1=dissatisfied and immobile for two subsequent year and remaining in this state during the next year (thus, prolonged job lock); $2=$ mobile but still dissatisfied with the job in the year after the job lock state; $3=$ immobile but satisfied with the job in the year after the job lock state; $4=$ mobile and satisfied with the job in the year after the job lock state.

The two transition models are schematically presented in Figure 3.1. These are first-order Markov models where the probabilities of the values of the next state depend on the first order, thus on the previous state. Employees move through the two states according to four transitions per model as depicted in Figure 3.1 and as defined by the two nominal variables described above. The movement of employees among states over time is tracked by transition probabilities. Hausman tests are run and show no dependence between categories of the dependent variables, which proves that the odds are independent of other alternatives. We also define one binary dependent variable to compare those in a job-lock state (dissatisfied and immobile for two subsequent years, coded with 1) to those who are 
Chapter 3: Why some employees fall into and fail to exit a job lock situation?

Figure 3.1. Transition models

Transition to job lock

Transition from job lock

-

Following year

Preceding year

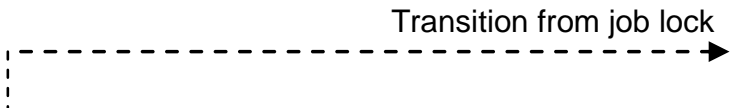

Dissatisfied

Dissatisfied

with the job

and

immobile

Dissatisfied
with the job
and
mobile

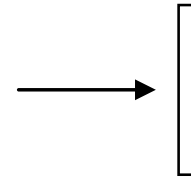

In job lock

$=$ dissatisfied with the job and immobile during 2 subsequent years

with the job

and

immobile

Satisfied

with the job

and
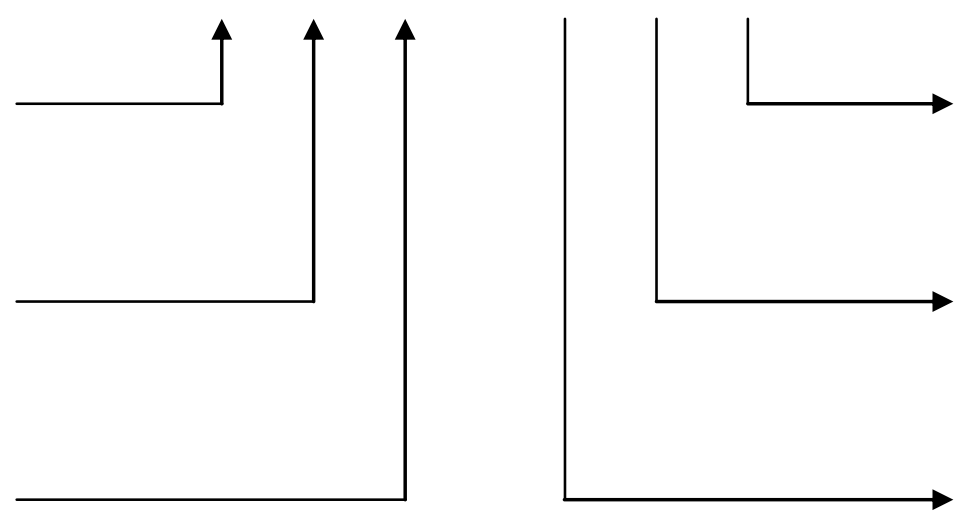

Dissatisfied with the job and

mobile

immobile

Satisfied

with the job

and

mobile

Satisfied with the job

and

immobile

Satisfied with the job and

mobile 
Chapter 3: Why some employees fall into and fail to exit a job lock situation?

dissatisfied with their job but remain mobile during at least one of the years (not in a job lock situation even though job dissatisfied for two subsequent years, coded with 0 ). This way, we include in our analysis all employees, who reported job dissatisfaction for two subsequent years (prolonged job dissatisfaction). The rest of the employees are omitted from the analysis.

\subsubsection{Operationalization of the explanatory variables}

The explanatory variables for our analysis represent six groups of factors (economics and psychology) that previous Chapter indicates as relevant in analyzing the state of job lock or its absence. These groups of factors include socio-demographic, employment, occupational, sectoral and contextual factors but also personality characteristics. As mentioned at the outset of this chapter, we specifically focus on self-esteem and procrastination as personality characteristics that can explain the transition to and from a job-lock situation or the absence of such transition.

We use the response to the following question as an indicator of self-esteem: "Have you recently been thinking of yourself as a worthless person?" ( 0 =high, stable self-esteem; $1=$ unstable, low self-esteem). The question is taken from the General Health Questionnaire (GHQ) included in the BHPS. The GHQ has been validated in nine countries (Goldberg et al., 1997) and has been used in various studies (Winefield, Goldney, Winefield, \& Tiggemann, 1989). The fact that the above question requires a self-reported evaluation, suggests that the answers to this question indicate explicit self-esteem. We apply the peak-end rule to construct the self-esteem variable for our analysis. The peak-end rule assumes that the value of an item (in this case, explicit self-esteem) which is measured at various points of time should not be represented by a simple average of all single evaluations. The value of that item can be better presented as a simple average of the peak - the most extreme value measured during the period, and the end - the value measured near the end of the period, i.e. the peak-end value 
Chapter 3: Why some employees fall into and fail to exit a job lock situation?

(Fredrickson \& Kahneman, 1993a). Following this rule, we construct the variable peak-end explicit self-esteem (called further on, self-esteem), which we use in the analysis. The application of the peak-end rule allows us to correct for eventual memory selectivity (Fredrickson \& Kahneman, 1993b).

None of the existing measures of procrastination are directly applicable to work-related behavior (Ferrari, et al., 1995). The BHPS provides us with a proxy to measure procrastination: "Have you recently felt capable of making decisions about things?". Based on this BHPS variable, we construct a dummy variable for our analysis that indicates procrastination (coded by 1 ) or the absence of it (coded by 0 ). This variable indicates decisional procrastination, but as indicated earlier in this chapter, decisional and behavior procrastination are highly related (Ferrari, 1994). Also, despite of the temporal wording of the question, we use repetitive measure and in this way, we account for this weakness. Moreover, the question is not specifically related to work environment but indicates procrastination in the pre-decisional phase in general.

Health problems related to anxiety, depression, etc. ('Do you have any of the health problems or disabilities: anxiety, depression or bad nerves, psychiatric problems'), is constructed as a dummy variable (coded: $0=$ absence; $1=$ presence). Age is measured as a continuous variable. The variables gender, marital status, working fulltime, member of the trade union, opportunities for promotion in the current job, belonging to the employer's pension scheme, training as a part of the present employment, are included in the analyses as dummies. Occupation is measured by the standard occupational classification (SOC). Nine dummy variables are included for occupation. Further, type of sector is included in the analysis as four dummy variables.

For an easier interpretation of the regression results, Appendix A presents the coding of all dummy variables used in the analysis. 
Chapter 3: Why some employees fall into and fail to exit a job lock situation?

\subsection{Data analysis}

Bivariate correlation analysis provides supporting information to design the model (Kwak \& Clayton-Matthews, 2002), i.e. information on the relevant variables to include in the model. Multi-nominal logistic regression is used to estimate the parameters of the two transition models: transition to and from a job-lock state. Thus, two multi-nominal logistic regressions are run separately. The baseline category in each regression analysis is the state of prolonged job lock (i.e. dissatisfaction and immobility for three subsequent years). In addition, binary regression is carried out to compare those in a job-lock state (dissatisfied and immobile for two subsequent years) to those who are dissatisfied with their job and mobile during at least one of the years (i.e. trying to adapt). For the sake of comparability, the set of explanatory variables remains the same across the models.

\subsection{Results}

Table 3.2. presents the results of the binary regression that analyses the differences between respondents who are in job lock (i.e. job dissatisfied and immobile during the two years) and those who are dissatisfied but mobile during at least one of the years. In total, 2949 employees report dissatisfaction with their job for two subsequent years and therefore, are included in our analysis (see Table 3.1.).

Of these, 1,344 respondents experience job lock (i.e. they remain immobile during the two years) and 1,605 respondents are mobile during at least one of the years. As the regression results suggest (see Table 3.2.), the two groups differ significantly in terms of sociodemographic, employment, occupational and sectoral factors (see coding of dummy variables in Appendix A). In particular, among those dissatisfied with their job for two subsequent years, job lock is more often observed among elderly, married, men, and those with poor 
Chapter 3: Why some employees fall into and fail to exit a job lock situation?

Table 3.1. Descriptive statistics

\begin{tabular}{|c|c|c|c|c|c|c|c|c|}
\hline \multirow{2}{*}{$\begin{array}{l}\text { Job dissatisfaction } \\
\text { during two subsequent } \\
\text { years and ... }\end{array}$} & \multicolumn{2}{|c|}{ Frequency } & \multirow{2}{*}{$\begin{array}{l}\text { Transition from ... } \\
\text { to job lock }\end{array}$} & \multicolumn{2}{|c|}{ Frequency } & \multirow{2}{*}{$\begin{array}{l}\text { Transition from } \\
\text { job lock to ... }\end{array}$} & \multicolumn{2}{|c|}{ Frequency } \\
\hline & $\mathrm{N}$ & $\%$ & & $\mathrm{~N}$ & $\%$ & & $\mathrm{~N}$ & $\%$ \\
\hline \multirow{2}{*}{$\begin{array}{l}0=\text { Mobile during } \\
\text { at least one of the } \\
\text { years } \\
\text { (not in job lock) }\end{array}$} & \multirow{2}{*}{1605} & \multirow{2}{*}{54.4} & $\begin{array}{l}1=\text { dissatisfied } \\
\text { and immobile }\end{array}$ & 484 & 61.4 & $\begin{array}{l}1=\text { dissatisfied } \\
\text { and immobile }\end{array}$ & 364 & 44.1 \\
\hline & & & $\begin{array}{l}2=\text { dissatisfied } \\
\text { and mobile }\end{array}$ & 51 & 6.5 & $\begin{array}{l}2=\text { dissatisfied } \\
\text { and mobile }\end{array}$ & 78 & 9.5 \\
\hline \multirow{2}{*}{$\begin{array}{l}1=\text { Immobile } \\
\text { during both years } \\
\text { (in job lock) }\end{array}$} & \multirow{2}{*}{1344} & \multirow{2}{*}{45.6} & $\begin{array}{l}3=\text { satisfied and } \\
\text { immobile }\end{array}$ & 206 & 26.1 & $\begin{array}{l}3=\text { satisfied and } \\
\text { immobile }\end{array}$ & 267 & 32.4 \\
\hline & & & $\begin{array}{l}4=\text { satisfied and } \\
\text { mobile }\end{array}$ & 47 & 6.0 & $\begin{array}{l}4=\text { satisfied and } \\
\text { mobile }\end{array}$ & 116 & 14.1 \\
\hline Total & 2949 & 100 & & 788 & 100 & & 825 & 100 \\
\hline
\end{tabular}

health, as well as among those in craft occupation, working fulltime, with an employerprovided pension scheme and without promotion opportunities. At the same time, job lock is less often observed among those with a managerial occupation. We do not find significant differences between the two groups with regard to the personality characteristics included in the analysis (peak-ends self-esteem and procrastination), as well as with regard to contextual factors (i.e. regional unemployment rate).

As much as $61.4 \%$ of those who experience job lock (see Table 3.1.) were dissatisfied and immobile during the preceding year (thus, they experience prolonged job lock). The other employees, who enter the job-lock state, were most often satisfied and immobile in the preceding year $(26.1 \%)$. From those who are in job lock, $44.1 \%$ remains dissatisfied and immobile in the following year. Those who exit from the job lock state, most often move to the 'satisfied and immobile' state (32.4\%) or 'satisfied and mobile' state (14.1\%).

Table 3.3. presents the results of the multi-nominal logistic regression. The first three columns of the table present the transitions from the job lock state to dissatisfied and mobile, satisfied 
Chapter 3: Why some employees fall into and fail to exit a job lock situation?

Table 3.2. Results of binary probit regression

\begin{tabular}{|c|c|c|c|}
\hline \multirow[t]{2}{*}{ Explanatory variable } & \multicolumn{3}{|c|}{$\begin{array}{l}\text { Job dissatisfaction for two subsequent years } \\
0=\text { not in job lock (i.e. mobile during at least one of } \\
\text { the years) } \\
1=\text { in job lock (i.e. immobile during both years) }\end{array}$} \\
\hline & Coefficient & Std. Error & Odds ratio \\
\hline \multicolumn{4}{|l|}{ Socio-demographic features: } \\
\hline Age & $0.024 * *$ & 0.003 & 1.035 \\
\hline Gender & $0.139^{*}$ & 0.058 & 1.261 \\
\hline Health status & $-0.419 * *$ & 0.106 & 0.505 \\
\hline Marital status & $0.127^{*}$ & 0.057 & 1.234 \\
\hline \multicolumn{4}{|l|}{ Personality attributes: } \\
\hline Min peak-end self-esteem & 0.054 & 0.073 & 1.076 \\
\hline Procrastination & -0.049 & 0.084 & 0.932 \\
\hline \multicolumn{4}{|c|}{$\begin{array}{l}\text { Type of occupation (reference category: clerical \& } \\
\text { secretarial): }\end{array}$} \\
\hline Manager \& administrators & $-0.369 * *$ & 0.097 & 0.545 \\
\hline Professional & 0.030 & 0.100 & 0.946 \\
\hline Associate professional/technical & -0.084 & 0.105 & 0.875 \\
\hline Craft & $0.448 * *$ & 0.094 & 2.093 \\
\hline Personal \& protective service & -0.203 & 0.108 & 0.718 \\
\hline Sales & -0.064 & 0.116 & 0.891 \\
\hline Plant \& machine & 0.095 & 0.088 & 1.171 \\
\hline Other occupations & 0.079 & 0.110 & 1.167 \\
\hline \multicolumn{4}{|l|}{ Employment conditions: } \\
\hline Fulltime contract & $0.360^{* *}$ & 0.087 & 1.794 \\
\hline Employer pension scheme & $0.318^{* *}$ & 0.076 & 1.677 \\
\hline Member of the trade unions & -0.035 & 0.082 & 0.949 \\
\hline On-the-job training & 0.071 & 0.055 & 1.128 \\
\hline Promotion opportunities & $-0.627 * *$ & 0.068 & 0.355 \\
\hline \multicolumn{4}{|c|}{$\begin{array}{l}\text { Type of sector (reference category: army and other } \\
\text { sector): }\end{array}$} \\
\hline Civil & $-0.388 * *$ & 0.141 & 0.524 \\
\hline Governmental & $-0.580 * *$ & 0.115 & 0.382 \\
\hline NHS or higher education & $-0.867 * *$ & 0.142 & 0.236 \\
\hline National industry & 0.099 & 0.207 & 1.137 \\
\hline Non-profit & $-0.859 * *$ & 0.213 & 0.239 \\
\hline Private & $-0.928 * *$ & 0.085 & 0.214 \\
\hline \multicolumn{4}{|l|}{ Work-related contextual features: } \\
\hline Regional unemployment rate & -0.005 & 0.013 & 0.995 \\
\hline Intercept & -0.123 & 0.220 & \\
\hline Observations & & 2949 & \\
\hline Pseudo $\mathrm{R}^{2}$ & & 0.147 & \\
\hline
\end{tabular}

*significant at $5 \%$ level; $* *$ significant at $1 \%$ level 
Chapter 3: Why some employees fall into and fail to exit a job lock situation?

and immobile, and satisfied and mobile states respectively. The last three columns present the transitions to a job lock state. The reference category for both models is dissatisfied and immobile. The coding of the dummy variables is presented in Appendix A. Table 3.4. highlights the results of the interaction terms included in the subsequent analysis. Specifically, the table presents the scores of the interaction terms separately for different extended versions of the models. Below, we summarize the main results for the transitions to and from the joblock state.

\subsubsection{Transitions to a job lock state}

As indicated in Table 3.3., the transition to job lock from the 'dissatisfied and immobile' state (thus, prolonged job lock) is associated with a high regional unemployment rate. The transition to job lock from a state characterized by job satisfaction, is associated with being in managerial, associate, or personal and protective service occupation as well as with low peakend self-esteem and a tendency to decisionally procrastinate. In case of the 'satisfied and mobile' state, the transition to job lock is also associated with sales and operative (plant \& machine) occupations. This transition is also negatively related to age, government or private sector. The transition to job lock from 'dissatisfaction and mobility' state, is negatively related to being married and having a craft occupation. Employees in personal and protective service occupations and those working in the private sector are more likely to transit to job lock from the 'dissatisfied and mobile' state. Our analysis shows no significant effect for variables indicating employment conditions. In addition to this, the interaction between peakend self-esteem and the regional unemployment rate appears significant (see Table 3.4.). Thus, when the regional unemployment rate is high, respondents with low peak-end selfesteem employees are more often 'satisfied and immobile' than 'dissatisfied and immobile'. 
Chapter 3: Why some employees fall into and fail to exit a job lock situation?

\subsubsection{Transitions from a job lock state}

As suggested by Table 3.3., the exit from job lock to any of the three states is associated with promotion opportunities. A high regional unemployment rate decreases the chance that an employee would transit to any other state than 'dissatisfied an immobile' (thus, it increases the chances of prolonged job lock). The exit from job lock to a state characterized with job satisfaction is negatively associated with age, and positively associated with a service occupation and the private sector. Managers in job lock often exit to the 'dissatisfied and mobile' state or the 'satisfied and immobile' state. Having an associate occupation is positively associated with exit to the 'satisfied and immobile' state and fulltime job is negatively associated with exiting to the 'satisfied and mobile' state. The probability to exit from job lock to a state characterized by job satisfaction is lower for those with low peak-end self-esteem.

Four interactions show a significant effect (Table 3.4.). First, the interaction between peakend self-esteem and health for the transition from 'satisfied and mobile'. At the same time the effect of peak-end self-esteem variable becomes not significant while the effect of the health variable does not change. Second, the interaction between procrastination and health. This changes the effect of procrastination to become significant while keeping the effect of the health variable. Third, the interaction between age and peak-end self-esteem. This changes the effect of self-esteem to insignificant while keeping the effect of age. Fourth, the interaction between peak-end self-esteem and the regional unemployment rate.

Additionally, we checked how many employees stay dissatisfied and immobile for 4 and 5 subsequent years. They are 136 and 47 respectively, which shows a decreasing trend. 
Chapter 3: Why some employees fall into and fail to exit a job lock situation?

Table 3.3. Results of multinominal logistic regression

\begin{tabular}{|c|c|c|c|c|c|c|}
\hline \multirow{3}{*}{ Explanatory variables } & \multicolumn{3}{|c|}{$\begin{array}{l}\text { Transition from job lock to...: } \\
\text { (reference category: dissatisfied and immobile) }\end{array}$} & \multicolumn{3}{|c|}{$\begin{array}{l}\text { Transition from ....to job lock: } \\
\text { (reference category: dissatisfied and immobile) }\end{array}$} \\
\hline & $\begin{array}{l}\text { Dissatisfied and } \\
\text { mobile }\end{array}$ & $\begin{array}{l}\text { Satisfied and } \\
\text { immobile }\end{array}$ & Satisfied and mobile & $\begin{array}{l}\text { Dissatisfied and } \\
\text { mobile }\end{array}$ & $\begin{array}{l}\text { Satisfied and } \\
\text { immobile }\end{array}$ & Satisfied and mobile \\
\hline & Odds ratio & Odds ratio & Odds ratio & Odds ratio & Odds ratio & Odds ratio \\
\hline $\begin{array}{l}\text { Socio-demographic features: } \\
\text { Age } \\
\text { Gender } \\
\text { Marital Status } \\
\text { Health problems: anxiety, depression, etc. }\end{array}$ & $\begin{array}{l}0.977 \\
1.298 \\
0.600 \\
2.129 \\
\end{array}$ & $\begin{array}{l}0.981 * \\
0.698 \\
0.905 \\
0.814 \\
\end{array}$ & $\begin{array}{l}0.933 * * \\
0.577 \\
0.846 \\
1.457 \\
\end{array}$ & $\begin{array}{l}1.008 \\
0.751 \\
0.405^{* *} \\
0.499 \\
\end{array}$ & $\begin{array}{l}0.989 \\
0.764 \\
0.743 \\
0.941 \\
\end{array}$ & $\begin{array}{l}0.928 * * \\
0.662 \\
0.496 \\
0.447 \\
\end{array}$ \\
\hline $\begin{array}{l}\text { Personality attributes: } \\
\text { Min Peak-end self-esteem } \\
\text { Procrastination }\end{array}$ & $\begin{array}{l}0.689 \\
1.137\end{array}$ & $\begin{array}{l}0.409^{* *} \\
1.149\end{array}$ & $\begin{array}{l}0.413^{*} \\
1.436 \\
\end{array}$ & $\begin{array}{l}0.685 \\
0.609\end{array}$ & $\begin{array}{l}0.557 * \\
1.982^{*} \\
\end{array}$ & $\begin{array}{l}0.121^{* *} \\
3.259^{*}\end{array}$ \\
\hline $\begin{array}{l}\text { Type of occupation (reference category: clerical \& secretarial): } \\
\text { Manager and administrators } \\
\text { Professional } \\
\text { Associate professional/technical } \\
\text { Craft } \\
\text { Personal \& protective service } \\
\text { Sales } \\
\text { Plant \& machine } \\
\text { Other occupations }\end{array}$ & $\begin{array}{l}2.974^{*} \\
0.870 \\
2.713 \\
0.342 \\
1.563 \\
1.820 \\
0.296 \\
0.706 \\
\end{array}$ & $\begin{array}{l}2.285^{*} \\
1.841 \\
3.805^{* *} \\
1.521 \\
3.381 * * \\
0.905 \\
0.925 \\
1.465 \\
\end{array}$ & $\begin{array}{l}2.185 \\
2.109 \\
2.652 \\
0.913 \\
4.110^{*} \\
1.947 \\
0.396 \\
0.580 \\
\end{array}$ & $\begin{array}{l}1.976 \\
2.404 \\
0.473 \\
0.100^{*} \\
7.748^{* *} \\
1.445 \\
0.778 \\
2.086 \\
\end{array}$ & $\begin{array}{l}3.371^{* *} \\
1.686 \\
2.989^{* *} \\
1.837^{*} \\
3.361^{* *} \\
1.560 \\
1.171 \\
1.712 \\
\end{array}$ & $\begin{array}{l}12.505^{* *} \\
8.758^{* *} \\
7.848^{*} \\
3.725 \\
3.215 \\
7.070^{*} \\
6.499^{* *} \\
1.903 \\
\end{array}$ \\
\hline $\begin{array}{l}\text { Type of sector: (Reference category: other sectors): } \\
\text { Private } \\
\text { Civil } \\
\text { Governmental }\end{array}$ & $\begin{array}{l}1.899 \\
1.731 \\
1.239\end{array}$ & $\begin{array}{l}1.977^{*} \\
0.999 \\
1.346\end{array}$ & $\begin{array}{l}3.112 * * \\
1.145 \\
0.907\end{array}$ & $\begin{array}{l}3.909 * \\
2.002 \\
0.847\end{array}$ & $\begin{array}{l}1.114 \\
0.631 \\
1.293\end{array}$ & $\begin{array}{l}0.225^{* *} \\
1.394 \\
0.276^{*}\end{array}$ \\
\hline $\begin{array}{l}\text { Employment conditions: } \\
\text { Fulltime contract } \\
\text { Employer pension scheme } \\
\text { On-job-training } \\
\text { Promotion opportunities } \\
\text { Member of the trade unions }\end{array}$ & $\begin{array}{l}0.430 \\
1.796 \\
0.984 \\
3.991 * * \\
0.532 \\
\end{array}$ & $\begin{array}{l}0.627 \\
1.349 \\
1.132 \\
2.329 * * \\
0.667\end{array}$ & $\begin{array}{l}0.129^{* *} \\
1.811 \\
0.764 \\
14.572^{* *} \\
0.608 \\
\end{array}$ & $\begin{array}{l}1.447 \\
0.832 \\
1.414 \\
0.829 \\
0.546\end{array}$ & $\begin{array}{l}0.735 \\
1.508 \\
0.923 \\
0.985 \\
0.968 \\
\end{array}$ & $\begin{array}{l}0.386 \\
0.660 \\
0.685 \\
0.976 \\
1.636 \\
\end{array}$ \\
\hline $\begin{array}{l}\text { Work-related contextual features: } \\
\text { Regional unemployment rate }\end{array}$ & $0.836 * *$ & $0.864 * *$ & $0.818^{* *}$ & $0.857^{*}$ & $0.794 * *$ & $0.828 *$ \\
\hline Other model characteristics & \multicolumn{3}{|c|}{$\begin{array}{l}\text { Observations }=825 \\
\text { LR chi } 2(\mathrm{df}=69)=287.25 \\
\text { Pseudo } 22=0.1437\end{array}$} & \multicolumn{3}{|c|}{$\begin{array}{l}\text { Observations }=782 \\
\text { LR chi } 2(\mathrm{df}=69)=192.43 \\
\text { Pseudo } 2=0.1238\end{array}$} \\
\hline
\end{tabular}

*significant at $5 \%$ level; ** significant at $1 \%$ level 
Table 3.4. Interaction terms

Variables/Interactions

Dependent variable:

Transition from job lock to....

(reference: dissatisfied and

immobile)

Satisfied and mobile

\begin{tabular}{|c|c|}
\hline $\begin{array}{l}\text { Peak-end self-esteem*mental health } \\
\text { problems }\end{array}$ & $0,076^{*}$ \\
\hline Peak-end self-esteem & 3,944 \\
\hline Mental health problems & 3,114 \\
\hline Mental health problems *procrastination & $0,088^{*}$ \\
\hline Mental health problems & 2.643 \\
\hline Procrastination & $10,680 *$ \\
\hline Age*peak-end self-esteem & $0,897 *$ \\
\hline Peak-end self-esteem & 19,341 \\
\hline Age & $0,942 * *$ \\
\hline $\begin{array}{l}\text { Regional unemployment rate*peak-end } \\
\text { self-esteem }\end{array}$ & $1,461^{*}$ \\
\hline Peak-end self-esteem & $0,014 * *$ \\
\hline \multirow[t]{3}{*}{ Regional unemployment rate } & $0,774 * *$ \\
\hline & $\begin{array}{l}\text { Dependent variable: } \\
\text { Transition from ... to job lock } \\
\text { (reference: stay dissatisfied and } \\
\text { immobile) }\end{array}$ \\
\hline & Satisfied and immobile \\
\hline $\begin{array}{l}\text { Regional unemployment rate*peak-end } \\
\text { self-esteem }\end{array}$ & $1,361 *$ \\
\hline Peak-end self-esteem & $0,033 * *$ \\
\hline Regional unemployment rate & $0,759 * *$ \\
\hline
\end{tabular}

*significant at 5\% level; ** significant at $1 \%$ level 


\subsection{Summary of main findings}

Overall, the results show that being older, being married, working in a craft occupation, in the government sector, having a full time job and high regional unemployment rate increase the likelihood that an employee enters the long-term job lock state. Furthermore, low peak-end self-esteem, mental health problems and decisional procrastination show significant effects on the probability to stay in long-term "job lock (failure to exit the job-lock state). Contrary, having a managerial, service or associate occupation, working in the private sector, and having promotion opportunities increase the chance of an exit from the state of job lock. A high regional unemployment rate is not statistically significant for those dissatisfied in two consequent years. It seems that a high regional unemployment rate provides incentives for employees who are dissatisfied to adapt by adjusting. Among dissatisfied employees, older workers are less likely to use mobility as an adaptation strategy. Further, possessing a company pension scheme increases the likelihood that the employee, who is dissatisfied, is immobile for two subsequent years.

\subsection{Discussion}

Our results highlight the process of the transition to and from a job-lock situation, as well as the situation of long-term job lock. We briefly discuss the key findings in the subsequent paragraphs.

\subsubsection{What factors push employees in a job lock state?}

Our results suggest that being older, married, with low peak-end self-esteem, working in a craft occupation, in the governmental sector, and high regional unemployment rate are push factors to a job lock state. 
Chapter 3: Why some employees fall into and fail to exit a job lock situation?

As previous research also shows, elderly employees are less mobile (Groot \& Verberne, 1997; Topel \& Ward, 1992). This can be explained by the fact that growing older is related to higher job investments made. However, preceding studies also show that elderly employees are more often job satisfied. Additionally, Clark (Clark, Oswald, \& Warr, 1996) showed that job satisfaction is U-shaped in age. In other words, employees at the beginning and end of their career are more inclined to experience satisfaction and those in the middle age are more often dissatisfied. Nevertheless, we find that age is more likely to be related to job lock. This can be explained by the fact that perceived control may diminish with age (Aldwin, 1991; Ben-Zur, 2002) and in turn, this may lead to diminished use of problem-focused coping and as a result affects well-being (Brandtstadter \& Baltes-Gotz, 1990).

Another important variable concerning mobility is marital status. Being married is negatively correlated with the probability of quitting when dissatisfied with the job (Weiss, 1984). Married employees are also less satisfied with their job than single individuals (Gazioglu \& Tansel, 2006) and more often fall in job lock. This situation is observed irrespective of previous findings that married people are in general more satisfied and happier. Based on the spillover theory however, one can expect that marital satisfaction would affect work satisfaction. Thought as previous studies have shown, the two variables not always change together - the changes in one domain do not fully match the changes in other areas (Diener, et al., 2009). Thus, it might be easier for an individual to accept dissatisfaction if it is related just to a certain domain (job dissatisfaction) when there is satisfaction in the other areas of life (marital state).

Employment, occupational, sectoral and contextual factors may also push individuals to a job lock state. As previous studies have shown when the regional unemployment rate increases employees are more likely to be immobile (Barwell, 2000). Furthermore, the high regional unemployment rates may lessen overall satisfaction by simply diminishing the supply of labor 
Chapter 3: Why some employees fall into and fail to exit a job lock situation?

opportunities. In support of the information about the trends in public sector employment in the UK (particularly the steady decline for those working for local governments), we found that those working in the governmental sector are more likely to be both job dissatisfied (Osward \& Gardner, 2001) and immobile (Postel-Vinay \& Turon, 2005). This has been explained by the increased workload and stress in this sector. Also we find that being in a craft occupation increases the likelihood that the employee would be 'dissatisfied and immobile' for a longer period of time (i.e. higher chance to enter prolonged 'job lock'). This might be explained by the specific skilled work that craft occupations require and the often small scale production of goods which may hinder both internal and external mobility when dissatisfied.

\subsubsection{Why do some employees fail to exit the job lock?}

The factors that push an employee into job lock (age, low peak-end self-esteem, and high regional unemployment rate) also play an essential role in the failure to exit job lock and entering long-term job lock. In addition to the already discussed variables, having a fulltime contract increases the probability to enter the long-term 'job lock' state than to move to any of the other states. This confirms the outcome of previous studies that fulltime workers are less mobile (Martin \& Sinclair, 2007) and less satisfied (Sinclair, et al., 1999). Besides, our study outlines tendencies (traits) to stay dissatisfied and immobile for fulltime employees. This can be explained by the importance of work to those who work fulltime. Additionally, it can be that commitment and job investments are higher for those working fulltime comparing with others in part time work. 
Chapter 3: Why some employees fall into and fail to exit a job lock situation?

\subsubsection{What factors are associated with the exit from the job lock state - pull factors?}

Some occupations play a significant role for the transitions from 'job lock' state. In particular, being in a managerial or administrator position, associate professional, personal and protective service increases the chance that the employee exits the 'job lock' state. Further, work in the private sector and promotion opportunities pull employees out of job lock. Holding a personal and protective occupation increases the chance that an employee moves to 'satisfied and immobile' or 'satisfied and mobile' instead of remaining in a job lock state. Individual abilities play an important role in occupational decision-making (Rosenberg \& Turner, 1990). Furthermore, every occupation requires certain skills that the employee can have a match with or not (Holland, 1985). It might be that career achievement brings not only promotion possibilities but also satisfaction (De Cenzo \& Robbins, 1996). Moreover, we may expect that career stages (exploration, establishment, mid-career, late career, and decline) (De Cenzo \& Robbins, 1996) are part of every occupation. Nevertheless, the duration of every stage would be different for different occupations which together with the individual importance of work and carrier can influence the transitions.

Besides, having promotion opportunities in the current job increases the likelihood that the employee moves to one of the other three states. In general having promotion opportunities in the current job increases overall job satisfaction (Fasang, Geerdes, \& Schoeman, 2009). And, promotion opportunities are themselves mobility opportunities, i.e. internal mobility.

\subsubsection{Mobility or adaptation - what coping strategy can help to exit a job lock state?}

Employees in a manager and administrator occupation, those in personal and protective service occupations, with promotion opportunities, working in the private sector use much more often mobility as a coping strategy in order to adjust to job dissatisfaction. 
Chapter 3: Why some employees fall into and fail to exit a job lock situation?

Thus, managers and administrators as well as personal and protective service occupations are capable to successfully adapt to job dissatisfaction by using active forms of adaptation. It might be that for employees in those occupations, job dissatisfaction is just one of the drivers for job mobility. Qualities to succeed in your job may be also essential qualities for successful adaptation.

At the same time, manager and administrator occupation, associate professional, personal and protective service occupations, sales, working in the private sector, and with promotion opportunities employ work adjustments as coping strategy (satisfied and immobile).

Thus, almost the same variables play a role in successful adaptation independent from the form of the adaptive strategy (either with job satisfaction or job mobility). We can conclude that people are either capable to successfully adapt or not irrespective of the coping strategy used.

\subsubsection{The relevance of self-esteem and procrastination in research on job lock}

Peak-end low self-esteem for both multinominal models is related to the transition to job lock or long-term 'job lock'. On the other hand, the analysis of employees who are dissatisfied for two years, does not show self-esteem to be significant compared to those who moved and those who stay in a job lock. Further, the findings support our expectation that the inclusion of the procrastination and psychological health variables in our model leads to a better explanation of long-term 'job lock'. Peak-end low self-esteem, mental health problems and decisional procrastination show significant effects on the probability to stay in long-term 'job lock'. Low self-esteem plays a role in failure to adapt to job dissatisfaction. Though, having high self-esteem does not guarantee successful adaptation.

Low self-esteem and mental health problems have a joint effect on the transition from a job lock state (shown by the significance of the interaction term). This is in line with the results 
Chapter 3: Why some employees fall into and fail to exit a job lock situation?

from previous research that depression and anxiety are some of the symptoms experienced by people with low self-esteem (Epstein, 1985; Leary, Tambor, Tendal, \& Downs, 1995).

Positive self-evaluations are vital for psychological health (Pyszczynski, Greenberg, Solomon, \& Arndt, 2004).

Additionally, the analysis comparing coping strategies by dissatisfied employees shows that those with poor health are much more often mobile. It might be that health deterioration leads to an adjusted job, internal mobility, or what some other studies show - the more severe the mental health the sooner employee leaves (Markowe \& Barber, 1953). Thus, mental health problems might be related to impulsivity (impulse to quit when job dissatisfied). Additionally, we may expect that health problems bring general dissatisfaction. We may expect that mental health diminishes the quality of life and influences overall happiness (Cheng \& Furnham, 2003). Though, the results of our study show that mental health has no separate effect on prolonged job lock or quitting job lock.

Due to the fact that procrastination has been seen as a risk factor for more serious depression and anxiety (Johnson, 1992), we include an interaction term between mental health problems and procrastination in our model. Decisional procrastination and mental health problems show dependency. Employees who procrastinate to make decisions and report mental health problems are less likely to be 'satisfied and mobile' compared to 'dissatisfied and immobile' and become stuck at their job in the long term (i.e. to experience job lock). While, decisional procrastination is shown to be preventing employees to enter a job lock state, procrastination proves to be much more related to job satisfaction. One explanation for that is that in the short run, it plays the role of an adapting mechanism. Though previous research shows that when procrastination is used in this way, it simply adds additional stress and becomes very inadequate (Beheshtifar, Hoseinifar, \& Moghadam, 2011). Thus, decisional procrastination is 
Chapter 3: Why some employees fall into and fail to exit a job lock situation?

a maladaptive coping mechanism for handling conflicts in decision making (Janis \& Mann, 1977).

We find that when the regional unemployment rate is high, employees with low self-esteem have less chance to experience job dissatisfaction. It might be that when there are fewer opportunities on the labor market, people see their present job in a more favorable light and report more satisfaction. Employees may also realize that they are happy to have a job at all, or it could be a selection effect where dissatisfied employees are more likely to be laid off. Additionally, this employees' behavior might be influenced not by the actual job availability but by their perceptions of job availability (Van Vianen, et al., 2003).

\subsection{Conclusion}

The aim of this study has been to explore the process of the transition to and from a job-lock situation, as well as the situation of long-term job lock. Our results provide insights in understanding individual differences in adaptation which help to illuminate when and why successful adaptation does or does not occur.

Another contribution of the present study is that by following the process, i.e. from dissatisfaction to job lock to long-term job lock, we are able to distinguish the essential variables which play a role in the state transitions. Further, we faced Diener's (Diener, et al., 2009) challenge to differentiate passive versus active coping in adaptation. The present study offers an understanding of the process of long-term 'job lock'. Further, by bringing light to the adaptation process we provide information that is useful to design successful interventions. Our findings contribute to the field of adaptation to job dissatisfaction and the limited research in the area of procrastination at work.

Nevertheless, the current findings should be interpreted with caution because of the following limitations of the present study: lack of differentiation of voluntary and involuntary job 
Chapter 3: Why some employees fall into and fail to exit a job lock situation?

mobility, mental health problems and the usage of a proxy measure of self-esteem and procrastination. Though, none of the existing measures of trait procrastination are directly appropriate to work related behavior (Ferrari, et al., 1995). More study is needed to develop a measurement instrument for procrastination at work. Further, it is important to distinguish between different types of procrastinators and find out which one is related to long-term job lock. Procrastination might be more complex than merely related to stress, mental health and hindrance of performance (Tice \& Baumeister, 1997). It can be that procrastination is not always dysfunctional. In some cases, procrastination behavior might lead to positive outcomes, such as a lower level of stress and depression and greater life satisfaction (Chu \& Choi, 2005; Knaus, 2000). Thus, there might be more than one kind of procrastinator. Several studies show that procrastinators are not a homogenous group and there are certain types of procrastinators who might be more prone to emotional problems (Schouwenburg, 1992): such as anxiety (Milgram, Gehrman, \& Keinan, 1992), arousal and avoidance motives (Ferrari, 1992b), optimistic and pessimistic (Lay, 1987), passive and active type (Chu \& Choi, 2005). Further, people may have a need to procrastinate in one area (work, relationships, insurance, etc.) more than in other areas. The results of this study also concern adaptation to job dissatisfaction and might be not applicable to adaptation in other areas of life. The extent of adaptation varies for different life events (Diener, et al., 2009). Irrespective of the study limitations, the results can be applied on different levels: at the individual, organizational (HRM, company physicians, managers, coaches, mental health professionals), and societal level (labor unions, government) by increasing awareness and knowledge, using them for prevention, in problem solving, and development of supportive programs.

In terms of practical implications, the current findings present a need to develop and incorporate programs tackling task avoidance and procrastination at the work place. 
Chapter 3: Why some employees fall into and fail to exit a job lock situation?

Additionally, counseling to support employees with dysfunctional procrastination tendency can be beneficial as employee's stress reduction may increase productivity. The results might be beneficial to those who are involved in employee selection and those who are responsible for making promotion decisions. 
Chapter 4: Job embeddedness and the self

\section{Chapter 4}

Job embeddedness and the self

I am thankful for the contribution of: A. Bos, H. Alberts, C. Meesters

My gratitude goes to M. Pavlova and W. Groot for their feedback and support 
Chapter 4: Job embeddedness and the self

\begin{abstract}
It is a challenge for organizations to retain their talented employees and for employees to attach and to embed to the organization. Recent research has shown that individual differences play an important role in the decision to stay or to leave the organization. Low self-esteem employees are more likely to become stuck—or “job locked.” This study tests Gilbert's model (Gilbert, 2005b) to job embeddedness, expecting that this can help detect those employees who have tendency to become job locked. Further, we integrate different self-aspects (global self-esteem, contingent self-esteem, self-determination, and selfcompassion) to job embeddedness.

Self-reported data were obtained from Dutch employees $(\mathrm{N}=113)$ via an online questionnaire. Structural Equation Modeling shows that all aspects of the self relate to both on-work and offwork job embeddedness. Further, self-determination directly influence job embeddedness components. Self-compassion's effect on job embeddeness is via its effect on these selfaspects. The model that shows best fit to the data is the one that combines both selfcompassion and self-determination in it. This study shows the importance of self-compassion and the self for the organizational life and employee wellbeing.
\end{abstract}


Chapter 4: Job embeddedness and the self

\subsection{Introduction}

During the last decade, the labor market has changed profoundly (Sullivan, 1999), as outlined in Chapter 1. These changes include an increase in job insecurity (Chung \& van Oorschot, 2011; Ferrie, Marmot, Griffiths, \& Ziglio, 1999) and in the number of people who are holding more than one job (London, 1996; Mars \& Lautenbach, 2013). Furthermore, competitiveness among workers appears to have amplified (Rosenthal, 1995; Tsipouri, 2005), while technological progress is going faster (Freeman, Soete, \& Efendioglu, 1995; Usanov \& Chivot, 2013). Short-term contracts have become more prevalent and the loyalty of employees appears to have diminished (Auer \& Cazes, 2000; Hamori \& Kakarika, 2009; Murrell, et al., 1996).

These changes are not just a part of on-work but also of off-work life. Everyone can be confronted with health problems, loss, divorce, or financial problems. Further, the dual-earner lifestyle where both partners are working and share care giving is becoming more the standard rather than the exception (Eby, Casper, Lockwood, Bordeaux, \& Brinley, 2005). When onwork and off-work domains are out of balance, they may negatively influence each other (Clark, 2000). These challenges demand adaptation from both organizations and their employees. This may make it even more difficult for employees to attach to the organization and embed there. Under these circumstances, it is challenging for organizations to retain talented employees.

In the organizational attachment literature, Mitchell, Holtom, Lee, Sablynski, and Erez (2001) introduced "job embeddedness" to summarize the various forces that attach the employee to the organization and keeps him/her from leaving his/her job. Job embeddedness promotes job retention much like other traditional attitudinal constructs, such as job satisfaction and organizational commitment. Yet this construct recognizes various forces embedding employees in jobs that are nonattitudinal (e.g., job sacrifices, such as loss of benefits when 
Chapter 4: Job embeddedness and the self

leaving) and external to workplaces, such as community fit and links. In other words, Mitchell and colleagues (2001) contend that employees may stay in a dissatisfying job if they find it too costly to quit or relocate elsewhere (which may entail family relocation).

Generally speaking, job embeddedness is often regarded as a positive phenomenon and has often been seen as a means to achieve job retention and high performance. More recently however, several scholars have noted potential drawbacks of high job embeddedness. One possible downside of job embeddedness is that employees who are dissatisfied with their job but who cannot leave or adapt (i.e., become stuck in an unfavorable job and experience job lock), may lose motivation, become frustrated, and exhibit counterproductive work behaviors (Crossley, et al., 2007). Furthermore, excessive job embeddedness may actually decrease employee performance. In particular, Sekiguchi, Burton, and Sablynski (2008) uncovered such effects when employees have poor quality relationships (poor leader-member exchange) or perceive themselves to be incompetent or an unworthy organizational member (low organizational-based self-esteem).

Apart from limited inquiry into the dark side of job embeddedness, we know little about how individual differences can harm employees who become highly embedded at work. Indeed, a recent theoretical extension of job embeddedness theory (Hom, et al., 2012) posited that individual differences (such as core self-evaluation, collectivist/individualist, and demographic characteristics) can moderate how embedding forces affect employees' decisions to stay or leave. Recent research offers more direct evidence of how individual differences can disadvantage embedded incumbents. Specifically, Huysse-Gaytandjieva, Groot, and Pavlova (2013a, 2013b) noted that self-esteem - a fundamental aspect of core selfevaluation that represents the "overall value that one places on oneself as a person" (Judge \& Bono, 2001) - relates to job lock and long-term job lock. However, knowledge about how individual differences may play a role in the negative side of job embeddedness, is still scarce 
Chapter 4: Job embeddedness and the self

and further research is needed (Barnard \& Curry, 2011; Crossley, et al., 2007; Holtom, et al., 2012; Sekiguchi, et al., 2008).

This study applies the knowledge from job lock studies to job embeddedness by attempting to distinguish those employees who are positively job embedded from those who feel stuck based on self-esteem. Yet we further differentiate different aspects of self-esteem: self-esteem level, self-esteem stability, contingent self-esteem, implicit self-esteem and motives (Bos, Huijding, Muris, Vogel, \& Biesheuvel, 2010; Crocker \& Canevello, 2012). Complete understanding of how self-esteem engenders positive or negative forms of job embeddedness necessitates taking into consideration these self-esteem components (Kernis \& Goldman, 2006). In sum, our study relates jointly self-concepts (global self-esteem, contingent selfesteem, self-determination, and self-compassion) to job embeddedness.

This chapter also contributes to the limited research of self-compassion and contingent selfesteem in organizational behavior. Further, the study adds to the paucity of studies on job embeddedness using non-US samples (Ramesh, 2007; Tanova \& Holtom, 2008). In parallel to job embeddedness, we also study job satisfaction and compare the factors associated with these two concepts.

As presented in Chapter 2 and Chapter 3, dissatisfaction with the job may lead to job lock-or the negative side of job embeddedness. We conduct a cross-sectional survey and apply structural equation modeling in order to test hypotheses defined in the next section. This small-scale cross-sectional study is a preliminary study on job lock as a negative aspect of job embeddedness and the study is intended to outline directions for future research on this topic. The chapter is organized as follows: first, the main concepts are described and hypotheses are formulated. Second, the method of the study is presented, followed by elaboration of the performed analyses. Third, the results are outlined followed by their discussion. This chapter is completed by a conclusion part where practical implementation is suggested. 
Chapter 4: Job embeddedness and the self

\subsection{Conceptual development}

Below the four main concepts are elaborated. In particular: job embeddedness, self-aspects, self-compassion, and job satisfaction.

\subsubsection{Job embeddedness}

Job embeddedness is expressed by a broad range of on-work (organizational) as well as offwork (community) factors, which influence employees to stay within the organization (Reitz \& Anderson, 2011). In particular, these factors can be divided into: 1) links: attachments to the job and the community; 2) fit: the extent to which an employee perceives he/she matches the job, organization, and community; 3) sacrifice: how much an employee perceives he/she gives up if he/she leaves the job (Mitchell, et al., 2001).

The model of job embeddedness describes 'links' as 'connections between a person and other people, groups, or organizations' (Mitchell, 2001). The more the connections, the more embedded a person is in that environment. Recently, the importance to consider not just the amount of the connections but also their quality has been underscored (Zhang, Fried, \& Griffeth, 2012). Many researchers have suggested that the greater the number of ties an individual has in the organization, the less likely s/he is to leave, since the employee is attached at both a functional as well as an emotional level (Burt, 2001; Kahn, 1998; Maertz \& Griffeth, 2004). There are plenty of studies showing the relationship between self-esteem and relationship qualities (Murray, Holmes, MacDonald, \& Ellsworth, 1998). Thus, by including the self-esteem variables in our model, we expect to estimate also the quality of those links. Mitchell and colleagues (2001) claim that people can become embedded in many ways and that the process may systematically vary by occupation or personality. Even though scientists have started to recognize the importance of individual differences, few studies paid attention to them in relation to job embeddedness. Although Hom and colleagues (2012) differentiate 
Chapter 4: Job embeddedness and the self

stayers into those who are enthusiastic (embedded engaged, engaged, slackers) and those who are reluctant (trapped, contractual), they did not identify individual differences that underlie such different forms of functional and dysfunctional embeddedness. A recent latent profile analysis by Woo and Allen (Woo \& Allen, 2013) identified clusters of embedded and detached stayers and showed that employees with low positive affectivity and high negative affectivity are more likely to stay while detached and/or dissatisfied.

\subsubsection{Self-aspects}

\section{Global self-esteem}

Global self-esteem represents the general value one places on himself/herself. It is related to the subjective sense of worthiness which influences how people present themselves to others and how they are perceived by the social environment (Zeigler-Hill, 2012). Self-esteem is vital to our behavior (Rosenberg, 1979).

\section{Contingent self-esteem}

Contingent self-esteem is an unstable self-esteem. It refers to self-worth dependent on external sources. It is based on perceived successes/failures in the domain to which the person's self-esteem is attached (Crocker \& Wolfe, 2001a). Crocker and Wolfe (2001b) have found that contingent self-esteem fluctuates around global self-esteem in the domains in which someone attaches his/her self-esteem (e.g. moral virtue, personal relationships or competence). This conditional self-view is considered vulnerable with consequences for well-being (Crocker \& Wolfe, 2001b).

\section{Self-determination}

Humans have three basic needs: autonomy (sense of self-determination), competence (sense of confidence and effectiveness), and relatedness (need for belongingness) (Deci \& Ryan, 1985b). The central idea of the self-determination theory is that when those needs are 
Chapter 4: Job embeddedness and the self

fulfilled, self-motivation and effective functioning are facilitated and individuals are operating from their true self (Deci \& Ryan, 1995). Individuals choose behaviors that are consistent with their deepest values in their way to achieve important goals (Deci, Connell, \& Ryan, 1989). The assumption of self-determination theory is that social contexts facilitate two major types of motivation through satisfaction of the three basic needs, namely autonomy (behavior is pleasurable and a personal choice), control (behavior is based on an expectation of a reward or punishment avoidance or feelings of guilt), and motivation (Deci \& Ryan, 2000). The self is seen as dynamic and flexible in its interplay with the environment, especially by its capacity to change, to adapt to diverse circumstances, and to integrate new components (Ryan \& Brown, 2003).

\subsubsection{Self-compassion}

As explained in Chapter 1, past research has demonstrated that three emotion regulation systems play a role in human behavior (Gilbert, 2010; LeDoux, 1998; Vonk \& Smit, 2012). In Compassion Focused Therapy, Gilbert distinguishes three different systems 1) the threat system; 2) the drive system; and 3) the connect system. The threat system's role is to quickly detect eventual threats and to choose a reaction (e.g., flight, fight, and freeze) and boost our emotions (e.g. anxiety, anger) (Gilbert, 2010). The threat system may stimulate or be stimulated by self-criticism. The drive system is related to resource-seeking, pursuing skills, and status. When in balance, it is related to the fulfillment of our goals. The connect system's role is to regain our balance in affectionate and kind ways, which is a sign of health and can improve our relationships (Leary, Tate, Adams, Allen, \& Hancock, 2007). The connect system is a major source of feelings of well-being and connectedness (Gilbert, 2009a). Even though every one of those systems has its own function, these functions also interact with each other (Gilbert, 2009a). Initially Gilbert's theory has been developed for people with 
Chapter 4: Job embeddedness and the self

chronic and complex mental health problems (Gilbert, 2010). Through its broadened application to non-clinical population, it can help improve understanding and address challenges with the human condition (e.g., schools, work, leadership).

Gilbert (Gilbert, 2005b) associates self-esteem, self-criticism, and self-compassion with the three brain emotional systems explained above. In particular, the physiological underpinnings of self-esteem are located in the drive system. Self-compassion and self-criticism are seen as two different inward social orientations: self-compassion relates to the connect system and self-criticism relates to the threat system. Distress is caused by imbalance between the systems, often associated with under-development of the connect system.

Empirical research on both organizational and community job embeddedness is very limited. The role that personality plays in influencing off-work embeddedness has already been recognized (Oyler, 2007). Nevertheless, as shown in Chapter 2 and 3, self-esteem is related to both on-work and off-work domains. This is also supported by previous studies (HuysseGaytandjieva, et al., 2013a; Huysse-Gaytandjieva, Groot, \& Pavlova, 2013b; Knee, Patrick, Vietor, Nanayakkara, \& Neighbors, 2002; Leary \& Downs, 1995; Neighbors \& Knee, 2003; Shackelford, 2001; Zeigler-Hill, Besser, \& King, 2011).

Self-compassion is defined as being "kind to oneself when confronting personal inadequacies or situational difficulties, framing the imperfection of life in terms of common humanity, and being mindful of negative emotions so that one neither suppresses nor ruminates on them" (Neff \& Beretvas, 2013). Further, self-compassion entails thinking about stressful circumstances (e.g. academic failure, divorce, chronic pain, etc.) in ways that improve coping (Allen \& Leary, 2010; Gillath, Shaver, \& Mikulincer, 2005). Thus self-compassion may be a valuable coping resource when people experience low global self-esteem or contingent selfesteem. 
Chapter 4: Job embeddedness and the self

This chapter focuses on the joint relationship between different aspects of the self (global selfesteem, contingent self-esteem, self-determination, and self-compassion) and job embeddedness. We also study the influence of self-esteem aspects on job satisfaction as another work-related concept that can identify those employees who have tendency to become job locked. Below we outline our hypotheses on the relation between job embeddedness and self that are tested in our study.

\subsubsection{Job embeddedness and job satisfaction}

Historically, job satisfaction is claimed to be the most important discriminator between employees who stay on the job and those who quit (Gaertner \& Nollen, 1992). Although job dissatisfaction is not the only path that leads to changes in employment, it is an unpleasant experience, which serves as a drive for action. The concept of job lock includes job satisfaction (Huysse-Gaytandjieva, et al., 2013a, 2013b). When individuals are dissatisfied with their job but neither leave the organization nor adapt to become more satisfied, they may experience a job lock situation. Thus, job lock represent be a form of negative or dysfunctional job embeddedness. Initially, job embeddedness has been theorized to represent a non-affective condition (Mitchell et al., 2001). Though in recent studies, the intention to stay/leave is explained by the withdrawal states, one of which is the affective force (Maertz \& Griffeth, 2004). In this study, we compare the factors associated with the two concepts to check whether they also show similarities.

\subsection{Hypotheses}

\subsubsection{Global self-esteem and the job embeddedness model}

Relation of global self-esteem to 'links'\& 'fit'

Employees develop durable affective bonds in their on-work and off-work domains. Those with high global self-esteem carry positive internal working models of relationships (Baldwin, 
Chapter 4: Job embeddedness and the self

2006; Impett \& Gordon, 2010). This allow them to enter relationships openly and base them on trust. Furthermore, high global self-esteem employees have positive expectations relating to their links at work and/or community. They expect those relationships to work well. When this is not the case, high global self-esteem people are equipped with adequate problem solving skills: expressing themselves confidently, asking what they want in an appropriate way, etc. Quite the reverse, those with low global self-esteem have tendency to become defensive. They may project their low self-value onto others by putting others down or performing an angry behavior as a cover of their low self-regard. Furthermore, employees with low global self-esteem are highly sensitive to criticism and any sign of rejection. Thus, it can be expected that when an employee has high self-esteem, he/she will easier establish more and positive relationships at work/home and will feel socially accepted and have a sense of belonging (fit).

Relation of global self-esteem to 'sacrifice' (a component of job embeddedness)

Low self-esteem individuals may sacrifice in order to gain love, acceptance, appreciation (Impett \& Gordon, 2010; Zeigler-Hill, 2013). Further, turnover is a risky decision (Allen, et al., 2007). People with lower self-esteem are reluctant to take risks and engage in new activities (Sorensen, 2001) and are more risk averse (Josephs, et al., 1992). Thus, it may be expected that low self-esteem employees may exaggerate the costs of leaving (perceiving excessive job sacrifice) in order to justify their decision to remain embedded and keep the status quo.

Hypothesis 1: Global self-esteem relates positively to 'links' and 'fit', and is negatively associated with 'sacrifice' in the job embeddedness model 
Chapter 4: Job embeddedness and the self

\subsubsection{Contingent self-esteem and the job embeddedness model}

Relation of contingent self-esteem to 'links'\& 'fit' (other job embeddedness components)

Humans' need to connect leads to comparison with others and speculations if individuals are alike, are they fulfilling expectations, whether they are accepted, whether they fit in (Gilbert, 2010). Furthermore, the drive to avoid inferiority can be behind many individual's motives. Therefore, contingent self-esteem may be related to the desire for success and desire to avoid failure, to insecure striving accompanied by fear of rejection (Neff, 2003b). Further, two main motivations behind achievement are growth-seeking vs. validation-seeking (Dykman, 1998). Validation seekers (those with contingent self-esteem) feel under constant stress to prove themselves as likable and acceptable to others, to fit with others (e.g., person-team fit; Hom et al., 2012).

\section{Relation of contingent self-esteem to 'sacrifice'}

Contingent self-esteem requires continuous validation (Vonk \& Smit, 2012). Thus, if an individual fails in the area of self-esteem contingency, he/she thinks of him/herself as inadequate and inferior, becoming shame-prone and self-critical. These individuals focus on comparing themselves with others and worrying whether they fit in or whether are inferior. Depending on the area of contingency (links and/or fit) the employee would make his/her endless investments. Thus, we can expect that employees with contingent self-esteem would make a lot of investments in their area of contingency. This may lead employee to the perception of having too much to lose (their hard-won social acceptance and social ties) if they have to leave.

Hypothesis 2: Contingent self-esteem is negatively associated with 'links' and 'fit' and positively to 'sacrifice' in the job embeddedness model 
Chapter 4: Job embeddedness and the self

\subsubsection{Self-determination and the job embeddedness model}

Relation of self-determination to 'links'\& 'fit'

The motivational part of self-esteem, self-determination, is related to stay/leave preferences in Hom et al.'s (2012) recent job embeddedness model. However, it is unclear as to how job embeddedness is related to the different components of self-esteem. Empirical studies show that self-determination is linked to relationships and satisfaction with them (Blais, Sabourin, Boucher, \& Vallerand, 1990; Downie, G., \& Koestner, 2008; Gaine \& La Guardia, 2009; Knee, et al., 2002), as well as to social comparison (Neighbors \& Knee, 2003), and thus to both on-work and off-work 'links' and on-work and off-work 'fit'.

Relation of self-determination to 'sacrifice'

Employees with high self-determination have a strong need for autonomy and feel much more in position of having personal choice. Thus, it is more likely that self-determined employee will perceive to have less to sacrifice as they can readily meet their needs elsewhere.

Hypothesis 3: Self-determination is positively related to 'links', 'fit', and negatively to 'sacrifice' in the job embeddedness model

\subsubsection{Moderating role of self-compassion}

The relationship between low self-esteem (low global self-esteem, contingent self-esteem, and low self-determination) and job embeddedness may depend on employees' self-compassion. Self-esteem is a driving force to resources. Though when critical, self-esteem becomes a threat, which when activated, elevates the need to protect and defend. Compassion is a balance force (Gilbert, 2009a; Gilbert \& Procker, 2006): it is vital in organizations (Frost, Dutton, Lilius, Kanov, \& Worline, 2005) and close relationships (Neff \& Beretvas, 2013). 
Chapter 4: Job embeddedness and the self

When employee is self-compassionate, he/she will be able to balance and be able to make choices unrelated to the ego defense.

Self-criticism results in negative feelings and is a poor motivational force (Blatt, Quinlan, Chevron, McDonald, \& Zuroff, 1982). Individuals set two types of interpersonal goals, namely self-image goals and compassionate goals (Crocker, Olivier, \& Nuer, 2009). Selfimage goals proved to be costly for belonging, and compassionate goals showed benefits for belonging (Crocker \& Canevello, 2008). Thus, employees who are low in self-esteem but are self-compassionate would be more likely to experience fit to organizations and communities than those who are not self-compassionate. Those with low self-esteem and lack of selfcompassion are going to operate from threat system or trying to compensate via over usage of the drive system by becoming overly competitive.

Hypothesis 4: Self-compassion plays a moderating role between global self-esteem and 'fit' and 'sacrifice' in the job embeddedness model

\subsubsection{Self-esteem and job satisfaction}

Core-self-evaluations proved to be a better predictor of job satisfaction compared to the BIG Five model (Judge \& Bono, 2001). And self-esteem is considered to be "the most fundamental manifestation of core self-evaluations as it represents the overall value that one places on oneself as a person" (Judge \& Bono, 2001). Chapter 2 and 3 show that global selfesteem is positively related to job satisfaction.

With regard with the second aspect of self, contingent self-esteem, the more the areas to which self-esteem is attached, the less job satisfied an employee will be. 
Chapter 4: Job embeddedness and the self

Furthermore, due to the fact that self-determined employees are intrinsically motivated (Deci \& Ryan, 1985b) and intrinsic motivation is related to job satisfaction, we can expect that selfdetermined employees will be also much more job satisfied.

Previous research shows that self-compassionate people are generally happier and more satisfied. Recent study showed moderate positive relationship between self-compassion and job satisfaction (Abaci \& Arda, 2013).

\section{Hypothesis 5:}

Global self-esteem, self-determination, and self-compassion are positively related to job satisfaction. Contingent self-esteem is negatively related to job satisfaction.

\subsection{Method}

\subsubsection{Participants}

The cross-sectional data for this study have been collected in 2013. We use a non-probability sampling method. The participants are employees in the Netherlands. They have been approached by email/intranet with a request to participate in the current study. The email/message contained a link to the online questionnaire. As an incentive to fill in the questionnaire, an opportunity to win a book voucher was provided to 10 randomly selected out of all completed questionnaires. The total sample comprised of 212 participants. From those, 113 participants filled in the questionnaire completely. The other participants had more than $30 \%$ missing values and therefore have been dropped from the study. The sample is equally distributed by gender with mean age of $46(\mathrm{SD}=10.473)$. In total, $70 \%$ of the sample has one or more children. Most of the employees are highly educated (88\%). From them, 43\% have a bachelor degree and $45 \%$ a master degree or higher. The distribution by occupation looks as follows: manager (19\%), professionals (31\%), technicians and associate 
Chapter 4: Job embeddedness and the self

professionals (20\%), clerical support workers (19\%), service and sales workers (9\%), and armed forces occupations (2\%).

\subsubsection{Measures}

Job embeddedness. We make use of the composite measure of job embeddedness because it includes both non-attitudinal and off-the-job components, which is central to embeddedness theory (Zhang, et al., 2012). Composite job embeddedness was measured with the 40 -item measure developed by Mitchell et al. (2001). The Dutch job embeddedness questionnaire can be found in Appendix B. Items related to community and organizational links were measured with fill-in type items. Items related to community and organizational fit as well as to community and organizational sacrifice, were assessed using a 5-point response scale. Even though that the nature of job embeddedness constructs, which are formative indicants, would suggest that internal consistency is not necessarily assumed, we computed reliability estimates. The estimated reliability scores (Cronbach's alpha) for the original subscales were as follows: organizational links $\alpha=0.59$, community links $\alpha=0.14$, organizational fit $\alpha=0.79$, community fit $\alpha=0.77$, organizational sacrifice $\alpha=0.79$, community sacrifice $\alpha=0.56$. We further analyzed the internal consistency between the items. The items of community links (items30. My family roots are in this community, 31. How many family members live nearby?, and 32. How many of your close friends live nearby?) showed very low internal consistency. When dropped, the reliability of community links increased from 0.14 to 0.69 . This way of measuring community links (without items 30,31,32) corresponds to the measurement of job embeddedness by Holtom (Holtom \& Inderrieden, 2006).

Global self-esteem. The Rosenberg Self-Esteem Scale (Rosenberg, 1979) was used, representing ten self-worth statements. Five of the items were positively worded and five were negatively worded items, ranging from strongly agree to strongly disagree. The 
Chapter 4: Job embeddedness and the self

Cronbach's alpha $=0.88$, which is in the range reported from previous studies (from 0.72 up to 0.90) (Gray-Little, Williams, \& Hancock, 1997).

Contingent self-esteem. We used Kernis and Paradise contingent self-esteem scale (Kernis, Paradise, Whitaker, Wheatman, \& Goldman, 2000). It consists of 15 items, answered on the scale from 'Not at all like me' to 'Very much like me'. Cronbach's alpha=0.86

Self-determination. Self-determination was measured with a 10 item instrument (Sheldon \& Deci, 1993). For each item, participants were asked to choose which of two statements feels more true, using a scale ranging from only A feels true (1) to only B feels true (9). Cronbach's alpha $=0.86$

Self-compassion. For the measurement of self-compassion, we used the short scale of the self-compassion measure of Raes and colleagues (Raes, Pommier, Neff, \& Van Gucht, 2011). This 12 -item scale has a near perfect correlation with the long 26-item scale when examining total scores. Participants were asked to indicate how often they behave in the described manner, using the scale from 1 almost never to 5 almost always. Cronbach's alpha= 0.61 Job satisfaction. As an overall measures of job satisfaction, we used the reliable (internal consistencies $\alpha$ at 0.80 or above) five-item version of Brayfield and Rothe's job satisfaction scale (Judge, Bono, \& Locke, 2000). Cronbach’s alpha=0.86

Control variables. Additionally, we used the following control variables (in the brackets is shown how those variables were measured): age (continuous), gender (dummy), children (dummy), occupation (categorical; International Standard Classification of Occupations), and education (categorical).

\subsection{Analyses}

In order to test the theory-driven hypotheses simultaneously, we used structural equation modeling (SEM), in particular path analysis, with an application of the AMOS 22.0 software 
Chapter 4: Job embeddedness and the self

package (Arbuckle \& Wothke, 1999). The maximum likelihood method of estimation was used.

On the model development stage, given the hypotheses, the following model exogenous variables were included: global self-esteem, contingent self-esteem, self-determination and self-compassion. The endogenous variables were the six components of job embeddedness (namely on-work 'links', 'fit', and 'sacrifice' and off-work 'links', 'fit' and 'sacrifice') and job satisfaction. Self-compassion was also considered as a moderator variable. Due to the fact that in our sample we had few respondents with low self-compassion $(n=6)$, we formulated the group by combining low and medium self-compassion $(n=34)$. The second group includes those with high self-compassion $(n=73)$. Additional control variables were also included age, gender, education, children, and occupation. All possible relations between endogenous, exogenous and control variables were included, as well as all possible relations between the disturbance terms for the endogenous variables.

After this basic full model was specified, we examined the data. Having in mind that SEM requires that the data should be multivariate normal, we checked data for skewness and kurtosis. For the skewness index, absolute values greater than 3.0 are perceived as excessive (Chou \& Bentler, 1995). For the kurtosis index, absolute values higher than 10.0 suggest a problem, and values higher than 20.0 are considered as excessive (Kline, 2005). Having in mind the nature of two of the endogenous variables and the skewness and kurtosis: links on $(\mathrm{sk}=5,787 ; \mathrm{ck}=39,112)$ and off-work $(\mathrm{sk}=2,134 ; \mathrm{ck}=5,306)$, we used a log transformation for them. We used univariate methods and the squared value of Mahalanobis distance $\left(\mathrm{D}^{2}\right)$ in order to examine and detect univariate outliers. By the univariate method, we took as a cutoff point of the standard z-scores over 2.5 which is appropriate for small sample size (Cousineau $\&$ Chartier, 2010). For the squared value of Mahalanobis distance $\left(\mathrm{D}^{2}\right)$, observation with a pvalue less than 0.001 is considered as multivariate outlier. Outliers were not identified in our 
Chapter 4: Job embeddedness and the self

dataset. There were no missing data. Our sample fulfils the requirements of a sample size of 100 as the minimum acceptable (Byrne, 2001).

On the model assessment stage, before testing the measurement invariance across groups of high and low-medium self-compassion, we started with the basic full model (fully saturated paths) which connected every exogenous variable (aspect of the self) to each endogenous variable (all six components of job embeddedness and to job satisfaction). When testing whether factor loadings and measurement error variances vary between groups, the results from the tests for configural and matrix invariance showed that the two groups are not invariant. Thus we could not proceed with multi group moderation test. Thought we tested Hypothesis 4 by creating moderation terms. For this purpose, the z-scores for the variables were created. Next, we took the z-scores of global self-esteem and self-compassion and produced an interaction term. We regressed the interaction term to fit on- and off- and to sacrifice on- and off-. Additionally we did competitive model testing which allowed us to compare the relative fit of several alternative models.

At the final stage, we assessed the validity of the structural model via GOF indexes and checked the significance of the regression weights, standardized regression weights, and squared multiple correlations. Model modifications threaten the validity of the study (MacCallum, Roznowski, \& Necowitz, 1992). In order to neutralize this risk, we used the single-sample expected cross-validation index (ECVI), which is proposed for comparing alternative model using only one sample of data (Browne \& Cudeck, 1989).

\subsection{Results}

The results of the correlational analyses can be found in Table 4.1. Table 4.2. presents the results of the measurement of alternative models. We compared those models by means of the Chi-square difference test (Schermelleh-Engel, Moosbrugger, \& Müller, 2003). In addition, 
Chapter 4: Job embeddedness and the self

the Root Mean Square Error of Approximation (RMSEA), the Comparative Fit Index (CFI), the Tucker-Lewis Index (TLI), and Parsimony-adjusted CFI (PCFT) were assessed. TLI, CFI, and RMSEA are advisable for continuous data and one-time analyses (Schreiber, Stage, King, Nora, \& Barlow, 2006). The following thresholds are recommended (Hu \& Bentler, 1999): TLI >.95; CFI > .95; RMSEA <.06. As can be seen in Table 4.2., the initial, full model is significant. Next, the model where self-compassion is used as motivational force instead of self-determination, is significant and shows very good fit to the data. Additionally estimates of the proportion of variance explained (R 2) for all dependent variables have been estimated. This information is helpful in determining which indicators contain the slightest measurement error. Table 4.3. shows the significant effects of the two motivational models and the full model. And Table 4.4. presents the significant effect of control variables in the those models. Below we present the results from the model which showed the best fit - the full model, including self-determination, self-compassion and job satisfaction. Global self-esteem is positively related to off-work links (H1). Global self-esteem is negatively related to on- and off- fit. Self-determination is negatively related to on-work fit and sacrifice (H3). Further, self-determination is positively related to job satisfaction (H5). The results from our analyses did not show effect of contingent self-esteem on job embeddedness (H2). Furthermore, selfcompassion did not show to play a moderation role between global self-esteem and fit and sacrifice (H4). Table 4.4. presents the coefficients for the control variables. Gender (positive) shows a significant effect on on-work fit. Having children has a positive effect on on-wok fit. The effect of the type of occupation on job embeddedness varies. Employees in managerial occupations perceive to have less fit on- work and have a sense to have less to sacrifice onwork. 
Table 4.1. Correlations, mean, standard deviation, minimum and maximum of all variables included in the analysis

\begin{tabular}{|c|c|c|c|c|c|c|c|c|c|c|c|c|c|c|c|c|}
\hline & $\stackrel{80}{\&}$ & $\begin{array}{l}\dot{\bar{v}} \\
\overline{0} \\
\bar{v}\end{array}$ & 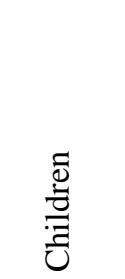 & 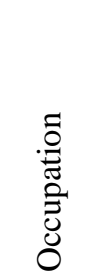 & 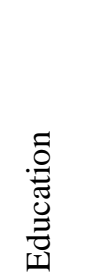 & 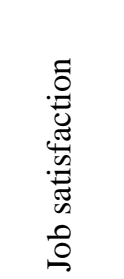 & 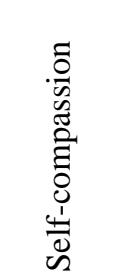 & 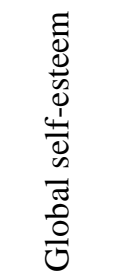 & 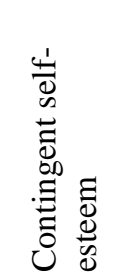 & 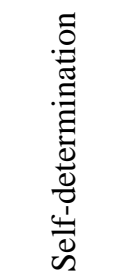 & 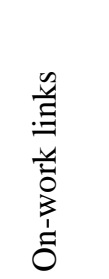 & 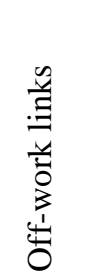 & 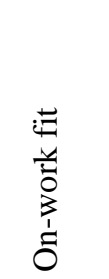 & 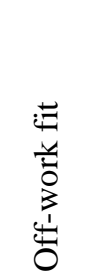 & 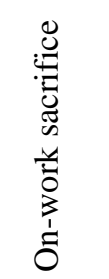 & 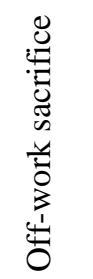 \\
\hline Age & 1 & & & & & & & & & & & & & & & \\
\hline Gender & $.324^{* *}$ & 1 & & & & & & & & & & & & & & \\
\hline Education & .025 & .106 & .056 & -.119 & 1 & & & & & & & & & & & \\
\hline Job satisfaction & .050 & -.036 & .094 & -.039 & $.221^{*}$ & 1 & & & & & & & & & & \\
\hline Self-compassion & $.226^{*}$ & $.289^{* *}$ & $.202^{*}$ & $-.204^{*}$ & .102 & $.352^{* *}$ & 1 & & & & & & & & & \\
\hline Global self-esteem & $.198^{*}$ & $.189^{*}$ & .139 & -.074 & $.272^{* *}$ & $.413^{* *}$ & $.537^{* *}$ & 1 & & & & & & & & \\
\hline Contingent self-esteem & -.162 & $-.278^{* *}$ & $-.248^{* *}$ & .044 & .119 & -.056 & $-.431^{* *}$ & $-.200^{*}$ & 1 & & & & & & & \\
\hline Self-determination & .133 & .158 & .173 & $-.210^{*}$ & .080 & $.519^{* *}$ & $.655^{* *}$ & $.555^{* *}$ & $-.297^{* *}$ & 1 & & & & & & \\
\hline On-work sacrifice & -.098 & -.131 & -.174 & $.192^{*}$ & -.090 & $-.429^{* *}$ & $-.187^{*}$ & $-.302^{* *}$ & .074 & $-.334^{* *}$ & -.093 & -.189 & $.645^{* *}$ & $.421^{* *}$ & 1 & \\
\hline Off-work sacrifice & -.016 & -.049 & -.111 & -.145 & .095 & $-.220^{*}$ & -.044 & -.136 & .033 & -.123 & .028 & .034 & $.194^{*}$ & $.707^{* *}$ & $.224^{*}$ & 1 \\
\hline Mean & 46.416 & 0.513 & 0.699 & 3.619 & 3.301 & 27.548 & 3.784 & 21.381 & 48.044 & 3.712 & 3.199 & 2.320 & 6.540 & 6.637 & 7.345 & 2.938 \\
\hline Standard Deviation & 10.473 & .502 & .461 & 1.277 & .766 & 5.298 & .808 & 5.833 & 8.557 & .695 & 1.051 & .997 & 2.105 & 2.272 & 2.039 & 1.241 \\
\hline Minimum & 24 & 0 & 0 & 1 & 1 & 10 & 1.57 & 0 & 17 & 1.70 & .69 & -1.98 & 3 & 3 & 3 & 1 \\
\hline Maximum & 64 & 1 & 1 & 6 & 4 & 35 & 5.50 & 30 & 72 & 5.00 & 6.75 & 4.30 & 12 & 13 & 13 & 5 \\
\hline
\end{tabular}

$* \mathrm{p}<.05 ; * * \mathrm{p}<.01$ 
Chapter 4: Job embeddedness and the self

Table 4.2.: Chi-square difference test and fit measures of alternative models

\begin{tabular}{|c|c|c|c|c|c|c|}
\hline Model & $\chi^{2}(\mathrm{df}) *$ & RMSEA & TLI & PCFI & CFI & ECVI \\
\hline $\begin{array}{l}\text { Full model excl. self- } \\
\text { compassion }\end{array}$ & $.990(3)^{* *}$ & .000 & 1.176 & .018 & 1.000 & 3.348 \\
\hline $\begin{array}{l}\text { Full model excl. self- } \\
\text { compassion, without job } \\
\text { satisfaction }\end{array}$ & $.99093)^{* *}$ & .000 & 1.178 & .020 & 1.000 & 3.009 \\
\hline $\begin{array}{l}\text { Full model incl. self- } \\
\text { compassion }\end{array}$ & $.896(1)^{* *}$ & .000 & 1.027 & .005 & 1.000 & 3.740 \\
\hline $\begin{array}{l}\text { Full model incl. self- } \\
\text { compassion excl. job } \\
\text { satisfaction }\end{array}$ & $.896(1)^{* *}$ & .000 & 1.027 & .006 & 1.000 & 3.383 \\
\hline $\begin{array}{l}\text { Full model with motivator } \\
\text { Self-compassion instead of } \\
\text { Self-determination }\end{array}$ & $.885(3) * *$ & .000 & 1.184 & .018 & 1.000 & 3.347 \\
\hline $\begin{array}{l}\text { Full model with motivator } \\
\text { Self-compassion instead of } \\
\text { Self-determination excl. } \\
\text { job satisfaction }\end{array}$ & $.777(1)^{* *}$ & .000 & 1.059 & .007 & 1.000 & 3.043 \\
\hline $\begin{array}{l}\text { Global Self-esteem to Job } \\
\text { Embeddedness (JE) }\end{array}$ & $1.909(5) * *$ & .000 & 1.150 & .037 & 1.000 & 2.660 \\
\hline $\begin{array}{l}\text { Global Self-esteem to JE } \\
\text { excl. job satisfaction }\end{array}$ & $1.176(3)^{* *}$ & .000 & 1.147 & .025 & 1.000 & 2.386 \\
\hline
\end{tabular}


Chapter 4: Job embeddedness and the self

\begin{tabular}{|c|c|c|c|c|c|c|}
\hline $\begin{array}{l}\text { Contingent self-esteem to } \\
\text { JE }\end{array}$ & $1.205(3) * *$ & .000 & 1.153 & .022 & 1.000 & 2.689 \\
\hline $\begin{array}{l}\text { Contingent self-esteem to } \\
\text { JE excl. job satisfaction }\end{array}$ & $1.057(2)^{* *}$ & .000 & 1.122 & .017 & 1.000 & 2.402 \\
\hline Self-determination to JE & $1.076(1)^{* *}$ & .026 & .982 & .007 & 1.000 & 2.724 \\
\hline $\begin{array}{l}\text { Self-determination to JE } \\
\text { excl. job satisfaction }\end{array}$ & $1.300(4) * *$ & .000 & 1.166 & .033 & 1.000 & 2.369 \\
\hline Self-compassion to JE & $1.978(5)^{* *}$ & .000 & 1.151 & .037 & 1.000 & 2.661 \\
\hline $\begin{array}{l}\text { Self-compassion to JE } \\
\text { excl. job satisfaction }\end{array}$ & $1.194(4)^{* *}$ & .000 & 1.176 & .033 & 1.000 & 2.368 \\
\hline $\begin{array}{l}\text { Global self-esteem and } \\
\text { Self-determination to JE }\end{array}$ & $1.550(4)^{* *}$ & .000 & 1.150 & .026 & 1.000 & 2.996 \\
\hline $\begin{array}{l}\text { Global self-esteem and } \\
\text { Self-determination to JE } \\
\text { excl. job satisfaction }\end{array}$ & $1.550(4)^{* *}$ & .000 & 1.151 & .029 & 1.000 & 2.675 \\
\hline $\begin{array}{l}\text { Contingent self-esteem and } \\
\text { global self-esteem to JE }\end{array}$ & $1.788(4)^{* *}$ & .000 & 1.145 & .026 & 1.000 & 2.998 \\
\hline $\begin{array}{l}\text { Contingent self-esteem and } \\
\text { global self-esteem to JE } \\
\text { excl. job satisfaction }\end{array}$ & $1.158(3)^{* *}$ & .000 & 1.161 & .022 & 1.000 & 2.689 \\
\hline
\end{tabular}

* H0: The over identified model fits the data as well as does a just-identified model; ** $\mathrm{p}<.05$ 
Chapter 4: Job embeddedness and the self

The model where self-compassion is used as motivational force shows that employees who are more self-compassionate are more likely to be job satisfied. In the model where selfdetermination is taken as motivational part of self, self-determination is positively related to job satisfaction. Though, when both self-compassion and self-determination are included in our final model, self-compassion does not show significant effect on job satisfaction. While, self-determination stays positively related to job satisfaction. Further as hypothesized, employees with high global self-esteem are more likely to be job satisfied in the model of self-compassion as a motivator. In general, in all tested alternative models, the models including job satisfaction showed better fit then those without.

The job embeddedness components show a relation to global self-esteem and selfdetermination but not to contingent self-esteem and self-compassion. The proportion of variance explained (R 2) for all dependent variables show that the model explains:

- $23 \%$ of the variance in on-work links

- $19 \%$ of the variance in off-work links

- $39 \%$ of the variance in on-work fit

- $19 \%$ of the variance in off-work fit

- $26 \%$ of the variance in on-work sacrifice

- $13 \%$ of the variance in off-work sacrifice

- $35 \%$ of the variance in job satisfaction

The results of the final, reduced model and the two motivational models are graphically displayed in Figure 4.1.

\subsection{Discussion}

This study takes an employee perspective to better understand job embeddedness. We hypothesized that different aspects of self would determine the way employee is attached to 
Figure 4.1.The models with standardized coefficients and significant relationships Controlled for age, gender, children, occupation, and education

Full model

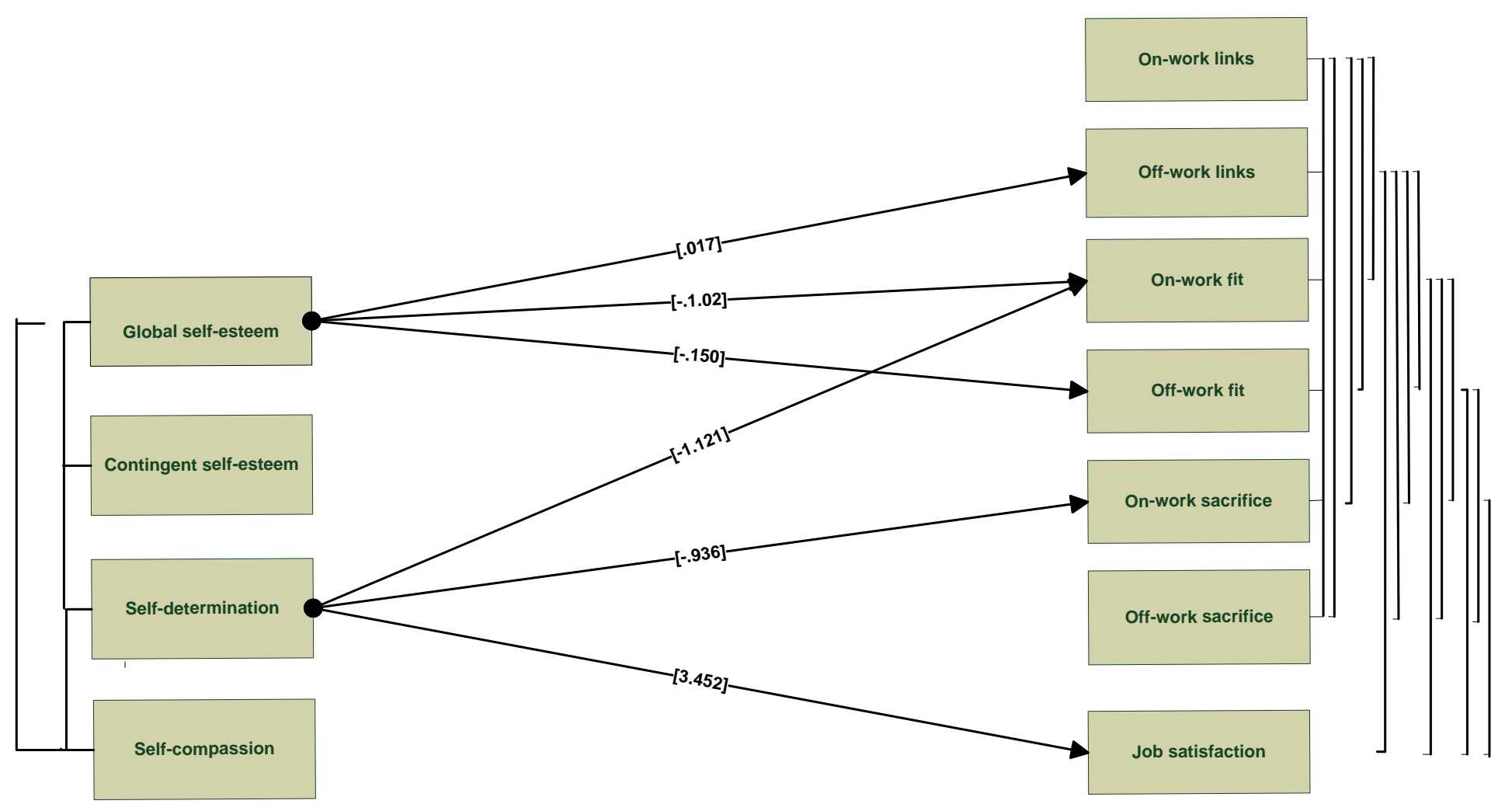


Chapter 4: Job embeddedness and the self

work. We expected that when self is self-critical (low global self-esteem, high contingent selfesteem, low self-determination), the employee will show the 'negative' side of embeddedness and become stuck. Though when self-compassion is high this will be less the case. The findings reveal that global self-esteem is related more to off-work dimensions of job embeddedness and self-determination more to on-work aspects of job embeddedness. Thus, in addition to the assertion that personality plays role by influencing off-work job embeddedness (Oyler, 2007), we also found an effect of self-esteem on on-work job embeddedness. The positive effect of global self-esteem on off-work 'links' is in line with previous studies which showed that secure individuals base their self-esteem on positive relationships with others. Global self-esteem has a negative effect on on-work 'fit' which might be due to a nonsupportive social environment which does not fulfill employees' social needs. Further global self-esteem proved to be also negatively related to off-work fit. One explanation for this may be that there are gender differences in deriving self-worth from relationships (Kwang, Crockett, Sanchez, \& Swann, 2013). Our results show that gender is positively related to onwork fit. Thus, it might be that for women identity is less dependent on work but is rooted in interpersonal relationships (Singh, et al., 2004).

Organizational researchers highlight the importance of distinguishing between self-esteem level and self-esteem contingencies (Ferris, Brown, Pang, \& Keeping, 2010). Yet the inclusion of contingent self-esteem in our model did not show any significant effect on job embeddedness or job satisfaction. The reason for that can be that we have no information about the area of contingency of self-esteem. Those whose self-esteem is contingent to the work area are more likely to engage in self-imposed behavior regulation than those whose self-esteem is not contingent to that area. If self-esteem is not contingent on a certain area, success or failure in that domain holds few implications for one's sense of self (Ferris, Brown, Lian, \& Keeping, 2009). 
Chapter 4: Job embeddedness and the self

The effect on the job embeddedness 'fit' is in the opposite direction than expected. Along with that, differences in the strength of the needs may exist (Deci \& Ryan, 2000). In particular, it may be that not all employees have the same need of autonomy (Sheldon, Turban, Brown, Barrick, \& Judge, 2003). Self-determination is also seen as a coping mechanism (Amiot, Blanchard, \& Gaudreau, 2008), which may provide an another explanation for our findings. However, the results may also reflect an environment that does not provide space for autonomy, structure, impersonal involvement (Ferris, et al., 2010). In advance, the results show that employees who are self-determined perceive that they have less to give up if they leave the job. This can be explained by two systems of self-control and selfregulation: cognitive and emotional system (Metcalfe \& Mischel, 1999). When an employee does not need to pursuit self-esteem or when he/she is self-determined, he/she can operate from the cognitive system that allows to 'keep goals in mind while pursuing them and monitoring progress along the route' and better fulfill their autonomy needs.

Further, if we look carefully at the self-determination and job embeddedness concepts, we can see certain similarities between them. Self-determination needs for relatedness resemble the 'link' concept, the need of competence, the 'fit' one, and this of autonomy, the 'sacrifice' one. The hypothesized moderating role of self-compassion was not supported ( $\mathrm{H} 4)$. This is likely due to the common method bias and the small sample size from which few employees reported low self-compassion scores. Research suggests that self-compassion is associated with holding realistic self-appraisals (Leary, et al., 2007), which in turn have been linked to self-improvement motivation (Breines \& Chen, 2012). More and more scholars are arguing that compassion may be better conceptualized not as an emotion itself but as a motivational drive that is enhanced or inhibited by certain emotional states. Thus, compassion can be defined by the characteristics of motivation: (a) activation/desire to initiate a behavior; (b) persistence/continued effort towards a goal even in the face of obstacles; and (c) intensity/the 
Chapter 4: Job embeddedness and the self

degree of energy and concentration required to pursue a goal (Bradley \& Lang, 1997; Singer \& Bolz, 2013; Singer \& Steinbeis, 2009).

Thus, self-compassion from one side may be a moderating force between self-critic (low global self-esteem) and job embeddedness. From the other side, compassion can be seen as an intrinsic motivational force itself that helps employees handle failures in difficult situations. For this reason, we tested a model in which instead of self-determination we used selfcompassion is a motivational force (Figure 4.3). The results show that self-compassion itself is not related to job embeddedness. Though, in self-compassion motivator model comparing to self-determination model (Figure 4.2.), global self-esteem shows significant negative effect on on-work sacrifice and positive effect on job satisfaction. Additionally self-compassion has a positive effect on job satisfaction. Thus, self-determination has its own power to influence job embeddedness. And it seems that self-compassion influence job embeddedness via its effect on self aspects.

The best fitting model is the model that includes both self-determination and self-compassion. Furthermore, there are similarities between the self-compassion literature and the selfdetermination literature suggesting that individuals who are self-compassionate will be more prone to autonomous motivation (Neff, 2003b). Self-compassion has been associated with feelings of autonomy, competence, relatedness, and self-determination (Magnus, Kowalski, \& McHugh, 2010; Neff, 2003a). Combining self-determination and self-compassion may be in line with research relating self-determination to quite ego (Niemiec, Ryan, \& Brown, 2006; Wayment, Bauer, \& Sylaska, 2014). Though, to our knowledge, there are no studies showing how self-determination and self-compassion may differ or complement each other in the area of work, they both lead to self-development. Without internalized compassion, individuals cannot be self-determined. Or else, it may be that people need self-compassion and selfdetermination on different moments in their self-development. 
Figure 4.2.

Self-determination as motivation

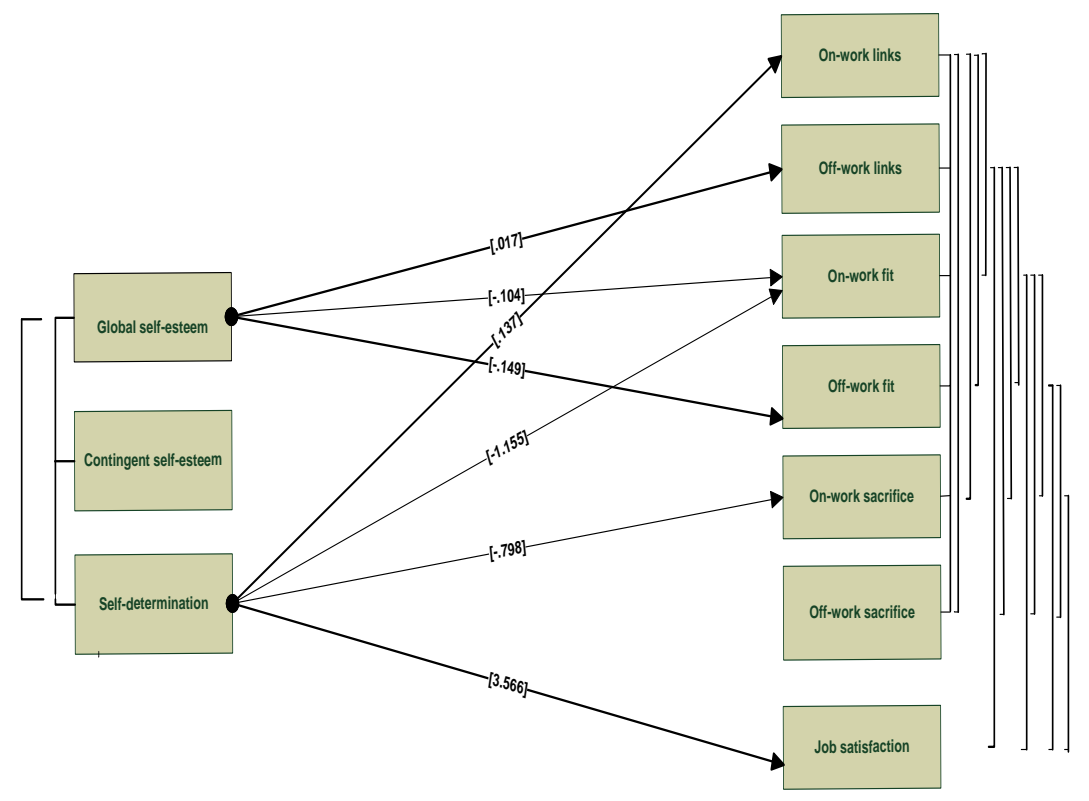

Figure 4.3.

Self-compassion as motivation

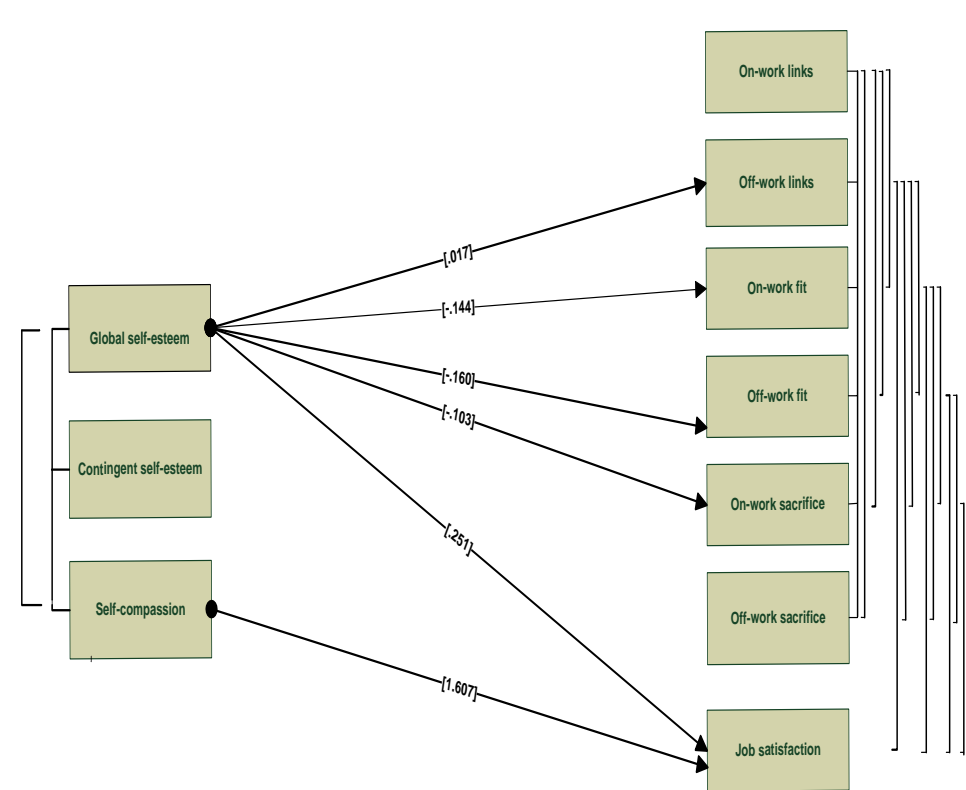


Chapter 4: Job embeddedness and the self

Table 4.3.: Comparing models with different motivators and the full model: unstandardized and standardized coefficients, standard error

\begin{tabular}{|c|c|c|c|c|c|c|}
\hline \multirow[b]{2}{*}{ Effects of $X \rightarrow Y$} & \multicolumn{3}{|c|}{ Motivational part of self-esteem: Self-determination } & \multicolumn{3}{|c|}{ Motivational part of self-esteem: Self-compassion } \\
\hline & $\begin{array}{l}\text { Unstandardized } \\
\text { coefficient }\end{array}$ & $\begin{array}{l}\text { Standard } \\
\text { error }\end{array}$ & $\begin{array}{l}\text { Standardized } \\
\text { coefficient }\end{array}$ & $\begin{array}{l}\text { Unstandardized } \\
\text { coefficient }\end{array}$ & $\begin{array}{l}\text { Standard } \\
\text { error }\end{array}$ & $\begin{array}{c}\text { Standardized } \\
\text { coefficient }\end{array}$ \\
\hline Global self-esteem $\rightarrow$ off-work links & $.019 * *$ & .008 & .254 & $.017 *$ & .008 & .226 \\
\hline Global self-esteem $\rightarrow$ off-work fit & $-.149 * *$ & .043 & -.384 & $-.160 * *$ & .043 & -.411 \\
\hline Global self-esteem $\rightarrow$ on-work sacrifice & -.059 & .037 & -.169 & $-.103 * *$ & .037 & -.294 \\
\hline Self-determination $\rightarrow$ on-work fit & $-1.155^{* *}$ & .287 & -.381 & - & - & - \\
\hline Self-determination $\rightarrow$ on-work sacrifice & $-.798 * *$ & .308 & -.272 & - & - & - \\
\hline Self-determination $\rightarrow$ job satisfaction & $3.566 * *$ & .746 & .468 & - & - & - \\
\hline Self-compassion $\rightarrow$ job satisfaction & - & - & - & $1.607 *$ & .733 & .245 \\
\hline $\begin{array}{l}* \mathrm{p}<.05 ; * * \mathrm{p}<.01 ; \text { Note: control variabl } \\
\text { age, gender, children, occupation, and } \\
\text { education }\end{array}$ & & & & & & \\
\hline
\end{tabular}


Chapter 4: Job embeddedness and the self

\begin{tabular}{lccc}
\hline \multicolumn{1}{c}{ Effects of $\mathrm{X} \rightarrow \mathrm{Y}$} & \multicolumn{2}{c}{ Full Model including both self-determination and self-compassion } \\
& $\begin{array}{c}\text { Unstandardized } \\
\text { coefficient }\end{array}$ & $\begin{array}{c}\text { Standard } \\
\text { error }\end{array}$ & Standardized coefficient \\
\hline Global self-esteem $\rightarrow$ off-work links & $.017^{*}$ & .009 & .232 \\
Global self-esteem $\rightarrow$ on-work fit & $-.102^{*}$ & .036 & -.283 \\
Global self-esteem $\rightarrow$ off-work fit & $-.150^{* *}$ & .045 & -.385 \\
Global self-esteem $\rightarrow$ on-work sacrifice & -.068 & .038 & -.194 \\
Global self-esteem $\rightarrow$ job satisfaction & .121 & .094 & .134 \\
Self-determination $\rightarrow$ on-work links & .121 & .078 & .189 \\
Self-determination $\rightarrow$ on-work fit & $-1.121^{* *}$ & .319 & -.370 \\
Self-determination $\rightarrow$ on-work sacrifice & $-.936^{* *}$ & .341 & -.319 \\
Self-determination $\rightarrow$ job satisfaction & $3.452^{* *}$ & .829 & .453 \\
Self-compassion $\rightarrow$ job satisfaction & .241 & .756 & .037 \\
\hline$* \mathrm{p}<.05 ; * * \mathrm{p}<.01$; Note: control & & & \\
variables: age, gender, children, & & & \\
occupation, and education & & & \\
& & & \\
\hline
\end{tabular}


Chapter 4: Job embeddedness and the self

Table 4.4.: Control variables for three of the alternative models

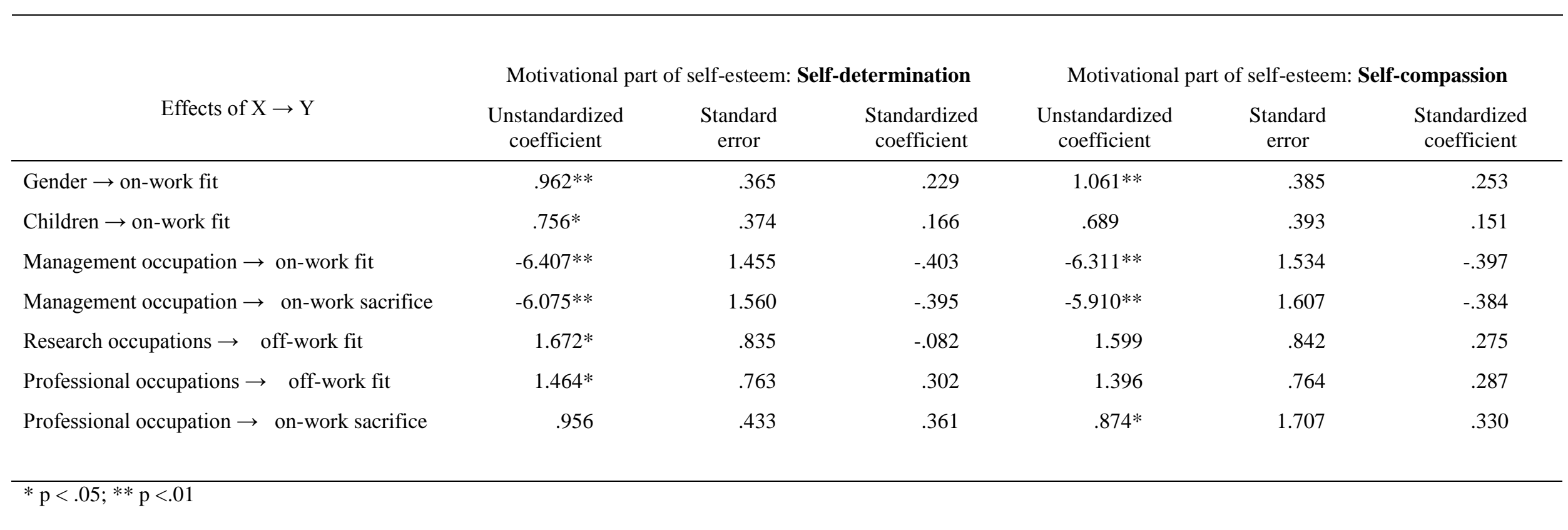


Chapter 4: Job embeddedness and the self

Combined model: with self-determination and self-

Effects of $\mathrm{X} \rightarrow \mathrm{Y}$ compassion

\begin{tabular}{lccc}
\multicolumn{1}{c}{ Effects of $\mathrm{X} \rightarrow \mathrm{Y}$} & $\begin{array}{c}\text { Unstandardized } \\
\text { coefficient }\end{array}$ & $\begin{array}{c}\text { compassion } \\
\text { Standard } \\
\text { error }\end{array}$ & $\begin{array}{c}\text { Standardized } \\
\text { coefficient }\end{array}$ \\
\hline Gender $\rightarrow$ on-work fit & $.971^{* *}$ & .366 & .232 \\
Children $\rightarrow$ on-work fit & $.758^{*}$ & .374 & .166 \\
Management occupation $\rightarrow$ on-work fit & $-6.429^{* *}$ & 1.457 & -.405 \\
Management occupation $\rightarrow$ on-work sacrifice & $-6.008^{* *}$ & 1.556 & -.390 \\
Research occupations $\rightarrow$ off-work fit & $1.669^{*}$ & .844 & .287 \\
Professional occupations $\rightarrow$ off-work fit & $1.462^{*}$ & .057 & .301 \\
Professional occupation $\rightarrow$ on-work sacrifice & -.559 & .657 & -.128
\end{tabular}

$* \mathrm{p}<.05 ; * * \mathrm{p}<.01$ 
Chapter 4: Job embeddedness and the self

\subsection{Strengths and limitations}

This is one of the first studies to examine the role of self-aspects in human behavior in an organization. The findings offer significant insights concerning the role of the self-aspects in organizational life. Combining self-determination and self-compassion offers interesting suggestions in creating more positive job embedded employees.

Though, as with any study, there are certain limitations that suggest potentially useful avenues for future research. Although we had enough power to demonstrate the effects, it should be mentioned that the findings come from a study with a cross-sectional design with a relatively small sample. Additionally, the results may be biased because it remains unclear to what extent the composite scale of job embeddedness can be generalized to other cultural settings (Crossley, et al., 2007). Thus, the current study has limited external validity.

For future research, we recommend longitudinal studies. Further, considering compassion as a flow: from self to self, from other to self, and from self to other, thus extra to self-compassion taking in consideration openness to receive compassion and giving compassion to others (Gilbert, 2005a). Further, people can pursue compassionate motives for different reasons, one of which may be to be liked or valued, from fears of rejection and desires for acceptance. Literature talks about submissive and genuine compassion (Catarino, Gilbert, Mcewan, \& Baiao, 2014). Future studies may consider to look closely on the motivation behind compassion.

\subsection{Conclusions}

This study advances understanding of job embeddedness by examining the role of individual self-esteem differences (Brayfield \& Crokett, 1955). In particular, low global self-esteem, high contingent self-esteem, low self-determination were expected to contribute to decreased well-being and to the negative side of job embeddedness. 
Chapter 4: Job embeddedness and the self

We demonstrated that all individual self-esteem differences are related to both on-work and off-work job embeddedness. Self-determination has direct influence on the different dimensions on job embeddedness. Self-compassion from the other side influences job embeddeness via its effect on the self-aspects. Though the model which integrates both selfdetermination and self-compassion proved to have the best fit.

The present study has practical implications for organizations that want to prevent the negative side of job embeddedness. Previous research has shown that compassion mind training (Gilbert \& Irons, 2005) is a useful training to increase self-compassion in different settings. This training could be offered to employees with self-attacking style in order to change it to caring and self-compassionate one. As a consequence we can expect more selfdetermined employees and positive job embeddedness. Finally, we can conclude that the present study contributes to the notion of the importance of self and self-compassion for organizational life and employee wellbeing. 


\section{Chapter 5}

\section{Low self-esteem predicts future unemployment}

This chapter draws upon: Huysse-Gaytandjieva, A., Groot, W., Pavlova, M., \& Joling, C. (2015) Low selfesteem predicts future unemployment. Journal of Applied Economics. Forthcoming 
Chapter 5: Low self-esteem predicts future unemployment

\begin{abstract}
Contrary to the plenitude of studies in social psychology on the effect of unemployment on individual self-esteem (state), there are few studies that have looked at the effect of selfesteem (trait) on becoming unemployed. While both hypotheses are probable, they are theoretically distinct and deal with two separate aspects of self-esteem: state and trait, which should be studied separately. Further, the few studies in social psychology on self-esteem as a trait, have mostly focused on people in childhood and adolescence, i.e. during a period when self-esteem is still changeable and fragile. Moreover, these studies often lack a distinction between moderating, mediating and confounding variables that is essential to identify causeeffect relationships .

This study fills previous research gaps and analyses whether people with low self-esteem are more likely to become unemployed than those with high self-esteem, and whether gender plays a moderating role in the relationship between self-esteem and becoming unemployed. The outcomes of a piecewise constant exponential model confirms our assumptions. Low self-esteem is highly significant in predicting the probability of becoming unemployed for women but not for men. However, low self-esteem has an effect on the chance of becoming unemployed regardless of gender for people who are technicians, associate professionals, or professionals.
\end{abstract}


Chapter 5: Low self-esteem predicts future unemployment

\subsection{Introduction}

Unemployment is one of the most dramatic events in one's life. Job loss leads to an income reduction (Waters \& Moore, 2001; Wilhelm \& Ridley, 1988), causes stress and leads to lower well-being (Creed, 1999; Goldsmith, Veum, \& Darity, 1996b; Waters \& Moore, 2001; Winefield \& Tiggemann, 1990). It lowers self-esteem (Creed, et al., 2001; Goldsmith, et al., 1996a; Hammer, 1993; Jahoda, 1982; Seligman, 1975; Shamir, 1986; Warr, 1989; Waters \& Moore, 2002b) and may subsequently cause a deterioration in health (Goldney, 1997) or depression (Howe, et al., 2004; Lerner, et al., 2004; Pearlin, et al., 1981; Schaufeli, 1988; Taris, 2002), admission to psychiatric hospitals (Blakely, et al., 2003) and, in some cases, even suicide (Blakely, et al., 2003; Lewis \& Sloggett, 1998; Preti \& Miotto, 1999). Social psychologists stress that involuntary joblessness harms people's psychological wellbeing and may lead to a "decline in cognitive performance, motivation and perception of selfworth" (Goldsmith, et al., 1996a, 1997). The research on this hypothesis looks at self-esteem as a state of mind (external sources of self-esteem) (Brown \& Marshall, 2006). However, an alternative reverse hypothesis in which self-esteem is a determinant of becoming unemployed and a cause of prolonged unemployment, has been formulated as well (Kasl, 1982). The investigation of this hypothesis requires looking at self-esteem as a trait (internal source of self-esteem). Although both hypotheses are possible, they are theoretically distinct and deal with two separate aspects of self-esteem: state and trait, which cannot be used interchangeably (Brown \& Marshall, 2006). Therefore, the hypotheses should be studied separately. Contrary to the plenitude of studies in social psychology on the effect of unemployment on individual self-esteem (state), there are few studies that have looked at the effect of selfesteem (trait) on becoming unemployed (Feinstein, 2000; Viinikainen \& Kokko, 2012). Further, the few studies in social psychology on self-esteem as a trait, have mostly focused on people in childhood and adolescence, i.e. during a period when self-esteem is still changeable 
Chapter 5: Low self-esteem predicts future unemployment

and fragile. Moreover, these studies often lack a distinction between moderating, mediating and confounding variables that is essential to identify cause-effect relationships (Greenland, 2003; Greenland \& Robins, 1986; Greenland, et al., 1999; Robins, et al., 2000).

At the same time, economic research has not considered self-esteem as an essential trait to understand individual economic behavior (Andolfatto \& Mongrain, 2004; McFadyen \& Thomas, 1997; Muller \& Plug, 2006). As a result, there is only a small literature on the effect of self-esteem on labor market activity (Baker, Glyn, Howell, \& Schmitt, 2004; Waddell, 2003). Nevertheless, self-esteem is regarded as one of "the most important primary goods" (Rawls, 1973). It influences cognition, behavior and people's affects (Leary \& Tangney, 2003). Diminished self-esteem lies at the bottom of major social problems (Mecca, et al., 1989). Particularly, self-esteem seems to be a psychological quality that helps people "in securing and holding employment” (Dooley \& Prause, 1997). Thus, individual traits such as self-esteem might be rewarded or punished on the labor market (Bowles, Gintis, \& Osborne, 2001).

The purpose of this study is to examine whether people with low self-worth are more likely to become unemployed than those with high self-worth. More specifically, we aim to assess whether self-esteem in a given year affects the dynamics of unemployment in the subsequent year. We pay specific attention to the role of gender. On the one hand, the social psychology literature suggests that men and women have significantly different levels of self-esteem (Kling, et al., 1999): women generally have lower self-esteem than men. On the other hand, studies in labor economics have shown that unemployment is more prevalent among women (Azmat, Güell, \& Manning, 2006). There are plenty of studies that relate a deterioration in self-esteem to unemployment (Artazcoz, Benach, Borrell, \& Cortès, 2004; McKee-Ryan, Song, Wanberg, \& Kinicki, 2005). Though, it is not clear what the role of gender is in the relationship between trait self-esteem and becoming unemployed. Therefore, in this chapter, 
Chapter 5: Low self-esteem predicts future unemployment

we bring the two perspectives together and study them jointly. Given the separate effect of gender on self-esteem and unemployment, as pointed above, we expect that gender moderates the effect of low self-worth on becoming unemployed. Particularly we address the question: Does low self-esteem increase the probability to become unemployed and how does this differ between genders?

Thus, we consider self-esteem as a trait and we pay specific attention to gender as a moderating factor. The analysis is based on data from the BHPS (Taylor, et al., 2010). The chapter is organized as follows: the next section explains the causal relationship between trait self-esteem and the risk of becoming unemployed. Then, a description of the data is given, and the model is presented. The analyses, the findings, and the discussion follow. Finally, the conclusions are summarized.

\subsection{Background}

In this section, we deduct our hypotheses from the psychological and social views on selfesteem presented in the literature. The relationships of confounding variables to self-esteem and to unemployment are clarified.

Self-esteem is considered to be a stable characteristic of one's personality (Crocker \& Park, 2003; Josephs, Bosson, \& Jacobs, 2003; Lecky, 1969; Nail, Misak, \& Davis, 2004; Robins, Trzesniewski, Tracy, \& Gosling, 2002; Shamir, 1986; Trzesniewski, Robins, Roberts, \& Caspi, 2003) and relatively resistant to change. Self-esteem is built in childhood (Adler, 1959; McGee, Williams, \& Nada-Raja, 2001) as a result of relational and temperamental factors. Children gradually internalize the beliefs about themselves that are communicated to them by the social environment (Bednar, Wells, \& Peterson, 1989). Basically self-esteem is used in the literature in three ways: trait self-esteem (global), state self-esteem and domain specific selfevaluations. To answer the question how these constructs are related, two models have been 
Chapter 5: Low self-esteem predicts future unemployment

developed: the bottom-up (evaluative feedback influences self-evaluations which define trait and state self-esteem) and the top-down model of self-esteem (once formed trait self-esteem influences self-evaluations and state self-esteem). The top-down model of self-esteem guides us in understanding the origin and function of self-esteem (Brown, Dutton, \& Cook, 2001). Self-evaluation and self-esteem are shown to be related to different aspects of psychological life (Brown \& Marshall, 2006).

To the best of our knowledge, this is the first study studying the effect of trait self-esteem on unemployment. In our study, we look upon self-esteem as an individual's sense of value or worth, or the extent to which a person values, appreciates, honors, or likes himself or herself (Rogers, 1951).

Research shows that self-esteem varies with age (Worell \& Goodheart, 2006). Age relates to different development stages (childhood, adolescence, adulthood, old age) during which different facets are used for self-evaluation. In adulthood work, career, partnership, children become important areas for self-evaluation.

Age is also related to career stages and accumulation of firm specific human capital. This is one of the explanations why younger people more often become involuntary unemployed. Furthermore, firms lay-off policies, such as in UK, apply the "last in, first out" (LIFO) rules, typically introduced at the will of unions, may more often lead to youth unemployment (Barwell, 2000).

A meta analysis (Kling, et al., 1999) shows that women generally have lower self-esteem than men. Rosenberg (Rosenberg, 1979) points out that "sex does not inform self-concept; being treated as a man or woman does". Boys and girls continuously receive information about how to fit into the societal gender roles (Sanchez \& Crocker, 2005). Maleness is related to authority, status, competence, social power, and influence. Femaleness is connected to the lack of authority, low status, incompetence, and little power and influence (Steward \& 
Chapter 5: Low self-esteem predicts future unemployment

McDermott, 2004). As a consequence, investment in gender ideals affects the self-esteem of women but not that of men (Egan \& Perry, 2001; Sanchez \& Crocker, 2005). Emergent gender differences in self-esteem are explained by attempts to match with gender role expectations and gender suitability of the situation, or to diverge from these expectations due to different tools to measure self-esteem (Owens, Stryker, \& Goodman, 2001).

Self-esteem has a strong relationship with happiness (Baumeister, et al., 2003). Intrinsically happy people may be more likely to get married (Kohler, Behrman, \& Skytthe, 2005).

Furthermore partnership makes people happier due to companionship and providing services for which the markets are missing or imperfect: support and help to deal with stress (Kohler, et al., 2005). Even though nowadays women in high-income countries are not as economically dependent as in the past, family work (housework and childcare) remains mostly a woman's task (Erickson, 2005). That is why working women may experience much more often a role conflict compared to men.

People with low self-esteem have low expectations of success, and as a result, they fail to make the best use of the capacities they have. People with low self-esteem are more concerned with self-protection (Josephs, et al., 1992). Subsequently, self-esteem correlates with investments in education (Covington, 1984; Feinstein, 2000; Groot, 1992; McKenna, 1996; Waddell, 2003) and achievements at school (Crocker, Karpinski, Quinn, \& Chase, 2003; Hair \& Graziano, 2003; Ross \& Broh, 2000; Waddell, 2003) for both genders and with investments in vocational training for men (Korman, 1966, 1967; Waddell, 2003). These factors influence job opportunities (Dooley \& Prause, 1997). Correspondingly, vocational training has a direct impact on the level of income and performance (Baumeister, et al., 2003; Fedor, Walter, Maslyn, \& Mathienson, 2001; Gavin, 1973; Levy \& Baumgardner, 1991; Martin \& Murberger, 1994; Shrauger \& Rosenberg, 1970). Therefore, it can be expected that people with low self-esteem make fewer investments in education and consequently have a 
Chapter 5: Low self-esteem predicts future unemployment

greater chance of ending up in a low income job in industries that pay less well. For both genders, high self-esteem is related to higher income (Emler, 2001; Goldsmith, et al., 1997). As people with low education in lower paid jobs are more likely to become unemployed, low self-esteem might indirectly affect unemployment chances.

Besides, people with low self-esteem choose passive ways of coping with perceived stressful events (Fineman, 1979) such as rejection, unsuccessful job interviews, or approaching unemployment. This can be explained by their attributional style (Hirschy \& Morris, 2002; Johnson, Metalsky, Rabkin, Williams, \& Remien, 2000; Miller \& Hoppe, 1994; Ralph \& Mineka, 1998; Southall \& Roberts, 2002), and internal locus of control (Kreger, 1995). Attributional style is related to achievements and performance (Poropat, 2002). However, attribution of failure has a different explanation between genders. Boys tend to explain failure by motivational problems and have an external locus of control. Girls are more inclined to explain failure by a lack of ability and hence have an internal locus of control. In particular, women more often use withdrawal and men are more likely to work even harder in order to demonstrate their capabilities (Langford \& Clance, 1993).

People search for information that is consistent with their own view about themselves (Lecky, 1969). Thus, due to their self-protecting orientation (Baumeister, 1999), people with lower self-esteem and an internal locus of control are more risk averse (Josephs, et al., 1992). As a consequence, in their attempt to protect a fragile ego, people with low self-esteem might use self-handicapping strategies in their work resulting in poorer performance and higher chances of risk of becoming unemployed. Low self-esteem might be a risk factor for unemployment because it facilitates a high predisposition to depression (Sorensen, 2001; Trzesniewski et al., 2006), anxiety (Epstein, 1985), stress (Caruthers, 2003; Jalajas, 1994) and unhealthy behaviors as alcohol and drug usage (Baumeister, et al., 2003; Byrne \& Mazarov, 2001; Seigley, 1999) for both genders (Ng \& Jeffery, 2003) that might lead to health deterioration 
Chapter 5: Low self-esteem predicts future unemployment

and from there to poorer job performance (Baumeister, et al., 2003; Gavin, 1973; Martin \& Murberger, 1994) and involuntary unemployment.

In summary, because of the higher likelihood of holding a bad job, of having a self-protective orientation, and a higher predisposition to depression, anxiety, stress, and unhealthy behaviors, people with low self-worth may be more likely to perform poorly and consequently be more likely to become involuntary unemployed. The effect of self-esteem on becoming unemployed is affected by gender. More specifically, a negative effect of low self- esteem is expected to be worse for women: that is, we expect that women with low self-worth will be more likely to be laid off than men with low self-worth.

Based on these insights, for the current study we formulate the following hypotheses:

- People with low self-worth are more likely to become unemployed than those with high self-worth.

- Gender exacerbates the effect of low self-worth on becoming unemployed.

\subsection{Data and operationalization of the variables}

We use data from the BHPS (Taylor, et al., 2010). In the BHPS, the unemployed are people who satisfy the following criteria (Thirteenth ICLS 1982): having no work; actively seeking for work; and currently available for work. Seeking (actively) for work when becoming unemployed may be highly correlated with self-esteem. Low self-esteem may actually lead people to stop searching for work. Thus the BHPS unemployment criteria may lead to bias of our results. Therefore, we use data on the employment status to create a lay-off variable (our dependent variable). It was coded as 1 if the respondent was employed at year $t$ and was unemployed at $t+1$, and 0 if the respondent was employed at both year $t$ and year $t+1$. The item that we use to measure self-esteem is: "Have you recently been thinking of yourself as a worthless person?". The fact that this is a self-reported outcome indicates that we 
Chapter 5: Low self-esteem predicts future unemployment

measure explicit self-esteem. The scale of answers ranged from 1 (not at all) to 4 (much more). The answers 1 and 2 were coded as 1 (high self-esteem). The answers 3 and 4 were coded as 0 (low self-esteem).

On the basis of the results of previous research and theories presented in the background section, as well as based on the data available in the BHPS dataset, the following explanatory variables were included in the model of unemployment in addition to self-esteem: age, education, being married or in a partnership, having a dependent child, health impairments due to alcohol and drug usage, depression, occupation (SOC), industry (SIC), regional unemployment rate, and union participation ${ }^{1}$. These additional explanatory variables have the function of control variables. As outlined in the background section of this study, they are found to influence unemployment and to be related to self-esteem. Therefore we account for them in the analysis, as far as the dataset allows, by including them as separate explanatory variables and by including their interactions with self-esteem when shown relevant in the preliminary analysis. The BHPS dataset does not provide information about other relevant control variables, such as performance and attributional style and therefore we are not able to include them in the analysis. Also, we are limited to the use of the indicators of the control variables as provided in the dataset. Below we explain how the explanatory variables are measured.

Health is a derived variable. Two variables that measure objective heath are included: anxiety, depression, etc. and health problems due to use of alcohol or drugs. Both health-related variables are incorporated in the analysis as dummies. The rest of the explanatory variables are based on the following questions: Dependent child: Is respondent the responsible adult for any child/ children aged 12 or under? Occupation: What was the respondent's (main) job last

\footnotetext{
${ }^{1}$ The variables of race and foreign birth were considered as possible confounders and were initially included as dummies in the probit analyses. The results showed that race has no relationship to self-esteem or to becoming unemployed. Foreign birth is not related to self-esteem but to becoming unemployed. Thus, both variables proved not to be confounders. Also, the variables were highly correlated to other control variables and therefore, were excluded from the analysis.
} 
Chapter 5: Low self-esteem predicts future unemployment

week? We included eight dummy variables for occupation. Industry: What does the firm/organization the respondent works for actually make or do? We included ten dummy variables for industry. We included information about the Regional Unemployment Rates in order to control for differences between regional labor markets, i.e. the demand side of the labor market. The information was gathered from published statistics (UK national statistics). We solved the problem of missing information for the values in year 1991 by including the mean score for that year.

The BHPS consists of multiple waves. For the analysis, we use the first eleven waves (19912001) with 51154 observations in total. In this sample, 7158 persons became unemployed during the 11-year period. Table 5.1. gives an overview of self-esteem rates in relation to employment status characteristics and shows that 2857 people reported low self-esteem, i.e. about $7 \%$ of the women and $4 \%$ of the men reported low self-esteem. In the analysis, cases with missing values have been deleted. The descriptives can be found in Appendix C.

\subsection{Statistical model}

To identify a causal relationship between self-esteem and unemployment, certain conditions must be fulfilled. First, the two variables (self-esteem and unemployment) must be related to each other. Second, the cause (self-esteem) must come before the effect (unemployment) in time (time precedence). Third, there must not be any other factor that is responsible for the correlation between self-esteem and unemployment (no spuriousness). Fourth, the cause (selfesteem) should enhance the probability of the effect (unemployment). Thus, we take the idea of Granger causality (Granger, 1969) and look at the effect of self-esteem in year t on becoming unemployed in the subsequent period, i.e. between $t$ and $t+1$. Granger causality examines whether the forecasts of the future events of unemployment can be improved if 
Chapter 5: Low self-esteem predicts future unemployment

Table 5.1. Self-esteem rates by gender and layoff

\begin{tabular}{|c|c|c|c|}
\hline & $\begin{array}{c}\text { Women } \\
\text { (\% within the gender group) }\end{array}$ & (\% with & $\begin{array}{l}\text { Men } \\
\text { in the gender group) }\end{array}$ \\
\hline Low self-esteem & 7.47 & & 3.95 \\
\hline \multirow[t]{2}{*}{$\begin{array}{l}\text { High self- } \\
\text { esteem }\end{array}$} & 92.53 & & 96.05 \\
\hline & $\begin{array}{c}\text { Not laid off } \\
\text { (number of respondents) (number }\end{array}$ & $\begin{array}{l}\text { Laid off } \\
\text { r of respondents) }\end{array}$ & $\begin{array}{c}\text { Total } \\
\text { (number of respondents) }\end{array}$ \\
\hline Low self-esteem & 2,444 & 413 & 2,857 \\
\hline $\begin{array}{l}\text { High self- } \\
\text { esteem }\end{array}$ & 41,552 & 6,745 & 48,297 \\
\hline Total & 43,996 & 7,158 & 51,154 \\
\hline
\end{tabular}

(besides all other available information) the current and the lagged values of self-esteem are also taken into account.

We control for confounding variables to provide support for the notion that the relationship between self-esteem and unemployment is not spurious. If the relationship between the variables does not change after the confounders have been included in the model, one can assume that association is not spurious.

We use discrete-time event history analysis to test the hypotheses. This is an appropriate technique for the investigation of causal relationships (Granger causality) in a time-related empirical representation of the structure of the causal arguments (Blossfeld \& Rohwer, 2002). The discrete-time event history analysis has been used in previous research to study unemployment (Ciucă \& Matei, 2011; Ribar, 2005; Tansel \& Taşçi, March 2010) but it has not been applied to the analysis of the impact of self-esteem on unemployment. The advantages of the method for our study are related to the possibility to account for censored observations (incomplete observation of the time to event) as well as time to event (unemployment). 
Chapter 5: Low self-esteem predicts future unemployment

A piecewise constant exponential model is used. This model splits time into periods (years).

We assumed that the transition rates are constant within every time interval but can change between intervals (Blossfeld \& Rohwer, 2002; Yamaguchi, 1991). The transition rate $\mathrm{r}_{j k}(\mathrm{t})$ from being employed (state $\mathrm{j}$ ) to the state of unemployment (state $\mathrm{k}$ ) is:

$\mathrm{r}_{j k}(\mathrm{t})=\exp \left\{\alpha_{l}^{(j k)}+\mathrm{A}^{(j k)} \alpha\right\}$ if $\mathrm{t} \in \mathrm{I} t$

For each transition $(\mathrm{j}, \mathrm{k}), \quad \alpha_{l}^{(j k)}$ is a constant coefficient associated with the $\mathrm{t}$ time period. A ${ }^{(j k)}$ is a vector of covariates, including self-esteem. $\alpha$ is an associated vector of coefficients. To become "at risk" the person should be employed in year t. Information about the covariates was taken from year $\mathrm{t}$ as well. The data were split into year-long episodes, or spells, so that covariates can be updated on an annual basis. We used covariates of year [t, $t+1]$ to predict becoming unemployed between year $[t, t+1]$. STATA software has been used in the analysis with the "stpiece" command.

\subsection{Preliminary analyses}

We performed several preliminary analyses. A Kaplan Meier curve is used as a descriptive method for evaluating the self-esteem variable. It is a helpful tool for visualizing the shape of the hazard function. The Kaplan Meier curves are presented separately for women and men in Figure 5.1. A, B. The downward hazard plots indicate that those with higher risk to become unemployed are first out of the data set.

Additionally, on the basis of the research findings on gender and self-esteem, we included in our preliminary analysis the interaction term (self-esteem * gender) in the model. This term, proved to be highly significant. Thus, gender seems to play a moderating role in the relationship between self-esteem and unemployment. For this reason, the remaining analyses are stratified by gender. 
Chapter 5: Low self-esteem predicts future unemployment

A key part of the model-building process is the selection of the predictor variables. We used a stepwise procedure to identify confounders. This selection procedure assumes that all variables selected are confounders (Hernan, Hernandez-Diaz, Werler, \& Mitchell, 2002). It is standard to use a stepwise procedure guided by a series of significance tests to select a single model, and then to make conditional inferences about the selected model. We observed what happens to the estimate of self-esteem when we controlled for confounders with a stepwise inclusion of the covariates. Table 5.2. presents the results. Model fitting is done separately for men and women. In model A, becoming unemployed is regressed on self-esteem. We added some socio-demographic characteristics in model B: age and education. Model C includes family information (partnership, dependent child). In Model D occupations are added. Model E inserts working sectors. In Model F health impairments information is added (depression, and health problems related to alcohol usage or drugs). Model $\mathrm{G}$ includes union membership and the regional unemployment rate. We compare the goodness-of-fit of the six models by means of Wald hypothesis testing. Wald hypothesis testing is used to compare nested discrete-time hazard models (Singer \& Willett, 2003; Yamaguchi, 1991). The null hypothesis is rejected, when the Wald chi-square statistics is large relative to critical values of the $\chi^{2}$ distribution. On the basis of the results of Wald hypothesis testing presented in Table 5.2., the full model, Model $\mathrm{G}$ appears to prove the best fit for the data. 
Chapter 5: Low self-esteem predicts future unemployment

Figure 5.1. Kaplan-Meier curves by gender and SE

A. The probability of becoming unemployed for women by SE

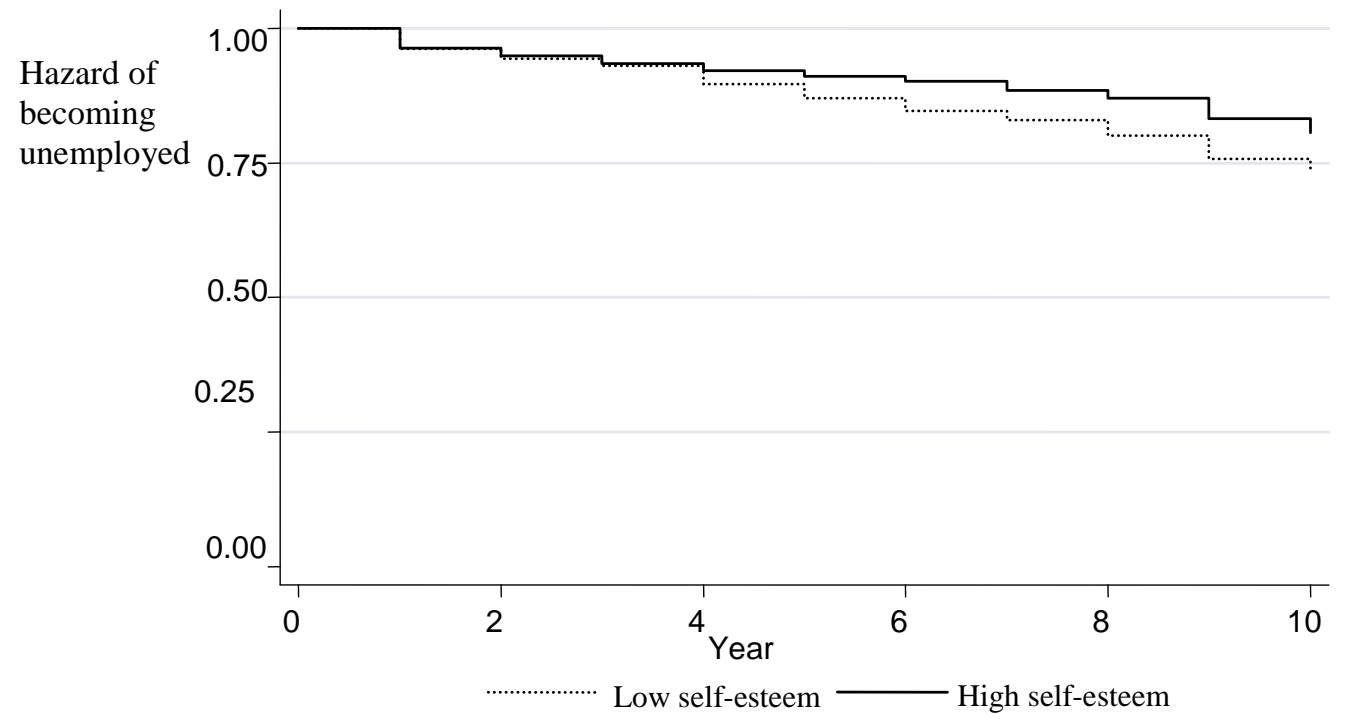

B. The probability of becoming unemployed for men by SE

1.00

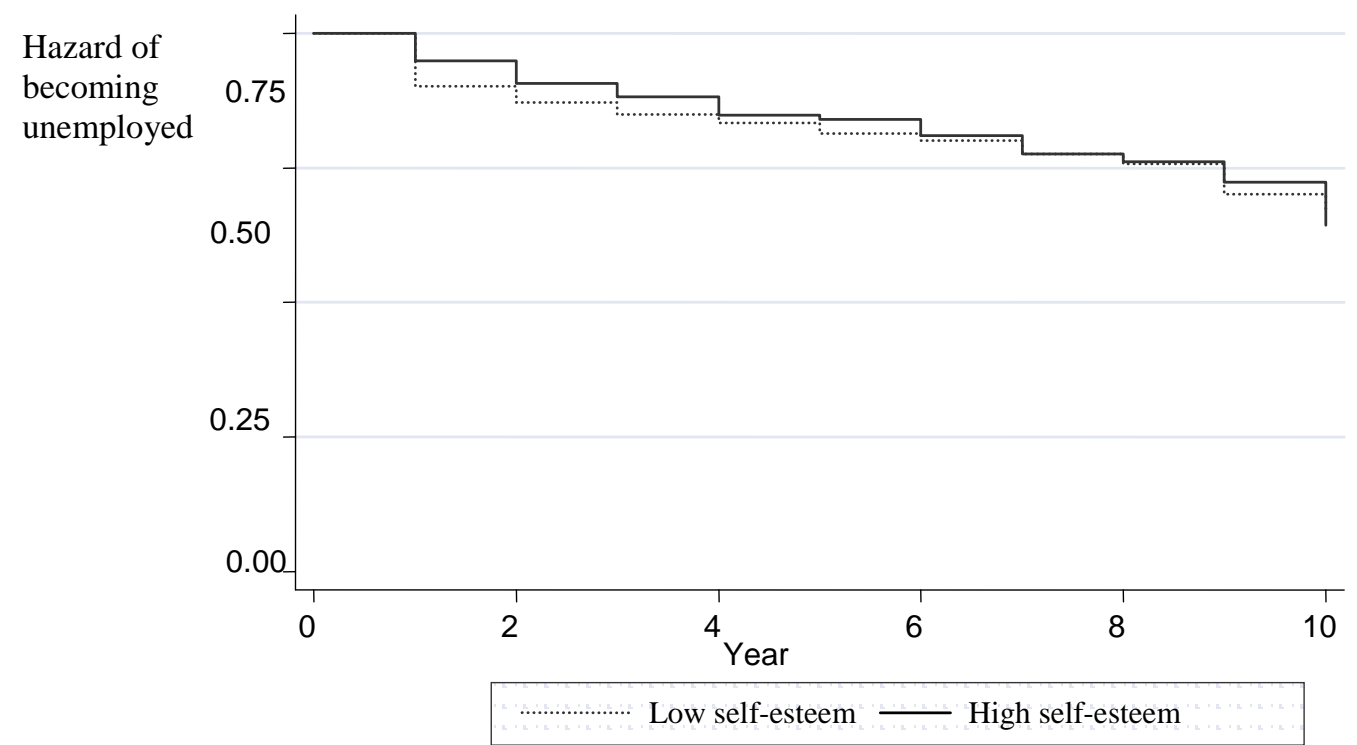


Chapter 5: Low self-esteem predicts future unemployment

Table 5.2. Model fitting

\begin{tabular}{|c|c|c|c|c|c|c|c|}
\hline & Model A & Model B & Model C & Model D & Model E & Model F & Model G \\
\hline \multicolumn{8}{|c|}{ A. Piecewise Constant Model (Women): } \\
\hline $\begin{array}{l}\text { Self-esteem } \\
\text { parameter } \\
\text { (St. error) }\end{array}$ & $\begin{array}{c}0.688 \\
(0.075) * *\end{array}$ & $\begin{array}{c}0.687 \\
(0.075) * *\end{array}$ & $\begin{array}{c}0.699 \\
(0.077) * *\end{array}$ & $\begin{array}{c}0.696 \\
(0.077) * *\end{array}$ & $\begin{array}{c}0.703 \\
(0.078) * *\end{array}$ & $\begin{array}{c}0.753 \\
(0.086) * *\end{array}$ & $\begin{array}{c}0.629 \\
(0.092) * *\end{array}$ \\
\hline \multicolumn{8}{|c|}{ Goodness-of-fit: } \\
\hline LL & -3012.22 & -2978.48 & -2948.38 & -2917.01 & -2874.83 & -2867.54 & -1587.17 \\
\hline Deviance & 6024.44 & 5956.96 & 5896.76 & 5834.02 & 5749.66 & 5735.08 & 3174.34 \\
\hline $\mathrm{N}$ parameters & 11 & 13 & 15 & 23 & 33 & 35 & 37 \\
\hline $\begin{array}{l}\text { Wald } \\
\text { hypothesis } \\
\text { testing }\end{array}$ & $12715.00 * *$ & $12540.83 * *$ & $12401.52 * *$ & $12241.76 * *$ & $12018.50 * *$ & $11987.91 * *$ & $7529.65 * *$ \\
\hline \multicolumn{8}{|c|}{ B. Piecewise Constant Model (Men): } \\
\hline $\begin{array}{l}\text { Self-esteem } \\
\text { parameter } \\
\text { (St. error) }\end{array}$ & $\begin{array}{c}0.987 \\
(0.115)\end{array}$ & $\begin{array}{l}0.954 \\
(0.111)\end{array}$ & $\begin{array}{c}0.956 \\
(0.113)\end{array}$ & $\begin{array}{l}0.964 \\
(0.115)\end{array}$ & $\begin{array}{c}0.935 \\
(0.111)\end{array}$ & $\begin{array}{c}0.961 \\
(0.116)\end{array}$ & $\begin{array}{l}1.009 \\
(0.186)\end{array}$ \\
\hline \multicolumn{8}{|c|}{ Goodness-of-fit: } \\
\hline LL & -4853.08 & -4763.29 & -4719.21 & -4644.87 & -4519.71 & -4504.40 & -2123.24 \\
\hline Deviance & 9706.16 & 9526.58 & 9438.42 & 9289.74 & 9039.42 & 9008.80 & 4246.48 \\
\hline $\mathrm{N}$ parameters & 11 & 13 & 15 & 23 & 33 & 35 & 37 \\
\hline $\begin{array}{l}\text { Wald } \\
\text { hypothesis } \\
\text { testing }\end{array}$ & $16172.89 * *$ & $15792.08 * *$ & $15614.45 * *$ & $15300.29 * *$ & $14867.12 * *$ & $14831.11 * *$ & $8963.70 * *$ \\
\hline
\end{tabular}


Chapter 5: Low self-esteem predicts future unemployment

\subsection{Estimation results and discussion}

Table 5.3. presents the results of the analyses of the effect of self-esteem on the probability of becoming unemployed. In Table 5.3., $\alpha_{l}^{(j k)}$ is a constant coefficient associated with the $1^{\text {th }}$ time period is presented. The $\alpha$ values are maximum likelihood estimates of the basic hazard function. The way they vary, determines the shape of this function and provide us with information about the risk (Singer \& Willett, 2003). In our case, the values of $\alpha$ are almost equal. Thus, the risk of event occurrence (unemployment) is not related to time, and the hazard function is flat. This result supports the assumption about the discrete-time hazard model that the shape of the hazard function is similar across groups but that its relative level differs (Singer \& Willett, 2003). As mentioned above, the role of gender is very important in understanding behavior (Steward \& McDermott, 2004). Therefore, the analysis is stratified by gender groups and the results for men and women are presented separately. Our study shows that low self-esteem is highly significant in predicting future unemployment for women but not for men. This is in line with previous studies which show the effect of low self-esteem on unemployment (Feinstein, 2000; Trzesniewski, et al., 2006). Contrary to our results, Feinstein finds an effect of self-esteem on male unemployment duration. This may be explained by the fact that he uses another operationalization (evaluation of mental and physical characteristics) and questionnaire (LAWSEQ) which is constructed to measure self-esteem in primary school children (Lawrence, 1981). Further, previous studies have included children and adolescents in their sample and are concerned with the effect on prolonged unemployment.

Furthermore, the difference between genders in the effect of self-esteem on becoming unemployed might be a result of measurement bias. We measure explicit self-esteem in this study. Thus, it might be that men give more socially desirable answers when they self-report 
Chapter 5: Low self-esteem predicts future unemployment

Table 5.3. Parameter estimates: Piecewise Constant Model: Full Model

\begin{tabular}{|c|c|c|}
\hline & Male & Female \\
\hline Parameters & Hazard Ratio (St. error) & Hazard Ratio (St. error) \\
\hline$\alpha_{1}$ & $0.007(0.002) * *$ & $0.004(0.002) * *$ \\
\hline$\alpha_{2}$ & $0.003(0.001) * *$ & $0.001(0.001) * *$ \\
\hline$\alpha_{3}$ & $0.002(0.001) * *$ & $0.002(0.001) * *$ \\
\hline$\alpha_{4}$ & $0.002(0.001) * *$ & $0.001(0.001) * *$ \\
\hline$\alpha_{5}$ & $0.003(0.001) * *$ & $0.002(0.001) * *$ \\
\hline$\alpha_{6}$ & $0.003(0.001) * *$ & $0.002(0.001) * *$ \\
\hline$\alpha_{7}$ & $0.004(0.001) * *$ & $0.002(0.001) * *$ \\
\hline$\alpha_{8}$ & $0.005(0.002) * *$ & $0.003(0.002) * *$ \\
\hline$\alpha_{9}$ & $0.007(0.002) * *$ & $0.006(0.003) * *$ \\
\hline$\alpha_{10}$ & $0.008(0.003) * *$ & $0.005(0.002) * *$ \\
\hline Age & $1.005(0.004)$ & $0.998(0.005)$ \\
\hline High Education & $0.751(0.063) * *$ & $0.665(0.069) * *$ \\
\hline In a partnership & $0.792(0.072) * *$ & $0.857(0.093)$ \\
\hline Dependent child & $2.108(0.870)$ & $1.094(0.115)$ \\
\hline Self-esteem & $1.009(0.186)$ & $0.628(0.092) * *$ \\
\hline Heath problems: due to alcohol or drugs & $3.189(1.347) * *$ & $1.742(1.228)$ \\
\hline Health problems: depression & $1.366(0.291)$ & $1.346(0.223)$ \\
\hline Occupation: manager & $1.047(0.130)$ & $1.522(0.275) *$ \\
\hline Occupation: professional & $0.850(0.150)$ & $1.697(0.381) *$ \\
\hline Occupation: technicians and associate professionals & $0.711(0.127)$ & $1.161(0.247)$ \\
\hline Occupation: clerks & $0.471(0.090) * *$ & $1.066(0.158)$ \\
\hline Occupation: person & $0.625(0.134) *$ & $1.380(0.231) *$ \\
\hline Occupation: sales & $1.088(0.192)$ & $0.902(0.179)$ \\
\hline Occupation: operative & $0.894(0.114)$ & $0.827(0.228)$ \\
\hline Occupation: other & $0.896(0.149)$ & $1.034(0.224)$ \\
\hline Sector: agriculture & $1.832(0.572) *$ & $4.800(3.118) *$ \\
\hline Sector: energy & $1.397(0.438)$ & $3.389(2.212)$ \\
\hline Sector: mineral & $1.248(0.331)$ & $3.106(1.811) *$ \\
\hline Sector: engineer & $1.448(0.309)$ & $4.790(2.208) * *$ \\
\hline Sector: manufacture & $1.730(0.362) * *$ & $5.263(2.296) * *$ \\
\hline Sector: constructure & $1.982(0.460) * *$ & $4.206(2.570) *$ \\
\hline Sector: distribution & $1.594(0.329) *$ & $3.346(1.414) * *$ \\
\hline Sector: transport & $1.122(0.270)$ & $5.018(2.288) * *$ \\
\hline Sector: banking & $1.590(0.342) *$ & $3.261(1.414) * *$ \\
\hline Sector: services & $0.883(0.197)$ & $2.285(0.965) *$ \\
\hline Regional unemployment rate & $1.250(0.027) * *$ & $1.192(0.032) * *$ \\
\hline Union participation & $0.663(0.058) * *$ & $0.615(0.066) * *$ \\
\hline
\end{tabular}

* significant at $5 \%$ level; ** significant at $1 \%$ level 
Chapter 5: Low self-esteem predicts future unemployment

self-esteem. Gender may moderate the relationship between explicit self-esteem and implicit self-esteem (Pelham et al., 2005).

Besides self-esteem, other factors are also statistically significant in explaining the risk of becoming unemployed. Higher education is statistically significant for both men and women. Men with a higher education are about $25 \%$ less likely to become unemployed compared to men with a low education $(100 *(0.751-1))$. Women with a higher education are $33 \%$ less likely to become unemployed compared to women with a lower education. In accordance with previous findings, a major benefit of education is the lower risk of unemployment at higher educational levels (Mincer, 1991). Further, education may be seen as a confounder that influences both self-esteem and the likelihood of becoming unemployed (Checchi \& Pravettoni, 2003; Francesconi, Orszag, Phelps, \& Zoega, 2000; Mincer, 1991; Ross \& Broh, 2000; Waddell, 2006). Better education leads to better jobs, broad access to jobs, and higher earnings (Checchi \& Pravettoni, 2003; Francesconi, et al., 2000; Groot, 1992; McKenna, 1996; Ross \& Broh, 2000). In addition, a higher regional unemployment rate increases the probability that workers of either gender will become unemployed. It increases the probability of job loss for men by $25 \%$ compared to those working in regions with a low unemployment rate. Higher regional unemployment rates might be seen as a stressful factor that demands adjustment. People with low self-esteem may be more risk averse and may deal with stress in more passive ways. Women living in regions with a higher unemployment rate have a $19 \%$ greater chance of becoming unemployed than women from areas with low unemployment. Men who are union member have a $34 \%$ lower chance to become unemployed than men who are not union members. Female union members are $39 \%$ less likely to lose their job than women who are not union members. The fact that union members have more employment protection might explain this. 
Chapter 5: Low self-esteem predicts future unemployment

Men in a partnership have $21 \%$ less chance of a job loss than single men. This could be explained by the idea that sharing one's life with someone brings support and helps people to manage life demands better (Kohler, et al., 2005). Health problems related to alcohol and drug use increase the chance of becoming unemployed by $44 \%$ in comparison with those who do not have such problems. People with low self-esteem more often use alcohol as a means to deal with pressure than others (Walitzer \& Sher, 1996). Alcohol use decreases the productivity of the labor market and increases the risk of becoming unemployed (Mullahy \& Sindelar, 1996). Men working in clerical and secretarial occupations have about $53 \%$ greater probability of losing their job than those who are not in these occupations. Women in managerial and professional occupations have a $52 \%$ higher probability of losing their job than women in other business groups. Women in professional occupations are $70 \%$ more likely to become unemployed than others. Working in personal occupations results in a $38 \%$ higher probability to become unemployed. An explanation for that might be that some occupations and industries are more vulnerable to cyclical unemployment. Low-skill occupations are generally more vulnerable to economic slowdowns as they tend to be more concentrated in cyclical industries.

Table 5.4. shows additional information for the interactions included in the analysis. The inclusion of interactions did not essentially change the other estimates. Due to the expected relationship between self-esteem and being married/in a partnership and the difference between genders, we include in the model the interaction terms between these two variables (Table 5.4.). The hazard rate shows that low self-esteem has an effect on the chance of becoming unemployed for married women and those in a partnership but not for men. Bearing in mind the role of women as homemakers, employed women might experience more role conflict. Low self-esteem is related to more gender-role conflict (Chusmir \& Koberg, 2001). 
Chapter 5: Low self-esteem predicts future unemployment

Table 5.4. Parameter estimates: Piecewise Constant Model including interaction terms (selfesteem*occupation and self-esteem*married or in a partnership)

\begin{tabular}{lcc}
\hline & Male & Female \\
\cline { 2 - 3 } $\begin{array}{l}\text { Interaction terms } \\
\text { SE*occupation) }\end{array}$ & Hazard Ratio (St. error) & Hazard Ratio (St. error) \\
\hline Self-esteem*manager & $0.858(0.550)$ & $0.279(0.292)$ \\
Self-esteem*professional & $1.398(0.994)$ & $4.711(2.848) * *$ \\
Self-esteem*associate & $3.692(2.161) * *$ & $2.877(1.540) *$ \\
Self-esteem*clerical & $2.147(0.984)$ & $1.620(1.281)$ \\
Self-esteem*person & $1.670(0.862)$ & $0.000(0.004)$ \\
Self-esteem*sales & $0.789(0.557)$ & $0.796(0.841)$ \\
Self-esteem*operativ & $1.469(1.235)$ & $1.406(0.833)$ \\
Self-esteem*other & $1.474(0.872)$ & $0.651(0.501)$ \\
Self-esteem*living together & $0.541(0.233)$ & $0.443(0.144) * *$ \\
\hline
\end{tabular}

* significant at $5 \%$ level; ** significant at $1 \%$ level

In addition to the stress of low self-esteem, unique female stressors such as motherhood, combining roles, working in nontraditional occupations, etc. (Iwasaki, MacKay, \& Mactavish, 2005) and the coping style of women make women with low self-esteem more vulnerable to becoming unemployed. Supportive to our results are those of the study of Hofstede (Hofstede, 2001) where the UK ranked high on masculinity. Hofstede (Hofstede, 2001) names masculinity versus femininity focuses on the degree to which "traditional" gender roles are assigned in a culture; i.e., men are considered aggressive and competitive, while women are expected to be gentler and taking care for home and family. Table 5.4. also gives the hazard rate when the interaction terms between self-esteem and occupation are included in the model. As we can see, low self-esteem has an effect on the chance of becoming unemployed regardless of gender when people are technicians and associate professionals (physical and engineering science associate professionals; life science and health associate professionals, etc.) and professionals in physics, mathematics and engineering, life science and health, etc. 
Chapter 5: Low self-esteem predicts future unemployment

In particular, people in associate and professional occupations with low self-esteem have a higher chance to become unemployed. Higher-level occupations impose more expectations and demands on the employee that might increase the fear of failure. Alternatively, low selfesteem might be a handicap and may be an impediment to productivity in associate and professional occupations. Consequently, these workers may be more prone to lay-off and redundancy.

In summary, gender appears to moderate the effect of low self-esteem on becoming unemployed. In higher-level occupations, low self-esteem has an effect on job loss that is independent of gender.

\subsection{Conclusion}

This study shows that low self-esteem (considered here as a trait) has an effect on becoming unemployed. Furthermore it shows that low self-esteem is more detrimental for women than for men when it concerns their labor market position. The study offers information that clarifies how unemployment manifests itself.

The results might be helpful to professionals who guide, teach, and coach people as teachers, human resource managers, and health professionals in helping working people avoid becoming unemployed by providing them with knowledge on the nature of self-esteem and directing them to learn practical skills to work with self-esteem (Dweck, 2000; Sorensen, 1998). Teaching employees with low self-esteem to control their low self-esteem instead of letting it to be in control (Sorensen, 1998) might be a strategy to reduce the chance of job loss. Further, teaching employees with low self-esteem new skills (how to respond to criticism, learn how to ask for what they want, coping with unhealthy values), helping them to change thinking patterns (becoming aware of the shoulds, disarm their own critics), and providing them with assertiveness training may benefit both individuals and organizations. Further, 
Chapter 5: Low self-esteem predicts future unemployment

other approaches as Acceptance and Commitment therapy (Hayes \& Strosahl, 2010; Luoma, et al., 2007; Torneke, 2010) and Compassion Focused therapy (Gilbert, 2010) concentrate on understanding and acceptance, rather than trying to change, may be of value. 


\section{Chapter 6}

\section{Why do we fail to adapt to a different culture?}

This chapter draws upon:

Huysse-Gaytandjieva, A., \& Boncheva, I. (2013). Why do we fail to adapt to a different culture? A development of a therapeutic approach. International Journal of Psychotherapy, 17(3), 43-58. 


\begin{abstract}
The aim of this study is to bring more understanding to the problems that immigrants face and to develop a therapeutic approach based on Positive Psychotherapy. Three groups of immigrants were formed, based on the main reasons why people migrate: work, contact and future. By the means of qualitative analysis, the problematic aspects of these groups were highlighted. The developed therapeutic approach is presented by going through the process of psychological intervention to discuss the psychodynamic of the person's problems with some of the most often used tools in Positive Psychotherapy. This includes the following therapy steps: observation, inventory, situational encouragement, verbalization, and broadening of the goals. The results show both similarities and differences between the groups. In $75 \%$ of the cases, the duration of the therapy reached 23 sessions. In $66.7 \%$ of the cases, the symptoms disappeared completely and in the rest of the cases, they diminished dramatically.

Due to the fact that Positive Psychotherapy presents a trans-cultural framework in which different methods can work and cooperate together, the research presented in this study can be of interest to psychotherapists, counselors, and psychiatrists regardless of their psychotherapy training. Furthermore, some ideas on application for purposes of prevention are presented.
\end{abstract}




\subsection{Introduction}

We are living in exciting times. Having a partner, neighbor, classmate or colleague of different color or ethnicity; working in one country and living in another; working for a foreign company, all these opportunities, which are, at the same time, challenges are nowadays becoming more a way of being, than an exception. As stimulating as trans-cultural relationships of different kinds (studying or working abroad, mixed marriages, foreign travel, etc.) can be, they may also at times call into question a person's personality or identity, especially when they are trying to adapt to another person's culture.

Cross-cultural adaptation has held a focus of attention for researchers, who have built models in their attempt to understand this process better. Yet, when it comes to the practice of counseling and psychotherapy, those models only have a limited application (Sobre-Denton \& Hart, 2008). In particular, psychotherapy is to, a great extent, a product of the Western culture (Dwairy \& Van Sickle, 1996) and "embedded within a particular mono-cultural framework" (Rawson, Whitehead, \& Luthra, 1999). Almost all therapeutic approaches focus on the self (Kirmayer, 2007) and underestimate the roles of family and culture (D'Ardenne \& Mahtani, 1989). Thus, they tend to put an emphasis on individualism. This limitation is necessitated within psychotherapy, to reconstruct a response to current cross-culture changes in society (McLeod, 2001). As a result of this, the focus of research that explores the provision of psychotherapy to people from different cultures has been a modification and adaptation of Western psychotherapy approaches (Black, et al., 1991; Chang, 1998; Elligan, 1997; Hwang, 2006).

This study presents an application of Positive Psychotherapy, a relatively short-term approach, which is based primarily on trans-cultural research (Peseschkian, 1987). As mentioned in Chapter 1, Positive Psychotherapy links the East's wisdom and intuitive thinking with the West's intellectual psychotherapeutic knowledge. It does so by 
concentrating on the intellect, as well as on the intuition and fantasy capacities, the emotion and sense sensitivity, and the ability to learn from the experiences of tradition. We study the application of Positive Psychotherapy only in the event of the immigrants who have sought psychotherapy. We can look upon the reason for leaving a country as indicating what the expectations of migration are. Expectations are perceived as a motivator, but also as a stress generator, especially when there is an expectation gap (Pitts, 2009). The expectations that the clients reported were translated to one of the four areas of the 'balance' model, which is an essential tool in Positive Psychotherapy for identifying conflicts and dealing with them: body, work, contact, and future. As a result, three groups were formed, those who migrate for: achievement \& work reasons; contacts \& partnership, and their dreams (or fantasies) of a better future.

The aim of this study is: (1) to illuminate and bring more understanding to the problems that immigrants from the above groups face; and (2) to develop a therapeutic approach for these groups, based on Positive Psychotherapy.

Due to the fact that Positive Psychotherapy presents a trans-cultural framework in which different methods can work and cooperate together (Peseschkian, Biland, \& Cope, 2010), the current research might be of interest to psychotherapists, counselors, and psychiatrists, regardless of their psychotherapy training. Moreover, the application of Positive Psychotherapy provides the opportunity for a short-term therapy, and its application can therefore contain and benefit from most of the costs of treatment. This is especially relevant in present times, when there is a huge pressure on the resources spent on health care. Although previous research reveals that short-term therapies, in general, carry some problems, especially when working with people from different cultures (Seeley, January 2004). The longitudinal effectiveness study of Tritt (Tritt, Loew, Meyer, Werner, \& Peseschkian, 1999b) reveals that patients treated with Positive Psychotherapy showed a distinct reduction of 
symptoms and improved the way that the patients feel and behave. Furthermore, a lasting stability of the therapeutic effects of Positive Psychotherapy was demonstrated.

In this chapter, the construct of this study is first defined, followed by a short literature review of some previous research. Next, the research methods that were applied are outlined. The results and their discussion are then presented; finally, we draw some conclusions about the therapy and research.

\subsection{Defining the constructs}

Different models or modalities come with different definitions of trans-cultural adaptation. As explained in Section 1.4.1, adaptation to a new culture has been identified as the phenomenon of 'culture-shock'. The sojourner might well go through three to five stages of emotional adaptation when abroad: (1) the honeymoon stage, leading to feelings of initial euphoria; (2) culture shock, resulting from feelings of disorientation; (3) hostility towards the host culture, leading to feelings of resentment; (4) initial adaptation, leading to a sense of autonomy within the host culture; and (5) assimilation into the host culture, leading to a sense of belonging to both the host and the home culture (Adler, 1975; Furnham \& Bochner, 1986). Others define trans-cultural adaptation as a commonplace process of learning, so as to live with the changed environment and differences (people, norms, standards, and customs) (Kim, 1988). Thus, trans-cultural adaptation can be seen as a dynamic interplay between stress-adaptation and growth. Additionally, trans-cultural adjustment refers to the degree of a sojourner's psychological comfort with various aspects of the host country (Black \& Gregersen, 1991). In this study, trans-cultural adaptation is operationalized as a process of interaction (attachment, differentiation, detachment) leading to a balance between four different modes: body, contacts, achievement and future. Below, we briefly highlight the existing theories 
related to the topic of our research and the theoretical background for the current study. Next, the explanation of the theoretical framework for this study is given.

\subsection{Review of trans-cultural adaptation theories}

The attention of the previous trans-cultural adaptation studies was mostly on the demographic characteristics (Polek, Wöhrle, \& van Oudenhoven, 2010; Ward, et al., 2001). Variables, which were found related to trans-cultural adjustments include: gender (Abbott, Wong, Williams, Au, \& Young, 1999; Klimidis, Stuart, Minas, \& Ata, 1994), age (Olaniran, 1996), marital status (Trice, 2004), academic level (Olaniran, 1996; Schram \& Lauver, 1988), language skills (Fletcher \& Stren, 1989), country of origin (Abe, Talbot, \& Geelhoed, 1988), previous international experience (Henderson \& Shibano, 1990), and length of stay (Trice, 2004).

The models of trans-cultural adaptation that previous studies offer can be basically categorized in four broad families: the U-Curve models; the anxiety/uncertainty management models; the transition models; and the stress-adaptation-growth models. The paper of SobreDenton (Sobre-Denton \& Hart, 2008) summarizes these models comprehensively. Most of these newly developed models of intercultural treatment rely on cultural knowledge - yet, intercultural therapeutic approaches that depend exclusively on cultural knowledge pose problems (Seeley, January 2004). Scientific studies exploring psychotherapy for people from different cultures have been focused on a psychotherapeutic adaptation and modification of Western insight-oriented psychotherapy approaches (Black, et al., 1991; Chang, 1998; Elligan, 1997; Hwang, 2006). For example, psychoanalytic psychotherapy is directed to look beyond the intra-psychic (Sanville, 2000), i.e. to review the concepts as either 'normal' or 'pathological', as well as certain models about the therapy relationship, culture, and culturally-tinted concepts, such as anger (Roland, 2006). Client-centered therapy is mostly not 
appreciated by clients, for whom dependence on authority is expected and personal independence is of less importance (Tseng, 1999). Further, only limited attention has been given to the cultural aspects by cognitive-behavioral therapists (Iwamasa \& Smith, 1996). Research and practice are needed to investigate in which ways cognitive-behavioral principles are culturally dependent (Renfrey, 1992).

\subsection{Methods}

The cases for this study come from two private psychotherapy practices of two independently working professionals (both Bulgarian by origin) in the Netherlands and Bulgaria. The psychotherapy took place during 2009-2010. The psychotherapy sessions were individual and face-to-face.

The qualitative analysis was organized in the following way: First, sample characteristics were given. We went through the process of psychological intervention, separately for each group, and discussed the psychodynamic of the problems and the most often used Positive Psychotherapy tools. These include the following 5 therapeutic steps: observation, inventory, situational encouragement, verbalization, and broadening of the goals. The psychological reasons given to come to therapy per group are depicted in the pie charts (Figure 6.1., below). The favored defenses, basic and inner subconscious conflict, and the most often used transference forms, are presented per group in Table 6.1..

Before proceeding to the presentation of the samples, the psychotherapists' self-reflection in relation to the topic of research, experience, personal conflict areas and how their rhomb looks like follow. This is done due to the fact that in qualitative research, "the researcher is the instrument" (Patton, 2001). Therefore a consideration of self as a researcher and self in relation to the topic of research is a prerequisite for coping with eventual bias. Further credibility checks were done by (Elliott, Fischer, \& Rennie, 1999): two psychotherapists who 
Figure 6.1.: Psychological reasons for searching therapy per group

\section{Group future - psychological reason searching therapy}

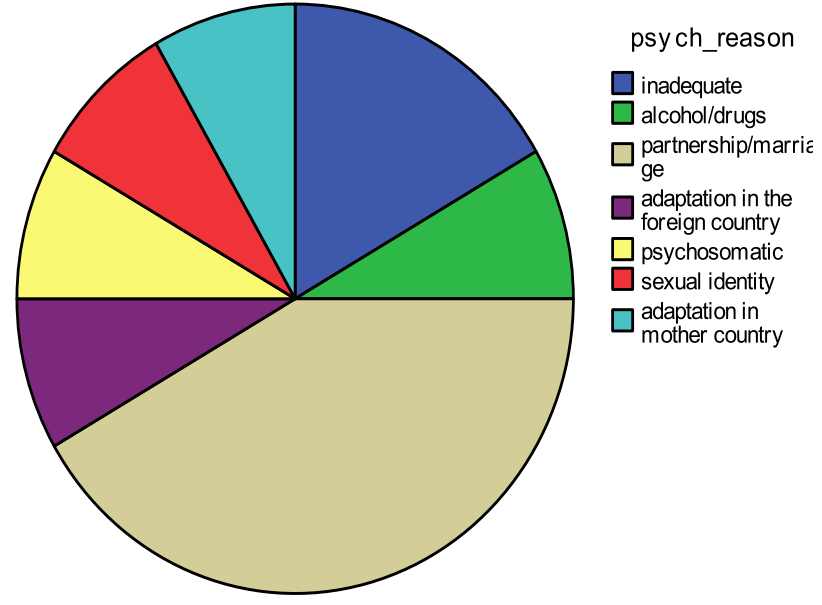

\section{Group achievement - psychological} reason searching therapy

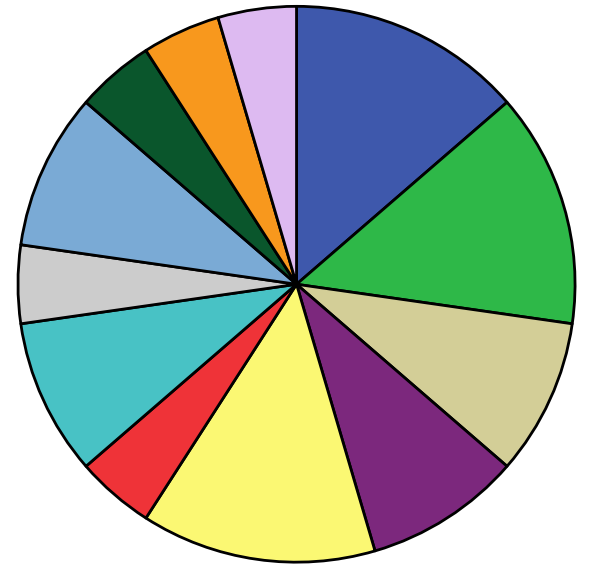

psych_reason

$\square$ alcohol/drugs

$\square$ partnership/marrie

ge

$\square$ fears/paranoid

$\square$ loss of meaning

adaptation in the

$\square$ foreign country

$\square$ responsibility

$\square$ psychosomatic

$\square$ learning problems

illegal

activities/aggressi on

adaptation in

mother country

$\square$ depression

belonging to an

ethnic group

\section{Group contact - psychological reason} searching therapy

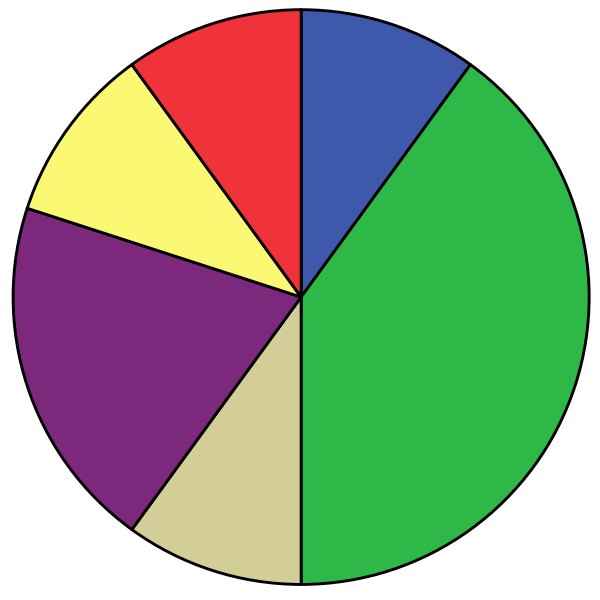

psych_reason

$\square$ alcohol/drugs

$\square$ partnership/marric

$\square$ fears/paranoid

illegal

$\square$ activities/aggressi

on

$\square$ adaptation in

mother country

$\square$ death of a loved

one 
have experience in working with people from different cultures and two academic professionals reviewed the research and provided their critical comments.

\subsection{Researcher as an instrument}

Both psychotherapists are Bulgarian. One of them is living and working in the Netherlands in a private psychotherapy practice. Following is the self-reflection of this therapist: "Transcultural adaptation is something that I have been going through myself not once in my life. My first trans-cultural experience was on young age, for my university study in Russia, and differs tremendously from the one I have had when I came for my post-academic study in the Netherlands. In my opinion, this has to do as with my personal psychodynamics as with the cultural distance between my mother country and the host one. My personal experience was that cultural distance was lower between Bulgaria and Russia and as a consequence less demanding for changes and adaptation. Further, my personal need for love, warmth (being primary type though with well developed secondary capacities) and my experience of Russian people as extremely warm and loving made the transition much easier. From the other side, Dutch people impressed me with their secondary capacities - of being open, outspoken that corresponded with my need, but also still challenging balance between sincere and polite. The Netherlands exposed me to a different environment - people of different culture, ethnos, colour working and living together. My trans-cultural experience have made me more open to differences of any kind, more tolerant. I look upon trans-cultural experiences as a challenge to our pre-existing conflict areas, as an opportunity to learn, expand, and grow. When I am under stress, I tend to withdraw in the future/fantasy area. I emotionally react with ideals and concepts. Symptoms often occur in the area of my body."

The second therapist stresses the relevance of trans-cultural adaptation topic due to the increasing movement of people, especially in Europe. "Bringing in new countries in the 
European Union, which not so long ago had other social and political structure, increases the need for help for self-help. Being working in academics and in my private practice, during the last 10 years I have been observing increasing number of students/people in working age who face psychogenic adaptation difficulties. Performed system therapy, in most of the cases short-term, proves to be successful. At this moment in my rhomb there is an accent on work, achievement and equal distribution in the other three areas. I give preference to tête-à-tête contacts. Though my work requires group work. I manage my inferior feelings by bringing more work achievements. In my behaviour, I show as a secondary type. My primary capacities are more hidden, not so expressive. Consequently, the emotionality shows up through the autonomic nervous system (anxiety states). “

\subsection{Results}

\subsubsection{Expectations in the area of achievement/work towards host country}

The first group are the people whose expectations towards a foreign country are related to possible achievements (studying and/or working abroad): twenty people in our study belonged to this group (16 students and 4 working individuals). The sample was equally distributed by gender. The majority in this group were young people between the ages of 21 24; $55 \%$ are from Bulgaria, 15\% from Nigeria, 10\% from Turkey, and 5\% from Cyprus, Macedonia, Greece, Germany and USA. In total, $90 \%$ of the sample were single, without children. All of them were either studying in a higher education institution or already had a university degree. In total, $70 \%$ did not have previous international experience, and $75 \%$ had not reported previous psychological problems. The command of foreign language was excellent (90\%). In $59.1 \%$ of the cases, the psychotherapy was conducted in the mother tongue of the patient. The self-reported self-deficit lies in the areas: either future (65\%) or contact $(35 \%)$. The patients in this group (numbers are put into brackets) described 
themselves as ambitious (19), capable of taking risks (18), idealistic (14), rigid (15), with a high need to prove themselves (20), inclined to future-oriented behavior (17), and more reactive than active (17). $72 \%$ of this group had been living for 2 years in the host country before coming to therapy. $81.8 \%$ were motivated and ready to work with the therapist.

\subsubsection{Observation/distancing}

During the primary interviews, we found the following psychological information related both to their symptoms and to actual conflict. The students were often motivated by their parents to study abroad. The perception was that studying abroad brings better opportunities for selfdevelopment and, as a consequence, a better life. Working abroad is viewed as financially attractive and facilitating a better quality of life. All the patients had selected their host country themselves. They seemed to have sufficient knowledge about local politics, culture and traditions. The presented actual conflict (AC) of this group was related to achievement, contact and future. Below, we go through them separately:

Actual conflict (AC) related to achievement: $59 \%$ of the sample reported actual conflict in the area of achievement/work. The subjects were doing their best to fulfill the study/work criteria. Those studying were also working in their free time. They had all graduated from their basic education and/or academic education very successfully. Thus, due to their desire to achieve top presentations, they had had a previously successful psychological experience. They lived with the concept that they could be successful in anything they wanted to. The reason why the students with problems in this area searched for psychological help was their understanding that regardless of their efforts (as invested time and energy), they were not quite as successful as they were, and could have been, in their mother country.

They felt tired and exhausted (78\%); easily irritated and short tempered (22\%); all of them had a fantasy to escape to less educational and/or work activities. 55.5\% realized that, instead 
of studying/working, which was the purpose of their stay, they had picked up an old hobby, or sport, or developed new esthetical interests, things that they had done in the past, and used these as relaxation and as free time activities. Now, instead of doing these things "after" study/work, it had become "instead" of study/work.

Most often we used the understanding of "positum" i.e. what is factual and given in order to help the client to create some distance from his problems. Thus in this way we let the client reconnect with his capacities to deal with challenges. The presumption is that every person carries enough of their own capabilities that provide them with an opportunity to adapt to any circumstances, but it takes time. Our first therapeutic task was to clarify a picture of their adaptation process. Towards this purpose, the following trans-cultural approach - and metaphors - proved to be very helpful: e.g. 1) cutting the roots of a young plant helps it to adapt better in a new soil; 2) a chameleon can change its color according to its surroundings, which makes it a better hunter and survivor; 3) connecting some parts of the stabilized, old and adding new strains, makes Dutch tulips so special, so unique.

Actual conflict (AC) in Contacts area: $31 \%$ of the clients in this group had actual conflict in this area of contact, with more reactive behaviors. They easily accepted a "helping hand" and successfully developed their initial contacts, showing a lot of "politeness/courtesy", instead of their less developed capability "sincere/openness" and also being able to draw good boundaries. On the one hand, they were easily able to adapt to new environments and social groups, but their symptoms showed the opposite: (1) depressive, closing themselves down stopping the contacts in the foreign country and frequent calls to the mother country $-71.4 \%$; (2) actual conflicts $-28.6 \%$

Actual Conflicts (AC) in Body area (10\%): Having in mind that the people in our sample are young, it is not surprising that they perceive their body as a "successful instrument" in resolving conflicts in the other two areas: contacts and achievement. These are physically 
healthy young people, who up till now have not suffered physically and/or psychologically. As a result, they find it very difficult to accept any manifesting symptoms. For $89.1 \%$ of the people from this group, the symptoms were somatic: in their body area (i.e. depression, dizziness, breathing problems, diarrhoea, etc.).

In order to explore the idea that a symptom is part of the language of the body, and functions as a reaction to the conflict, we asked the patients the following questions: "How does the symptom affect these four areas?" "If there is a message that your body wants to pass to you, what does your body wants to tell you?" "How the symptoms affect the things you do, your work/study?" "How have your contacts changed as a consequence of these symptoms?" "How your goals have changed since you experienced these symptoms?"

Additionally, in some cases (numbers are enclosed in brackets), the symbolic of the psychological problem (10), of the symptom (2) and both (5) have been given. Some examples are: there was an intense relationship to the body; depression, which means that the person was capable of reacting with deep emotionality; dizziness, which means that he/she was able to recognize the abundance of stimulus; breathing problems, which indicates that he/she was able to hold on to, and capable to call the attention that he/she needs; diarrhea, which suggests capability to substitute emotionally for real performance (Alexander, 1950). 
Table 6.1.: Psychodynamic information per group

\begin{tabular}{|c|c|c|c|c|c|c|}
\hline \multirow{4}{*}{$\begin{array}{l}\text { Groups: } \\
\text { Expectations } \\
\text { towards host } \\
\text { country }\end{array}$} & & Basic conflict & $\begin{array}{c}\text { Inner } \\
\text { subconscious } \\
\text { conflict }\end{array}$ & $\begin{array}{c}\text { Personality } \\
\text { structure }\end{array}$ & Defenses & Transference \\
\hline & Work & fantasy/future & $\begin{array}{l}\text { subconsciously } \\
\text { unbearable } \\
\text { situation, } \\
\text { decompensation } \\
\text { of coping } \\
\text { strategies }\end{array}$ & neurotic & $\begin{array}{l}\text { regression, } \\
\text { sublimation }\end{array}$ & $\begin{array}{c}\text { anger, } \\
\text { dependency }\end{array}$ \\
\hline & Contacts & fantasy/future & $\begin{array}{c}\text { conflict } \\
\text { symbolical } \\
\text { manifestation in } \\
\text { the body or the } \\
\text { psyche }\end{array}$ & borderline & $\begin{array}{c}\text { splitting } \\
\text { and passive } \\
\text { aggression }\end{array}$ & discontent \\
\hline & Future & $\begin{array}{c}\text { psychic } \\
\text { adaptation, } \\
\text { compensation } \\
\text { and defense } \\
\text { mechanisms }\end{array}$ & hopelessness & neurotic & $\begin{array}{c}\text { fantasy and } \\
\text { regression }\end{array}$ & anxiety \\
\hline
\end{tabular}

\subsubsection{Inventory}

We have tried to understand which of the adaptation strategies, depicted in the used metaphors, is closer to the existing psychological experience of every individual. The usage of the rhombus, "body-work-contacts-fantasy/future" and the pictures, plus the inheritance from the parents and mother-country experience, to adapt to other stressful situations (the rhombus: "I - you - we - primal we") has filled the condition. In $36.4 \%$ of the cases, the Wiesbaden Inventory for Positive Psychotherapy and Family Therapy (WIPPF is a personality questionnaire based on the theory of Positive Psychotherapy) (Peseschkian \& Deidenbach, 1988) has been used. By stimulating the patient to go back to the forgotten/suppressed good previous experience, we supported him to get to the Basic Conflict (BC). The BC was formed in the fantasy/future area: "I would like to prosper here", "I have tried everything, but I do not succeed"; "Should I stay or should I go? The first, brings me 
difficulties, problems and physical discomforts. But if I go back, this would mean that I haven't succeeded. Just the idea of this makes me fall apart”.

The patients also experienced anger towards their own decision about changes. They reported inferior feelings - "incapable", "good for nothing”. Additionally, they were envious towards those native and foreign people who did succeed. They tried to protect themselves from the envious environment. They experienced social isolation with a deep wish to pull themselves together and made helpless attempts to adapt. The people from this group frequently fix their attention on the existential question: "Why am I here? What should I do with myself?"

\subsubsection{Situational encouragement}

The people in this group predominantly have secondary capabilities, according to the definition of N. Peseschkian (Peseschkian, 1987). They are active and effective. In their activities they are good tacticians, but bad strategists. They have difficulties to work in a team.

Based on the differentiating analytical inventory (DAI, Appendix F), for clarifying the relationship between the primary and secondary capabilities, we found they gained successful psychological experience in the host country. With the help of the therapeutic tools "visualization" of the conflict and "paradoxical intention", we let the client realize the positive sides in the conflict contents of the relationships between "time-achievementcontact".

\subsubsection{Verbalization/Inventory}

For the bridge between their past successful experiences and the current problem, we built on the foundation of what was accepted in the client's picture of themselves; that which was the most appropriate for him/her in order to visualize the problem. We commented on their 
capacity to use their secondary nature and be able to estimate the risk and make long-term plans, to be strategic. Most of the patients belonged to the courteous and vacillating reaction type.

\subsubsection{Broadening of the goals}

Living in a foreign country, and in a different culture, accompanied by the desire to realize one's goals faster, often leads to difficulties with adaptation. There is some misunderstanding that adaptation to a new country means leaving behind the old, known, established behaviors, thus substituting one with the other. Nearly every time, we managed to lead patients, step by step, to see their opportunities and to set concrete goals, and thus, in this way, we supported the patients to get in touch with their deeper understanding, so that they can use their old ways of functioning in the new circumstances; and we guided them towards setting up small steps in their process of adaptation. In $77.3 \%$ of the cases, the therapy lasted for 15 sessions; in $72.7 \%$, the symptoms disappeared completely and, in the rest of the cases, they diminished dramatically.

\subsubsection{Expectations in the area of contact/partnership towards host country}

In total, 10 people belong to this second group, whose expectations towards the host country were in the area of contact. As much as $80 \%$ of these people, were women between the age of 25 and 54. In total, 50\% were Bulgarian, and the rest were equally distributed between Russia, Germany, Egypt, USA, and Australia. In 50\% of the cases, the Netherlands was the (new) host country. Most of them were highly educated; all the relationships were transcultural; $20 \%$ of the sample had children; $50 \%$ had previous psychological problems. They all had an excellent command of the foreign language. In $80 \%$ of the cases, the psychotherapy has been conducted in the mother tongue of the patient. Self-deficit was split between future 
$(70 \%)$ and contact (30\%). The patients in this group described themselves (orally, DAI, or WIPPH) as: loving (9), sensitive (7), idealistic (8), responsible (9), having emotional reactions with ideals and concepts (9), more reactive (9), and - in their social behavior - more fixed to concepts and ideals (9). In total $90 \%$ of this group had been living the host country for between 1 to 5 years, before coming to the therapy. $80 \%$ were motivated and ready to work with the therapist.

\subsubsection{Observation and distancing}

Most of the people in this group (70\%) met their partners before they left their mother country. Though the relationship had been the main reason to move to a foreign country, a big part of this group state that the benefits of living abroad (security, financial, prestige) played a additional role in making their decision to migrate. The presented actual conflict (AC) of this group is related to contact, body, and future. The actual conflicts in the different areas are discussed separately, below.

$A C$ in the contact area: $60 \%$ of the clients have actual conflict in this area. People showed good social skills and well-developed secondary capacities. However, the fixation on concepts and ideals makes their behavioral repertoire appear rigid and inflexible. They are fixated to the relationship with their partner and other contacts are very limited. Thus, their partner is expected to fulfill all of their needs. As a consequence, their needs were not satisfied and they have built up frustration and felt isolated and lonely, i.e. not loved. A positive interpretation of the expressed contacts' dissatisfaction was given: their capacity to search for the best; a way to follow their emotions. Further, their capability to be devoted to their partner and relationship, and being monogamous was emphasized.

$A C$ in the body area: $20 \%$ of the patients came to therapy searching for a solution to their frightening body sensations and alcohol abuse problems. Thus, they were searching for a 
solution for their symptomatic issues. These were highly emotional people, who had suppressed their emotionality. We used the positive interpretation again: they were able, when there is no other safe way to feel, to use their body as an instrument. And, for those with alcohol abuse - they were capable to find a way to protect and warm themselves.

$A C$ in the future area: Some patients came to therapy due to problems in adapting to their mother country (reverse cultural shock) and/or trauma: death of a dear one. Additionally, to the psychological problems, we used metaphors also for their reported symptoms. Fear had been seen as the ability to distance oneself from things which are experienced as threatening. Paranoia as the capability to concentrate on one thing. As a reaction to the spontaneous words of the clients: "Who am I? I did not feel absolutely comfortable in the host country but now neither in my mother country.", "I cannot handle his loss. I am falling apart. How can I proceed my life without him?" we often used storytelling.

\subsubsection{Inventory}

Work on stage one and the inventory took around 3 sessions. In the inventory stage, a process of differentiation takes place. Here we came close to the basic conflict - most of the people of this group have learnt that they are loved, when they are accepted as they are. Consequently, when they come across situations when their partner stands his ground and draws boundaries, they perceive this as a lack of love, and then look for justice or retribution. The work with WIPPH and/or DAI helped to bring more understanding to these in the interaction partnership models. Furthermore, to help with the adaptation to more individualistic countries, the relationship to 'I' (area of senses; parents/sublings-child) and 'Thou' (area of achievement; parents between themselves)', instead of 'We' (area of contact; parents-environment) and 'Origin we' (area of intuition; parents religion) and a trans-cultural approach has been used in $50 \%$ of the cases. Further, the work with positum helped to see the whole, not just the missing 
parts but also the existing ones. We worked with the capabilities and went to the origin of the problem by means of the balance model. Love/acceptance -justice, trust capacities showed relationship.

\subsubsection{Situational encouragement}

The patients shared their psychological experience of having love and stable contacts just when they are showing strong emotional reactions. The following misunderstandings played a role in the conflict formation: love-marriage, friendship-marriage, justice, trust, developmentfixation.

In the verbalization stage, we paid special attention to the capacity of the patient to verbalize and communicate. Most of the patients were of the courteous type ("He knows that it is hurtful for me, but he doesn't care"; “He is interested just in himself”) and the vacillating type ("I bottled up this for years until I could not bear it anymore"; "I could not control myself anymore and I became hysteric"). We verbalized the fact that their positive experience is on the basis of an adult-child relationship, where they have been in the role of the child and that a balanced view is lacking. As they want to achieve something, their partner has a right for that as well. We worked through diverse conflict situations using 'What is - what ought to be' strategies. Furthermore, we talked about the three stages of interaction and the importance of differentiation.

\subsubsection{Broadening of the goals}

In this phase, we encouraged the patients to see the other aspects of life outside of the contact area, thus the conflict-free areas, thus broadening the fixed position they had. After the patients realized the restricted way that they interpret other people's actions, we guided them towards exploring new ways to relate. 
In $70 \%$ of the cases, the duration of the therapy was reaching 23 sessions. $60 \%$ of the patients reported a complete disappearance of the symptoms: the other $40 \%$ had had a decrease in their symptoms.

\subsubsection{Expectations in the area of future/fantasy towards host country}

The third group are the people $(n=12)$ who had general idealized expectations towards the foreign country for a better life and a great future. In total $75 \%$ of the sample are females from the 20 to 43 age group and were made up as follows: from Bulgaria (83.3\%), Austria (8.3\%), and Russia (8.3\%). Those who were married (58.3\%), more often than not had a partner from a different nationality. Most of the people had a university degree. In total $41.7 \%$ had had previous international experience. Their command in the local language was very good. None of them had reported previous psychological problems. The therapist and patient were often from the same nationality and the therapy was conducted in the mother tongue of the patient.

The self-deficit areas were split between body (33\%), contact (50\%) and future (17\%). People of this group described themselves as: "someone you can rely on" (9), "oriented to precision and perfectionism" (10), “impatient” (7), “doubtful” (10), “with unstable confidence" (10). $83 \%$ of this group had been living for a maximum of 6 years in the host country before coming to therapy. All the patients were motivated and showed a readiness to work with the therapist.

\subsubsection{Observation and distancing}

During the first interview, and the following 3 sessions, we provided some psychological safety and created a climate of understanding and trust. The people in this group had experienced themselves as successful in their mother country. For most of them, prestige was the driving force for migration. They had no concrete expectations, but had a more general 
positive expectation from the host country - for better jobs, income, fulfilling relationships, opportunities, thus a better future.

Active complaints $(A C)$ in the contact area: The patients in this group $(\mathrm{n}=6)$ reported their $\mathrm{AC}$ as repetitive, micro-traumatic, partnership/marriage problems. The patients were showing good social skills for initiating, or establishing a contact, even though what restricted their contacts was their perception that all contacts should be perfect and they should be perfect in their interactions. Furthermore, due to the fact that most had trans-cultural marriages/relationships, their perceptions for good, perfect contacts apparently differed from those of their partners. As Peseschkian (Peseschkian, 1987) claims, we could see that the tradition/future and reason components are all interconnected. We used symbols and storytelling, which helped the patients to take a look at the situation from some distance and get another perspective.

$A C$ in the body area: People of this group $(\mathrm{n}=4)$ presented as actual conflict: alcohol abuse, sexual identity, and psychosomatic complaints (gastric neuroses). Thus, the conflict symbolically manifested in the body. We have been working with the symptom: the meaning of it for the patient, the patient's relationship with the symptom, how the loved one and surroundings react on it. Use of storytelling: Identity story (Kaniok \& Kaniok, 2008) and the Greeks myth of Hermaphrodite proved very helpful.

People who reported actual conflict in the area of future (2) expressed difficulty to function due to feelings of inadequacy and hopelessness (e.g. "I do not know what I should do?"; "I do not see a way out"). In $58 \%$ of the patients of this group, the self-deficit $(n=7)$ is in the future area. Symbols and myths have been used and show that fantasy is a capacity to imagine and think creatively, but is also a way to cope with conflicts. To summarize, the actual conflicts for this group are: micro traumas and $\mathrm{AC}$, which reactivated the sleeping $\mathrm{BC}$. 


\subsubsection{Inventory}

The patients experienced high distress due to identity disturbance, sexual identity problems, and psychosomatic complaints. We went on searching, in which areas, in what circumstances, and with whom patients experienced distress and we reviewed the learned coping skills to deal with it. In order to understand presented self-worth problems, we aimed to uncover the generalized capacity self-evaluations. We raised patients' consciousness by using the 'balance' model and WIPPH. Following this, their actual capacities showed issues about relationship: prestige, contact and sexuality.

On the stage of situational encouragement, we taught the patients relaxation techniques (Schultz's autogenic training and mindfulness exercises) which helped them better manage their distress and became more aware of the present moment. Further, we worked for resource-activation of the patient: the ability to use past successes in conflict solution.

\subsubsection{Verbalization}

In the verbalization stage, we observed the communicative capacities of the patients, their ability to express conflicts and problems in the four qualities of life. Most of them are courteous type of people. They are disappointed that their expectations are not met and withdraw, often react with psychosomatic complaints. We asked, "With whom it is most difficult to be sincere/open?" and used trans-cultural examples to develop a counter concept: being occupied by fantasies and thoughts allows people to return to the past. Stepping away from analytical thinking, the patients behaved as a child, unable to make a distinction between reality, imagination and causal relationships. We often used: storytelling, verbalization, and the 'balance' model to empower the understanding of the client's conflicts and their underdeveloped capacities. 


\subsubsection{Broadening of the goals}

Bearing in mind that people from this group habitually used fantasy as an escape, it has been essential repeatedly to go through the broadening of their goals. In particular, we tried to help patients to make practical decisions and concrete plans (daily, weekly, narrowing of the goals in the future area). Together with the patients we went on a trip in the past to rediscover their capacities to deal with distress by looking how they managed distressful situations in the past. We often asked: "What would you do if our plan of broadening of the goals would not work?" This led to a general improvement of quality of life and self-esteem.

\subsection{Summary of the results}

In $75 \%$ of the cases (including the three groups), the duration of the therapy was reaching 23 sessions. In $66.7 \%$ of the cases, the symptoms disappeared completely and the rest of the cases diminished dramatically. Working with all three groups periodically, we have been examining our psychotherapeutic work as a help for self-help. This in itself helped the clients to develop further their adaptation capabilities in the following behavioral steps: Body - searching for common ways to take care of the body with the native people. For the patients with symptomatic, this was the first area where they observed an occurring change. During the therapy, they shared the release they experienced due to the positive interpretation of the symptom as a capability of their body to let them know that it needs better care. Achievement - going on with the past proven successful strategies in new circumstances; searching for "niche" to show own uniqueness and individuality and not depersonalization; searching for the similarities with the native people. The patients experienced, as a release, the idea that they have a right to be different and, in this sense, to earn the respect of the others when allowing themselves to do things in their own old ways. This created space and allowed them to show creativity and be more successful in their activities. 
Contact - my communicative capabilities - How do I give a helping hand? How do I accept a helping hand? The patients' gave satisfactory feedback about the fact that they realized what they had achieved when behaving in a certain way and, in this way, needed to keep their communication capabilities in the conscious field. For some of them, it was essential to realize that it was not the change of the country and/or partner that will solve their problems, but working on their own communication capabilities.

Fantasy/Future - How can I contribute to the hosting country? Which are my valuable personal characteristics that make me unique? Where I can invest them most adequately? What new steps would I like to take? What would I like to achieve in the short and long term? The patients had been sharing that they were happy when they could integrate their own emotional and rational needs and, in order to achieve a better adaptation in the host country, was due to the fact that they got in touch with the entity and richness of their own personality.

\subsection{Discussion and conclusion}

The aim of this study was to bring more understanding to the problems that the three groups of migrants faced and to develop a therapeutic approach for these groups, based on Positive Psychotherapy principles. We highlighted the problematic of the groups. Further, the psychotherapy method showed disappearance $(68 \%)$ and lessening $(32 \%)$ of their symptoms during the conducted short-term therapy (mean=15 sessions).

The results of this study may be interesting, not just for therapy purposes, but also for prevention. In our opinion, the presented approach is a good prevention strategy because:

- it works trans-culturally and in this way supplies a bridge for the foreigner

- it provides new understandings about what it means to be a foreigner, of the whole as assimilation of both the positive and negative

- it helps to clean up cross-cultural misunderstandings 
- it works motivationally on the basis of finding and activating the person's internal reserves and those that are not being used, or are subconscious and perceived as less essential capacities.

Further, on the following levels it might be beneficial to include a mental health professional to work preventively and support those experiencing trans-cultural adaptive problems, in order to help them to reach the feeling of 'being a foreigner means to be a magnificent nuance of a color spectrum':

- on the municipality level: where integration programs are most often running and information about the number of trans-cultural marriages/relationships is available;

- on company levels (with HR departments, unions or company physicians);

- on higher educational settings - e.g. in universities, colleges, etc. 
Chapter 7

General discussion 


\subsection{Introduction}

The aim of this dissertation has been to explore the factors which influence adaptation to job dissatisfaction and labor market behavior. Three objectives have been formulated: 1) to expand our understanding of how and why employees might fail to adapt to job

dissatisfaction; 2) to explore the role of personality in labor market behavior and in adaptation in case of job dissatisfaction; 3) to understand the problematic of a group of employees with difficulties to adapt to a foreign culture.

Chapter 2 and 3 address the first objective. In Chapter 2, we combined the existing knowledge from psychology and economics and provide a new perspective on job lock (experiencing job dissatisfaction for two subsequent years and remaining immobile). Furthermore, we identified a set of factors which explain why some employees fail to adapt when dissatisfied with their job. In Chapter 3, we investigated the process of transition to a job-lock situation and failure to exit this state, thus entering long-term job lock. The second objective of this dissertation guided the studies in Chapter 2, 3, $4 \& 5$. The following personality characteristics were studied: 1) global self-esteem in relation to job lock (Chapter 2, 3), job embeddedness (Chapter 4) and unemployment (Chapter 5); 2) decisional procrastination and the chance to enter job lock and stay in this state (Chapter 3); 3) contingent self-esteem, self-determination, and self-compassion in relation to job embeddedness and job satisfaction (Chapter 4). In Chapter 6 we addressed the third objective of the dissertation. There, we studied the difficulties to adapt to foreign culture and we also discussed the psychodynamics of immigrants' problems.

Thus, the scope of this dissertation has been the employees' adaptation to changes related to employment. We studied the changes on different levels from individual perspective: organizational (Chapter 2, $3 \& 4$ ), country (Chapter 5) and trans-cultural (Chapter 6). On the organizational level, unmet employee expectations manifesting in the form of job 
Chapter 7: General discussion

dissatisfaction are studied. On the country level, the investigation has focused on unmet expectations towards one' own self in the form of low self-esteem leading to unemployment. And on the trans-cultural level, unmet opportunity expectations taking the form of migration are studied. This chapter presents and elaborates on the main findings, limitations and suggestions for future research by discussing six statements. They are presented in the following order: organizational, country and trans-cultural level. The chapter ends with the discussion of the implications.

\subsection{Presenting the six statements and elaborating on them}

\section{Statement 1: Job lock is related to employee's personal characteristics as well as on- work and off-work related factors.}

As outlined in Chapter 1, the job lock phenomenon has been seen by economists as job immobility related to non-transferability of job investments (pension funds and/or health care benefits). Psychologists from the other side, use the term 'being stuck' when talking about employees who stay when job dissatisfied. Explanations based on continuance commitment, job investments and job embeddedness have been provided in the psychology literature. In Chapter 2 of the dissertation, we developed a new perspective on job lock. We operationalized job lock as the failure to adapt to job dissatisfaction during two subsequent years in terms of internal or external job turnover even when the employee experiences continuous job dissatisfaction.

In our goal to expand our understanding of how and why employees might fail to adapt to job dissatisfaction, we study the effect of a combination of factors derived from the economic and psychology literature, on job lock. We combined process ('whys' of quitting) and content ('hows' of quitting) turnover approaches, and studied simultaneously the effect of two groups 
of factors: personal characteristics as well as on-work and off-work related factors (Chapter 2, 3, 4). Further, those two groups have been divided into six sub-groups of factors and their joint effect on job lock has been tested. In the group of personal characteristics, we included socio-demographic features and personality attributes. The group of on-work and off-work related factors contains: type of occupation, sector, employment conditions, work-related contextual features, and tenure.

The results of our studies confirm the expectation of a joint effect of those factors on job lock. In particular, the results of the first study (Chapter 2) show that young male employees, with low self-esteem, who have health problems, working fulltime for a long time with the employer, with an employer pension scheme, and without promotion opportunities are more likely to be job locked. Further, employees from certain sectors are more likely to be in job lock than the others (e.g. civil and national sector). However, holding particular occupations (managerial, associate professional, personal and protective occupations) diminishes the chance that the employee will be job locked.

Thus, job lock depends not only on employee's personal characteristics but also on on-work and off-work related factors. An implication of this is that job lock cannot be influenced just by the employee nor by just changing environmental factors (i.e. sector, occupation). Nevertheless, previous research has shown that personality plays a role in the choice of occupation (Leung, 2008; Reardon \& Lenz, 1999; Schneider, 1987; Wang, Jome, Haase, \& Bruch, 2006) and interpersonal relationships (Leary \& Downs, 1995). This is also in tune with Swann's self-verification theory, which states that individuals are motivated to verify their pre-existing self-views (Kwang \& Swann, 2010; Swann, 1983). Furthermore, low self-esteem employees are much more influenced by external factors (Brockner, 1988), and thus more influenced by the organizational characteristics, contrary to high self-esteem employees who are driven by needs and abilities, thus by internal factors (Turban \& Keon, 1993). Therefore, 
people with low self-esteem are more likely to end up in bad relationships (jobs, intimate relationships) and experience a sense of lesser control over those external factors. Our job lock studies combine the knowledge of two sciences: labor economics and organizational psychology. We contribute to the economics literature by providing a new and clear definition of job lock (Chapter 2). Additionally to on-work factors that have already been studied, we include personality as well (Chapter 2, 3). It has been claimed that dissatisfied employees who stay differ from those who leave (Cho, et al., 2009; Steel \& Lounsbury, 2009a; Westaby, 2005a). Though, very little is known about how those who stay differ from those who leave. Related to this our study in Chapter 3 shows that employees in manager and administrator occupations, those in personal and protective service occupations, with promotion opportunities, working in the private sector use much more often mobility as a coping strategy in order to adjust to job dissatisfaction. Moreover, there has been very little empirical evidence about individual differences (Cho, et al., 2009; Steel \& Lounsbury, 2009a). Thus, our contribution to the psychology studies in this field is the differentiation of those who stay from those who leave. For future research, it would be beneficial to differentiate voluntary and involuntary mobility when studying job lock. Also, future job lock studies could include more off-work factors (the community target of attachment).

\section{Statement 2: The same factors that push an employee into job lock also lead him/her to long-term job lock.}

In our new perspective on job lock presented in this dissertation, we incorporate a time dimension. As explained in Chapter 1, even though previous research specified turnover as a time-based process (Bergman, Payne, \& Boswell, 2012; Hom, et al., 2012), it is not clear how long different phases last. Neither the job embeddedness model, the model trying to explain those who stay, includes the notion of time. There is no evidence if individual differences 


\section{Chapter 7: General discussion}

play a role between short and long-term inability to adapt. Further, research did not give an answer why some employees who experience job lock are able to exit this state while others remain in job lock. In advance, it is unclear for those employees who quit job lock state, how this happens. Do they adapt by becoming satisfied, do they use mobility as a way of dealing with dissatisfaction, or a combination of both? Furthermore, previous turnover studies most often measured intentions to move or search behavior, instead of actual behavior (mobility). In order to fill in the void in the scientific literature, the primary goal of our second study (Chapter 3) was to learn more about the process of transition from and to job lock. Based on the research that shows that the average thinking about quitting is 1 year (Hanisch, 2002), we assumed that if an employee is continuously (for 2 subsequent years) dissatisfied with his/her job and at the same time stays in the same job, then the employee is in a state of job lock (Chapter 2). We took this newly developed perspective of job lock, which integrates the notion of time and using the two dimensions of job lock (job dissatisfaction and job immobility) to build a transitional model. The employees who failed to exit the job lock state were compared with those who were in one of the three transitions: adjusting and becoming satisfied in the same job (immobile and job satisfied), changing jobs and becoming satisfied (mobile and job satisfied), or changing jobs but again become dissatisfied with the new job (mobile and job dissatisfied). And for those who quit job lock, we were interested to investigate how this happens, by using the transition states.

The results showed the following push factors to job lock: being older, married, with low peak-end self-esteem, working in a craft occupation, in the governmental sector, and high regional unemployment rate. Furthermore, employees with low self-esteem, mental health problems and who have a tendency to decisionally procrastinate are more likely to stay longer in job lock. In addition, having a fulltime contract increases the probability to enter the longterm 'job lock' state than to move to any of the other states. 
The factors that push an employee into job lock, in particular - age, low peak-end self-esteem, and a high regional unemployment rate - also play a vital role in the failure to exit job lock and to enter long-term job lock. Employees are either successfully adapting to job dissatisfaction or not, independently from the way they adapt (becoming satisfied or mobile). Almost the same variables play a role in an employee's failure to adapt in a short term as in a long term. This may be explained by the fact that employees often use the same adaptive strategies and do not often change these strategies. Younger employees are more opt to enter job lock state. Though elderly employees are much more often in long term job lock. As explained in Chapter 1, in our new perspective on job lock, we used the work adaptation theory (Rosse \& Miller, 2000), which postulates job dissatisfaction and emotion as behavioral drivers. Self-esteem is related to both job satisfaction and emotional regulation (Gilbert, 1989; Orth, Robins, \& Widaman, 2012). Further, as shown in Chapter 2, job satisfaction and selfesteem share the same content and direction (Alavi \& Askaripur, 2003; Huysse-Gaytandjieva, et al., 2013a), as also shown in Chapter 2 of this dissertation. It may be that dissatisfaction itself is not a problem but it becomes a problem when it is experienced repetitively by employees with low self-esteem who fail to adapt to it. Low self-esteem employees are risk averse (Cameron, Stinson, Gaetz, \& Balchen, 2010; Josephs, et al., 1992). They much more often attribute job dissatisfaction to the self and this activates the threat system. Furthermore, the threat system is additionally triggered by the low self-esteem itself which is an internal threat. Thus, from the perspective of job lock, low self-esteem can be seen as an adaptive response to threat (Gilbert, 2002). Furthermore, employees behavior may be highly influenced by perceived job availability and not the actual one (Van Vianen, et al., 2003).

The results in this dissertation provide suggestions about:

- detecting the employees who are at risk to become job locked 
- building a job-lock program for employees, which can be used both for preventive and curative purposes, thus handling the entrance to job lock and at the same time preventing long-term job lock.

In future research, it might be advised to differentiate the various types of exits that employees exhibit both in the short and the long term, such as unemployment, selfemployment, sickness, and pension.

Statement 3: Self-determination has direct effect on job embeddedness components, while self-compassion influences job embeddedness via its effect on the self-aspects. Fourteen turnover models have been used to explain both the determinants of leaving and staying (see Chapter 1). As a consequence of the comprehension that those who stay and those who leave differ, job embeddedness (Mitchell, et al., 2001) was developed. Job embeddedness incorporates the diverse on-work and off-work connections (links, fit, sacrifice) which attach the employee to the organization and prevent him/her from leaving. 'Links' refers to the connections between an employee and other people, groups, or organizations. 'Fit' represents employee's perceived compatibility with the job, organization, and community. And 'sacrifice' relates to the perceived material or psychological costs which employee has to forfeit by leaving. As outlined in Chapter 1, until recently, job embeddedness has been considered just as a positive phenomenon. Presently, the idea that it might have a negative side is considered. Still, how individual differences may play a role in the negative side of job embeddedness, is scarce (Barnard \& Curry, 2011; Crossley, et al., 2007; Holtom, et al., 2012; Sekiguchi, et al., 2008).

Previous research shows (Huysse-Gaytandjieva, et al., 2013a, 2013b) that low self-esteem employees are more likely to become stuck, be job locked. In Chapter 4, we combine our job lock findings (Chapter 2, 3) with job embeddedness. We incorporate individual differences in 
self-esteem: level (global self-esteem), contingencies ('if ...then..' rules), and motives (selfdetermination).When self is critical (low self-worth, contingent self-esteem, low selfdetermination), the threat response is activated and the need to protect and defend elevates. Here comes the need for a balance force. Compassion is seen as such (Gilbert, 2009a). Compassion is related to kindness, common humanity and mindfulness (Neff, 2003a). It is a healing force that is vital in organizations (Frost, et al., 2005) and in close relationships (Neff \& Beretvas, 2013).

Self-determination theory emphasizes both personality and contextual factors as influential in the extent to which an employee internalizes goals and tasks. As well as individual differences in self-regulation are seen as impacting the internalization process (Deci \& Ryan, 1985a). The growth impulse that every person has is influenced not just from environment but also by people's own inner processes (Sheldon, et al., 2003). Thus, even though that there has been a limited research on that, there is an understanding that individual differences are important to consider when studying self-determination (Deci \& Ryan, 2000).

The findings from our study tell us that global self-esteem relates more to off-work dimensions of job embeddedness and self-determination more to on-work aspects of job embeddedness. Global self-esteem relates positively to off-work 'links' and negatively to both on-work and off-work 'fit'. Self-determination relates negatively to on-work 'fit' and 'sacrifice' and positively to job satisfaction. Contingent self-esteem did not show any significant effect on job embeddedness and job satisfaction. Self-compassion proved to be positively related to job satisfaction and global self-esteem negatively to on-work 'sacrifice' in the model where we use self-compassion as a motivational force. Those effects of both global self-esteem and self-compassion disappeared in the full model, where selfdetermination is included. Further, the positive relation between self-determination and onwork 'links' disappeared when self-compassion is included in the model. 


\section{Chapter 7: General discussion}

Lee and his colleagues (2004) showed that off-the-job embeddedness predicts withdrawal, whereas on-the job embeddedness is negatively related to turnover and positively to performance and organizational citizenship behaviors. Having in mind these findings and the results from our study, we can conclude that global self-esteem is much more related to withdrawal (which confirms the results from our job lock studies), while self-determination to increased performance.

It might be that different elements of self-determination relate differently to self-esteem and job embeddedness (e.g. relatedness, may be related to self-compassion and to 'links' from job embeddedness model). Or that not all employees has the same need for self-development. For example employees who are job locked/showing the dark side of job embeddedness may prefer stability and status quo instead of stimulation of their growth.

The concepts of self-determination and self-compassion have a lot of similarities. As stated in previous studies they are both seen as a part of quieting the ego, balancing it (Wayment, et al., 2014). Though, as far as we are concerned, how exactly self-determination and selfcompassion are alike and how they differ in helping employees be positively job embedded is not clarified previously. However, self-compassion is needed when people have difficulties and/or are suffering. Thus, it is important to study self-determination and self-compassion together. Our study results confirm this notion by showing that self-compassion influences job embeddedness via its influence on self-aspects. From the other side, self-determination shows direct effect on the job embeddedness components as elucidated above. Our study on job lock as a negative aspect of job embeddedness is a preliminary one and is intended to outline directions for future research on this topic. If further research will confirm that job lock can be defined by certain components of job embeddedness, this would mean that job lock can be measured with them. These knowledge will be a contribution to the theory of those employees who stay. Further it will make it possible to differentiate those 
employees who are opt to become job locked from those who are positively embedded. Thus this information can be helpful predicting what type of employee someone would be. Knowledge about the individual differences that affect employees' external and internal mobility is important for companies' retention policy.

\section{Statement 4: Low self-esteem increases the risk to become unemployed.}

Until now, we discussed the findings at an organizational level. This statement refers to the country level. In Chapter 5, we studied individual adaptation at the country level. Specifically, the goal of the study in that chapter was to expand our knowledge about the effect of low selfesteem on future unemployment. The relationship between self-esteem and unemployment has been extensively studied before. Though, previous studies have mainly focused on the effect of prolonged unemployment on self-esteem. There are very few studies on the reverse effect, i.e. on the influence of low self-esteem on unemployment. However, the samples of those few studies were children and adolescents, when self-esteem is fragile and not stable (Trzesniewski, et al., 2006). At the same time, several previous studies show that women much more often have lower self-esteem then men (Kling, et al., 1999). Further, unemployment is also higher among women (Azmat, et al., 2006). Though it has been unclear what is the gender role in the relationship between trait self-esteem (enduring personality characteristic) and becoming unemployed.

In Chapter 5, we tested our hypothesis that employees with low self-worth are more likely to become unemployed and that gender differences exist. The top-down model of self-esteem (once formed trait self-esteem influences self-evaluations and state self-esteem) (Brown, et al., 2001) guided us in this study. Our results show that low self-esteem is highly significant in predicting the probability of becoming unemployed for women but not for men. Specifically, low self-esteem has an effect on the chance of becoming unemployed for 
married women and those in a partnership but not for men. While, males, with health problems related to alcohol and drug use, have a higher chance to become unemployed. Low self-esteem has an effect on the chance of becoming unemployed regardless of gender for some occupations. In particular, people in associate and professional occupations with low self-esteem have a higher chance to become unemployed. Further, a higher regional unemployment rate increases the probability that workers of either gender will become unemployed. For both genders, high education and union participation prevent the employee from becoming unemployed.

The results can be explained by the fact that employers prefer more secure people and thus there is evidence of some discrimination of self-esteem by hiring (MacGregor \& Holmes, 2011). Further, previous studies have shown the importance of self-esteem for assertive job search behavior (Ellis \& Taylor, 1983; Schmit, Amel, \& Ryan, 1993). Moreover, high selfesteem individuals are given more difficult tasks at work and therefore, they have more opportunities to succeed (Judge \& Bono, 2001). Furthermore, the result that self-esteem is a predictor of future unemployment for women but not for men can be explained by social gender stereotype (Fortin, 2005). The gender differences in self-esteem may perhaps also be part of the explanation why unemployment rates among women are consistently higher than unemployment rates among men in many countries. From an early age, boys and girls are often treated differently (Sadker \& Sadker, 1994) and diverse gender norms are prescribed (Rudman \& Glick, 2001). As a result, later in adult life working women are often exposed to a role conflict.

The results of our study discussed here, suggest some practical implications. Preventive measures can be taken by parents and schools to emphasize the importance of equally treating boy and girls, and the effect of female self-esteem on labor market outcomes. Offering working women information about the nature of self-esteem and the ways to deal with low 
self-esteem in the form of training can prevent women from becoming unemployed and may help to close the gender gap in unemployment rates. Further, future studies on the relationship between job lock and becoming unemployed are recommended.

\section{Statement 5: Trans-cultural adaptation is a process of interaction.}

This statement refers to our results on a trans-cultural level. Having in mind that we are living in time of the free movement of human capital and globalization of businesses, trans-cultural adaptation is expected to have an important effect on immigrants' health. In Chapter 6, we pay attention to the trans-cultural problems which immigrants face. There, on the basis of Positive Psychotherapy, we developed an approach which can be used for prevention purposes.

We look upon trans-cultural adaptation as a process of interaction (attachment, differentiation, detachment) leading to a balance between four different modes: body, contacts, achievement, and future. People relate to their environment with attachment (closeness) and detachment (autonomy) (Zimberoff \& Hartman, 2002) based on the attachment style developed through their early interactions with caregivers (Ainsworth, 1985; Bartholomew \& Horowitz, 1991; Bowlby, 1969; Griffin \& Bartholomew, 1994). Finally striving to balance attachment (freedom from fear of abandonment) with detachment (freedom from fear of overwhelming), it results in the freedom to explore the external and internal worlds (Holmes, 1993). When the immigrant's stage of interaction confronts the host's (employee, partner, etc.) stage of interaction, a conflict situation can arise. The stages of interaction are stages of expectation (Peseschkian, 1987). Based on immigrants' expectations towards the host country, three groups were formed: achievement and work reasons; contacts and partnership, and their 
dreams (or fantasies) of a better future. The expectation is that people carry enough capabilities which help them to adapt, but time is necessary for successful adaptation.

The results in Chapter 6 show that the actual conflict (actual problem) was most often in the same area where the expectations were laying. For the group of those whose expectations were in the area of achievement/work, $59 \%$ of the actual conflict was in the same area. And for those whose expectations were in the area of contacts, $60 \%$ of the actual conflict was in area of contact. For both groups, the basic conflict and the self-deficits were in fantasy/future area. For the group whose expectations were in the area of future, actual conflict split between contact and body area, with self-deficits mainly in contact area. The basic conflict of this group was in psychic adaptation, compensation and defense mechanisms. After conducted short term therapy (mean of 15 sessions) in $66.7 \%$ of the cases, the symptoms disappeared completely and in the rest of the cases they diminished dramatically. Our results confirm previous studies which show that people who keep something from their own culture and take something from the host culture adapt better.

By changing environment, migrating people do not solve the difficulties experienced with the interaction. Vice versa, much more often migration is leading to an increase of those problems to such extent that they cannot be ignored. Thus, migration can serve as an urge to bring changes and grow. It is important to make potential migrants and those who have already migrated aware about the relationship between expectations and the problematic areas of interaction. Further adaptation to a different culture takes time. Migration is a long-term investment (Hagen-Zanker, 2010; Huysse-Gaytandjieva \& Boncheva, 2013) as also shown in Chapter 6 of this dissertation.

Due to the fact that Positive Psychotherapy (presented in Chapter 1) draws a trans-cultural framework in which different methods can work together (Peseschkian, et al., 2010), our study is interesting for clinical professionals regardless of their psychotherapy training. 
Furthermore, application of Positive Psychotherapy in other areas, as counseling, education, prevention and management training (Peseschkian, 1987), makes the results of our study even more valuable.

\section{Statement 6: Self-esteem has an important economic value.}

Humans carry an unique capability - to be able to be an object and a subject at the same time - to self-reflect. This may be an explanation of the interest in self-esteem with more than 35,000 publications written on the topic (Zeigler-Hill, 2013). Despite the big number of studies, there is still confusion about the operationalization of what self-esteem is, its measures, and its role (Leary, 2006). Though, without doubt, at least two of the benefits of high self-esteem are clear in the literature. First, self-esteem influences how people present themselves to others and how they are perceived by the social environment (Zeigler-Hill, 2012). Thus, self-esteem is not only an internal experience but also an interpersonal signal in the social world (Zeigler-Hill, 2013). Second, high self-esteem protects people from negative experiences.

The results of this dissertation show self-esteem to be related to job dissatisfaction, job immobility and being in job lock (Chapter 2); long-term job lock (Chapter 3), negative job embeddedness (Chapter 4), and becoming unemployed (Chapter 5). Thus, self-esteem has an economic value. Even though that there is previous research which show the effect of selfesteem on job satisfaction (Judge, et al., 2001; Salmela-Aro \& Nurmi, 2007), relating selfesteem to the other work related phenomenon, as it is done in this dissertation, is novel. Furthermore, some causal relationships of self-esteem on becoming unemployed are shown in the dissertation. 
Thus, it is important for future studies on job satisfaction, job mobility, job lock, and job embeddedness to consider self-esteem as an essential variable in their framework.

We would like to call attention to the fact that low self-esteem is a stigma and a mark of shame in society (Zeigler-Hill, 2013). It is essential to recognize the importance that selfesteem has for the human relations (job and intimate relations). It is inevitable that human beings will proceed comparing themselves to others and evaluate themselves. The focus should not be on changing self-esteem, but on becoming aware of its nature and its way of functioning. This will help individuals to have the freedom to make own choices independently of the self-esteem.

\subsection{Theoretical implications/relation to prior research}

In the previous section we have discussed the main findings of the five studies formulated as six statements. In this section, the broader theoretical implications of the empirical findings are explored. Next some policy recommendations are provided.

In this dissertation, we have developed a new perspective on being stuck/job locked, which represents a dysfunctional retention. Several theoretical notions have played a role in the development of our understanding of job lock. In particular, the Miller and Rosse's model of adaptation (Miller \& Rosse, 2002), job embeddedness (Mitchell, et al., 2001), Depue’s emotion regulation system classification (Depue \& Morrone-Strupinsky, 2005), and the link of self to those emotion regulation systems (Gilbert \& Irons, 2005), have been presented in Chapter 1 and used throughout the dissertation.

The Miller and Rosse's model of adaptation emphasizes the importance of job (dis)satisfaction and emotions as drivers of behavior. Job satisfaction is expected to lead to adaptive behavior. Emotions are seen as the proximal cause of impulsive behavior. Though, only workplace emotions are included in this model. Holding the premise of this theory that 


\section{Chapter 7: General discussion}

job dissatisfaction is a primary motivator for adaptation, we add the categorization of the three emotional regulation systems of Depue and his colleagues (Depue \& MorroneStrupinsky, 2005). In particular: drive (a focus on doing and achieving), threat (a focus on threat and self-protection), and soothing system (a focus on contentment and feeling safe). Further, we incorporate Gilbert's (Gilbert, 2005b) association of self-esteem, self-criticism, and self-compassion in the three brain emotional systems. Self-esteem relating to drive, selfcriticism (low global self-esteem, high contingent self-esteem, low self-determination) relating to threat, and self-compassion relating to connect system. Thus, we look at selfesteem as a form of safety behavior (Gilbert \& Irons, 2005; Gilbert \& Procker, 2006). We find that, when the employee does not adapt either by job satisfaction or mobility, there is an issue of safety. Thus in the job lock phenomenon, low self-esteem is an employee's adaptive reaction to threat.

Our contribution to Gilbert's work is that we tested its premises in a non-clinical, working population. Further, we empirically tested for individual differences in self-esteem: global self-esteem, contingent self-esteem and self-determination, which has not been done before. As already mentioned in statement 2, we incorporate the time dimension in our operationalization of job lock. Further we not just hypothesize the role of time in this phenomenon but we also empirically studied short and long-term job lock.

The findings in this dissertation provide some suggestions for policy implementation. We describe a number of human resource policy considerations below, categorized in three groups:

Human capital: Humans cannot escape from self-evaluation. Having high self-critic can be threatening. It is important of an individual to be aware of his/her own self-esteem and learn not to identify with it. Increased awareness of the nature of self-esteem on different levels in the organizations can be provided in the form of encouragement of life-long learning 
Chapter 7: General discussion

(mentoring), promotion of health and fitness (stress counseling) (Navare, 2008), offering compassion mind workshops (Gilbert \& Irons, 2004; Hayes \& Strosahl, 2010).

Performance effectiveness: In particular, improved recruitment process and on-job counseling by including personality testing of individual differences in self-esteem is needed. This can contribute to a better allocation of staff as well as identifying job lock vulnerable employees. Additionally, knowledge about the individual characteristics that affect employees' external and internal mobility is important for companies' retention policy.

Corporate culture: Promoting a trans-cultural orientation on all levels in the organizations and learning trans-cultural conflict management skills are important for a better adaptation of immigrant employees and improved relationships. 


\section{References}

Abaci, R., \& Arda, D. (2013). Relationship between self-compassion and job satifaction in white collar workers. Procedia - Social and Behavioral Sciences, 106, 2241 - 2247.

Abbott, M., Wong, S., Williams, M., Au, M., \& Young, W. (1999). Chinese migrants' mental health and adjustment to life in New Zealand. Australian and New Zealand Journal of Psychiatry, 33, 13-21.

Abe, J., Talbot, D. M., \& Geelhoed, R. J. (1988). Effects of a peer program on international student adjustment. Journal of College Student Development, 39(6), 539-547.

Abraham, R. (1999). The relationship between differential inequity, job satisfaction, intention to turnover, and self-esteem. The Journal of Psychology, 133(2), 205-215.

Adams, S. (2004). Employer-provided health insurance and job change. Contemporary Economic Policy, 22(3), 357-369.

Adler, A. (1959). The practice and theory of individual psychology. Totowa: Littlefield, Adams.

Adler, S. (1975). The transitional experience: an alternative view of culture shock. Journal of Humanistic Psychology, 15, 13-23.

Adler, S. (1980). Self-esteem and causal attributions for job satisfaction and dissatisfaction. Journal of Applied Psychology, 65(3), 327-332.

Adnet, N., Bougheas, S., \& Georgellis, Y. (2004). On the trade-off between work-related training ad labor mobility: the role of firing and exit costs. Journal of Economics, 82(1), 49-70.

Ainsworth, M. D. S. (1985). Attachments across the lifespan. Bulletin of the New York Academy of Medicine, 61, 792-812.

Alavi, H., \& Askaripur, M. (2003). The relationship between self-esteem and job satisfaction of personnel in government organizations. Public Personnel Management, 32(4), 591600.

Aldwin, C. (1991). Does age affect the stress and coping process? Implications of age differences in perceived control. Journal of Gerontology: Psychological Sciences, 46(4), 174-180.

Alexander, F. (1950). Psychosomatic medicine. Its Principles and Applications.: W. W. Norton \& Company Inc.

Allen, A., \& Leary, M. (2010). Self-compassion, stress and coping. Social and Personality Psychology Compass, 4(2), 107-118.

Allen, D., Renn, R., Moffitt, K., \& Vardaman, J. (2007). Risky business: the role of risk in voluntary turnover decisions. Human Resource Management Review, 17, 305-318.

Allen, N., \& Meyer, J. (1990). The measurement and antecedents of affective, continuance, and normative commitment. Journal of Occupational Psychology, 63(1), 1-18.

Amiot, C., Blanchard, C., \& Gaudreau, P. (2008). The self in change: a longitudinal investigation of coping and self-determination processes. Self and Identity, 7, 204 224.

Andersen, T., Haahr, J., Hansen, M., \& Holm-Pedersen, M. (April 2008). Job mobility in the European Union: optimising its social and economic benefits (pp. 158): Danish Technological Institute.

Anderson, L. (1994). A new look at an old construct: cross-cultural adaptation. International Journal of Intercultural Relations, 18(3), 293-328.

Andolfatto, D., \& Mongrain, S. (2004). Self-esteem and labour market choices., 2005, from http://www.cirpee.uqam.ca/JOURNEES2004/Mongrain.pdf

Ang, K., Goh, C., \& Koh, H. (1993). The impact of age on the job satisfaction of accountants. Personnel Review, 22(1), 31-39. 
Arbuckle, J. L., \& Wothke, W. (1999). Amos 4.0 user's guide. Chicago: Smallwaters.

Arnold, H., Feldman, D., \& Purbhoo, M. (1985). The role of social-desirability response bias in turnover research. Academy of Management Journal, 28(4), 955-966.

Aroian, K. J., \& Norris, A. E. (2002). Assessing risk for depression among immigrants at twoyear follow-up Archives of Psychiatric Nursing, 16(6), 245-253.

Artazcoz, L., Benach, J., Borrell, C., \& Cortès, I. (2004). Unemployment and mental health: understanding the interactions among gender, family roles, and social class. American Journal of Public Health, 94(1), 82-88.

Auer, P., \& Cazes, S. (2000). The resilience of the long-term employment relationship: evidence from the industrialized countries. International Labour Review 139(4), 379408.

Azmat, G., Güell, M., \& Manning, A. (2006). Gender gaps in unemployment rates in OECD countries. Journal of Labor Economics, 24(1), 1-37.

Bacchiega, A., \& Borzaga, C. (2001). Social enterprise as a incentive structures. In C. Borzaga \& J. Defourny (Eds.), The emergence of social enterprise (pp. 273-295). London: Routledge.

Bacchiega, A., \& Borzaga, C. (2003). The economics of the third sector: toward a more comprehensive approach. In H. K. Anheier \& A. Ben-Ner (Eds.), The Study of the Nonprofit Enterprise: theories and approaches (pp. 27-48). New York: Kluwer Academic/Plenum Publishers.

Baker, D., Glyn, A., Howell, D., \& Schmitt, J. (2004). Unemployment and labour market institutions: the failure of the empirical case for deregulation. Policy Integration Department Statistical Development and Analysis Unit International Labour Office, Working Paper, N 43.

Baldwin, M. (2006). Self-esteem and close relationship dynamics. In M. Kernis (Ed.), Selfesteem issues and answers. A sourcebook of current perspectives (pp. 359-366). New York and Hove: Psychology Presss.

Bansak, C., \& Raphael, S. (2008). The state children's health insurance program and job mobility: identifying job lock among working parents in ner-poor households. Industrial and Labor Relations Review, 61(4), 564-579.

Barnard, L., \& Curry, J. (2011). Self-compassion: conceptualizations, correlates, \& interventions. Review of General Psychology, 15(4), 289-303.

Barrick, M., \& Mount, M. (1991). The big five personality dimentions and job performance: a meta analysis. Personnel Psychology, 44, 1-26.

Bartholomew, K., \& Horowitz, L. M. (1991). Attachment styles among young adults: A test of a four-category model. Journal of Personality and Social Psychology, 61, 226-244.

Barwell, R. (2000). Age structure and the UK unemployment rate. The bank of England's Working Paper Series, ISSN 1368-5562.

Baumeister, R. (1999). The self in social psychology.: Psychology Press Taylor \& Francis Group.

Baumeister, R., Campbell, J., Krueger, J., \& Vohs, K. (2003). Does high self-esteem cause better performance, interpersonal success, happiness, or healthier lifestyles?

Psychological Science In The Public Interest, 4(1), 1-44.

Baumeister, R., Smart, L., \& Boden, J. (1996). Relation of threatened egoism to violence and aggression: the dark side of high self-esteem. Psychological Review, 103, 5-33.

Baumeister, R. F. (1993). Self-esteem. The puzzle of low self-regard. New York: Plenum Press.

Bednar, L., Wells, G., \& Peterson, R. (1989). Self-esteem: paradoxes and innovations in clinical theory and practice. Washington: American Psychological Association. 
Beehr, T. A., \& Gupta, N. (1978). A note on the structure of employee withdrawal. Organizational Behavior and Human Performance, 21, 73-79.

Beerel, A. (2009). Leadership and change management. California: SAGE Publications.

Beheshtifar, M., Hoseinifar, H., \& Moghadam, M. (2011). Effect procrastination on workrelated stress. European Journal of Economics, Finance and Administrative Sciences(38), 59-64.

Ben-Zur, H. (2002). Coping, affect and aging: the roles of mastery and self-esteem. Personality and Individual Differences, 32, 357-372.

Bender, K., \& Heywood, J. (2006). Job satisfaction on the highly educated: the role of the gender, academic tenure, and earnings. Scotish Journal of Political Economy, 53(2), 253-279.

Benjamin, K., Pransky, G., \& Savageau, J. (2008). Factors associated with retirement-related job lock in older workers with recent occupational injury. Disability and Rehabilitation, 30(26), 1976-1983.

Bergami, M., \& Bagozzi, R. (2000). Self-categorization, affective commitment and group self-esteem as distinct aspects of social identity in the organization. British Journal of Social Psychology, 39, 555-577.

Berger, M., Black, D., \& Scott, F. (2004). Is there job lock? Evidence from the pre-HIPAA era. Southern Economic Journal 70(4), 953-976.

Bergman, M., Payne, S., \& Boswell, W. (2012). Sometimes pursuits don’t pan out: anticipated destinations and other caveats: comment on Hom, Mitchell, Lee, and Griffeth (2012). Psychological Bulletin, 138(5), 865- 870.

Beswick, G., Rothblum, E., \& Mann, L. (1988). Psychological antecedents of student procrastination. Australian Psychologist, 23(2), 207-217.

Bhugra, D. (2004). Migration, distress and cultural identity. British Medical Bulletin, 69, $129-141$.

Black, S., \& Gregersen, H. (1991). Antecedents to cross-cultural adjustment for expatriates in Pacific Rim assignments. Human Relations, 44, 497 - 515

Black, S., Mendenhall, M., \& Oddou, G. (1991). Toward a comprehensive model of international adjustment: an integration of multiple theoretical perspectives. The Academy of Management Review, 16(2), 291-317.

Blais, M. R., Sabourin, S., Boucher, C., \& Vallerand, R. (1990). Toward a motivational model of couple happiness. Journal of Personality and Social Psychology, 59, 1021-1031.

Blakely, T., Collings, S., \& Atkinson, J. (2003). Unemployment and suicide. Evidence for a causal association? Journal of Epidemiology and Community Health, 57, 594-600.

Blascovich, J., \& Tomaka, J. (1991). Measures of self-esteem. In J. Robinson, P. Shaver \& L. Wrightsman (Eds.), Measures of Personality and Social Psychological Attitudes (Vol. 1 ): Academic Press.

Blatt, S. J., Quinlan, D. M., Chevron, E. S., McDonald, C., \& Zuroff, D. (1982). Dependency and self-criticism: psychological dimensions of depression. Journal of Consulting and Clinical Psychology, 50, 113-124.

Blau, G. (1993). Further exploring the relationship between job search and voluntary individual turnover. Personnel Psychology, 46, 313-330.

Blossfeld, H., \& Rohwer, G. (2002). Techniques of event history modeling. New approaches to causal analysis. Mahwah, New Jersey, London: Lawrence Erlbaum Associates, Publishers.

Bluedorn, A. C. (1982). A unified model of turnover from organizations. Human Relations, $35,135-153$. 
Booth, L. A., \& Francesconi, M. (1999). Job mobility in 1999s Britain: does gender matter? ISER Working Papers 199-26.

Booth, L. A., Francesconi, M., \& Garcia-Serrano, C. (1999). Job tenure and job mobility in Britain. Industrial and Labor Relations Review, 53(1).

Bos, A. E. R., Huijding, J., Muris, P., Vogel, L. R. R., \& Biesheuvel, J. (2010). Global, contingent and implicit self-esteem and psychopathological symptoms in adolescents. Personality and Individual Differences, 48, 311-316.

Boudreau, J., Boswell, W., Judge, T., \& Bretz, R. (2001). Personality and cognitive ability as predictors of job search among employed managers. Personnel Psychology, 54, 25-50.

Bowlby, J. (1969). Attachment (Vol. 1). New York: Basic Books.

Bowles, S., Gintis, H., \& Osborne, M. (2001). Incentive-enhancing preferences: personality, behavior and earning. American Economic Review, 91(2), 155-158.

Boyle, M., \& Lahey, J. (2010). Health insurance and the labor supply decisions of older workers: Evidence from a U.S. Department of Veterans Affairs expansion. Journal of Public Economics, 94, 467-478.

Bradley, M. M., \& Lang, P. J. (1997). Emotion and motivation. In J. T. Cacioppo, L. G. Tassinary \& G. Berntson (Eds.), Handbook of psychophysiology (pp. 581- 607). Cambridge: Cambridge University Press.

Branden, N. (1998). Self-esteem at work: how confident people make powerful companies. San Francisco: Jossey-Bass.

Brandtstadter, J., \& Baltes-Gotz, B. I. P. B. M. (1990). Personal control over development and quality of life perspectives in adulthood. In P. Baltes \& M. Baltes (Eds.), Successful aging (pp. 197-221). Melbourne, Australia: Press Syndicate of the University of Cambridge.

Brayfield, A., \& Crokett, W. (1955). Employee attitudes and employee performance. Psychological Bulletin, 52(5), 396-424.

Breines, J., \& Chen, S. (2012). Self-compassion increases self-improvement motivation. Personality and Social Psychology Bulletin. doi: 10.1177/0146167212445599

Bretz, R. D., Boudreau, J. W., \& Judge, T. A. (1994). Job search behavior of employed managers. Personnel Psychology, 47, 275-301.

Brockner, J. (1988). Self-esteem at work. Research, theory, and practice.: Lexongton Books.

Brown, J., Dutton, K., \& Cook, K. (2001). From the top down: self-esteem and selfevaluation. Cognition and Emotion, 15(5), 615-631.

Brown, J. D., Cai, H., Oakes, M. A., \& Deng, C. (2009). Cultural similarities in self-esteem functioning. Journal of Cross-Cultural Psychology, 40(1), 140-157.

Brown, J. D., \& Marshall, M. (2006). The three faces of self-esteem. In M. Kernis (Ed.), Selfesteem: issues and answers (pp. 4-9). New York: Psychology Press.

Browne, M. W., \& Cudeck, R. (1989). Single sample cross-validation indices for covariance structures. Multivariate Behavioral Research, 24, 445-455.

Burka, J., \& Yuen, L. (1983). Procrastination: why you do it and what to do about it.: Addison-Wesley.

Burt, R. S. (2001). Attachment, decay and social networks. Journal of Organizational Behavior, 126(22), 619-643.

Byrka, K. (2009). Attitude-behavior consistency. Technische Iniversiteit Eindhoven.

Byrne, B. M. (2001). Structural equation modeling with AMOS: basic concepts, applications and programming. New Jerrsey: Lawrence Erlbaum Associates Inc.

Byrne, D., \& Mazarov, J. (2001). Self-esteem, stress and cigarette smoking in adolescents. Stress and Health, 17, 105-110. 
Cameron, J. J., Stinson, D. A., Gaetz, R., \& Balchen, S. (2010). Acceptance in the eye of the beholder: self-esteem and motivated perceptions of acceptance from the opposite sex Journal of Personality and Social Psychology, 99, 513-529.

Campbell, J., Chew, B., \& Scratchley, L. (1991). Cognitive and emotional reactions to daily events: the effects of self-esteem and complexity. Journal of Personality, 59(3), 473 505.

Carsten, J. M., \& Spector, P. E. (1987). Unemployment, job satisfaction, and employee turnover: a meta-analystic test of the Muchinsky model. Journal of Applied Psychology, 72, 374-381.

Caruthers, N. (2003). Stress and self-esteem., from http://clearinghouse.mwsc.edu/maniscripts/25.asp

Carver, C., Scheier, M., \& Weintraub, J. (1989). Assessing coping strategies: a theoretically based approach. Journal of Personality and Social Psychology, 56(2), 267-283.

Catarino, F., Gilbert, P., Mcewan, K., \& Baiao, R. (2014). Compassion motivations: distinquishing submissive compassion from genuine compassion and its association to shame, submissive behavior, depression, anxiety and stress. Journal of Social and Clinical Psychology, 33(5), 399-412.

Chang, S. (1998). Case study. An effective analytical psychotherapy in crosscultural context. An East Asian student in the United States. American Journal of Psychotherapy, 52(2), 229-239.

Checchi, D., \& Pravettoni, G. (2003). Self-esteem and educational attainment. XVIII AIEL Conference, Working Paper n. 30.2003.

Cheng, H., \& Furnham, A. (2003). Personality, self-esteem, and demographic predictions of happiness and depression. Personality and Individual Differences, 34, 921-942.

Chmiel, N. (2000). Introduction to work and organizational psychology. A European perspective. Oxford: Blackwell Publishing.

Cho, S., Johanson, M., \& Guchait, P. (2009). Employees intent to leave: a comparison of determinants of intent to leave versus intent to stay. International Journal of Hospitality Management, 28, 374-381.

Chou, C. P., \& Bentler, P. M. (1995). Estimates and tests in structural equation modeling. In R. H. Hoyle (Ed.), Structural equation modeling: Concepts, issues and applications (pp. 37-55). Thousand Oaks: SAGE.

Chu, A., \& Choi, J. (2005). Rethinking procrastinaton: positive effects of "active" procrastination behavior on attitudes and performance. Journal of Social Psychology, 145(3), 245-264.

Chung, H., \& van Oorschot, W. (2011). Institutions versus market forces: explaining the employment insecurity of European individuals during (the beginning of) the financial crisis. Journal of European Social Policy 21(4), 287-301.

Chusmir, L., \& Koberg, C. (2001). Perceived work competency and sex role conflict: an empirical study. The Journal of Psychology, 123(6), 537-546.

Ciucă, V., \& Matei, M. (2011). Survival rates in unemployment International Journal of Mathematical Models and Methods in Applied Sciences, 5(2), 362-370.

Clark, A. (1997a). Job satisfaction and gender: Why are women so happy at work? Labour Economics, 4(4), 341-372.

Clark, A., Oswald, A., \& Warr, P. (1996). Is job satisfaction U-shaped in age? Journal of Occupational and Organizational Psychology, 69, 57-81.

Clark, E. (1996). Job satisfaction in Britain. British Journal of Industrial Relations, 34, 189217.

Clark, E. (1997b). Job satisfaction and gender: why are women so happy at work? Labour Economics, 4, 341-372. 
Clark, S. (2000). Work/family border theory: a new theory of work/family balance. Human Relations, 53(6), 747-770.

Connolly, S. (2004). Thought Field Therapy: Clinical applications, integrating TFT in psychotherapy George Tyrrell Press.

Cope, T. (2008). Positive Psychotherapy's Theory of the capacity to know as explication of unconscious contents Journal of Religion and Health, 48(1), 79-89.

Cousineau, D., \& Chartier, S. (2010). Outliers detection and treatment: a review. International Journal of Psychological Research, 3(1), 58-67.

Covington, M. (1984). The motive for self-worth. In R. Ames \& C. Ames (Eds.), Research on motivation in education. Student motivation. (Vol. 1): Academic Press, Inc.

Cranny, J. C., Smith, C. J., \& Stone, P. C. (1992). Job satisfaction: how people feel about their jobs and how it affects their performance. New York: Lexington Books.

Creed, P. (1999). Personality characteristics in unemployed australian males - implications for "drift" hypothesis in unemployment. Psychological Reports, 84, 477-480.

Creed, P., Bloxsome, T., \& Johnston, K. (2001). Self-esteem and self-efficacy outcomes for unemployed individuals attending occupational skills training programs. Community, Work and Family, 4(3), 285-303.

Creed, P., Machin, M., \& Hicks, R. (1999). Improving mental health status and coping abilities for long-term unemployed youth using cognitive-behaviour therapy based training interventions. Journal of Organizational Behavior, 20(6), 963-978.

Crocker, J., \& Canevello, A. (2008). Creating and undermining social support in communal relationships: the role of compassionate and self-image goals. Jounal of Personality and Social Psychology, 95, 555-575.

Crocker, J., \& Canevello, A. (2012). Self and Identity. Dynamics of Persons and Their Situations The Oxford Handbook of Personality and Social Psychology (pp. 263-286).

Crocker, J., Karpinski, A., Quinn, D., \& Chase, S. (2003). When grades determine self-worth: consequences of contingent self-worth for male and female engineering and psychology majors. Journal of Personality and Social Psychology, 85(3), 507-516.

Crocker, J., Luhtanen, R., Cooper, M., \& Bouvrette, A. (2003). Contingencies of self-worth in college students: theory and measurement. Journal of Personality and Social Psychology, 85(5), 894-908.

Crocker, J., Olivier, M., \& Nuer, N. (2009). Self-Image goals and compassionate goals: costs and benefits. Self Identity, 8(2-3), 251-269.

Crocker, J., \& Park, L. (2003). Seeking self-esteem: construction, maintenance, and protection of self-worth. Handbook of self and identity. (pp. 291-313). New York: Guilford.

Crocker, J., \& Wolfe, C. (2001a). Contingencies of self-worth. Psychological Review, 108(3), 593-623.

Crocker, J., \& Wolfe, C. T. (2001b). Contingencies of self-worth. . Psychological Review, $108,593-623$.

Crossley, C., Bennett, R., Jex, S., \& Burnfield, J. (2007). Development of a global measure of job embeddedness and integration into a traditional model of voluntary turnover. Journal of Applied Psychology, 92(4), 1031-1042.

D'Ardenne, P., \& Mahtani, A. (1989). Transcultural counselling in action. London: SAGE.

Dalton, D., \& Todor, W. (1993). Turnover, transfer, absenteeism: an interdependent perspective. Journal of Management, 19(2), 193-219.

Dawis, R., \& Lofquist, L. (1984). A psychological theory of work adjustment. An individualdifferences model and its applications. Minneapolis: Univeristy of Minnesota Press.

De Cenzo, D., \& Robbins, S. (1996). Human Resource Management.: John Wiley \& Sons Inc. 
Deci, E., Connell, J., \& Ryan, R. (1989). Self-determination in a work organization. Journal of Applied Psychology, 74(4), 580-590.

Deci, E., \& Ryan, A. (1985a). The general causality orientations scale: self-determination in personality Journal of Research in Personality, 19, 109-134.

Deci, E. L., \& Ryan, R. M. (1985b). Intrinsic motivation and self-determination in human behavior. . New York: Plenum Press.

Deci, E. L., \& Ryan, R. M. (1995). Human autonomy: The basis for true self-esteem. In M. H. Kemis (Ed.), Efficacy, agency, and self-esteem (pp. 31-49). New York: Plenum

Deci, E. L., \& Ryan, R. M. (2000). The "what" and "why" of goal pursuits: Human needs and the self-determination of behavior. Psychological Inquiry, 11, 227-268.

Depue, R., \& Morrone-Strupinsky, J. (2005). A neurobehavioral model of affiliative bonding: implications for conceptualizing a human trait of affiliation. Behavioral and Brain Sciences, 28, 313-395.

Diener, E., \& Diener, C. (1996). Most people are happy. Psychological Science, 7(3), 181185.

Diener, E., Lucas, R., \& Scollon, C. (2009). Beyond the hedonic treadmill: revising the adaptation theory of well-being. The science of well-being (Vol. 37, pp. 103-118).

Disney, R., \& Emmerson, C. (2002). Choice of pension scheme and job mobility in Britain. The Institute for Fiscal Studies, (WP02/09).

Dooley, D. (2003). Unemployment, underemployment, and mental health: conceptualizing employment status as a continuum. American Journal of Community Psychology, $32(1 / 2), 9-20$.

Dooley, D., \& Prause, J. (1997). Effect of students' self-esteem on later employment status: interactions of self-esteem with gender and race. Applied Psychology: An International Review, 46(2), 175-198.

Dorsey, S. (1995). Pension portability and labor market efficiency: a survey of the literature. Industrial and Labor Relations Review, 48, 276-292.

Downie, M., G., M., \& Koestner, R. (2008). What makes for a pleasant social interaction? Motivational dynamics of interpersonal relations. The Journal of Social Psychology, 148(5), 523-534.

Dwairy, M., \& Van Sickle, T. (1996). Western psychotherapy in traditional Arabic societies. Clinical Psychology Review, 16(3), 231-249.

Dweck, C. (2000). Self-theories: their role in motivation, personality, and development.: Psychology Press Taylor \& Francis Group.

Dwoskin, H., \& Canfield, J. (2007). The Sedona method. Your key to lasting happiness, success, peace, and emotional well-being. Sedona: Sedona Press.

Dykman, B. M. (1998). Integrating cognitive and motivational factors in depression: initial tests of a goal orienattion approach. Journal of Personality and Social Psychology, 74, 139-158.

Eagly, A., \& Chaiken, S. (1993). The psychology of attitudes.: Harcourt Brace College Publishers.

Eby, L., Casper, W., Lockwood, A., Bordeaux, C., \& Brinley, A. (2005). Monograph work and family research in IO/OB: content analysis and review of the literature (19802002). Journal of Vocational Behavior, 66, 124-197.

Effert, B. R., \& Ferrari, J. R. (1989). Decisional procrastination: examining personality correlates. Journal of Social Behavior and Personality, 4, 151-156.

Egan, S., \& Perry, D. (2001). Gender identity: a multidimensional analysis with implications for psychosocial adjustment. Developmental Psychology, 37(4), 451-463.

Ehrenberg, G. R., \& Smith, S. R. (2000). Modern Labor Economics: Theory \& Public Policy. Boston: Addison-Wesley 
Elias, P. (1994). Job-related training, trade union membership, and labour mobility: a longitudinal study. Oxford Economic Papers, 46, 563-578.

Elligan, D. (1997). Case report. Culturally sensitive integration of supportive and cognitive behavioral therapy in the treatment of a bicultural dysthymic patient. Cultural Diversity and Mental Health, 3(3), 207-213.

Elliott, R., Fischer, C., \& Rennie, D. (1999). Evolving guidelines for publication of qualitative research studies in psychology and related fields.

. British Journal of Clinical Psychology, 38, 215-229.

Ellis, A., \& Knaus, J. (1979). Overcoming Procrastination. . New York: Institute for Rational Living.

Ellis, R., \& Taylor, M. (1983). Role of self-esteem within the job search process. Journal of Applied Psychology, 68(4), 632-640.

Emler, N. (2001). Self-esteem. The costs and causes of low self-worth.

Epstein, S. (1985). Anxiety, arousal, and self-concept. Issues in Mental Health Nursing, 7(14), 265-305.

Erickson, R. (2005). Why emotion work matters: sex, gender, and the division of household labor. Journal of Marriage and Family, 67, 337-351.

Erikson. (1980). Identity and the life cycle. New York London: W. W. Norton \& Company.

Erikson, E. H. (Ed.). (1964). Insight and Responsibility. NewYork: Norton.

Faragher, E., Cass, M., \& Cooper, C. (2005). The relationship between job satisfaction and health: a meta analysis. Occupational and Environmental Medicine, 62, 105-112.

Farrell, D., \& Rusbult, C. (1981). Exchange variables as predictors of job satisfaction, job commitment, and turnover: the impact of rewards, costs, alternatives, and investments. Organizational Behavior and Human Performance, 27, 78-95.

Fasang, A., Geerdes, S., \& Schoeman, K. (2009). Which type of job mobility makes people happy? A comparative analysis of European welfare regimes. Working paper. Yale University.

Fedor, D., Walter, D., Maslyn, J., \& Mathienson, K. (2001). Performance improvement efforts in response to negative feedback: the roles of source power and recipient selfesteem. Journal of Management, 27, 79-97.

Feinstein, L. (2000). The relative economic importance of academic, psychological and behavioral attitudes developed in childhood. unpublished, (Paper No CEPDP0443).

Ferrari, J. (1991). Self-handicapping by procrastinators: protecting self-esteem, social esteem or both? Journal of Research in Personality, 25, 245-261.

Ferrari, J. (1992a). Procrastinators and perfect behavior: an exploratory factor analysis of selfpresentation, self-awareness, and self-handicapping components. Journal of research in personality, 26, 75-84.

Ferrari, J. (1994). Dysfunctional procrastination and its relationship with self-esteem, interpersonal dependency, and self-defeating behaviors. Personality and Individual Differences, 17(5), 673-679.

Ferrari, J., \& Emmons, R. (1994). Procrastination as revenge: do people report using delays as a strategy for vengeance? Personality and Individual Differences, 17(4), 539-544.

Ferrari, J., Johnson, J., \& McCown, W. (1995). Procrastination and task avoidanve. Theory, research, and treatment. New York and London: Plenum Press.

Ferrari, J., O'Callaghan, J., \& Newbegin, I. (2005). Prevalence of procrastination in United States, United Kingdon, and Australia: arousal and avoidance delays among adults. North American Journal of Psychology, 7(1), 1-6.

Ferrari, J. R. (1992b). Psychometric validation of two adult measures of procrastination: arousal and avoidance measures. Journal of Psychopathology and Behavioral Assessment, 14, 97-100. 
Ferrie, J., Marmot, M., Griffiths, J., \& Ziglio, E. (1999). Labor market changes and job insecurity: a challenge for social welfare and health promotion (Vol. 81). Copenhagen: WHO

Ferris, D., Brown, H., Pang, F., \& Keeping, L. (2010). Self-esteem and job performance: the moderating role of self-esteem contingencies. Personnel Psychology, 63, 561-593.

Ferris, L., Brown, D., Lian, H., \& Keeping, L. (2009). When does self-esteem relate to deviant behavior? The role of contingencies of self-worth Journal of Applied Psychology, 94(5), 1345-1353.

Fineman, S. (1979). A psychosocial model of stress and its application to managerial unemployment. Human Relations, 32(4), 323-345.

Fitzenberger, B., \& Kunze, A. (2005). Vocational training and gender: wages and occupational mobility among young workers. Oxford Review of Economic Policy, 21(3), 392-415.

Fletcher, J., \& Stren, R. (1989). Language skills and adaptation: a study of foreign students in a Canadian University. Curriculum Inquiry, 19(3), 293-308.

Fortin, N. (2005). Gender role attitudes and labour-market outcomes of women across OECD countries. Oxford Review of Economic Policy, 21(3), 416-438.

Francesconi, M., Orszag, M., Phelps, E., \& Zoega, G. (2000). Education and the natural rate of unemployment. Oxford Economic Papers, 52, 204-223.

Frayne, C., \& Geringer, M. (2000). Self-management training for imporving job performance: a field experiment involving salespeople. Journal of Applied Psychology, 85, 361-372.

Fredrickson, B. L., \& Kahneman, D. (1993a). Duration neglect in retrospective evaluations of affective episodes. Journal of Personality and Social Psychology, 65(1), 45-55.

Fredrickson, B. L., \& Kahneman, D. (1993b). Duration neglect in retrospective evaluations of affective episodes. Journal of Personality and Social Psychology, 65(45-55).

Freeman, C. L., Soete, L., \& Efendioglu, U. (1995). Diffusion and the employment effects of information and communication technology. International Labour Review, 134, 587603.

Freud, S. (Ed.). (1971). The psychopathology of everyday life New York, London: W. W. Norton \& Company.

Friedland, D., \& Price, R. (2003). Underemployment: consequences for the health and wellbeing of workers. American Journal of Community Psychology, 32(1/2), 33-45.

Frost, P., Dutton, J. M., S., Lilius, J., Kanov, J., \& Worline, M. (2005). Seeing organizations differently: three lenses on compassion. Mitchigan Ross School of Business.

Fuller, A., \& Ward, T. (2012). Employment, social affairs \& inclusion. Mobility in Europe 2012 (pp. 158): European Commission.

Furnham, A., \& Bochner, S. (1986). Culture shock. Psychological reations to unfamiliar environments. London: Methuen \& Co, Ltd.

Gaertner, K., \& Nollen, S. (1992). Turnover intentions and desire among executives. Human Relations, 45, 447-465.

Gaine, G., \& La Guardia, J. (2009). The unique contributions of motivations to maintain a relationship and motivations toward relational activities to relationship well-being. Motivation and Emotion, 33, 184-202.

Gallo, F. (2002). Energy psychology in psychotherapy. A comprehensive sourcebook. New York, London: W. W. Norton \& Company.

Gallo, F. (2005). Energy psychology: Explorations at the interface of energy, cognition, behavior, and health. Boca Raton, London: CRC Press.

Gao, F., Luo, N., Thumboo, J., Fones, C., Li, S., \& Cheung, Y. (2004). Does the 12-item General Health Questionnaire contain multiple factors and do we need them? Health 
and Quality of Life Outcomes, 2(63). Retrieved from http://www.hqlo.com/content/pdf/1477-7525-2-63.pdf

Gavin, J. (1973). Self-esteem as moderator of the relationship between expectancies and job performance. Journal of Applied Psychology, 58(1), 83-88.

Gazioglu, S., \& Tansel, A. (2006). Job satisfaction in Britain: individual and job related factors. Applied Economics, 38, 1163-1171.

Gerhart, B. (1990). Voluntary turnover and alternative job opportunities. Journal of Applied Psychology, 75, 467-476.

Gibson, B. (2007). A multi-agent systems approach to microeconomic foundations of macro, from http://www.uvm.edu/ wgibson/Research/Gibson_MAS_0.3.pdf

Gilbert, P. (1989). Human nature and suffering. London: Lawrence Erlbaum Associates.

Gilbert, P. (2002). Evolutionary approaches to psychopathology and cognitive therapy. Cognitive Psychotherapy: An International Quarterly, 16, 263-294.

Gilbert, P. (2005a). Compassion. Conceptualisations, research and use in psychotherapy. London and New York: Routledge Taylor \& Francis Group.

Gilbert, P. (2005b). Social mentalities: a biopsychosocial and evolutionary approach to social relationships. . In M. Baldwin (Ed.), Interpersonal cognition. (pp. 299-333). New York: Guilford Press.

Gilbert, P. (2009a). The compassionate mind: Coping with the challenges of living. London: Constable Robinson.

Gilbert, P. (2009b). Introducing compassion-focused therapy. Advances in Psychiatric Treatment, 15, 199-208.

Gilbert, P. (2010). Compassion focused therapy. London \& New York: Routledge Taylor \& Francis Group.

Gilbert, P., \& Irons, C. (2004). A pilot exploration of the use of compassionate images in a group of self-critical people. Memory 12, 507-516.

Gilbert, P., \& Irons, C. (2005). Focused therapies and compassionate mind training for shame and self-attacking. In P. Gilbert (Ed.), Compassion: conceptualisations, research and use in psychotherapy (pp. 263-326): Routledge.

Gilbert, P., \& Procker, S. (2006). Compassionate mind training for people with high shame and self-criticism: overview and pilot study of a group therapy approach. Clinical Psychology \& Psychotherapy, 13, 353-379.

Gillath, O., Shaver, P., \& Mikulincer, M. (2005). An attachment-theoretical approach to compassion and altruism. In P. Gilbert (Ed.), Compassion. Conceptualisations, research and use in psychotherapy (pp. 121-147). London and New York: Routledge.

Gilleskie, D., \& Lutz, B. (2002). The impact of employer-provided health insurance on dynamic employment transitions. The Journal of Human Resources, XXXVII(1), 129162.

Goldberg, D., Gater, R., Sartorius, N., Ustun, T., Piccinelli, M., Gureje, O., \& Rutter, C. (1997). The validity of two versions of the GHQ in the WHO study of mental illness in general health care. Psychological Medicine, 27, 191-197.

Goldney, R. (1997). Unemployment and health: a re-appraisal. International Arch Occupational Environmental Health, 70, 145-147.

Goldsmith, A., Sedo, S., Darity, W., \& Hamilton, D. (2004). The labor supply consequences of perceptions of employer discrimination during search and on-the-job: Integrating neoclassical theory and cognitive dissonance. Journal of Economic Psychology, 25, 15-39.

Goldsmith, A., Veum, J., \& Darity, W. (1996a). The impact of labor force history on selfesteem and its component parts, anxiety, alienation and depression. Journal of Economic Psychology, 17, 183-220. 
Goldsmith, A., Veum, J., \& Darity, W. (1996b). The psychological impact of unemployment and joblessness. Journal of Socio-Economics, 25(3), 333-358.

Goldsmith, A., Veum, J., \& Darity, W. (1997). Unemployment, joblessness, psychological well-being and self-esteem: theory and evidence. Journal of Socio-Economics, 26(2), 133-158.

Gollwitzer, P. M. (1996). The volitional benefits of planning. . In P. M. Gollwitzer \& J. A. Bargh (Eds.), The psychology of action: Linking cognition and motivation to behavior (pp. 287-312). New York: Guilford.

Granger, C. (1969). Investigating causal relations by econometric models and cross-spectral methods. Econometrica, 37(3), 424-438.

Gray-Little, B., Williams, V., \& Hancock, T. (1997). An item response theory analysis of the Rosenberg self-esteem scale. Personality and Social Psychology Bulletin, 23(5), 443451.

Graziano, W. G., Jensen Campbell, L. A., \& Finch, J. F. (1997). The self as a mediator between personality and adjustment. Journal of Personality and Social Psychology, 73(2), 392-404.

Greenberg, J., \& Baron, R. (2003). Behavior in organizations: understanding and managing the human side of work. NJ: Pearson education International.

Greenland, S. (2003). Quantifying biases in causal models: classical confounding vs colliderstratification bias. Epidemiology, 14, 300-306.

Greenland, S., \& Robins, J. (1986). Identifiability, exchangeability, and epidemiological confounding. International Journal of Epidemiology, 15(3), 413-419.

Greenland, S., Robins, J., \& Pearl, J. (1999). Confounding and collapsibility in causal inference. Statistical Science, 14(1), 29-46.

Griffeth, R., \& Hom, P. (2004). Innovative theory and empirical research on employee turnover: Information Age Publishing.

Griffeth, R., Hom, P., \& Gaertner, S. (2000). A meta-analysis of antecedents and correlates of employee turnover: update, moderator tests, and research impications for the next millenium. Journal of Management, 26(3), 463-488.

Griffin, D., \& Bartholomew, K. (1994). Models of the self and other - fundamental dimensions underlying measures of adult attachment. Journal of Personality and Social Psychology, 67, 430-445.

Groot, W. (1992). Essays on unemployment and education., Amsterdam.

Groot, W., \& Verberne, M. (1997). Aging, job mobility, and compensation. Oxford Economic Papers, 49, 380-403.

Gruber, J., \& Madrian, B. (1994). Health insurance and job mobility: the effects of public policy on job-lock. Industrial and Labor Relations Review, 48(1), 86-102.

Gruber, J., \& Madrian, C. B. (1993). Limited insurance portability and job mobility: the effects of public-policy on job-lock. NBER Working Paper Series no. 4479 (Vol. 4479): National Bureau of Economic Research.

Gustman, A., Mitchell, O., \& Steinmeier, T. (1994). The role of pensions in the labor market. A survey of the literature. Industrial and Labor Relations Review, 47(417-438).

Hagen-Zanker, J. (2010). Modest expectations. Causes and effects of migration on migrant households in source countries Boekenplan, Maastricht.

Hair, E., \& Graziano, W. (2003). Self-esteem, personality and achievement in high school: a perspective longitudinal study in Texas. Journal of Personality, 71(6), 971-994.

Hamersma, S., \& Kim, M. (2009). The effect of parental Medicaid expansions on job mobility. Journal of Health Economics, 28, 761-770.

Hammer, T. (1993). Unemployment and mental health among young people: a longitudinal study. Journal of Adolescence, 16(4), 407-420. 
Hamori, M., \& Kakarika, M. (2009). Exrternal labor market startegy and career success: CEO careers in Europe and the United States. Human Resource Management, 48 (3), 355378.

Hanisch, K. (2002). The timing of thinking about quitting. The effect on job attitudes and behaviors. In M. Koslowsky \& M. Krausz (Eds.), Voluntary employee withdrawal and inattendance. A current perspective. (pp. 193-211). New York: Kluwer Academic/Plenum Publishers.

Hanisch, K., \& Hulin, C. (1990). Job attitudes and organizational withdrawal: an examination of retirement and other voluntary withdrawal behaviors. Journal of Vocational Behavior, 37, 60-78.

Hanisch, K., \& Hulin, C. (1991). General attitudes and organization withdrawal: an evaluation of a causal model. Journal of Vocational Behavior, 39, 110-128.

Hanisch, K., Hulin, C., \& Roznowski, M. (1998). The importance of individuals' repertoires of behaviors: the scentific appropriateness of studying multiple behaviors and general attitudes. Journal of organizational behavior, 19, 463-480.

Harriott, J., \& Ferrari, J. (1996). Prevalence of procrastination among samples of adults. Psychological reports, 78, 611-616.

Harris, D., \& Adams, S. (2007). Understanding the level and causes of teacher turnover: a comparison with other professions. Economics of Education Review, 26, 325-337.

Hayes, S. (2005). Get out of your mind and into your life. The new acceptance and commitment therapy. Oakland: New Harbinger Publications, Inc.

Hayes, S., \& Strosahl, K. (2010). A practical guide to acceptance and commitment therapy. NY: Springer.

Heckman, J. (1979). Sample selection bias as a specification error. Econometrica 47(1), 153161.

Helman, C. (2007). Culture, health, and illness. London Hodder Arnold.

Henderson, J., \& Shibano, G. (1990). Follow-up of international graduate students in agricultural education at the Ohio State University. Journal of Agricultural Education, spring, 71-74.

Henne, D., \& Locke, E. A. (1985). Job dissatisfaction: What are the consequences? International Journal of Psychology, 20, 221-240.

Hernan, M., Hernandez-Diaz, S., Werler, M., \& Mitchell, A. (2002). Causal knowledge as a prerequisite for confounding evaluation: an application to birth defect epidemiology. American Journal of Epidemiology, 155(2), 176-184.

Herzberg, F., Mausner, B., \& Snyderman, B. (1964). The motivation to work.: John Wiley \& Sons, Inc.

Hirschy, A., \& Morris, J. (2002). Individual differences in attributional style: the relational influence of self-efficacy, self-esteem, and sex role identity. Personality and Individual Differences, 32, 183-196.

Hischman, A. (1970). Exit, voice, and loyalty. Responses to decline in firms, organizations, and states.: Harvard University Press.

Hofstede, G. (2001). Culture's consequences. Comparing values, behaviors, institutions, and organizations across nations.: Sage Publications.

Hofstede, G., \& McCrae, R. (2004). Personality and culture revised: linking traits and dimensions of culture. Cross-Cultural Research, 38(1), 52-88.

Holland, L. (1985). Making vocational choices: a theory of vocational personalities and work environments. New Jersey: Prentice-Hall.

Holmes, J. (1993). Attachment theory: a biological basis for psychotherapy? . British Journal of Psychiatry, 163, 430-438. 
Holtom, B., Burton, J., \& Crossley, G. (2012). How negative affectivity moderates the relationship between shocks, embeddedness and worker behaviors. Journal of Vocational Behavior, 80, 434-443.

Holtom, B., \& Inderrieden, E. (2006). Integrating the unfolding model and job embeddedness model to better understand voluntary turnover. Journal of Managerial Issues, XVIII(4), 435-452.

Holtz-Eakin, D., Penrod, J., \& Rosen, H. (1996). Health insurance and the supply of entreprenuers. Journal of Public Economics, 62, 209-235.

Hom, P., Caranikas-Walker, F., Prussia, G., \& Griffeth, R. (1992). A meta-analysis structural equations analysis of a model of employee turnover. Journal of Applied Psychology, 77, 890-909.

Hom, P., \& Griffeth, R. (1995). Employee turnover. Ontario: South Western Publishing.

Hom, P., Mitchell, T., Lee, T., \& Griffeth, R. (2012). Reviewing employee turnover: focusing on proximal withdrawal states and an expanded criterion. Psychological Bulletin, 138(5), 831-858.

Hom, P. W., \& Griffeth, R. W. (1991). Structural Equations Modeling Test of a Turnover Theory : Cross-Sectional and Longitudinal Analyses. Journal of Applied Psychology, 76(3), 350-366.

Horan, P., Di Stefano, C., \& Motl, R. (2003). Wording effects in self-esteem scales: methodological artifact or response style? Structural Equation Modeling, 10(3), 435455.

Howe, G., Levy, M., \& Caplan, R. (2004). Job loss and depressive symptoms in couples: common stressors, stress transmission, or relationship disruption? Journal of Family Psychology, 18(4), 639-650.

Hu, L. T., \& Bentler, P. M. (1999). Cutoff criteria for fit indices in covariance structure analysis: Conventional criteria versus new alternatives. Structural Equation Modeling, $6,1-55$.

Hughes, J., \& Bozionelos, N. (2007). Work-life balance as source of job dissatisfaction and withdrawal attitudes. An exploratory study on the views of male workers. Personnel Review, 36(1), 145-154.

Hulin, C. (1991). Adaptation, persistence, and commitment in organizations. In M. Dunette \& L. Hough (Eds.), Handbook of industrial and organizational psychology (Vol. 2, pp. 445-505). Palo Alto: Consulting Psychologist Press.

Hulin, C., Roznowski, M., \& Hachiya, D. (1985). Alternative opportunities and withdrawal decisions: empirical and theoretical discrepancies and an integration. Psychological Bulletin, 97(2), 233-250.

Huysse-Gaytandjieva, A., \& Boncheva, I. (2013). Why do we fail to adapt to a different culture? A development of a therapeutic approach. International Journal of Psychotherapy, 17(3), 43-58.

Huysse-Gaytandjieva, A., Groot, W., \& Pavlova, M. (2013a). A new perspective on job lock. Social Indicators Research, 112(3), 587-610. doi: DOI 10.1007/s11205-012-0072-2

Huysse-Gaytandjieva, A., Groot, W., \& Pavlova, M. (2013b). Why do some employees fall into and fail to exit a job-lock situation? Journal of Environmental and Public Health. doi: $10.1155 / 2013 / 839349$

Hwang, W. (2006). The psychotherapy adaptation and modification framework. Application to Asian Americans. American Psychologist, 61(7), 702-715.

Iaffaldano, M., \& Muchinsky, P. (1985). Job satisfaction and job performance: a metaanalysis. Psychological Bulletin, 97(2), 251-273.

Impett, E., \& Gordon, A. (2010). Why do people sacrifice to approach rewards versus to avoid costs? Insights from attachment theory. Personal Relationships, 17, 299-315. 
Ippolito, R. (1991). Encouraging long-term tenure: wage tilt or pensions? Industrial and Labour Relations Review, 44(3), 520-535.

Iwamasa, G., \& Smith, S. (1996). Ethnic diversity in behavioral psychology: a review of the literature. Behavioral Modification, 20, 45-59.

Iwasaki, Y., MacKay, K., \& Mactavish, J. (2005). Gender-based analysis of coping with stress among professional managers: leisure coping and non-leisure coping. Journal of Leisure Research, 37(1), 1-28.

Jackofsky, E. F., \& Peters, L. H. (1983). Job Turnover Versus Company Turnover: Reassessment of the March and Simon Participation Hypothesis. Journal of Applied Psychology, 68(3), 490-495.

Jahoda, M. (1981). Work, employment, and unemployment. American Psychologist, 36(2), 184-191.

Jahoda, M. (1982). Employment and unemployment. A social-psychological analysis.: Cambridge University Press.

Jalajas, D. (1994). The role of self-esteem in the stress process: empirical results from job hunting. Journal of Applied Social Psychology, 24(22), 1984-2001.

James, W. (1890). The principles of psychology. (Vol. Vol. 1 \& 2). New York: Holt.

Janis, I. L., \& Mann, L. (1977). Decision making: a psychological analysis of conflict, chance and commitment. NY: Free Press.

Jaros, S. (1997). An assessment of Meyer and Allen's (1991) three-component model of organizational commitment and turnover intentions. Journal of Vocational Behavior, 51, 319-337.

Jex, S. M., \& Elacqua, T. C. (1999). Self-esteem as a moderator: A comparison of global and organization-based measures. Journal of Occupational and Organizational Psychology, 72, 71-81.

Johnson, J. (1992). The SS-77. A measure of psychological symptom severity. Princeton: NorthShore Press.

Johnson, J., Metalsky, G., Rabkin, J., Williams, J., \& Remien, R. (2000). Attributional style, self-esteem, and human immunodeficiency virus: a test of the hopelessness and selfesteem theories of depression. Journal of Psychopathology and Behavioral Assessment, 22, 23-46.

Jorgensen, R., \& Dusek, J. (1990). Adolescent adjustment and coping strategies. Journal of Personality, 58(3), 503-513.

Josephs, R., Bosson, J., \& Jacobs, C. (2003). Self-esteem maintenance processes: why low self-esteem may be resistant to change. Personality and Social Psychology Bulletin, 29(7), 920-933.

Josephs, R., Larrick, R., Steele, C., \& Nisbett, R. (1992). Protecting the self from the negative consequences of risky decisions. Journal of Personality and Social Psychology, 62, 26-37.

Judge, T., \& Bono, J. (2001). Relationship of core self-evaluations traits - self-esteem, generalized self-efficacy, locus of control, and emotional stability - with job satisfaction and job performance: a meta-analysis. Journal of Applied Psychology, 86(1), 80-92.

Judge, T., Bono, J., \& Locke, E. (2000). Personality and job satisfaction: the mediating role of job characteristics. Journal of applied psychology, 85(2), 237-249.

Judge, T., \& Hulin, C. (1991). Job satisfaction and subjective well-being as determinants of job adaptation. Center for Advanced Human Resource Studies, CAHRS Working Paper Series. 
Judge, T., \& Hulin, C. (1993). Job satisfaction as a reflection of disposition: a multiple source causal analysis. Organizational Behavior and Human Decision Processes, 56, 388421.

Judge, T., Thoresen, C., Bono, J., \& Patton, G. (2001). The job satisfaction-job performance relationship: a qualitative and quantitative review. Psychological bulletin, 127(3), 376407.

Kahn, W. A. (1998). Relational systems at work. Research in organizational behavior. 20, 3976.

Kahneman, D., Diener, E., \& Schwarz, N. (1999). Well-being: the foundations of hedonic psychology. NY: Pussel Sage Foundation.

Kaniok, E., \& Kaniok, L. (2008). Identiteit Het geluk van TAO. Verhalen en parabels uit China. (pp. 122). Rotterdam: Asoka.

Kapur, K. (1998). The impact of health on job mobility: a measure of job lock. Industrial and Labor Relations Review, 51(2), 282-298.

Karanikola, M. N., Papathanassoglou, E. D., Giannakopoulou, M., \& Koutroubas, A. (2007). Pilot exploration of the association between self-esteem and professional satisfaction in Hellenic hospital nurses. Journal of Nursing Management, 15(1), 78-90.

Kasl, S. V. (1982). Strategies of research on economic instability and health. Psychological Medicine, 12, 637-649.

Kennedy, S., Drago, R., Sloan, J., \& Wooden, M. (1994). The effect of trade unions on the provision of training: Australian evidence. British Journal of Industrial Relashions, 32(4), 565-580.

Kernis, M., Paradise, A., Whitaker, D., Wheatman, S., \& Goldman, B. M. (2000). Master of one's psychological domain? Not likely if one's self-esteem is unstable. Personality and Social Psychology Bulletin, 26(10), 1297-1305

Kernis, M. H., \& Goldman, B. M. (2006). Assessing stability of self-esteem and contingent self-esteem. In M. Kernis (Ed.), Self-esteem issues and answers: A source book of current perspectives (pp. 77-82). New York: Psychology Press.

Kim, J., \& Philips, P. (2010). Health insurance and worker retention in the construction industry. Journal of Labor Research, 31, 20-38.

Kim, Y. Y. (Ed.). (1988). Communication and cross-cultural adaptation: an integrative theory. Clevedon, Philadelphia: Multilingual Matters.

Kinicki, A., \& Latack, J. (1990). Explication of the construct of coping with involuntary job loss. Journal of Vocational Behavior, 36, 339-360.

Kirmayer, L. (2007). Psychotherapy and the cultural concept of the person. Thranscultural Psychiatry, 44(2), 232-257.

Kirschenbaum, A., \& Weisberg, J. (1994). Job search, intentions, and turnover: the mismatched trilogy. Journal of Vocational Behavior, 44, 17-31.

Klimidis, S., Stuart, G., Minas, I., \& Ata, A. (1994). Immigrants status and gender effects on psychopathology and self-concept in adolescents: a test of migration-mobility hypothesis. Comprehensive Psychiatry, 35(5), 393-404.

Kline, R. B. (2005). Principles and practice of structural equation modeling. New York: Guilford.

Kling, K., Hyde, J., Showers, C., \& Buswell, B. (1999). Gender differences in self-esteem: a meta-analysis. Psychological Bulletin, 125(4), 470-500.

Knaus, W. J. (2000). Procrastination, blame, and change. Journal of Social Behavior and Personality 15, 153-166.

Knee, C. R., Patrick, H., Vietor, N. A., Nanayakkara, A., \& Neighbors, C. (2002). Selfdetermination as growth motivation in romantic relationships. Personality and Social Psychology Bulletin, 28, 609-619. 
Kohler, H., Behrman, J., \& Skytthe, A. (2005). Partner + children = happiness? The effects of partnership and fertility on well-being. Population and Development Review, 31(3), 407-445.

Kolb, B., \& Gibb, R. (2008). Principles of neuroplasticity and behavior. Cognitive neurorehabilitation: Evidence and application In D. Stuss, G. Winocur \& I. Robertson (Eds.), Cognitive neurorehabilitation: Evidence and application (pp. 6-21). New York: Cambridge University Press.

Kong, F., Perrucci, C., \& Perrucci, R. (1993). The impact of unemployment and economic stress on social support. Community Mental Health Journal, 29(3), 205-221.

Korman, A. K. (1966). Self-esteem variable in vocational choice. Journal of Applied Psychology, 50, 479-486.

Korman, A. K. (1967). Self-esteem as a moderator of the relationship between self-perceived abilities and vocational choice. Journal of Applied Psychology, 51(1), 65-67.

Korman, A. K. (1977). Organizational behaviour.

Krausz, M. (2002). The many faces of voluntary employee turnover, A multifacet and multilevel perspective. In M. Koslowsky \& M. Krausz (Eds.), Voluntary employee withdrawal and inattendance. A current perspective.: Kluwer Academic.

Krausz, M., Sagie, A., \& Bidermann, Y. (2000). Actual and preferred work schedules and scheduling control as determinants of job-related attitudes. Journal of Vocational Behavior, 56, 1-11.

Kreger, P. (1995). Self-esteem, stress, depression among graduate students. Psychology Reports, 76(1), 345-346.

Kwak, C., \& Clayton-Matthews, A. (2002). Multinominal logistic regression. Nursing Research, 51(6), 404-410.

Kwang, T., Crockett, E., Sanchez, D., \& Swann, W. (2013). Men seek social standing, women seek companionship: sex differences in deriving self-worth from relationships. Psychological Science, 24 (7), 1142-1150.

Kwang, T., \& Swann, W. (2010). Do people embrase praise even when they feel unworthy? A review of critical tests of self-enhancement versus self-verification. Personality and Social Psychology Bulletin, 14, 263-280.

Lane, R. (1993). The market experience.: Cambridge University Press.

Langford, J., \& Clance, P. (1993). The impostor phenomenon: recent research findings regarding dynamics, personality and family patterns and their implications for treatment. Psychotherapy, 30/Fall(3), 1-8.

Lawrence, D. (1981). The development of self-esteem questionnaire. British Journal of Educational Psychology, 51(2), 245-251.

Lay, C. (1987). A modal profile analysis of procrastinators: a search for types. Personality and Individual Differences, 8, 705-714.

Lazarus, R. S., \& Folkman, S. (1984). Stress, appraisal, and coping. NY: Springer Publishing Company.

Leary, M. (2006). What are the most pressing issues facing researchers? In M. Kernis (Ed.), Self-esteem. Issues and answers. A sourcebook of current perspectives. New Yourk and Hove: Psychology Press.

Leary, M., \& Downs, D. (1995). Interpersonal functions of self-esteem motive. The selfesteem system as a sociometer. In M. Kernis (Ed.), Efficacy, agency, and self-esteem (pp. 123-144). NY: Plenum Press.

Leary, M., Tambor, E., Tendal, S., \& Downs, D. (1995). Self-Esteem as an interpersonal monitor: the sociometer hypothesis. Jounal of Personality and Social Psychology, 68(3), 518-530.

Leary, M., \& Tangney, J. (2003). Handbook of self and identity.: The Guilford Press. 
Leary, M., Tate, E., Adams, C., Allen, A., \& Hancock, J. (2007). Self-compassion and reactions to unpleasant self-relevant events: the implications of treating oneself kindly. Journal of Personality and Social Psychology, 92(5), 887-904.

Lecky, P. (1969). Self-consistency. A theory of personality. Garden City, New York: Doubleday \& Company, Inc.

LeDoux, J. (1998). The emotional brain. London: Weidenfeld \& Nicolson.

Lee, T., Sablinski, C., Burton, J., \& Holtom, B. (2004). The effects of job embeddedness on organizational citizenship, job performance, volitional absences, and voluntary turnover. Academy of Management Journal, 47(5), 711-722.

Lee, W. T., \& Mitchell, R. T. (1994). An alternative approach: the unfolding model of voluntary employee turnover. The Academy of Management Review, 19(1), 51-89.

Lerner, D., Adler, D., Chang, H., Lapitsky, L., Hood, M., Perissinotto, C., . . Rogers, W. (2004). Unemployment, job retention, and productivity loss among employees with depression. Psychiatric Services, 55(12), 1371-1378.

Leung, A. (2008). The big five career theories. In J. A. Athanasou \& R. Van Esbroeck (Eds.), International Handbook of Career Guidance (pp. 115-132): Springer Science + Business Media B.V.

Levy, P., \& Baumgardner, A. (1991). Effects of self-esteem and gender on goal choice. Journal of Organizational Behavior, 12, 529-541.

Lewis, G., \& Sloggett, A. (1998). Suicide, deprivation, and unemployment: record linkage study. British Medical Journal, 317, 1283-1286.

Lichter, D. T. (1983). Socio-economic returns to migration among married women. Social Forces, 62(2), 487-503.

Locke, E. A., \& Latham, G. P. (1990). Work motivation and satisfaction: light at the end of the tunnel. Psychological Science, 1, 240-246.

Locke, E. A., McClear, K., \& Knight, D. (1996). Self-esteem and work. Internaltional Review of Industrial and Organizational Psychology, 11, 1-33.

London, M. (1996). Redeployment and continuous learning in the 21st century: hard lessons and positive examples from the downsizing era. Academy of Management Executive, 10, 67-79.

Long, J. (1997). Regression Models for categorical and limited dependent variables.: SAGE Publications.

Longmore, M. A., Manning, W. D., Giordano, P. C., \& Rudolph, J. L. (2004). Self-esteem, depressive symptoms, and adolescents' sexual onset. . Social Psychological Quarterly, 67(3), 279-295.

Luoma, J., Hayes, S., \& Walser, R. (2007). Learning ACT. An acceptance \& commitment therapy skills-training manual for therapists. Oakland: New Harbinger Publications, Inc.

MacCallum, R., Roznowski, M., \& Necowitz, L. (1992). Model modifications in covariance structure analysis: the problem of capitalization on chance. Psychological Bulletin, 111(3), 490-504.

MacGregor, J. C. D., \& Holmes, J. G. (2011). Rain on my parade: perceiving low self-esteem in close others hinders positive self-disclosure. Social Psychological and Personality Science, 2, 523-530.

Madrian, C. B. (1994). Employment-based health insurance and job mobility: is there evidence of job-lock? The Quarterly Journal of Economics, 109(1), 27-54.

Maertz, C., \& Griffeth, R. (2004). Eight motivational forces and voluntary turnover: a theoretical synthesis with implications for research. Journal of Management, 30(5), 667-683. 
Magnus, C., Kowalski, K., \& McHugh, T. (2010). The role of selfcompassion in women's self-determined motives to exercise and exercise-related outcomes. Self and Identity, 9, 363-382.

March, J., \& Simon, H. (1958). Organizations.: John Wiley \& Sons, Inc.

Markowe, M., \& Barber, L. (1953). Mental health in relation to the labour turnover of unskilled workers in a large industrial establishment. British Journal of Social and Preventive Medicine, 7, 205-210.

Mars, G., \& Lautenbach, H. (2013). More than half a million people have two jobs, from http://www.cbs.nl/en-GB/menu/themas/arbeid-socialezekerheid/publicaties/artikelen/archief/2013/2013-4002-wm.htm

Martin, B., \& Murberger, M. (1994). Effects of self-esteem and assigned goals on actual and perceived performance. Journal of Social Behavior and Personality, 9(1), 81-87.

Martin, J. E., \& Sinclair, R. R. (2007). A typology of the part-time workforce: differences on job attitudes and turnover. Journal of Occupational and Organizational Psychology 80, 301-319.

Martin, T., \& Schermerhorn, J. (1983). Work and nonwork influences on health: a research agenda using inability to leave as a critical variable. Academy of Management Review, 8(4), 650-659.

Maydell-Stevens, E., Masgoret, A., \& Ward, T. (2007). Problems of psychological and sociocultural adaptation among Russian-speaking immigrants in New Zealand. Social Policy Journal of New Zealand, March.

Mayo, E. (1993). The human problems of industrial civilization. NY: Macmillan.

McFadyen, R., \& Thomas, J. (1997). Economic and psychological models of job search behavior of the unemployed. Human Relations, 50(12), 1461-1484.

McGee, R., Williams, S., \& Nada-Raja, N. (2001). Low self-esteem and hopelessness in childhood and suicidal ideation in early adulthood. Journal of Abnormal Child Psychology, 29(4), 281-291.

McGraty, R., Atkinson, M., Tiller, W., Glein, R., \& Warkins, A. (1995). The effects of emotion on short-term power spectrum analysis of heat-rate variability. The American Journal of Cadiology, 76(15), 1089-1092.

McGraty, R., Atkinson, M., \& Tomasino, D. (2003). Impact of a workplace Stress reduction program on blood pressure and emotional health in hypertensive epmployees. The Journal of Alternative and Complimentary Medicine, 9(3), 355-369.

McGregor, I., \& Marigold, D. (2003). Defensive zeal and the uncertain self: what makes you so sure? Journal of Personality and Social Psychology, 85(5), 838-852.

McKee-Ryan, F. M., Song, Z., Wanberg, C. R., \& Kinicki, A. J. (2005). Psychological and physical well-being during unemployment : a meta-analytic study. Journal of Applied Psychology, 90(1), 53-76.

McKenna, C. (1996). Education and the distribution of unemployment. European Journal of Political Economy, 12, 113-132.

McLeod, J. (Ed.). (2001). Qualitative reseach in counselling and psychotherapy: SAGE.

Mecca, A., Smelser, N., \& Vasconcellos, J. (1989). The social importance of self-esteem.: University of California Press.

Meng, R. (1990). The relationship between unions and job satisfaction. Applied Economics, $22,1635-1648$.

Metcalfe, J., \& Mischel, W. (1999). A hot/cool system analysis of delay of gratification: dynamics of willpower. Psychological Review, 106, 1-17.

Meyer, J., \& Allen, N. (1991). A three-component conceptualization of organizational commitment. Human Resource Management Review, 1, 64-98. 
Milgram, N., Gehrman, T., \& Keinan, G. (1992). Situational and personal determinants of academic procrastination. Journal of General Psychology, 11, 123-133.

Miller, H., \& Rosse, J. (2002). Emotional reserve and adaptation to job dissatisfaction. In J. Brett \& F. Drasgow (Eds.), The psychology of work. Theoretically based empirical research. (pp. 205-231). Mahwah, New Jersey, London: Lawrence Erlbaum Associates.

Miller, M., \& Hoppe, S. (1994). Attributions for job termination and psychological distress. Human Relations, 47(3), 307-327.

Mincer, J. (1991). Education and unemployment (pp. 1-34): NBER WORKING PAPERS SERIES.

Mitchell, C. (2001). Attributions of responsibility for problem cause and problem solution: their relation to self-esteem. The Journal of Psychology, 122(5), 511-518.

Mitchell, R. T., Holtom, B. C., Lee, W. T., Sablynski, J. C., \& Erez, M. (2001). Why people stay: using job embeddedness to predict voluntary turnover. Academy of Management Journal, 44(6), 1102-1121.

Mitchell, R. T., Holtom, B. C., Lee, W. T., Sablynski, J. C., \& Erez, M. (in press). Why people stay: using job embeddedness to predict voluntary turnover. Academy of Management Journal.

Mitchell, T., \& Lee, T. (2001). The unfolding model of voluntary turnover and job embeddedness: foundations for comprehesive theory of attachment. Research in Organizational Behavior, 23, 189-246.

Mobley, W. (1977). Intermediate linkages in the relationship between job satisfaction and employee turnover. Journal of Applied Psychology, 62(2), 237-240.

Mobley, W., Griffeth, R., Hand, H., \& Meglino, B. (1979). Review and conceptual analysis of the employee turnover process. Psychological Bulletin, 86(3), 493-522.

Moncheit, A., \& Cooper, P. (1994). Health insurance and job mobility: theory and evidence. Industrial and Labor Relations Review, 48(1), 68-85.

Muchinsky, P., \& Morrow, P. (1980). A multidisciplinary model of voluntary employee turnover. Journal of Vocational Behavior, 17, 263-290.

Mullahy, J., \& Sindelar, J. (1996). Employment, unemployment, and problem drinking. Journal of Health Economics, 15, 409-434.

Muller, G., \& Plug, E. (2006). Estimating the effect of personality on male-female earnings. Industrial and Labor Relations Review, 60(1), 3-22.

Murray, S. L., Holmes, J., MacDonald, G., \& Ellsworth, P. (1998). Through the looking glass darkly? When self-doubts turn Into relationship insecurities. Journal of Personality and Social Psychology, 75(6), 1459-1480.

Murrell, A. J., Frieze, I. H., \& Olson, J. E. (1996). Mobility strategies and career outcomes: a longitudinal study of MBAs Journal of Vocational Behavior, 49, 324-335.

Nail, P., Misak, J., \& Davis, R. (2004). Self-affirmation versus self-consistency: a comparison of two competing self-theories of dissonance phenomena. Personality and individual differences, 36, 1893-1905.

Navare, S. (2008). Counseling at work place: a proactive human resource initiative. Indian Journal of Occupational and Environmental Medicine, 12(1), 1-2.

Near, J., Rice, R., \& Hunt, R. (1978). Work and extra-work correlates of life and job satisfaction. Academy of Management Journal, 21(2), 248-264.

Neff, K. (2003a). The development and validation of a scale to measure self-compassion. Self and Identity, 2, 223-250.

Neff, K. (2003b). Self-compassion: an alternative conceptualization of a healthy attitude toward oneself. Self and Identity, 2, 85-101. 
Neff, K., \& Beretvas, N. (2013). The role of self-compassion in romantic relationships. Self and Identity, 12(1), 78-98.

Neighbors, C., \& Knee, R. (2003). Self-determination and the consequences of social comparison. Journal of Reseach in Personality, 37, 529-546.

Nelson, A., \& LeRouge, C. (2001). Self esteem: moderator between role stress fit and satisfaction and commitment? Paper presented at the Proceedings of the 2001 ACM SIGCPR Conference on Computer personnel research.

Nezlek, J., \& Kuppens, P. (2008). Regulating positive and negative emotions in daily life. Journal of Personality, 76(3), 561-579.

Ng, D., \& Jeffery, R. (2003). Relationship between perceived stress and health behaviors in a sample of working adults. Health Psychology, 22(6), 638-642.

Nicoletti, C. (2006). Differences in job dissatisfaction across Europe. In I. W. Paper (Ed.): The Institute for Social and Economic Research (ISER).

Niemiec, C., Ryan, R., \& Brown, K. (2006). The role of awareness and autonomy in quieting the ego: a self-determination theory perspective. In H. Wayment \& J. Bauer (Eds.), Transcending self-interest. psychological explorations of the quiet ego (pp. 107-116). Washington: American Psychological Association.

O'Donoghue, T., \& Rabin, M. (1998). Procrastination in preparing for retirement. Retrieved 15.03., 2007

Olaniran, B. A. (1996). Social skills acquisition: a closer look at foreign students on college campuses and factors influencing their level of social difficulty in social situations. . Communication Studies, 22, 72-88.

Orth, U., Robins, R. W., \& Widaman, K. F. (2012). Life-span development of self-esteem and its effects on important life outcomes. Journal of Personality and Social Psychology, $102,1271-1288$.

Oshagbemi, T. (1999). Overall job satisfaction: how good are single versus multiple-item measures? Journal of Managerial Psychology 14(5), 388-403.

Osward, A., \& Gardner, J. (Writers). (2001). What has been happening to job satisfaction in Britain?

Owens, T., Stryker, S., \& Goodman, N. (2001). Extending self-esteem theory and research. Sociological and psychological currents.: Cambridge University Press.

Oyler, J. (2007). Core self-evaluations and job satisfaction: the role of organizational and community embeddedness. The Faculty of Virginia Polytechnic Institute and State University.

Parker, S., Chmiel, N., \& Wall, T. (1997). Work characteristics and employee well-being within context of strategic downsizing. Journal of Occupational Health Psychology, 2(4).

Parkes, R. (1994). Personality and coping as moderators of work stress processes: models, methods and measures. Work and Stress, 8(2), 110-129.

Patton, M. Q. (Ed.). (2001). Qualitative evaluation and research methods. Thousand Oaks, CA: Sage Publications.

Pearlin, L., Lieberman, M., Menaghan, E., \& Mullan, J. (1981). The stress process. Journal of Health and Social Behavior, 22, 337-356.

Pelham, B., Koole, S., Hardin, C., Hetts, J., Seah, E., \& DeHart, T. (2005). Gender moderates the relationship between implicit and explicit self-esteem. Journal of Experimental Social Psychology, 41, 84-89.

Pelham, B., \& Swann, W. (1989). From self-conceptions to self-worth: on the sources and structure of global self-esteem. Journal of Personality and Social Psychology, 57(4), 672-680.

Pervin, L. A. (1975). Personality: theory, assessment \& research. New York: Wiley. 
Peseschkian, N. (1987). Positive Psychotherapy. Theory and practice of a new method. Berlin Heidelberg New York Tokyo: Spring-Verlag.

Peseschkian, N., Biland, F., \& Cope, T. (2010). Symptom, conflict and conflict-resolution: The application of five stages of Positive Psychotherapy in first interview and therapy. International Journal of Psychotherapy 39-49.

Peseschkian, N., \& Deidenbach, H. (1988). Wiesbadener inventar zur positiven psychotherapie und familietherapie (WIPPF). Berlin, Heidelberg, New York: Springer.

Peterson, C., Maier, S., \& Seligman, M. (1993). Learned helplessness. A theory for the age of personal control.: Oxford University Press.

Petty, M., McGee, G., \& Cavender, J. (1984). A meta-analysis of the relationships between individual job satisfaction and individual performance. The academy of management review, 9(4), 712-721.

Pitts, M. (2009). Identity and the role of expectations, stress, and talk in short-term student sojourner adjustment: An application of the integrative theory of

communication and cross-cultural adaptation. International Journal of Intercultural Relations, 33, 450-462.

Polek, E., Wöhrle, J., \& van Oudenhoven, J. (2010). The role of attachment styles, perceived discrimination, and cultural distance in adjustment of German and Eastern European immigrants in the Netherlands. Cross-Cultural Research, 44(1), 60-88.

Poropat, A. (2002). The relationship between attributional style, gender and the five-factor model of personality. Personality and individual differences, 33, 1185-1201.

Porter, L. W. S., R. M. (1973). Organizational work, and personal factors in employee turnover and absenteeism. Psychological Bulletin, 80, 151-176.

Postel-Vinay, F., \& Turon, H. (2005). The Public Pay Gap in Britain: Small Differences That (Don't?) Matter. No. 05/121.

Preti, A., \& Miotto, P. (1999). Suicide and unemployment in Italy. Journal of Epidemiology and Community health, 53(11), 694-701.

Pulakos, E., Arad, S., Donovan, M., \& Plamondon, K. (2000). Adaptability in the workplace: development of a taxomy of adaptive performance. Journal of Applied Psychology, $85(4), 612-624$.

Pyszczynski, T., Greenberg, J., Solomon, S., \& Arndt, J. (2004). Why do people need selfesteem? A theoretical and empirical review. Psychological Bulletin, 130(3), 435-468.

Raes, F., Pommier, E., Neff, K., \& Van Gucht, D. (2011). Construction and factorial validation of a short form of the self-compassion scale. Clinical Psychology and Psychotherapy, 18, 250-255.

Ralph, J., \& Mineka, S. (1998). Attributional style and self-esteem: the prediction of emotional distress following a midterm exam. Journal of Abnormal Psychology, 107(2), 203-215.

Ramesh, A. (2007). Replicating and extending job embeddedness across cultures: employee turnover in India and the United States. Dissertation. The University of Maryland.

Raphael, S., \& Winter-Ebmer, R. (1999). Identifying the effect of unemployment on crime. CEPR Discussion Papers, 2129.

Rawls, J. (1973). Theory of justice. Harvard: Belknap Press.

Rawson, D., Whitehead, G., \& Luthra, M. (1999). The challenges of counselling in a multucultural society. In S. Palmer \& P. Laungani (Eds.), Councelling in a multicultural society (pp. 6-33). Los Angeles, London, New Delhi, Singapore, Washington: SAGE.

Reardon, R., \& Lenz, J. (1999). Holland's theory and career assessment. Journal of Vocational Behavior, 55, 102-113 
Recktor, N., \& Roger, D. (1997). The stress buffering effects of self-esteem. Personality and Individual Differences, 23(5), 799-808.

Reitz, O., \& Anderson, M. (2011). An overview of job embeddedness. Journal of Professional Nursing, 27(5), 320-327.

Renfrey, G. (1992). Cognitive-behavior therapy and the native American client. Behavior Therapy, 23, 321-340.

Ribar, D. C. (2005). Transitions from welfare and the employment prospects of low-skill workers. Southern Economic Journal, 71(3), 514-533.

Robins, J., Hernan, M., \& Brumback, B. (2000). Marginal structural models and causal inference in epidemiology. Epidemiology, 11, 550-560.

Robins, R., Hendin, H., \& Trzesniewski, K. (2001). Measuring global self-esteem: construct validation of a single-item measure and the Rosenberg self-esteem scale. Personality and Social Psychology Bulletin, 27(2), 151-161.

Robins, R., Trzesniewski, K., Tracy, J., \& Gosling, S. (2002). Global self-esteem across the life span. Psychology and Aging, 17(3), 423-434.

Rogers, C. R. (1951). Client-centered therapy: it's current practice, implications and theory. Boston: Houghton Mifflin.

Roland, A. (2006). Across civilizations: psychoanalytic therapy with Asians and Asians Americans. Psychotherapy: theory, research, practice, training., 43(4).

Rosenberg, M. (1979). The nature of self-esteem. Conceiving the self. (pp. 1-51). Malabar, Florida: Krieger Publishing Company.

Rosenberg, M., Schooler, C., Schoenbach, C., \& Rosenberg, F. (1989). Global self-esteem and specific self-esteem: different concepts, different outcomes. American Sociological Review, 60, 141-156.

Rosenberg, M., \& Turner, R. (Eds.). (1990). Social psychology. Sociological perspectives.: Transaction Pub.

Rosenthal, N. H. (1995). The nature of occupational employment growth: 1983-1993. Monthly Labor Review, 118(45-54).

Ross, C., \& Broh, B. (2000). The roles of self-esteem and the sense of personal control in the academic achievement process. Sociology of Education, 73(73), 270-284.

Rosse, J., Boss, R., \& Johnson, A. (1991). Conceptualizing the role of self-esteem in the burnout process. Group and Organization Studies, 16(4), 428-451.

Rosse, J., \& Hulin, C. (1985). Adaptation to work: an analysis of employee health, withdrawal and change. Organizational Behavior and Human Decision Processes 36(4), 324-347.

Rosse, J., \& Miller, H. (1984). An adaptation cycle interpretation of absence and withdrawal. In P. Goodman \& R. Atkin (Eds.), Absenteeism: New approaches to understanding, measuring and managing employee absence. San Francisco: Jossey-Bass.

Rosse, J., \& Miller, H. (2000). Toward a comprehensive model of the employee adaptation. Paper presented at the Annual meeting of the Western decision Sciences Institute, Maui, Hawaii.

Rosse, J., \& Noel, T. (1996). Leaving the organization. In R. K. Murphy (Ed.), Individual differences and behavior in organizations. (pp. 451-504). San Francisco: Jossey-Bass Publishers.

Rosse, J., \& Saturay, S. (2004). Individual differences in adaptation to work dissatisfaction. Paper presented at the Meeting of the Western Academy of Management, April 1-4, Anchorage, Alaska.

Royalty, A. (1998). Job-to-job and job-to-nonemployment turnover by gender and education level. Journal of Labor Economics, 16(2), 392-443. 
Rudman, L., \& Glick, P. (2001). Prescriptive gender stereotypes and backlash toward agentic women. Journal of Social Issues, 77, 1004-1010.

Ryan, R. M., \& Brown, K. (2003). Why we don't need self-esteem: on fundamental needs, contingent love, and mindfulness. Psychological Inquiry, 14(1), 27-82.

Sablynski, C., Lee, T., Mitchell, T., Burton, J., \& Holtom, B. (2002). Turnover: an integration of Lee and Mitchell's unfolding model and jib embeddedness construct with Hulin's withdrawal construct. In J. Brett \& F. Drasgow (Eds.), The psychology of work. Theoretically based empirical research. (pp. 189-203). Mahwah, New Jersey, London: Lawrence Erlbaum Associates Publishers.

Sadker, M., \& Sadker, D. (1994). Failing at fairness: how our schools cheat girls. New York: Touchstone.

Saka, N., \& Gati, I. (2007). Emotional and personality-related aspects of persistent career decision-making difficulties. Journal of Vocational Behavior, 71, 340-358.

Salmela-Aro, K., \& Nurmi, J. (2007). Self-esteem during university studies predicts career characteristics 10 years later. Journal of Vocational Behavior, 70, 463-477.

Sanchez, D., \& Crocker, J. (2005). How investment in gender ideals affects well-being: the role of external contingencies of self-worth. Psychology of Women Quarterly, 29, 6377.

Sanville, J. (2000). Intracultural and intercultural dialogue in psychoanalytic psychotherapy and psychoanalysis. Clinical Social Work Journal, 28(4), 417-429.

Schaufeli, W. (1988). Unemployment and psychological health., Rijksuniversiteit, Groningen.

Schermelleh-Engel, K., Moosbrugger, H., \& Müller, H. (2003). Evaluating the fit of structural equation models: tests of significance and descriptive goodness-of-fit measures Methods of Psychological Research Online 8(2), 23-74.

Schmit, M. J., Amel, E. L., \& Ryan, A. M. (1993). Self-reported assertive job-seeking behaviors of minimaly educated job hunters. Personnel Psychology, 46, 105-124.

Schneider, B. (1987). The people make the place. Personnel Psychology, 40, 437-453.

Schouwenburg, H. (1992). Procrastinators and fear of failure: a exploration of reasons for procrastination. European Journal of Personality, 6, 225-236.

Schram, J. L., \& Lauver, P. J. (1988). Alienation in international students. Journal of College Student Development, 29(2), 146-150.

Schreiber, J., Stage, F., King, J., Nora, A., \& Barlow, E. (2006). Reporting Structural Equation Modeling and Confirmatory Factor Analysis Results: a review. The Journal of Educational Research, 99(6), 323-337.

Schwartz, B., Ward, A., Monterosso, J., Lyubomirsky, S., White, K., \& Lehman, D. (2002). Maximazing versus satisficing: happiness ia matter of choice. Journal of personality and social psychology, 83(5), 1178-1197.

Schwartz, C. H., \& Boehnke, K. (2004). Evaluating the structure of human values with confirmatory factor analysis. Journal of Reseach in Personality, 38, 230-255.

Schweitzer, R., Seth-Smith, M., \& Callan, V. (1992). The relationship between self-esteem and psychological adjustment in young adolescents. . Journal of Adolescence, 15, 8397.

Seeley, K. (January 2004). Short-term intercultural psychotherapy: ethnographic inquiry. Social Work, 49(1), 121-130.

Seigley, L. (1999). Self-esteem and health behavior: theoretic and empirical links. Nursing Outlook, 47(2), 74-77.

Sekiguchi, T., Burton, J., \& Sablinski, C. (2008). The role of job embeddedness on employee performance: the interactive effects with leader-member exchange and organizationbased self-esteem. Personnel Psychology, 61, 761-792. 
Seligman, M. (1975). Helplessness: on depression, development and death. San Francisco: W. H. Freeman.

Selye, H. (1946). The general adaptation syndrome and the diseases of adaptation. Journal of Clinical Endocrinology, 6, 117-231.

Selye, H. (1956). The stress of life. NY: McGraw-Hill.

Senecal, C., \& Guay, F. (2000). Procrastination in job-seeking: an analysis of motivational processes and feelings of hopelessness. Journal of Social Behavior and Personality, $15(5), 267-282$.

Shackelford, T. (2001). Self-esteem in marriage. Personality and Individual Differences, 30, 371-390.

Shamir, B. (1986). Self-esteem and the psychological impact of unemployment. Social Psychology Quarterly, 49, 61-72.

Sheldon, K., \& Deci, E. (1993). The Self-Determination Scale., University of Rochester, Rochester.

Sheldon, K., Elliot, A., Kim, Y., \& Kasser, T. (2001). What is satisfying about satisfying events? Testing 10 candidate psychological needs. Journal of Personality and Social Psychology, 80(2), 325-339.

Sheldon, K., Turban, D., Brown, K., Barrick, M., \& Judge, T. (2003). Applying selfdetermination theory to organizational research. Research in Personnel and Human Resources Management, 22, 357-393.

Shrauger, J., \& Rosenberg, S. (1970). Self-esteem and the effects of success and failure feedback on performance. Journal of Personality, 33, 404-414.

Simpson, W. (1992). Urban structure and the labour market: worker mobility, commuting and underemployment in cities. Oxford: Clarendon Press.

Sinclair, R. R., Martin, J. E., \& Michel, R. P. (1999). Full-time and part-time subgroup differences in job attitudes and demographic characteristics. Journal of Vocational Behavior 55, 337-357.

Singer, J., \& Willett, J. (2003). Applied longitudinal data analysis. Modeling change and event occurrence.: Oxford University Press.

Singer, T., \& Bolz, M. (2013). Compassion. Bridging practice and science. Munich: Max Planck Society.

Singer, T., \& Steinbeis, N. (2009). Differential roles of fairness- and compassion-based motivations for cooperation, defection, and punishment. Annals of the New York Academy of Sciences, 1167, 41-50.

Singh, P., Finn, D., \& Goulet, L. (2004). Gender and job attitudes: a re-examination and extension. Women in Management Review, 19(7), 345-355.

Sirois, F. (2004). Procrastination and intentions to perform health behaviors: the role of selfefficacy and the consideration of future consequences. Personality and individual differences, 37, 115-128.

Sirois, F., Melia-Gordon, M., \& Pychyl, T. (2003). "I'll look after my health, later": an investigation of procrastination and health. Personality and individual differences, 35, 1167-1184.

Sobre-Denton, M., \& Hart, D. (2008). Mind the gap: Application-based analysis of cultural adjustment models. International Journal of Intercultural Relations, 32, 538-552.

Societal and economic effects on quality of life and well-being: preference identification and priority setting in response to changes in labour market status. (2006) (pp. 82). University of Aberdeen, Scotland: Centre for European Labour Market Research

Sorensen, M. (1998). Breaking the chain of low self-esteem. Sherwood: Wolf Publishing Co. Sorensen, M. (2001). Low self-esteem. Misunderstood and misdiagnosed. Sterwood: Wolf Publishing Co. 
Sousa-Poza, A. (2000). Well-being at work: a cross-national analysis of the levels and determinants of job satisfaction. The Journal of Socio-Economics, 29, 517-538.

Southall, D., \& Roberts, J. (2002). Attributional style and self-esteem in vulnerability to adolescent depressive symptoms following life stress: a 14-week perspective study. Cognitive Therapy and Research, 25(5), 563-579.

Spector, P. E. (1997). Job satisfaction. Application, assessment, causes, and consequences.: SAGE Publications.

Steel, R., \& Lounsbury, J. (2009a). Turnover process models: review and synthesis of a conceptual literature. Human Resource Management Review, 19, 271-282.

Steel, R. P., \& Lounsbury, J. W. (2009b). Turnover process models: review and synthesis of a conceptual literature. Human Resource Management Review, 19(4), 271-282. doi: doi: 10.1016/j.hrmr.2009.04.002

Steers, R., \& Mowday, R. (1981). Employee turnover and postdecision accomodation processes. In B. Staw \& L. Cummings (Eds.), Research in organizational behavior. Greenwich: JAI Press.

Steward, A., \& McDermott, C. (2004). Gender in psychology. Annual Review of Psychology, $55,519-544$.

Stroupe, K., Kinney, E., \& Kniesner, T. (2000). Chronic illness and health insurance-related job lock. Journal of Policy Analysis and Management, 20(3), 525-544.

Sullivan, S. E. (1999). The changing nature of careers: a review and research agenda. Journal of Management, 25, 457-484.

Swann, W. (1983). Self-verification: bringing social reality into harmony with the self. In J. Suls \& A. Greenwald (Eds.), Social psychological perspectives on the self (Vol. 2, pp. 33-66). Hillsdale: Erlbaum.

Tafarodi, R., Marshall, T., \& Milne, A. (2003). Self-esteem and memory. Journal of Personality and Social Psychology, 84(1), 29-45.

Tang, T. L. P., \& Gilbert, P. R. (1994). Organization-Based Self-Esteem among MentalHealth Workers - a Replication and Extension. Public Personnel Management, 23(1), 127-134.

Tanova, C., \& Holtom, B. (2008). Using job embeddedness factors to explain voluntary turnover in four European countries. The International Journal of Human Resource Management, 19(9), 1553-1568.

Tansel, A., \& Taşçi, M. (March 2010). Hazard analysis of unemployment duration by gender in a developing country: the case of Turkey. Paper presented at the Discussion Paper Series.

Taris, T. (2002). Unemployment and mental health: a longitudinal perspective. International Journal of Stress Management, 9(1), 43-57.

Taylor, M. F., Brice, J., Buck, N., \& Prentice-Lane, E. (2010). British Household Panel Survey User manual., from http://www.iser.essex.ac.uk/bhps/documentation/pdf_versions/volumes/bhpsvola.pdf

Thompson, S., Foubister, T., \& Mossialos, E. (2009). Financing health care in the European Union. Challenges and policy responses Observatory Study Series N 17.

Tice, D., \& Baumeister, R. (1997). Longitudinal study of procrastination, performance, stress, and health: the costs and benefits of dawdling Psychological Science, 8(6), 454-458.

Topel, R., \& Ward, M. (1992). Job Mobility and the Careers of Young Men. The Quarterly Journal of Economics, 107(2), 439-479.

Torneke, N. (2010). Learning RFT. An introduction to Relational Frame Theory and its clinical application. Oakland: Context Press. 
Triandis, H. (2002). Motivation to work in cross-cultural perspective. In J. Brett \& F. Drasgow (Eds.), The psychology of work. Theoretically based empirical research (pp. 101-117). Mahwah, New Jersey, London: Lawrence Erlbaum Associates.

Trice, A. (2004). Mix it up: international graduate students' social interactions with American students. Journal of College Student Development, 45(6), 671-687.

Tritt, K., Loew, T., Meyer, M., Werner, B., \& Peseschkian, N. (1999a). Positive psychotherapy: effectiveness of an interdisciplinary approach. The European Journal of Psychiatry, 13(4), 231-241.

Tritt, K., Loew, T., Meyer, M., Werner, B., \& Peseschkian, N. (1999b). Positive psychotherapy: effectiveness of an interdisciplinary approach. The European Journal of Psychiatry, 13(4), 231-241.

Trzesniewski, K., Moffitt, T., Donnellan, M., Robins, R., Poulton, R., \& Caspi, A. (2006). Low self-esteem during adolescence predicts poor health, criminal behavior, and limited economic prospects during adulthood. Developmental Psychology, 42(2), 381390.

Trzesniewski, K., Robins, R., Roberts, B., \& Caspi, A. (2003). Personality and self-esteem development across the life span. Advances in Cell Aging and Gerontology, 15, 163185.

Tseng, W. (1999). Culture and psychotherapy: review and practical guidelines. Transcultural Psychiatry, 36(2), 131-179

Tsipouri, L. (2005). Flexibility and competitiveness: labour market flexibility, innovation and organisational performance (FLEX-COM) (pp. 121). EU Research on social sciences and humanities: European Commission.

Turban, D., \& Keon, T. (1993). Organizational attractiveness: an interactionist perspective. Journal of Applied Psychology, 78(2), 184-193.

Tversky, A., \& Kahneman, D. (1981). The framing of decision and the psychology of choice. Science, 211(4481), 453-458.

Udechukwu, I., \& Mujtaba, B. (2007). Determining the probability that an employee will stay or leave the organization: a mathematical and theoretical model for organizations Human Resource Development Review, 6(2), 164-184.

UK national statistics. (2012), from http://www.statistics.gov.uk/hub/index.html

Usanov, A., \& Chivot, E. (Cartographer). (2013). The European labor market and technology: employemnt, inequality, and productivity.

Van Eerde, W. (2000). Procratination: self-regulation in initiating aversive goals. Applied Psychology: An International Review, 49(3), 372-389.

Van Eerde, W. (2003a). A meta-analyitically derived nomological network of procrastination. Personality and individual differences, 35, 1401-1418.

Van Eerde, W. (2003b). Procrastination at work and time management training. The Journal of Psychology, 137(5), 421-434.

Van Ham, M. (2002). Job access, workplace mobility, and occupational achievement: Utrecht.

Van Hooft, E., Born, M., Taris, T., Van der Flier, H., \& Blonk, R. (2005). Bridging the gap between intentions and behavior: implementation intentions, action control, and procrastination. Journal of vocational behavior, 66.

Van Saane, N., Sluiter, J., Verbeek, H., \& Frings-Dresen, M. (2003). Reliability and validity of instruments measuring job satisfaction - a systematic review. Occupational Medicine, 53, 191-200.

Van Vianen, A., Feij, J., Krausz, M., \& Taris, R. (2003). Personality factors and adult attachment affect in job mobility. International Journal of Selection and Assessment, $11(4), 253-264$. 
Vasileva, K. (2010). Populations and social conditions. Eurostat Statistics in focus, 45.

Viinikainen, J., \& Kokko, K. (2012). Personality traits and unemployment: Evidence from longitudinal data. Journal of Economic Psychology, 33(6), 1204-1222.

Vonk, R., \& Smit, H. (2012). Optimal self-esteem is contingent: intrinsic versus extrinsic and upward versus downward contingencies. European Journal of Personality, 26, 182193.

Voss, K., Markiewicz, D., \& Doyle, A. B. (1999). Friendship, marriage, and self-esteem. Journal of Social and Personal Relationships, 16, 103 - 122.

Waddell, G. (2003). Fix your attitude: labor-market consequences of poor attitude and low self-esteem in youth.

Waddell, G. (2006). Labor-market consequences of poor attitude and low self-esteem in youth. Economic Inquiry, 44(1), 69-97.

Walitzer, K., \& Sher, K. (1996). A prospective study of self-esteem and alcohol use disorders in early adulthood: evidence for gender differences. Alcoholism: Clinical and Experimental Research, 20(6), 1118-1124.

Wang, N., Jome, L., Haase, R., \& Bruch, M. (2006). The role of personality and career decision-making self-efficacy in the career choice commitment of college students. Journal of Career Assessment, 14(3), 312-332.

Wanous, J., Reichers, A., \& Hudy, M. (1997). Overall job satisfaction: how good are singleitem measures? Journal of Applied Psychology, 82(2), 247-252.

Ward, C., Bochner, S., \& Furnham, A. (2001). The psychology of culture shock. Philadelphia: Routledge.

Warr, P. (1983). Work, jobs and unemployment. Bulletin of British Psychological Society, 36, 305-311.

Warr, P. (1987). Work: unemployment and mental health. Oxford: Oxford University Press.

Warr, P. (1989). Work, unemployment and mental health. Oxford: Clarendon Press.

Warr, P. (2002). Psychology at work.: Penguin Books.

Warters, L., \& Roach, D. (1973). Job attitudes as predictors of termination and absenteeism: consistency over time and across organizational units. Journal of Applied Psychology, 57(3), 341-342.

Waters, L., \& Moore, K. (2001). Coping with economic deprivation during unemployment. Journal of Economic Psychology, 22, 461-482.

Waters, L., \& Moore, K. (2002a). Predicting self-esteem during unemployment: the effect of gender, financial depriviation, alternate roles, and social support. Journal of Employment Counseling, 39, 171-189.

Waters, L., \& Moore, K. (2002b). Self-esteem, appraisal and coping: a comparison of unemployed and re-employed people. Journal of Organizational Behavior, 23, 593604.

Wayment, H., Bauer, J., \& Sylaska, K. (2014). The quiet ego scale: measuring the compassionate self-identity. Journal of Happiness Studies. doi: 10.1007/s10902-0149546-Z

Webb, T., \& Sheeran, P. (2006). Does changing behavioral intentions engender behavior change? A meta-analysis of the experimental evidence. Psychological Bulletin, 132(2), 249-268.

Weich, S., \& Lewis, G. (1998). Poverty, unemployment, and common mental disorders: population based cohort study. British Medical Journal, 317, 115-119.

Weiss, a. (1984). Determinants of quit behavior. Journal of Labor Economics, 2, 371-387.

Westaby, J. (2005a). Behavioral reasoning theory: identifying new linkages underlying intentions and behavior. Organizational Behavior and Human Decision Processes 98, 97-120. 
Westaby, J. (2005b). Behavioral reasoning theory: identifying new linkages underlying intentions and behavior. Organizational Behavior and Human Decision Processes, 98, 97-120.

Wilhelm, M., \& Ridley, C. (1988). Unemployment induced adaptations: relationships among economic responses and individual and marital well-being. Lifestyles: Family and Economic Issues., 9(1), 5-20.

Winefield, H., Goldney, R., Winefield, A., \& Tiggemann, M. (1989). The General Health Questionnaire: reliability and validity for Australian youth. The Australian and New Zealand Journal of Psychiatry, 23(1), 53-58.

Winefield, H., \& Tiggemann, M. (1990). Employment status and psychological well-being: a longitudinal study. Journal of Applied Psychology, 75, 455-459.

Woo, S., \& Allen, D. (2013). Toward an inductive theory of stayers and seekers in the organization. Journal of Business and Psychology. doi: doi:10.1007/s10869-013-9303$\mathrm{z}$

Wood, R., \& Bandura, A. (1989). Social Cognitive Theory of Organizational Management. Academy of Management Review, 14(3), 361-384.

Worell, J., \& Goodheart, C. (2006). Handbook of girls' and women's psychological health. Gender and well-being across the life span. New York: Oxford University Press.

Yamada, A., \& Singelis, T. (1999). Biculturalism andself-construal. International Journal of Intercultural Relations, 23, 697-710.

Yamaguchi, K. (1991). Event history analysis. Applied Social Research Methods Series, 28.

Yeatts, D., Folts, E., \& Knapp, J. (2000). Older workers' adaptation to a changing workplace: employment issues for the 21st century. Educational Gerontology, 26, 565-582.

Zeigler-Hill, V. (2012). The extended informational model of self-esteem. In S. De Wals \& K. Meszaros (Eds.), Handbook on psychology of self-esteem (pp. 211-226). New York: Hauppauge.

Zeigler-Hill, V. (2013). Self-esteem. East Sussex: Psychology Press.

Zeigler-Hill, V., Besser, A., \& King, K. (2011). Contingent self-Esteem and anticipated reactions to interpersonal rejection and achievement failure. Journal of Social and Clinical Psychology, 30(10), 1069-1096.

Zhang, M., Fried, D., \& Griffeth, R. (2012). A review of job embeddedness: conceptual, measurement issues, and directions for future research. Human Resource Management Review, 22, 220-231.

Zimberoff, D., \& Hartman, D. (2002). Attachment, detachment, nonattachment: achieving synthesis Journal of Heart-Centered Therapies, 5(1), 3-94.

Zlatanovic, L. (2000). The role of the person's self-concept in quality of life research. The Scientific Journal Facta Univesitatis, 2(7), 391-397. 


\section{Appendix}

Appendix A: Coding of the dummy variables used in the analysis in Chapter 3

Dummy variables

Dummy codes

$0 \quad 1$

Gender

Marital status

Health problems: anxiety, depression, etc.

Decisional procrastination

Self-worth

Private sector

Civil sector

Governmental sector

Fulltime contract

Employer pension scheme

On-job-training

Promotion opportunities

Member of the trade unions
Female

Separated; divorced; widowed; never married

No

More than usual; same as usual

Not at all; no more than

usual

No

No

Yes

No

Yes

No

Yes

No

Yes

No

Yes

No

Yes

No

Yes 
Appendix B: Job embeddedness questionnaire used in Chapter 4 (in Dutch)

1. Sinds wanneer bent $\mathrm{u}$ werkzaam in uw huidige baan?

2. Sinds wanneer werkt u voor deze organisatie?

3. Sinds wanneer werkt $u$ al binnen deze sector?

4. Met hoeveel collega's hebt u regelmatig contact?

5. Hoeveel medewerkers zijn sterk van u afhankelijk?

6. Van hoeveel werkteams maakt $\mathrm{u}$ deel uit?

7. Van hoeveel werkoverleggen maakt $\mathrm{u}$ deel uit?

8. Ik kan goed overweg met de mensen op mijn werk.

9. Mijn collega's lijken op mij.

10. Deze baan maakt goed gebruik van mijn vaardigheden en talenten.

11. Ik heb het gevoel dat ik geschikt ben voor deze organisatie.

12. Ik pas bij de cultuur van deze organisatie.

13. Ik houd van de autoriteit en de verantwoordelijkheid die ik heb bij deze organisatie.

14. Mijn waarden zijn verenigbaar met die van deze organisatie.

15. Ik kan mijn professionele doelen bereiken bij deze organisatie.

16. Ik voel me goed bij mijn professionele groei en ontwikkeling.

17. Ik heb veel vrijheid in mijn baan om te beslissen hoe ik mijn doelen nastreef.

18. De extraatjes die ik krijg op mijn werk zijn uitstekend.

19. Ik heb het gevoel dat de mensen op mijn werk mij erg respecteren.

20. Ik zou veel opofferen als ik deze baan zou verlaten.

21. Ik heb hier uitstekende kansen op promotie.

22. Ik word goed beloond voor mijn prestaties.

23. De secundaire arbeidsvoorwaarden van mijn baan zijn goed.

24. Mijn werkgever stimuleert mijn gezondheid.

25. De pensioenvoorziening van deze organisatie is uitstekend.

26. De vooruitzichten om bij deze organisatie te blijven werken zijn uitstekend.

27. Bent u momenteel getrouwd?

28. Als u getrouwd bent, werkt uw echtgeno(o)t(e) buitenshuis?

29. Bent $u$ de eigenaar van het huis waarin $u$ woont?

30. Mijn familiewortels liggen in deze gemeenschap.

31. Hoeveel van uw familieleden wonen dichtbij?

32. Hoeveel van uw goede vrienden wonen dichtbij?

33. Ik houd van de plaats waar ik woon.

34. De weersomstandigheden in mijn woonplaats zijn geschikt voor mij.

35. Deze gemeenschap past goed bij mij.

36. Ik denk aan de gemeenschap waarin ik leef als thuis.

37. Ik kan de vrijetijdsactiviteiten waarvan ik houd, uitoefenen in de omgeving waarin ik leef.

38. Het zou erg moeilijk zijn deze gemeenschap te verlaten.

39. Ik ontvang veel respect van de mensen uit mijn gemeenschap.

40. Mijn omgeving is veilig. 
Appendix C: Descriptives related to the analysis in Chapter 5

\begin{tabular}{|c|c|c|c|c|c|c|c|c|c|c|c|}
\hline 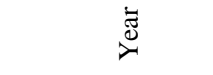 & $\bar{\sigma}$ & ๙ૅ & ڤે & گ̆ & ڤ & ஓ & $\hat{\sigma}$ & $\stackrel{\circ}{2}$ & ڤે & ¿্ণ & $\overline{\check{d}}$ \\
\hline \multicolumn{12}{|c|}{ Mean (SD) for continuous variables and $\mathrm{n}(\%)$ for dummy variables } \\
\hline Age & $44.42(18.46)$ & $43.93(18.45)$ & $43.83(18.39)$ & $43.82(18.43)$ & $44.02(18.48)$ & $43.71(18.46)$ & $44.70(18.74)$ & $44.97(18.74)$ & $45.28(18.68)$ & $45.19(18.60)$ & $45.35(18.58)$ \\
\hline \multirow{2}{*}{ Gender } & $5431(52.9 \%)$ & $5215(53 \%)$ & $5124(53.24 \%)$ & $5041(53.2 \%)$ & $4929(53.3 \%)$ & $5003(53 \%)$ & $5981(53.4 \%)$ & $5851(53.6 \%)$ & $8436(54 \%)$ & $8420(54 \%)$ & $10237(54.3 \%)$ \\
\hline & $4833(47.1 \%)$ & $4630(47 \%)$ & $4476(46.6 \%)$ & $4440(46.8 \%)$ & $4320(46.7 \%)$ & $4435(47 \%)$ & $5212(46.6 \%)$ & $5055(46.4 \%)$ & $7187(46 \%)$ & $7177(46 \%)$ & $8630(45.7 \%)$ \\
\hline \multirow{2}{*}{ High Education } & $3754(36.6 \%)$ & $3970(40.3 \%)$ & $4194(43.7 \%)$ & $4230(44.6 \%)$ & $4281(46.3 \%)$ & $4425(46.9 \%)$ & $5068(45.3 \%)$ & $5163(47.3 \%)$ & $7423(47.5 \%)$ & $7809(50 \%)$ & $9424(49.9 \%)$ \\
\hline & $6510(63.4 \%)$ & $5975(59.7 \%)$ & $5406(56.3 \%)$ & $5251(55.4 \%)$ & 4968 (53.7\%) & $5013(53.1 \%)$ & $6125(54.7 \%)$ & $5743(52.7 \%)$ & $8200(52.5 \%)$ & $77984(50 \%)$ & $9443(50.1 \%)$ \\
\hline \multirow{2}{*}{ In a partnership } & $4223(41.1 \%)$ & $4250(43.2 \%)$ & $4191(43.7 \%)$ & $4220(44.5 \%)$ & $4129(44.6 \%)$ & $4305(45.6 \%)$ & $5259(47 \%)$ & $5092(46.7 \%)$ & $7278(46.6 \%)$ & $7346(47.1 \%)$ & $8877(47.1 \%)$ \\
\hline & $6041(58.9 \%)$ & $5595(56.8 \%)$ & $5409(56.3 \%)$ & $5261(55.5 \%)$ & $5120(55.4 \%)$ & $5133(54.4 \%)$ & $5934(59 \%)$ & $5814(53.3 \%)$ & $8345(53.4 \%)$ & $8257(52.9 \%)$ & $9990(52.9 \%)$ \\
\hline \multirow{2}{*}{ Dependent child } & $9433(91.9 \%)$ & $9099(92.4 \%)$ & $8861(92.3 \%)$ & 8709 (91.9\%) & $8466(91.5 \%)$ & $8640(91.5 \%)$ & $10232(91.4 \%)$ & 9958 (91.3\%) & $14229(91.1 \%)$ & $14200(91 \%)$ & $17169(91 \%)$ \\
\hline & $832(8.1 \%)$ & $746(7.6 \%)$ & $739(7.7 \%)$ & $772(8.1 \%)$ & $783(8.5 \%)$ & $798(8.5 \%)$ & $961(8.6 \%)$ & $948(8.7 \%)$ & $1394(8.9 \%)$ & $1403(9 \%)$ & $1698(9 \%)$ \\
\hline \multirow{2}{*}{ Self-esteem } & $1170(11.4 \%)$ & $1193(12.1 \%)$ & $1290(13.4 \%)$ & $1146(12.1 \%)$ & $1202(13 \%)$ & $1098(11.6 \%)$ & $1414(12.6 \%)$ & $1276(11.7 \%)$ & $1933(12.4 \%)$ & $2028(13 \%)$ & $2722(14.4 \%)$ \\
\hline & $9094(88.6 \%)$ & $8652(87.9 \%)$ & $8310(86.6 \%)$ & $8335(87.9 \%)$ & $8047(87 \%)$ & $8340(88.4 \%)$ & $9779(87.4 \%)$ & $9630(88.3 \%)$ & $13690(87.6 \%)$ & $13575(87 \%)$ & $16145(85.6 \%)$ \\
\hline \multirow{2}{*}{$\begin{array}{l}\text { Heath problems: } \\
\text { due to alcohol or } \\
\text { drugs }\end{array}$} & $10222(99.6 \%)$ & $9812(99.7 \%)$ & $9563(99.6 \%)$ & $9449(99.7 \%)$ & $9207(95.5 \%)$ & $9401(99.6 \%)$ & $11128(99.4 \%)$ & $10854(95.5 \%)$ & $15557(99.6 \%)$ & $15536(95.5 \%)$ & $18763(99.4 \%)$ \\
\hline & $42(0.4 \%)$ & $33(0.3 \%)$ & $37(0.4 \%)$ & $32(0.3 \%)$ & $42(0.5 \%)$ & $37(0.4 \%)$ & $65(0.6 \%)$ & $52(0.5 \%)$ & $66(0.4 \%)$ & $67(0.5 \%)$ & $104(0.6 \%)$ \\
\hline \multirow{2}{*}{$\begin{array}{l}\text { Health problems: } \\
\text { depression }\end{array}$} & $9736(94.9 \%)$ & $9256(94 \%)$ & 9014 (93.9\%) & $8893(93.8 \%)$ & $8645(93.5 \%)$ & $8798(93.2 \%)$ & $10298(92 \%)$ & $10040(92.1 \%)$ & $14525(93 \%)$ & $14272(91.5 \%)$ & $17183(91.1 \%)$ \\
\hline & $528(5.1 \%)$ & $589(6 \%)$ & $586(6.1 \%)$ & $588(6.2 \%)$ & $604(6.5 \%)$ & $640(6.8 \%)$ & $895(8 \%)$ & $866(7.9 \%)$ & $1098(7 \%)$ & $1331(8.5 \%)$ & $1684(8.9 \%)$ \\
\hline
\end{tabular}




\begin{tabular}{|c|c|c|c|c|c|c|c|c|c|c|c|}
\hline 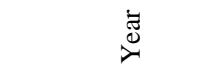 & $\bar{\sigma}$ & ऽ̆ & & ఫે & $\stackrel{2}{\sigma}$ & よ̆ & $\hat{\sigma}$ & $\stackrel{\infty}{\stackrel{\infty}{\sigma}}$ & $\stackrel{\partial}{\sigma}$ & ષ્ત & వ్రి \\
\hline \multicolumn{12}{|c|}{ Mean (SD) for continuous variables and $\mathrm{n}(\%)$ for dummy variables } \\
\hline \multirow{2}{*}{$\begin{array}{l}\text { Occupation: } \\
\text { manager }\end{array}$} & $9499(92.5 \%)$ & $9090(92.3 \%)$ & $8802(91.7 \%)$ & $8686(91.6 \%)$ & $8440(91.3 \%)$ & $8570(90.8 \%)$ & $10221(91.3 \%)$ & $9957(91.3 \%)$ & $14332(91.7 \%)$ & $14262(91.4 \%)$ & $17517(92.8 \%)$ \\
\hline & $765(7.5 \%)$ & $755(7.7 \%)$ & $798(8.3 \%)$ & 795 (8.4\%) & $809(8.7 \%)$ & $868(8.2 \%)$ & $972(8.7 \%)$ & $949(8.7 \%)$ & $1291(8.3 \%)$ & $1341(8.6 \%)$ & $1350(7.2 \%)$ \\
\hline \multirow{2}{*}{$\begin{array}{l}\text { Occupation: } \\
\text { professional }\end{array}$} & $9681(94.3 \%)$ & $9292(94.4 \%)$ & $9035(94.1 \%)$ & $8914(94 \%)$ & $8647(93.5 \%)$ & $8848(93.7 \%)$ & $10552(94.3 \%)$ & $10240(93.9 \%)$ & $14733(94.3 \%)$ & $14705(94.2 \%)$ & $17985(95.3 \%)$ \\
\hline & $583(5.7 \%)$ & $553(5.6 \%)$ & $565(5.9 \%)$ & $567(6 \%)$ & $602(6.5 \%)$ & $590(6.3 \%)$ & $641(5.7 \%)$ & $666(6.1 \%)$ & $890(5.7 \%)$ & $898(5.8 \%)$ & $882(4.7 \%)$ \\
\hline \multirow{2}{*}{$\begin{array}{l}\text { Occupation: } \\
\text { technicians and } \\
\text { associate } \\
\text { professionals }\end{array}$} & $9627(93.8 \%)$ & $9243(93.9 \%)$ & $8998(93.7 \%)$ & $8874(93.6 \%)$ & $8654(93.6 \%)$ & $8839(93.7 \%)$ & $10493(93.7 \%)$ & $10214(93.7 \%)$ & $14468(93.8 \%)$ & $14567(93.4 \%)$ & $17748(94.1 \%)$ \\
\hline & $637(6.2 \%)$ & $602(6.1 \%)$ & $602(6.3 \%)$ & $607(6.4 \%)$ & $595(6.4 \%)$ & $599(6.3 \%)$ & $700(6.3 \%)$ & $692(6.3 \%)$ & $975(6.2 \%)$ & $1036(6.6 \%)$ & $1119(5.9 \%)$ \\
\hline \multirow{2}{*}{$\begin{array}{l}\text { Occupation: } \\
\text { clerks }\end{array}$} & $9183(89.5 \%)$ & $8805(89.4 \%)$ & $8605(89.6 \%)$ & $8513(89.8 \%)$ & $8335(90.1 \%)$ & $8481(89.9 \%)$ & $10114(90.4 \%)$ & $9812(90 \%)$ & $14162(90.6 \%)$ & $14117(90.5 \%)$ & $17414(92.3 \%)$ \\
\hline & $1081(10.5 \%)$ & $1040(10.6 \%)$ & $995(10.4 \%)$ & $968(10.2 \%)$ & $914(9.9 \%)$ & $957(10.1 \%)$ & $1079(9.6 \%)$ & $1094(10 \%)$ & $1461(9.4 \%)$ & $1486(9.5 \%)$ & $1453(7.7 \%)$ \\
\hline \multirow{2}{*}{ Occupation: craft } & $9381(91.4 \%)$ & $9064(92.1 \%)$ & $8888(92.6 \%)$ & $8773(92.5 \%)$ & $8573(92.7 \%)$ & $8695(92.1 \%)$ & $10408(93 \%)$ & $10132(92.9 \%)$ & $14558(93.2 \%)$ & $14523(93.1 \%)$ & $17788(94.3 \%)$ \\
\hline & $883(8.6 \%)$ & $781(7.9 \%)$ & $712(7.4 \%)$ & $708(7.5 \%)$ & $676(7.3 \%)$ & $743(7.9 \%)$ & $785(7 \%)$ & $774(7.1 \%)$ & $1065(6.8 \%)$ & $1080(6.9 \%)$ & $1079(5.7 \%)$ \\
\hline \multirow{2}{*}{$\begin{array}{l}\text { Occupation: } \\
\text { person }\end{array}$} & $9658(94.1 \%)$ & $9226(93.7 \%)$ & $8980(93.5 \%)$ & $8868(93.5 \%)$ & $8635(93.4 \%)$ & $8774(93 \%)$ & $10393(92.9 \%)$ & $10139(93 \%)$ & $14529(93 \%)$ & $14538(93.2 \%)$ & $17795(94.3 \%)$ \\
\hline & $606(5.9 \%)$ & $619(6.3 \%)$ & $620(6.5 \%)$ & $613(6.5 \%)$ & $614(6.6 \%)$ & $664(7 \%)$ & $800(7.1 \%)$ & $767(7 \%)$ & $1094(7 \%)$ & $1065(6.8 \%)$ & $1072(5.7 \%)$ \\
\hline \multirow{2}{*}{ Occupation: sales } & $9808(95.6 \%)$ & $9379(95.3 \%)$ & $9170(95.5 \%)$ & $9010(95 \%)$ & $8792(95.1 \%)$ & $9005(95.4 \%)$ & $10671(95.3 \%)$ & $10357(95 \%)$ & $14891(95.3 \%)$ & $14842(95.1 \%)$ & $18081(95.8 \%)$ \\
\hline & $456(4.4 \%)$ & $466(4.7 \%)$ & $430(4.5 \%)$ & $471(5 \%)$ & $457(4.9 \%)$ & $433(4.6 \%)$ & $522(4.7 \%)$ & $549(5 \%)$ & $732(4.7 \%)$ & $761(4.9 \%)$ & $786(4.2 \%)$ \\
\hline \multirow{2}{*}{$\begin{array}{l}\text { Occupation: } \\
\text { operative }\end{array}$} & $9671(94.2 \%)$ & $9327(94.7 \%)$ & $9089(94.7 \%)$ & $8969(94.6 \%)$ & $8727(94.5 \%)$ & $8933(94.6 \%)$ & $10531(94.1 \%)$ & $10298(94.4 \%)$ & $14746(94.4 \%)$ & $14750(94.5 \%)$ & $18104(96 \%)$ \\
\hline & $593(5.8 \%)$ & $518(5.3 \%)$ & $511(5.3 \%)$ & $512(5.4 \%)$ & $512(5.5 \%)$ & $505(5.4 \%)$ & $662(5.9 \%)$ & $608(5.6 \%)$ & $877(5.6 \%)$ & $853(5.5 \%)$ & $763(4 \%)$ \\
\hline
\end{tabular}




\begin{tabular}{|c|c|c|c|c|c|c|c|c|c|c|c|}
\hline 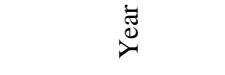 & $\bar{\sigma}$ & ऽે & 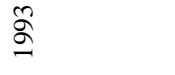 & 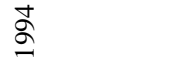 & $\stackrel{2}{\curvearrowright}$ & ڤั & $\hat{\sigma}$ & $\stackrel{\infty}{2}$ & ڤे & ¿্ণ & ¿্ণ \\
\hline \multicolumn{12}{|c|}{ Mean (SD) for continuous variables and $\mathrm{n}(\%)$ for dummy variables } \\
\hline \multirow{2}{*}{ Occupation: other } & $9717(94.7 \%)$ & $9376(95.2 \%)$ & $9117(95 \%)$ & $9014(95.1 \%)$ & $8811(95.3 \%)$ & $8998(95.3 \%)$ & $10640(95.1 \%)$ & $10343(94.8 \%)$ & $14768(94.5 \%)$ & $14845(95.1 \%)$ & $18067(95.8 \%)$ \\
\hline & $547(5.3 \%)$ & $469(4.8 \%)$ & $483(5 \%)$ & $467(4.9 \%)$ & $438(4.7 \%)$ & $440(4.7 \%)$ & $553(4.9 \%)$ & $563(5.2 \%)$ & $855(5.5 \%)$ & $758(4.9 \%)$ & $800(4.2 \%)$ \\
\hline \multirow{2}{*}{$\begin{array}{l}\text { Sector: } \\
\text { agriculture }\end{array}$} & $10142(98.8 \%)$ & $9745(99 \%)$ & $9494(98.9 \%)$ & $9368(98.8 \%)$ & $9149(99 \%)$ & $9340(99 \%)$ & $11086(99 \%)$ & $10776(98.8 \%)$ & $15408(98.6 \%)$ & $15403(98.7 \%)$ & $18686(99 \%)$ \\
\hline & $122(0.4 \%)$ & $100(1 \%)$ & $106(1.1 \%)$ & $113(1.2 \%)$ & $100(1 \%)$ & $98(1 \%)$ & $107(1 \%)$ & $130(1.2 \%)$ & $215(1.4 \%)$ & $200(1.3 \%)$ & $181(\%)$ \\
\hline \multirow{2}{*}{ Sector: energy } & $10128(98.7 \%)$ & $9727(98.8 \%)$ & $9500(99 \%)$ & 9398 (99.1\%) & $9179(99.2 \%)$ & 9327 (99\%) & $11109(99.2 \%)$ & $10827(99.3 \%)$ & $15470(99 \%)$ & $15460(99.1 \%)$ & $18734(99.3 \%)$ \\
\hline & $136(0.3 \%)$ & $118(1.2 \%)$ & $100(1 \%)$ & $83(0.9 \%)$ & $70(0.8 \%)$ & $111(1 \%)$ & $84(0.8 \%)$ & $79(0.7 \%)$ & $153(1 \%)$ & $143(0.9 \%)$ & $133(0.7 \%)$ \\
\hline \multirow{2}{*}{ Sector: mineral } & $10088(98.3 \%)$ & $9692(98.4 \%)$ & $9445(98.4 \%)$ & $9324(98.3 \%)$ & $9095(98.3 \%)$ & $9273(98.2 \%)$ & $11022(98.5 \%)$ & $10714(98.2 \%)$ & $15380(98.4 \%)$ & $15357(98.4 \%)$ & $18638(98.8 \%)$ \\
\hline & $176(1.7 \%)$ & $153(1.6 \%)$ & $155(1.6 \%)$ & $157(1.7 \%)$ & $154(1.7 \%)$ & $165(1.8 \%)$ & $171(1.5 \%)$ & $192(1.8 \%)$ & $243(1.6 \%)$ & $246(1.6 \%)$ & $229(1.2 \%)$ \\
\hline \multirow{2}{*}{ Sector: engineer } & $9665(94.2 \%)$ & $9324(94.7 \%)$ & $9127(95.1 \%)$ & $9024(95.2 \%)$ & $8671(93.7 \%)$ & $8926(94.6 \%)$ & $10713(95.7 \%)$ & $10369(95.1 \%)$ & $14965(95.8 \%)$ & $14929(95.7 \%)$ & $18174(96.3 \%)$ \\
\hline & $599(5.8 \%)$ & $521(5.3 \%)$ & $473(4.9 \%)$ & 457 (4.8\%) & $578(6.3 \%)$ & $512(5.4 \%)$ & $480(4.3 \%)$ & $537(4.9 \%)$ & $658(4.2 \%)$ & $674(4.3 \%)$ & $693(3.7 \%)$ \\
\hline \multirow{2}{*}{$\begin{array}{l}\text { Sector: } \\
\text { manufacture }\end{array}$} & $9666(94.2 \%)$ & $9312(94.6 \%)$ & $9073(94.5 \%)$ & $8992(94.8 \%)$ & $8793(95 \%)$ & $8852(93.8 \%)$ & $10672(95.3 \%)$ & $10347(94.9 \%)$ & $14887(95.2 \%)$ & $14861(95.2 \%)$ & $18202(96.5 \%)$ \\
\hline & $598(5.8 \%)$ & $533(5.4 \%)$ & $527(5.5 \%)$ & $489(5.2 \%)$ & $456(5 \%)$ & $586(6.2 \%)$ & $521(4.7 \%)$ & $559(5.1 \%)$ & $746(4.8 \%)$ & $742(4.8 \%)$ & $665(3.5 \%)$ \\
\hline \multirow{2}{*}{$\begin{array}{l}\text { Sector: } \\
\text { constructure }\end{array}$} & $9920(96.6 \%)$ & $9534(96.8 \%)$ & $9600(100 \%)$ & $9159(96.6 \%)$ & $9249(100 \%)$ & $9142(96.8 \%)$ & $10871(97.1 \%)$ & $10562(96.8 \%)$ & $15094(96.6 \%)$ & $15088(96.7 \%)$ & $18334(97.2 \%)$ \\
\hline & $598(3.4 \%)$ & $311(3.2 \%)$ & - & $322(3.4 \%)$ & - & $296(3.2 \%)$ & $322(2.9 \%)$ & $344(3.2 \%)$ & $529(3.4 \%)$ & $515(3.3 \%)$ & $533(2.8 \%)$ \\
\hline \multirow{2}{*}{$\begin{array}{l}\text { Sector: } \\
\text { distribution }\end{array}$} & $9072(88.4 \%)$ & $8645(87.8 \%)$ & $8409(87.6 \%)$ & $8194(86.4 \%)$ & $9235(99.8 \%)$ & $8435(89.4 \%)$ & $9925(88.7 \%)$ & $9460(86.7 \%)$ & $13701(87.7 \%)$ & $13727(88 \%)$ & $16979(90 \%)$ \\
\hline & $1192(11.6 \%)$ & $1200(12.2 \%)$ & $1191(12.4 \%)$ & $1287(13.6 \%)$ & $14(0.2 \%)$ & $1003(10.6 \%)$ & $1268(11.3 \%)$ & $1446(13.3 \%)$ & $1922(12.3 \%)$ & $1876(12 \%)$ & $1888(10 \%)$ \\
\hline
\end{tabular}




\begin{tabular}{|c|c|c|c|c|c|c|c|c|c|c|c|}
\hline$\stackrel{\varpi}{\Xi}$ & $\bar{\Omega}$ & ๙ิ & ڤે & 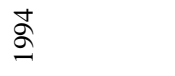 & $\stackrel{n}{2}$ & よ̊ & ลิ & $\stackrel{\infty}{\circ}$ & ڤે & ¿্ণ & $\overline{\check{~}}$ \\
\hline \multicolumn{12}{|c|}{ Mean (SD) for continuous variables and $\mathrm{n}(\%)$ for dummy variables } \\
\hline \multirow{2}{*}{ Sector: transport } & 9916 (96.6\%) & $9516(96.7 \%)$ & $9269(96.6 \%)$ & $9165(96.7 \%)$ & $8843(95.6 \%)$ & $9136(96.8 \%)$ & $10843(96.9 \%)$ & $10483(96.1 \%)$ & $15050(96.3 \%)$ & $15008(96.2 \%)$ & $18280(96.9 \%)$ \\
\hline & $348(3.4 \%)$ & $329(3.3 \%)$ & $331(3.4 \%)$ & $316(3.3 \%)$ & $406(4.4 \%)$ & $302(3.2 \%)$ & $350(3.1 \%)$ & $423(3.9 \%)$ & $573(3.7 \%)$ & $595(3.8 \%)$ & $587(3.1 \%)$ \\
\hline \multirow{2}{*}{ Sector: banking } & $9563(93.2 \%)$ & $9150(92.9 \%)$ & $8903(92.7 \%)$ & $8774(92.5 \%)$ & $8541(92.3 \%)$ & $8740(92.6 \%)$ & $10377(92.7 \%)$ & $10012(91.8 \%)$ & $14463(92.6 \%)$ & $14378(92.1 \%)$ & $17642(93.5 \%)$ \\
\hline & $701(6.8 \%)$ & $695(7.1 \%)$ & $697(7.3 \%)$ & $707(7.5 \%)$ & $708(7.7 \%)$ & $698(7.4 \%)$ & $816(7.3 \%)$ & $894(8.2 \%)$ & $1160(7.4 \%)$ & $1225(7.9 \%)$ & $1225(6.5 \%)$ \\
\hline \multirow{2}{*}{ Sector: services } & $8372(81.6 \%)$ & $8002(81.3 \%)$ & $7766(80.9 \%)$ & $7706(81.3 \%)$ & \multirow{2}{*}{$\begin{array}{l}7393(79.9 \%) \\
1856(20.7 \%)\end{array}$} & $7632(80.9 \%)$ & $9391(83.9 \%)$ & $8848(81.1 \%)$ & $12587(80.6 \%)$ & $12544(80.4 \%)$ & $15703(83.2 \%)$ \\
\hline & $1892(18.4 \%)$ & $1843(18.7 \%)$ & $1834(19.1 \%)$ & $1775(18.7 \%)$ & & $1806(19.1 \%)$ & $1802(16.1 \%)$ & $2058(18.9 \%)$ & $3036(19.4 \%)$ & $3059(19.6 \%)$ & $3164(16.8 \%)$ \\
\hline $\begin{array}{l}\text { Regional } \\
\text { unemployment rate }\end{array}$ & $8.45(1.52)$ & $9.68(1.48)$ & $10.19(1.69)$ & 9.55 (1.99) & $8.47(1.70)$ & $7.95(1.63)$ & $6.76(1.75)$ & $5.84(1.63)$ & $6.30(1.76)$ & $5.90(1.77)$ & $4.12(2.30)$ \\
\hline \multirow{2}{*}{$\begin{array}{l}\text { Union } \\
\text { participation }\end{array}$} & $8464(82.5 \%)$ & $9469(96.2 \%)$ & $9252(96.4 \%)$ & $9161(96.6 \%)$ & $7848(84.9 \%)$ & $8022(85 \%)$ & $9656(86.3 \%)$ & $9346(85.7 \%)$ & $13308(85.2 \%)$ & $13315(85.3 \%)$ & $16017(84.9 \%)$ \\
\hline & $1800(17.5 \%)$ & $376(3.8 \%)$ & $348(3.6 \%)$ & $320(3.4 \%)$ & $1401(15.1 \%)$ & $1416(15 \%)$ & $1537(13.7 \%)$ & $1560(14.3 \%)$ & $2315(14.8 \%)$ & $2288(14.7 \%)$ & $2850(15.1 \%)$ \\
\hline
\end{tabular}


Appendix D: Balance model

Future plans, spirituality, hope, problem solving skills

\section{Future/fantasy}

Good relationships with significant persons, conflict resolution, assertiveness
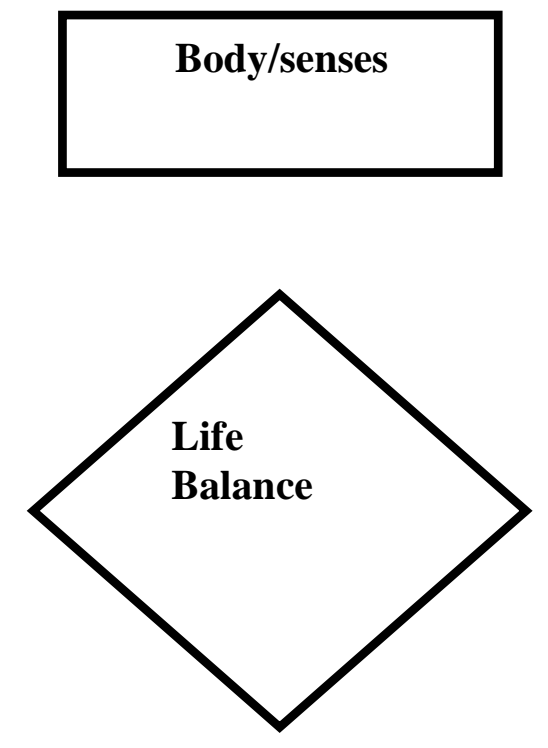

Family/contact
Physical aspects of wellness, nutrition, exercise, fitness, stress

management, relaxation

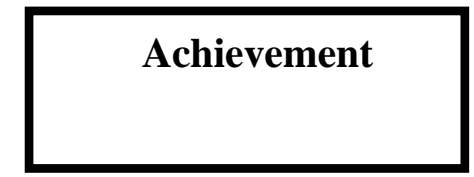

Academic skills, time management, test preparation, goal setting, selfesteem

\section{Four forms of conflict processing as description of disorders}

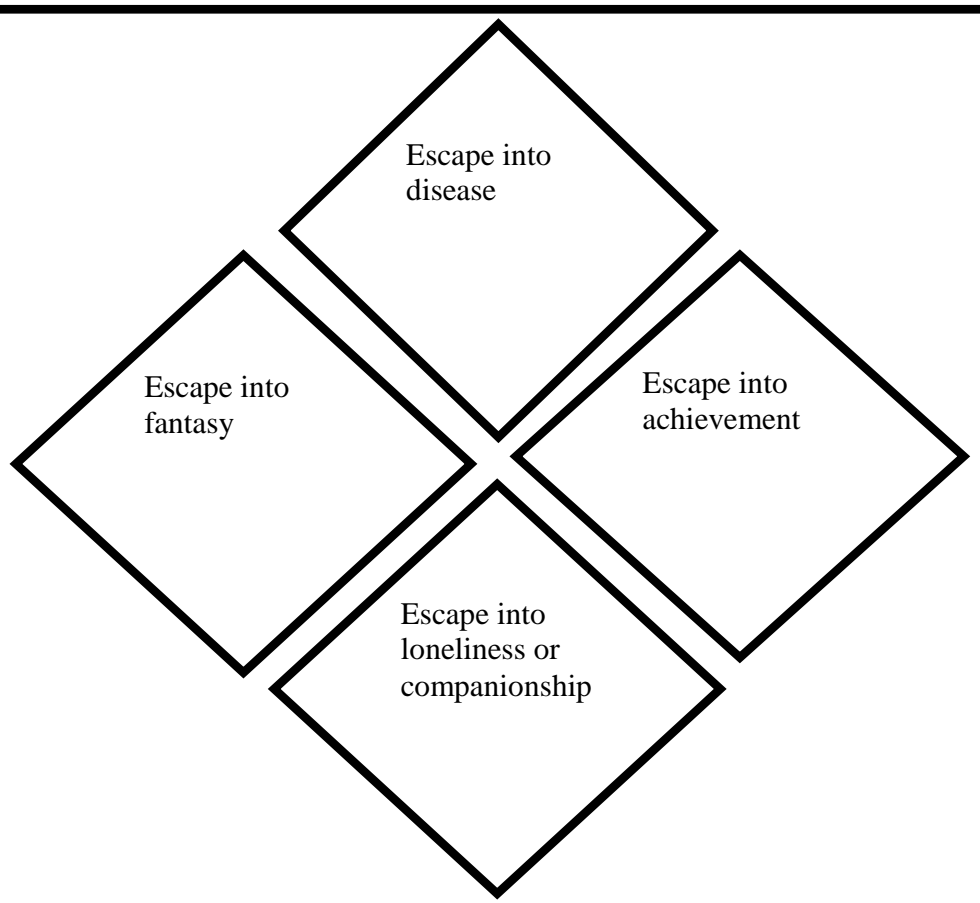


Appendix E: Basic, actual and subconscious conflict

\begin{tabular}{ccc}
\hline \multicolumn{1}{c}{ Basic Conflict } & Actual conflict & Inner subconscious conflict \\
\hline $\begin{array}{l}\text { Former Experience of the } \\
\text { environment, one self and } \\
\text { the interaction }\end{array}$ & $\begin{array}{c}\text { Actual situation, } \\
\text { life event, mictrotraumatic } \\
\text { situation } \\
\begin{array}{c}\text { Psychic Adaptation, } \\
\text { mempation and Defense } \\
\text { mechanisms }\end{array}\end{array}$ & $\begin{array}{c}\text { Subconsciously unbearable } \\
\text { situation, decompensation of } \\
\text { coping strategies }\end{array}$ \\
$\begin{array}{c}\text { Development of personality } \\
\text { and individual structure }\end{array}$ & $\begin{array}{c}\text { Micro or Macro- trauma } \\
\text { Basic Conflict }\end{array}$ & Hopelessness \\
& Conflict symbolical \\
& & $\begin{array}{c}\text { manifestation in the body or } \\
\text { the psyche }\end{array}$ \\
\hline
\end{tabular}


Appendix F: Differentiation Analysis Inventory (DAI)

\section{Differentiation Analysis Inventory (DAI)}

Capacity to know - Secondary capabilities

Capacity to love - Primary Capabilities

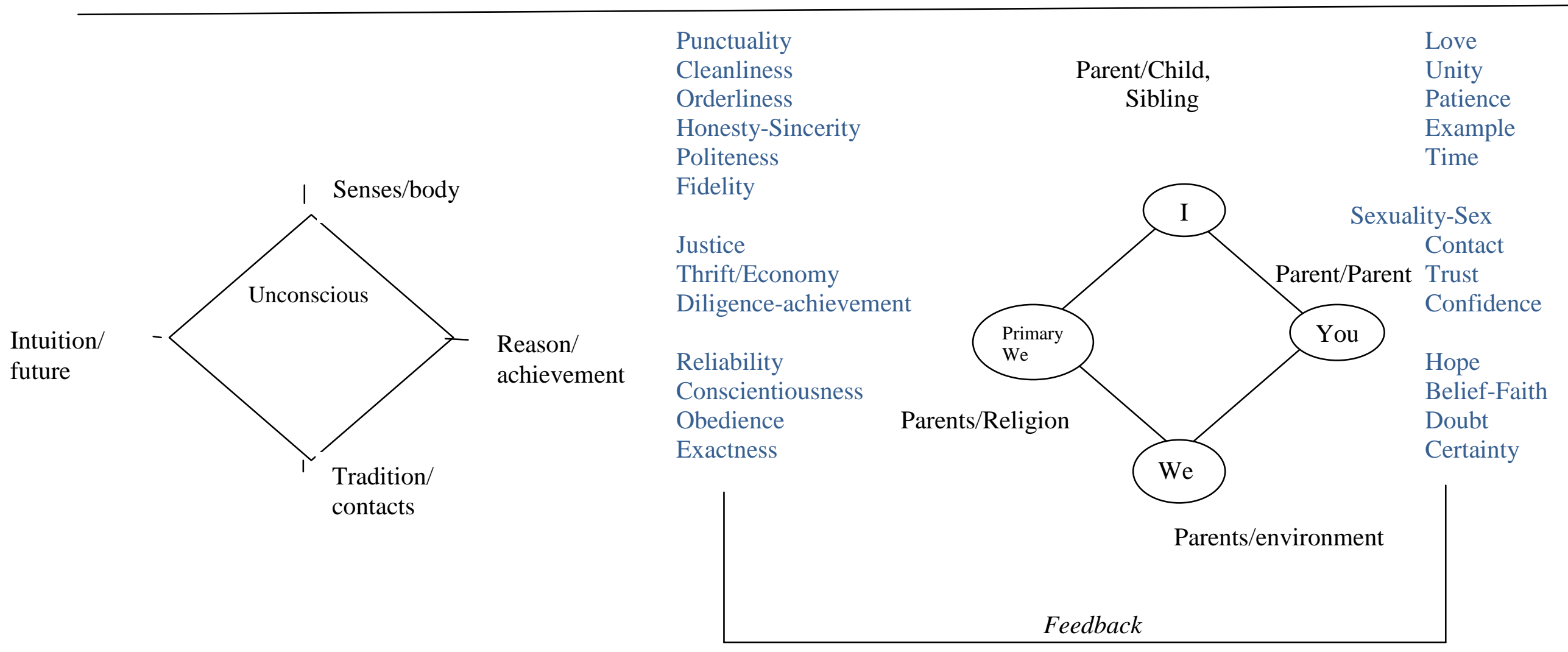


Summary 
While changes always have been a part of life, nowadays the rate of changes is speeding up. As a result, workplaces require almost continuous adaptation by employees. The aim of this dissertation is to explore the factors which influence adaptation to job dissatisfaction and labor market behavior. On the basis of this aim, three objectives have been formulated: 1) to expand our understanding of how and why employees might fail to adapt to job

dissatisfaction; 2) to explore the role of personality in labor market behavior and in adaptation in case of job dissatisfaction; 3) to understand the problems of a group of people with difficulties to adapt to a foreign culture.

Chapter 1 provides a general introduction to the dissertation. It outlines the scope of the study, aims and objectives, and goes through the basic theories related to adaptation. The focus is on employees' adaptation to changes related to employment at different levels: failure to adapt on organizational (Chapter2, 3, 4); country (Chapter 5) and trans-cultural level (Chapter 6).

At the organizational level, this dissertation focuses on employees' responses to job dissatisfaction as an antecedent of adaptation at the work place, as well as on the importance of personality in the adaptation process and labor market behavior. In Chapter 2, we develop a new perspective on job lock which helps us to deepen our understanding of why some employees are job locked/stuck at work even though continuously dissatisfied. We classify a set of factors which explain why some employees fail to adapt to job dissatisfaction into: employee's personal characteristics (socio-demographic features, personality attributes) and work-related factors (employment conditions, work-related contextual features). Further, we foresee that variation may exist between different occupations in different sectors with regard to how employees deal with job dissatisfaction. For this reason, occupation and sector have been included as an additional set of factors. We use the British Household Panel Survey (BHPS) which is an annual longitudinal survey. Data for the period from 1991 to 1996 with 
14,341 individuals is included in the analysis. We test the effect of the above mentioned factors (explanatory variables) on each of the dependent variables: job dissatisfaction, job immobility and job lock by making use of a binary probit regression. In order to correct for the non-randomly selected sample, we perform a Heckman type two-step procedure. In total, $6.6 \%$ of the employees in our study are in job lock. From all socio-demographic features included in our analysis, age appears to be a significant determinant of the absence of job turnover and being in job lock (both when we consider all employees and when we consider only those dissatisfied with their job). Gender and health status appear to be significant determinants of job dissatisfaction and being in job lock (when we consider all employees). Being male significantly increases the chance of being dissatisfied and being in a job lock (when we take into account all employees).

Self-esteem (specifically, minimum peak-end self-esteem) is used in our analysis to represent the personality attributes that might contribute to falling in a state of job lock. The results show that self-esteem has an effect on job immobility, currently experienced job dissatisfaction and job lock. Type of occupation appears significant for job dissatisfaction and being in job lock (when we take into account all employees). Specifically employees working as managers and administrators, administrative professionals, personal and protective occupations are less likely to be dissatisfied with their job and in a job lock. Having a fulltime job, employment pension scheme and promotion opportunities are significant for the state of job dissatisfaction and being in job lock (when we consider all employees). The type of sector proves to be a strong predictor for the states of being dissatisfied and being in job lock when we take into account all employees. Employees in the non-profit sector are less likely to be dissatisfied and are less likely to be in job lock than in other sectors. The regional unemployment rate is insignificant for being job dissatisfied, job immobile and in job lock. Further, tenure appears to be a significant predictor for job turnover and being in job lock. 
Thus, both employee's personal characteristics as well as on-work and off-work related factors are related to job lock.

In Chapter 3, using the two factor structure of job lock (job dissatisfaction and job immobility) developed in Chapter 1, we built a transitional model. We are interested why some employees exit job lock and others stay stuck. Further, for those who quit job lock, we are interested to know how this happens - by becoming satisfied, by using mobility, or a combination of both. We use the combination of factors which proved to be influential for job lock (Chapter 1 and Chapter 2). We include an additional factor, decisional procrastination (avoidance behavior), which is seen as a consequence of pre-existing personality characteristics. The parameters of the two transition models (transition to and from a job lock state) are estimated by multinominal logistic regression. The explanatory variables are kept the same across the models in order to be able to compare the results. Binary regression is performed to compare those in job lock and those who are job dissatisfied but mobile in at least one of the years. Data from the BHPS are used. In total, 2,949 employees reporting job dissatisfaction for two subsequent years are included in the analysis. From them, 1,344 employees experience job lock and 1,605 are mobile during at least one of the years. Among those dissatisfied with their job for two subsequent years, job lock is more often observed among elderly, married, men, and those with poor health, as well as among those in a craft occupation, working fulltime, with an employer-provided pension scheme and without promotion opportunities. Overall, job lock is less often observed among those with a managerial occupation. We do not find significant differences between the two groups (those in job lock and those who are job dissatisfied but mobile in at least one of the years) with regard to the personality characteristics included in the analysis (peak-ends self-esteem and procrastination), as well as with regard to contextual factors (i.e. regional unemployment rate). 
As much as $61.4 \%$ of those who experience job lock were dissatisfied and immobile during the preceding year (thus, they experience prolonged job lock). The other employees, who enter the job-lock state, were most often satisfied and immobile in the preceding year (26.1\%). From those who are in job lock, $44.1 \%$ remains dissatisfied and immobile in the following year. Those who exit from the job lock state, most often move to the 'satisfied and immobile' state $(32.4 \%)$ or 'satisfied and mobile' state (14.1\%). The results imply that being older, married, with low peak-end self-esteem, working in a craft occupation, in the governmental sector, and a high regional unemployment rate are push factors to a long term job lock state. Further, age, low peak-self-esteem, and a high regional unemployed rate push employee into job lock and describe the failure to exit job lock and to enter long-term job lock. Some occupations (a managerial or administrator position, associate professional, personal and protective service), private sector and promotion opportunities are the factors that pull the employee from the job lock state. Employees in a manager and administrator occupation, those in personal and protective service occupations, with promotion opportunities, working in the private sector use much more often mobility as a coping strategy in order to adjust to job dissatisfaction. At the same time, manager and administrator occupation, associate professionals, personal and protective service occupations, sales, working in the private sector, and with promotion opportunities employ work adjustments as coping strategy (satisfied and immobile).

Peak-end low self-esteem, mental health problems and decisional procrastination show significant effects on the probability to stay in long-term job lock. Low self-esteem and mental health problems have a joint effect on the transition from a job lock state (shown by the significance of the interaction term). Employees who procrastinate to make decisions and report mental health problems are less likely to be 'satisfied and mobile' compared to 'dissatisfied and immobile' and become stuck at their job in the long term (i.e. to experience 
job lock). While, decisional procrastination is shown to be preventing employees to enter a job lock state, procrastination proves to be much more related to job satisfaction. Further, when the regional unemployment rate is high, employees with low self-esteem have less chance to experience job dissatisfaction. So, almost the same variables determine if the employee would successfully adapt independently of the adaptive strategy used.

In Chapter 4, we combine the concept of job lock (as developed in Chapter 1) with this of job embeddedness. Job embeddedness is a broad range of on-work (organizational) as well as offwork (community) factors which influence employees to stay within the organization. These factors are divided into: 1) links: attachments to the job and the community; 2) fit: the extent to which an employee perceives he/she matches the job, organization, and community; 3 ) sacrifice: how much an employee perceives he/she needs to give up if he/she leaves the job. For long, job embeddedness has been seen just as a positive phenomenon. Though, the scientists begin to recognize that it can have a negative side, as those employees who feel stuck in a dissatisfying job may lose motivation, experience increased frustration, decrease performance, and exhibit counterproductive behavior. The role of individual differences for job lock is highlighted in Chapter 2 and 3. The knowledge about how individual differences may play a role for job embeddedness is scarce. In Chapter 4, we relate jointly self-concepts (global self-esteem, contingent self-esteem, self-determination, and self-compassion) to job embeddedness. The three emotional regulation systems of Depue and his colleagues (Depue \& Morrone-Strupinsky, 2005) are used and related to compassion mind theory (Gilbert, 2009a). We hypothesize that when the different aspects of self are self-critical (low global self-esteem, high contingent self-esteem, low self-determination) and self-compassion is low, the employee will be less embedded and/or will show the 'negative' side of embeddedness, be stuck. Though when self-compassion is high, this will less be the case. Cross-sectional data are used from the employees in the Netherlands. In total, 113 participants filled in the 
questionnaire completely and are included in our analyses. In order to test the hypotheses simultaneously, we used structural equation modelling, in particular path analysis (AMOS 22.0). We demonstrated that the self-aspects relate to both on-work and off-work job embeddedness. While self-determination influence directly job embeddedness components while self-compassion effects job embeddeness via its effect on the self-aspects.

The model that shows best fit to the data is the one which combines both self-compassion and self-determination in it. This study shows the importance of self-compassion and the self for the organizational life and employee wellbeing.

In Chapter 5, we study adaptation on a country level. We examine whether people with low self-esteem are more likely to become unemployed than those with self-worth. There is enough scientific proof that men and women differ in their level of self-esteem, with women having in general lower self-esteem than men. Further, unemployment is more prevalent among women. Therefore, we specifically look at the role of gender, expecting gender to moderate the effect of low self-esteem on becoming unemployed.

The top-down model of self-esteem (trait self-esteem influences self-evaluations and state self-esteem) is used in this study. We hypothesize that: 1) people with low self-worth are more likely to become unemployed than those with high self-worth; 2) gender exacerbates the effect of low self-worth on becoming unemployed.

From the BHPS we use the first eleven waves (1991-2001) with 51,154 observations in total. In this sample, 7,158 persons became unemployed during the 11 -year period, and $7 \%$ of the women and $4 \%$ of the men reported low self-esteem. We use discrete-time event history analysis, which is a technique for the investigation of causal relationships (Granger causality) in a time-related empirical representation of the structure of the causal arguments, to test the hypotheses. The results confirm our hypothesis that low self-esteem is highly significant in predicting future unemployment for women but not for men. Low self-esteem has an effect on 
the chance of becoming unemployed for married women and those in a partnership but not for men. Male employees who experience health problems related to alcohol and drug use, have a higher chance to become unemployed. Irrespective of gender, low self-esteem has an effect on the chance of becoming unemployed for some occupations. People in associate and professional occupations with low self-esteem have a higher chance to become unemployed. In advance, a higher regional unemployment rate increases the probability that employees of either gender will become unemployed. Also, a higher education and union participation prevent the employee from becoming unemployed irrespective of gender.

Having in mind that migration will be a perpetual part of Europe's future and that every aspect of the adaptation process can be influenced by culture, in Chapter 6, we concentrate on transcultural adaptation. Particularly, we attempt to bring understanding to trans-cultural adaptation of a group of immigrants and develop a therapeutic approach for them. Crosscultural adaptation has been a research focus of many academics, who in their attempt to understand this phenomenon, built models. Though, in the practice of counseling and psychotherapy, those models have only a limited appliance. Furthermore, the psychotherapy approaches are to a great extent, a product of the Western culture which led to a need for a revision and adaptation of the western psychotherapy approaches.

Data for this study are collected from two private psychotherapy practices of two independently working professionals (both Bulgarian by origin) in the Netherlands and Bulgaria. The psychotherapy took place during 2009-2010. Three groups of immigrants are formed, based on the reasons why people migrate: work, contact and future. Qualitative analysis is used to highlight the problematic aspects of these groups. Positive Psychotherapy, as an interdisciplinary approach, is applied. Positive Psychotherapy is a trans-cultural framework in which different methods can work together. Further, it is applied also in areas other than psychotherapy, such as counseling, education, prevention and management. 
We look upon trans-cultural adaptation as a process of interaction (attachment, differentiation, detachment) leading to a balance between four different modes: body, contacts, achievement and future. The results showed that for the group whose expectations were in the achievement and contact area, the actual conflict (actual problem) was most often in the same area where the expectations were laying. For both groups (with expectations in achievement and contact area), the basic conflict and the self-deficits were in the fantasy/future area. For the group whose expectations were in the area of future, the actual conflict was split between the contact and body area, with self-deficits mainly in the contact area. The basic conflict of this group was in psychic adaptation, compensation and defense mechanisms. The short term therapy led to completely disappearing of the symptoms in $66.7 \%$ of the cases and dramatically diminishing in the rest of the cases.

By changing environment, migrating people do not solve the difficulties experienced with the interaction. The relationship between expectations and the problematic areas of interaction exist. Further, trans-cultural adaptation takes time. By keeping something from their own culture and taking something from the host culture the adaptation process goes more smoothly.

In Chapter 7, we shortly present and discuss the main findings, its limitations, and provide suggestions for future research. We do this by formulating and discussing six statements. The study implications are highlighted. The research on the organization level suggests that job lock is related to employee's personal characteristics as well as to on-work and off-work related factors. Further, it proves that the same factors that push an employee into job lock lead him/her to long-term job lock. Self-determination has a direct effect on job embeddedness components, while self-compassion influences job embeddeness via its effect on self-aspects. On a country level, low self-esteem proves to place the employee at risk to 
become unemployed. And on trans-cultural level, trans-cultural adaptation shows to be a process of interactions. 


\section{Samenvatting}

Veranderen hoort bij het leven. Maar het tempo en de diepgang van veranderingen nemen steeds verder toe. Op het werk vereist dit van medewerkers een steeds grotere flexibiliteit en een permanente aanpassing. In dit proefschrift worden de factoren verkend die deze aanpassing in arbeidsmarktgedrag beïnvloeden in het algemeen en van dat van ontevreden medewerkers in het bijzonder. Het niet tijdig en voldoende aanpassen aan de nieuwe eisen uit omgeving leidt tot scala aan persoonlijke, bedrijfsmatige en maatschappelijke problemen.

Ook op de arbeidsmarkt geldt een 'survival of the fittest': werknemers die efficiënt en effectief weten om te gaan met de constant wijzigende eisen uit de omgeving hebben meer succes en blijven gezonder en inzetbaar.

Meer specifiek staan de volgende drie onderzoeksdoelstellingen centraal:

1) het vergroten van ons begrip waarom medewerkers niet van baan veranderen ondanks dat ze ontevreden zijn over hun huidige baan

2) het verkennen van de rol van persoonlijkheid in arbeidsmarktgedrag en aanpassing aan ontevredenheid met werk

3) het doorgronden van de aanpassingsproblemen van mensen die moeite hebben om zich aan te passen aan een buitenlandse cultuur

De algemene introductie van de dissertatie staat centraal in hoofdstuk 1. Na de behandeling van scope, doel- en probleemstelling, worden de basistheorieën over aanpassing (adaptation) beschreven. De focus ligt daarbij op aanpassingen aan werkgerelateerde veranderingen. Hierbij worden drie niveaus onderscheiden: lokaal, c.q. organisatie (hoofdstuk 2, 3, 4), nationaal (hoofdstuk 5) en internationaal, c.q. transcultureel (hoofdstuk 6). Op organisatieniveau richt de dissertatie zich op de gedragsreacties van werknemers op ontevredenheid met hun werk en het belang van persoonlijkheid in dit proces van aanpassing 
op de arbeidsmarkt. Hierbij wordt onderscheid gemaakt tussen het herdefiniëren en meten van 'job lock' (hoofdstuk 2), het ontstaan van 'long term job lock' en de migratie uit situaties van ‘job lock’ (Hoofdstuk 3), alsmede de relatie tussen 'job lock’ en 'job embeddedness'(hoofdstuk 4) . Hierbij wordt onder 'job lock' verstaan langdurig ontevredenheid zonder werknemers zich soms niet aanpassen en dus letterlijk en figuurlijk opgesloten raken in hun baan. Onder 'job embeddedness' wordt verstaan een brede range van factoren die werknemers beïnvloeden om bij hun huidige werkgever te blijven.

In hoofdstuk 2 wordt hiertoe eerst een nieuwe kijk op 'job lock' gepresenteerd. Dit met het doel om ons te verdiepen in de vraag 'waarom langdurig ontevreden werknemers zich soms niet aanpassen en dus letterlijk en figuurlijk opgesloten raken in hun baan'. Allereerst zijn de factoren geclassificeerd die 'job lock' mogelijk verklaren: persoonskenmerken van de werknemers (sociaal-demografisch en persoonlijkheidsattributen) en werk gerelateerde factoren (werkcondities en werk gerelateerde context). Een van onze aannamen betreft dat er variatie bestaat in de problematiek van job lock tussen verschillende beroepsgroepen en in verschillende sectoren. Derhalve zijn beroepen en branches meegenomen als aanvullende variabelen.

Voor deze deelstudie is gebruik gemaakt van de British Household Panel Survey (BHPS), een longitudinale database. De data voor de gehele periode 1991-1996 bevat 14.341 individuen en deze zijn meegenomen in de analyse. In het onderzoek is het effect getest van de hierboven genoemde verklarende factoren op 'ontevredenheid met werk', 'niet van baan veranderen' en 'opgesloten zitten in een baan'. Hierbij is gebruik gemaakt van binary probit regressie. Om te corrigeren voor een scheve verdeling in de steekproef is de Heckman twostep procedure uitgevoerd. In totaal verkeert $6.6 \%$ van de werknemers in job lock. Van alle sociaal-demografische factoren die zijn meegenomen in het onderzoek vormt leeftijd een significante verklaring voor de afwezigheid van arbeidsmobiliteit en aanwezigheid van 
job lock. Dit geldt zowel als naar alle medewerkers wordt gekeken, als wanneer alleen de ontevreden respondenten in beschouwing worden genomen. De jongere medewerker heeft een hogere kans om een job locker te worden. Geslacht en gezondheid blijken ook significante verklarende factoren voor ontevredenheid met werk en job lock, kijkende naar de hele populatie. Mannen hebben een significant hogere kans op werkgebonden ontevredenheid en om in job lock terecht te komen. Eigenwaarde (meer specifiek 'minimum peak-end selfesteem') is in onze analyse gebruikt om persoonlijkheidsattributen te representeren, die mogelijk bijdragen aan het ontstaan van job lock. Uit ons onderzoek blijkt dat eigenwaarde een belangrijk effect heeft op het niet veranderen van baan, de actueel ervaren ontevredenheid met het werk en daarmee met job lock. Ook bepaalde beroepsgroepen blijkt werkgebonden ontevredenheid en job lock vaker voor te komen. Dit geldt wanneer alle werknemers in beschouwing worden genomen. Zo hebben managers, administratieve medewerkers, alsmede mensen in verzorgende en beschermende beroepen een kleinere kans om ontevreden te zijn met hun werk en in job lock terecht te komen.

Kijkend naar alle werknemers zijn voltijdse betrekkingen, de aanwezigheid van pensioenregelingen en promotiekansen eveneens gecorreleerd met ontevredenheid op het werk en met job lock. De sector waarin de werknemer werkt, heeft eveneens een sterk voorspellende waarde op ontevredenheid en job lock (als we alle medewerkers in de analyse betrekken). Zo hebben werknemers uit de non-profit minder kans op ontevredenheid en job lock, in vergelijking tot andere sectoren. De regionale werkloosheidscijfers blijken daarentegen niet significant voor ontevredenheid, mobiliteit en job lock. Dit weer in tegenstelling tot de duur van het dienstverband.

Samenvattend kan worden gesteld dat zowel werk- als niet werk gerelateerde factoren het fenomeen job lock verklaren. Dit betekent dat job lock niet beïnvloed kan worden door de werkwerker noch door verandering van de omgevingsfactoren sec. Bij het ontwikkelen van 
interventieprogramma's moeten dus alle verklarende variabelen worden meegenomen. Tevens kunnen op basis van dit onderzoek risicoprofielen worden opgesteld.

In hoofdstuk 3 wordt een overgangsmodel gebouwd, waarbij we gebruik maken van de dubbele structuur van job lock (ontevreden en niet mobiel) zoals ontwikkeld in hoofdstuk 1. Wij zijn geïnteresseerd in de vraag waarom sommige werknemers een transitie doorlopen en de situatie van job lock weten te verlaten, terwijl anderen hierin blijven hangen. Verder willen wij begrijpen hoe werknemers zich bevrijden uit hun job lock situatie: worden zij tevreden, mobiel of er sprake van een combinatie hiervan?

Voor dit deelonderzoek hanteren we dezelfde factoren die van invloed zijn voor het ontstaan van job lock (hoofdstukken 1 en 2). Verder nemen we een additionele factor in beschouwing, namelijk uitstelgedrag. Procrastinatie als uitstel- en vermijdingsgedrag wordt hier beschouwd als een effect van reeds eerder aanwezige persoonlijkheidskarakteristieken.

De parameters van onze twee transitiemodellen worden geschat met behulp van multinominal logistic regressie. De verklarende variabelen zijn constant gehouden over beide modellen om de resultaten te kunnen vergelijken. Een 'binary regression' is uitgevoerd om mensen in job lock te kunnen vergelijken met ontevreden, maar wel mobiele werknemers. Ook hier zijn de meerjarige datareeksen van BHPS voor onze studie benut. In totaal geven 2,949 werknemers gedurende 2 aaneensluitende jaren aan ontevreden te zijn met hun werk. Van deze groep bevinden 1,344 werknemers in job lock en tonen 1.605 medewerkers zich mobiel tijdens een periode van minimaal een jaar.

Maar liefst 61,4\% van de job lockers was in het voorafgaande jaar al ontevreden en immobiel en ervaren dus een situatie van verlengde job lock. Kijken wij naar het volgende jaar, blijft $44.1 \%$ ontevreden en niet mobile en woord de situatie van job lock gestretcht. Job lock blijkt hiermee niet alleen een omvangrijk maar tevens een hardnekkig maatschappelijk vraagstuk. De overige werknemers blijven in het opvolgende jaar immobiel, maar rapporteren wel een 
hogere tevredenheid (26.1\%) en doorbreken zo de situatie van job lock. Zij die de job lock status achter zich laten, bewegen meestal naar het quadranten 'tevreden, maar niet mobiel' $(32,4 \%)$ of 'tevreden en mobiel' (14.1\%).

De resultaten duiden er op dat ouderen, gehuwden, mensen met een lage 'peak-end selfesteem', handenarbeiders, ambtenaren en hoge regionale werkloosheidpercentages als push factors fungeren voor job lock. Leeftijd, lage eigenwaarde en hoge regionale werkloosheid duwen werknemers in job lock en verklaren het onvermogen deze situatie te doorbreken en dus te vervallen in een langdurige job lock (meer dan 2 jaar). Sommige beroepen (leidinggevend, administratief, alsmede professionele, persoonlijke en beveiligingsdiensten), de private sector en promotiekansen vormen enkele omstandigheden waarin medewerkers zich relatief vaker aan job lock ontworstelen. In deze omstandigheden slagen werknemers er veel vaker in om mobiliteit als coping strategie te hanteren als antwoord op hun ontevredenheid met werk of baan. Maar ook worden soms aanpassingen op het werk als strategie gehanteerd. Deze medewerkers worden na verloop van tijd weer tevreden over de werksituatie, zonder van baan/werkgever te veranderen. Eigenwaarde, mentale gezondheid en uitstelgedrag verhogen de kans op lange termijn job lock significant. Lage eigenwaarde gecombineerd met mentale gezondheidsproblemen vergroten de kans op verlengde job lock. Voor medewerkers die besluiten uitstellen en mentale gezondheidsproblemen rapporteren is de kans klein dat zijn 'tevreden en mobiel' worden, dit in vergelijking tot 'ontevreden en niet mobiel'. Zij ervaren hierdoor vaker een lange termijn job lock. Uitstelgedrag voorkomt dat medewerkers in de situatie van job lock terecht komen. Procrastinatie blijkt veel meer gerelateerd aan tevredenheid met werk te zijn. Verder in de omstandigheid van hoge regionale werkloosheid rapporteren medewerkers met een laag zelfbeeld minder werk gerelateerde ontevredenheid. Samenvattend kan worden gesteld dat vrijwel dezelfde variabelen een succesvolle aanpassing verklaren, onafhankelijk van de toegepaste coping strategie. 
Dit kan verklaard worden door het feit dat medewerkers vaak dezelfde aanpassingsstrategie benutten en bovendien deze strategie zelden veranderen.

In hoofdstuk 4 worden de concepten job lock (zoals beschreven in hoofdstuk 1) en job embeddedness aan elkaar gerelateerd. Hierbij wordt onderscheid gemaakt tussen werk/organisatie en niet-werk/community gerelateerde factoren. Het concept van job embeddedness incorporeert drie onderdelen 1) binding: de band met het werk en de community 2) fit: de mate waarin de werknemers ervaart dat hij matcht met de baan, de organisatie en de community en 3) opoffering: de mate waarin de werknemer verlies ervaart als de baan wordt opgegeven. Lange tijd is 'job embeddedness' in de literatuur beschouwd als een positief fenomeen. Recentelijk herkennen wetenschappers ook een keerzijde. Immers werknemers die ontevreden vastzitten in een baan, kunnen motivatie verliezen, frustratie ervaren, minder presteren en contraproductief gedrag etaleren. De invloed van individuele factoren op job lock zijn in hoofdstuk 2 en 3 aan de orde gesteld. De kennis van hoe deze individuele verschillen van invloed zijn op job embeddedness is tot dusver beperkt. In hoofdstuk vier worden eerst concepten met betrekking tot zelf (global self-esteem, contingent self-esteem, self-determination, and self-compassion) gerelateerd aan job embeddedness. Hiertoe zijn de drie emotionele reguleringssystemen (Depue \& Morrone-Strupinsky, 2005) gebruikt en gerelateerd aan de compassion mind theorie (Gilbert, 2009a).

Onze hypothese is dat indien verschillende aspecten van ons 'zelf' kritisch zijn (lage globale self esteeem, hoge contingent self-esteem, lage self-determination) en zelfcompassie laag is, de medewerkers de schaduwkant van job embeddenesss ervaren en vastzitten in hun baan. Het tegenovergestelde geldt als zelfcompassie hoog is. Voor het onderzoek is gebruik gemaakt van cross-sectional data van medewerkers uit Nederlandse organisaties. In totaal 113 respondenten hebben de vragenlijst volledig ingevuld en zijn meegenomen in de analyse. 
Om de hypothesen simultaan te kunnen testen, is gebruik gemaakt van structural equation modelling, in het bijzonder path analysis (AMOS 22.0).

Uit het onderzoek blijkt dat 'zelf' gerelateerd is aan job embeddedness, voor zowel werk en niet-werkgerelateerde factoren. Zelfbeschikking (self-determination) beïnvloedt de componenten van job embeddedness direct. Dit in tegenstelling tot zelfcompassie (selfcompassion) waar de beïnvloeding indirect verloopt via de verschillende aspecten van 'zelf'. Het model met de beste fit is degene waarin zelfcompassie en zelfbeschikking worden gecombineerd. Deze studie toont het belang van zelf compassie en zelf aan voor organisaties en het welzijn van de werknemers. Wetende dat zelfcompassie getraind kan worden, bieden de resultaten aanknopingspunten voor het ontwerp van preventieve maatregelen en interventies.

In hoofdstuk 5 staat adaptatie op nationaal niveau centraal. Onderzocht wordt of mensen met een lage eigenwaarde een hogere kans hebben om werkloos te worden. Er is overvloedig wetenschappelijk bewijs dat mannen en vrouwen verschillen in hun niveau van eigenwaarde, waarbij vrouwen lager scoren dan mannen. Bovendien zijn vrouwen vaker werkloos.

Dit heeft geleid tot de keuze om tijdens het onderzoek specifiek te kijken naar geslacht. De verwachting is dat geslacht fungeert als een moderator voor eigenwaarde en werkloosheid. Het top-down model voor eigenwaarde is gebruikt in deze studie. Onze hypothese is 1) dat mensen met een lage eigenwaarde eerder werkloos worden en dat 2) geslacht het effect van eigenwaarde op werkloosheid versterkt. Van de BHPS gebruiken wij de eerste 11 onderzoeksjaren (1991-2001), met 51,154 metingen in totaal. In de steekproef rapporteren 7,158 personen werkloosheid gedurende de periode van 11 jaar. $7 \%$ van de vrouwen en $4 \%$ van de mannen beoordelen hun eigenwaarde minimaal een keer in deze periode als laag. Voor het onderzoek is gebruik gemaakt van 'discrete-time event history' analyse. Dit is een techniek voor het onderzoeken van causale relaties (Granger causality) in een 
tijdsgerelateerde empirische structuur van causale relaties. De resultaten bevestigen de hypothese dat een lage eigenwaarde sterk significant gerelateerd is aan werkloosheid voor vrouwen. Meer precies verhoogt een lage eigenwaarde de kans om werkloos te worden voor getrouwde of samenwonende vrouwen, maar niet voor mannen. Mannelijke medewerkers die worstelen met alcohol en drugs gerelateerde gezondheidsproblemen, hebben wel een hogere kans om werkloos te worden. Voor bepaalde beroepen en omstandigheden heeft een lage eigenwaarde - onafhankelijk van het geslacht- effect op werkloosheid. Zo hebben mensen in vrije beroepen met een lage eigenwaarde een hogere kans om hun baan te verliezen. Hetzelfde effect treedt op in omstandigheden van hoge regionale werkloosheid. Daarentegen verlagen een hoger opleidingsniveau en vakbondslidmaatschap de kans op werkloosheid, ongeacht het geslacht.

Preventieve maatregelen kunnen genomen worden door ouders en scholen. Dit kan door het belang te onderstrepen van gelijke behandeling tussen jongens en meisjes voor de toekomst van vrouwen op de arbeidsmarkt. Verder kan werkende vrouwen informatie worden aangeboden over de werking van eigenwaarde en manieren om om te gaan met een laag zelfbeeld. Dit kan werkloosheid bij vrouwen voorkomen en bijdragen aan het overbruggen van de kloof in werkloosheidsverschillen tussen man en vrouw.

Migratie is een vast onderdeel van Europa's toekomst. Bovendien beïnvloedt cultuur elk aspect van aanpassing. Daarom wordt in hoofdstuk 6 ingegaan op transculturele adaptatie. Arbeidsmigranten moeten in verhouding een nog grotere inspanning leveren om aansluiting te vinden en te houden met hun nieuwe dynamische omgeving. Ze kunnen bovendien minder steun ontlenen aan hun sociale omgeving. Dit leidt tot een verhevigde problematiek en een behoefte aan ondersteuning op het gebied van mentale vragen en klachten.

In dit hoofdstuk wordt een poging ondernomen om het proces van transculturele adaptatie te doorgronden en het effect van interventie in de vorm van therapeutische begeleiding verkend. 
Cross-culturele aanpassing is uitgebreid wetenschappelijk onderzocht en er bestaan inmiddels diverse modellen om dit fenomeen te duiden. In de dagelijkse praktijk van job coaching, job counseling en therapie zijn deze modellen evenwel beperkt toepasbaar.

De meest gangbare psychotherapeutische modaliteiten zijn namelijk voor een groot deel het product van onze Westerse cultuur, met focus op individualisme en zelf. Dit vraagt om revisie en aanpassing om beter in te spelen op de problemen die voortvloeien uit de grote stromen arbeidsmigranten. De data voor deze deelstudie zijn verzameld uit twee private psychotherapie praktijken. De behandelingen vonden plaats in de periode 2009-2010. Bij alle behandelingen is gebruik gemaakt van een interdisciplinaire benadering, de zogenaamde Positieve Psychotherapie (PP). Deze benadering biedt een trans-cultureel raamwerk waarin verschillende modaliteiten in combinatie kunnen worden benut. Bovendien wordt PP buiten psychotherapie worden toegepast, zoals counseling. educatie, preventie en management. Er zijn drie groepen immigranten onderscheiden, gebaseerd op de belangrijkste reden waarom mensen migreren: werk, contacten en toekomst. Een kwalitatieve analyse is gehanteerd om de problematiek van de migrantengroepen te duiden.

De transculturele adaptatie is bekeken als een interactie proces (hechting, differentiatie en onthechting), dat streeft naar balans in vier gebieden (lichaam, contacten, succes en toekomst). De resultaten laten zien dat verwachtingen op het gebied van succes en contact meestal samenvallen met actuele conflicten in dezelfde gebieden. Voor twee groepen met verwachtingen op het gebied van succes en contact, ligt het basisconflict en dus te korten in het gebied van toekomst. Voor de groep met verwachtingen op het gebied van toekomst, lag het actuele conflict tussen contact en lichaam en zelftekorten met name in contact. Het basisconflict voor deze groep bestaat uit psychische aanpassing, compensatie en verdedigingsmechanismen. 
De korte termijn therapie op basis van Positive Psychotherapie leidde in $66.7 \%$ van de gevallen tot het volledig verdwijnen van de symptomen en een sterke reductie in de overige cases. Door van omgeving te veranderen worden de problemen van migranten in interactie niet opgelost, maar eerder uitvergroot. Er bestaat een directe relatie tussen verwachtingen en probleemgebieden. Hierdoor is transculturele aanpassing - naast alle praktische hindernissen complex en vraagt tijd.

Migranten lossen geen problemen met interactie op door van omgeving te veranderen. In tegenstelling veel vaker leidt migratie tot een dermate vergroting van de problematiek dat deze niet langer kan worden ontkend. Migratie dwingt als het ware tot het doorvoeren van veranderingen en persoonlijke groei. Het is van belang mensen die emigratie overwegen en zij die al geëmigreerd zijn bewust te maken van de relatie tussen verwachtingen en probleemgebieden in interactie. Uit het onderzoek blijkt dat het proces van aanpassing beter verloopt als de arbeidsmigrant zich aanpast aan de cultuur van het gastland, maar daarbij de eigen cultuur niet opoffert.

In het hoofdstuk 7 worden de belangrijkste bevindingen samengevat en besproken. Er wordt ingegaan op de beperkingen van het onderzoeken en suggestie gedaan voor toekomstig onderzoek. Als structuur is gekozen voor het formuleren en bespreken van een zestal stellingen waarin de implicaties van het onderzoek worden benadrukt.

Het onderzoek op organisatie niveau laat zien dat job lock is gerelateerd aan de persoonlijke kenmerken van de werknemer evenals aan 'on-work and off-work' gerelateerde factoren. Verder is aangetoond dat dezelfde factoren een rol spelen bij job lock en lange termijn job lock. Zelfbeschikking beïnvloedt de componenten van job embeddedness direct. Dit in tegenstelling tot zelfcompassie waar de beïnvloeding indirect verloopt via de verschillende aspecten van 'zelf'. 
Op nationaal niveau is aangetoond dat een laag zelfbeeld het risico verhoogt om werkloos te worden. Tenslotte blijkt uit dit onderzoek dat op internationaal niveau transculturele adaptatie primair een proces van interactie is. 


\section{Acknowledgements}

The road to my $P h \mathcal{D}$ dissertation has been a challenging one. These years were a roller coaster for me, full with polarities. It was a time of confrontations, repetitive tests with seemingly just two possible end options: to fail to adapt or to grow. Luckily I walked this road accompanied. I have a gratitude to all of you, who went along with me. I am thankful that I recognized you and I embraced the gifts you were offering me.

First I would like to thank those who made this adventure for me possible: Wim Groot, Peter Janssen, and Frits van Merode. Thank you for the trust in me. Dear Wim, I find it difficult to find words which can express my gratitude to you as my supervisor, my mentor, someone who made me feel protected and supported in the life storms that I passed through during all these years. Thankyou! Peter, your death has been a big loss for me. I have missed tremendously our conversations, brainstorming, your careful read on my drafts and feedback. Often later, when I faced difficulties during the PhD project, I asked myself 'What Peter would of said to me in such a situation?'. I really hope that you are content with the final result. Frits, though that we had a short time working together, I still remember and appreciate your critical voice and sense of humor during our discussions.

Musa Milena, thank you for the friendship. Thank you for your appreciation of my ideas and conviction of the value of my work, which helped me to start over and over again after moments of discouragement. Thank you for making econometrical issues comprehensible.

$\mathcal{N}$ ext, I am thankful to my BEOZ colleagues - for the great time we had together. Special thanks go for: Anna-for the interest in my PhD studies; for the silence that we could share together; for the love and friendship

Carina - for the cozy time together sharing a working room, for the statistical discussions Catelijne - for your friendliness, your involvement and help on the manuscript we worked on together Regiene - for your statistics group idea and the fun we had together with Carina and you Susanne - for sharing our academic hassles and successes together and the friendship 
Silvia - for the talks during our travel time together, for your eagerness to help me with the data collection for my last study

Inge, Angelique, Aggie - it was great to get to know you and combine my research time with working together with you on educational tasks

Thanks you, Arjan, Hugo, Cor, for the interesting discussions, valuable comments on the drafts of our paper. Arjan, with your trust in me and your positivism, you have been an extreme support for me during the completion phase of my PhD dissertation. That meant a lot to me.

Suus and Brigitte, thank you arranging the practicalities in the final phase.

Thank you, Nic, for the friendship and English editing of my dissertation!

Erik - thank you for holding a safe space for me during these years

Subsequently, I would like to thank my family and friends in Bulgaria. Mаминқе и дядо, бrazoдаря за всичко, което направихте за мен, за да съм тази, която съм днес. ТТтко, леля Жана, леля Снежи, свако, Краси, Алеқс, Ваня Бончева, Фаниела, Веско, Сиси, Меги, Таля - Благодаря ви за безусловната обич и подкрепа!

Didi and Marieke, thankyou for your love and support! I am proud to have you by my side as paranymphs.

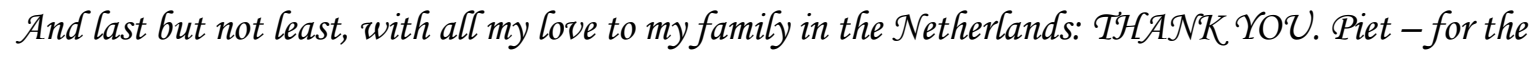
patience and the understanding for working at the evenings and in the weekends. Iris and Polle - for the laughter and contagious joy. 


\section{Curriculum Vitae}

Anna Huysse-Gaytandjieva was born on $14^{\text {th }}$ May 1970. She graduated cum laude the Medical University, Varna. She specialized in psychotherapy and worked actively for the establishment of the Positive Psychotherapy Association in Bulgaria. Anna holds an European Certificate for Psychotherapy.

In 1999, Anna was offered a scholarship for her post-graduated study in Public Health at Maastricht University, the Netherlands. After successfully finishing this program, she worked as a researcher at the Department of Health Organization, Policy and Economics (BEOZ), Maastricht University. At the same faculty, Anna started with her $\mathrm{PhD}$ and combined this with educational tasks. In 2007, Anna opened her own Psychological practice in the Maastricht area. During the period 2011-2013, Anna Huysse-Gaytandjieva was elected and worked as a member of the Board of the directors of the World Organization of Positive Psychotherapy, Wiesbaden, Germany and at the NGVH, a professional organization for psychotherapy, the Netherlands. On the basis of her scientific work, Anna has developed a training in supporting organizations to become more passionate. 